\title{
FRAMING SOCIAL INTERACTION
}

CONTINUITIES AND CRACKS IN GOFFMAN'S FRAME ANALYSIS 


\section{Framing Social Interaction}

This book is about Erving Goffman's frame analysis as it, on the one hand, was presented in his 1974 book Frame Analysis and, on the other, was actually conducted in a number of preceding substantial analyses of different aspects of social interaction, such as face-work, impression management, fun in games, behaviour in public places, and stigmatisation. There was, in other words, a frame analytic continuity in Goffman's work. In an article published after his death in 1982, Goffman also maintained that he, throughout his career, had been studying the same object: the interaction order. In this book, the author states that Goffman also applied an overarching perspective on social interaction: the dynamic relation between ritualisation, vulnerability, and working consensus. However, there were also cracks in Goffman's work and one is shown here with reference to the leading question in Frame Analysis - what is it that's going on here? While framed on a 'microsocial' level, that question ties in with 'the interaction order' and frame analysis as a method. If, however, it is framed on a societal level, it mirrors metareflective and metasocial manifestations of changes and unrest in the interaction order that, in some ways, herald the emphasis on contingency, uncertainty and risk in later sociology. Through analyses of social media as a possible new interaction order - where frame disputes are frequent and of interactional power, the applicability of Goffman's frame analysis is illustrated. As such, this book will appeal to scholars and students of social theory, classical sociology, and social interaction.

Anders Persson is Professor of Sociology and Educational Sciences respectively at Lund University, Sweden. 


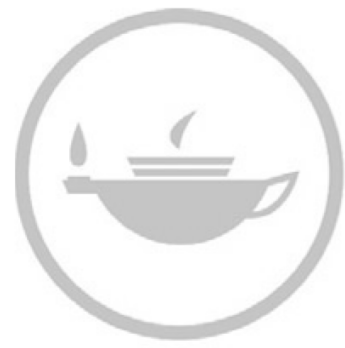

Taylor \& Francis
Taylor \& Francis Group http://taylorandfrancis.com 


\title{
Framing Social Interaction
}

Continuities and Cracks in Goffman's

Frame Analysis

\author{
Anders Persson
}


First published 2019

by Routledge

2 Park Square, Milton Park, Abingdon, Oxon OX14 4RN

and by Routledge

711 Third Avenue, New York, NY 10017

Routledge is an imprint of the Taylor \& Francis Group, an informa business

\section{(C) 2019 Anders Persson}

The right of Anders Persson to be identified as author of this work has been asserted by him in accordance with sections 77 and 78 of the Copyright, Designs and Patents Act 1988.

All rights reserved. No part of this book may be reprinted or reproduced or utilised in any form or by any electronic, mechanical, or other means, now known or hereafter invented, including photocopying and recording, or in any information storage or retrieval system, without permission in writing from the publishers.

The Open Access version of this book, available at www.taylorfrancis.com, has been made available under a Creative Commons Attribution-Non Commercial-No Derivatives 4.0 license.

Trademark notice: Product or corporate names may be trademarks or registered trademarks, and are used only for identification and explanation without intent to infringe.

British Library Cataloguing-in-Publication Data

A catalogue record for this book is available from the British Library

Library of Congress Cataloguing-in-Publication Data

A catalog record has been requested for this book

ISBN: 978-1-4724-8258-7 (hbk)

ISBN: 978-1-315-58293-1 (ebk)

Typeset in Times New Roman

by codeMantra

This book was translated by Lena Olsson, with the exception of chapter seven.

Parts of this book have been adapted and translated from Ritualisering och sårbarhet: ansikte mot ansikte med Goffmans perspektiv på social interaction by Anders Persson (C) Liber, 2012. 


\section{Contents}

Preface vii

1 Introduction 1

PART I

Goffman and the interaction order $\quad 7$

2 Goffman style: outsider on the inside 9

3 The interaction order is in the balance: the dynamic relation between ritualisation, vulnerability, and working consensus

PART II

Frame and framing

4 Frame Analysis and frame analysis

5 The development of Goffman's interactional and situational frame concept

6 Continuities and cracks in Goffman's frame analysis

\section{PART III}

Framing social media, online chess, and power

7 A new interaction order? - framing interaction in social media

8 Frame disputes in online chess and chat interaction 
vi Contents

9 Interactional power - influencing others by framing social interaction

\section{PART IV}

Conclusions

10 Concluding remarks

Epilogue: framed boundlessness - action and everyday life in Las Vegas

Complete bibliography: Erving Goffman's writings 


\section{Preface}

The Canadian-American sociologist Erving Goffman (1922-82) studied social interaction in a society where old-fashioned customs encountered modernising forces that were transforming political life, working life, everyday life, and other lives. He defended his doctoral dissertation in 1953. In the speech he would have delivered as president of the American Sociological Association at the 1982 congress had he not been prevented by illness, Goffman referred to the interaction order that he had investigated. This interaction order changed a great deal during the thirty years that Goffman was active, but much of what was valid at the beginning of this period was still valid at its close. During the thirty-five years that have passed since Goffman's death, the interaction order has presumably changed to a greater extent than earlier, at any rate in certain parts of the world; e.g., when it comes to relationships between young and old, men and women, authorities and others. What we call globalisation has resulted in the spread not only of goods, food dishes, labour, the market economy, refugees, traditions, illnesses, Western democracy, Islamist terror, identities, models of organisation, military activities for policing the world, bed bugs, music styles, and consumption goods, but also of different ways of interacting socially. Furthermore, new media - in particular mobile phones, the Internet, and social media - have exposed the interaction order to a transformational pressure, in that spatial proximity is no longer a prerequisite for social interaction. Many societies have thus come to be meeting places for hyper-modern forms of social interaction and old-fashioned social customs, which sometimes leads to conflict but is also most likely handled in precisely the smooth way that Goffman felt characterised the interaction order. Quite a few of Goffman's texts feel dated, not least because of a language that was then completely normal but which has later been transformed in many ways. However, his substantial analyses are amazingly vital and can be applied to current social phenomena, something I will illustrate in this book by exploring in depth Goffman's frame concept and frame analyses.

Ever since I became seriously interested in Goffman's sociology twenty-five years ago, his texts have stimulated my own research on schools, power, education, politics, and social interaction. In 2012 I published a comprehensive 
book (448 pages) in Swedish: Ritualisation and Vulnerability - Face to Face with Goffman's Perspective on Social Interaction (Persson, 2012b), a book that aims both to introduce Goffman's sociology and to study certain aspects of it closer, among other things Goffman's frame perspective as it is presented in his book Frame Analysis. However, Frame Analysis has been a mystery to me since I first became acquainted with it. At first I believed that I myself was the reason why I found the book mysterious, because, among other things, English is not my native tongue, but I then realised that the book was sophisticated, multifaceted, contradictory, and a number of other things. This was probably important in the context, but what finally made me believe that I understood the book was that I began framing Frame Analysis as a book in which a method for studying the many realities of social interaction was developed in a rather praxis-oriented way. This framing has opened a number of opportunities for understanding and using Frame Analysis, which are presented and discussed in the present book. The purpose of this book is to investigate Erving Goffman's frame perspective: both the way it is presented in Frame Analysis from 1974, and as it is practised in Goffman's substantial analyses of frames, in particular those that precede Frame Analysis.

Scholarly research is an activity that develops in interplay and tension between the anchoring in, renewal of, and breaching of traditions, and then both positive and negative influences are of importance. Goffman had fairly little to say about this when it came to his own sociology, but in return there is an extensive body of literature that critically investigates and makes detailed connections between Goffman's sociology and that of others, and that point out a number of different and contradictory influences: Durkheim, Simmel, Freud, Cooley, Parsons, Lorenz, and Hughes. I have chosen another path in this book, but I can assure the reader that I am well acquainted with a significant part of the literature regarding Goffman's sociology. This other path means that I have chosen to study Goffman's entire oeuvre against the background of the frame analysis he describes in his book Frame Analysis. I have then searched for a frame analytical pattern in Goffman's texts, and the results are presented in Chapters 4, 5, and 6. The pattern I found is strongly connected to two other recurring characteristics of Goffman's sociology. First, a single object of study: the interaction order, which is described in Chapters 3 and 6 . Second, an overarching perspective that functions as a kind of framework for interpretation throughout all of Goffman's works: which is described as 'the dynamic relation between ritualisation, vulnerability, and working consensus', and presented in Chapter 3. In addition, the book in your hand is introduced in Chapter 1, and Goffman himself, his position within the sociological scholarly community, and his scholarly vision are described in Chapter 2. Furthermore, in Chapters 7, 8, and 9 I attempt to illustrate in three studies how the framing perspective can be used. The first study deals with social interaction in social media, and through a frame analysis I attempt to show that a new interaction order is developing 
in social media that diverges in a number of different ways from the interaction order that Goffman studied. The same set of problems is dealt with in the second study, this time applied to online chess, because chess has proven to be very constant over time, but in its online variant it is changing faster than ever before, something that is illustrated and explained with the help of parts of Goffman's conceptual apparatus. In the third study, which concerns social interaction and the exercise of power, I attempt to show that Goffman's interaction order to a great extent has to do with influence and the avoidance of influence, and that it, in combination with framing, can be developed into a kind of power perspective. In the final chapter I present a number of concluding remarks, and in an epilogue I reflect on the fascinating phenomenon of Las Vegas, a city whose very conditions of existence are a framed boundlessness, and where Goffman himself conducted participant observations of gambling. The book also includes a complete bibliography of Goffman's published texts.

Former versions of chapter 2, 3, 5 and Epilogue have been published in Swedish in my book Ritualisering och sårbarhet - ansikte mot ansikte med Goffmans perspektiv på social interaktion (Persson, 2012b). A former version of chapter 7 has been published in the journal Language, Discourse and Society (Persson, 2012a). Finally, chapter 8 has been published in Swedish in Arsbok 2015 (Yearbook 2015) by Vetenskapssocieteten i Lund (The Science Society of Lund) (Persson, 2015).

I would like to thank the following institutions and persons for support in writing this book. The Department of Educational Sciences and the Joint Faculties of Humanities and Theology at Lund University, for stimulating working conditions; The Swedish Writers' Union, the Elisabeth Rausing Memorial Fund, and The Swedish Association for Educational Writers, for financial support to the translation of the manuscript from Swedish to English; colleagues at the Department of Educational Sciences for everyday supportive, social interaction; the participants in the UFO-seminar (the Educational Research Seminar at Lund University) for improving comments on one of the chapters in this book; two anonymous reviewers; translator Dr Lena Olsson; Editor Neil Jordan and Editorial Assistant Alice Salt, Copyeditor Sarah Sibley and Production Editor Joanna Hardern all at Routledge, for refining my text.

Thanks to colleagues and friends: Dr and Editor Peter Söderholm, Dr Gunnar Andersson, Dr Sinikka Neuhaus, Professor Emeritus Wade Nelson, Professor and former Dean Lynn Åkesson, Head of Faculty Office Gunnel Holm, Professor Johannes Persson, Dr Henrik Rahm, Dr Stéphanie Cassilde, doctoral students Ingrid Bosseldal, Malin Christersson, and Janna Lundberg.

Finally, most thanks go to my wife Titti and our children Jonn, Max and Julia for all their loving support and critique during a good part of our lives. 


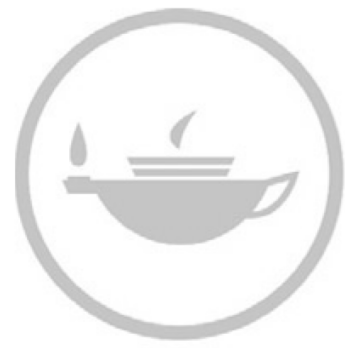

Taylor \& Francis
Taylor \& Francis Group http://taylorandfrancis.com 


\section{Introduction}

In the autumn of 2016 two prominent American men caused dismay by violating the norms of social interaction. One of them was a Republican presidential candidate who with his populist bluster transformed - and continues to transform - American politics into a theatre of the absurd. The second was a musician and poet whose Nobel Prize in literature had just been made public, and who for this reason did nothing other than remain silent. A discussion in the media is underway about the message of the presidential candidate and about whether the old protest singer is a worthy prizewinner. It is, however, interesting that the discussion is also about how these two men create disorder by breaking the frame of what the Canadian-American sociologist Erving Goffman (1922-82) called the interaction order, and then primarily with respect to ceremonial rules of behaviour or, to use another word, etiquette. As such, violations against frames are analysed by Goffman in his book Frame Analysis, and in the case of the Nobel prizewinner we may perhaps understand his actions in the following way: 'every celebration of a person gives power to that person to misbehave unmanageably' (Goffman, 1974, p. 431). However, the actions of the presidential candidate can hardly be understood in this way.

\section{Trump, Dylan, and frame-breaking}

In an article in Washington Post the presidential candidate's lack of selfdiscipline is emphasised: 'Again and again he couldn't help himself', and 'temperament matters'. Trump crowns his contempt for women as independent individuals with the words, 'such a nasty woman' instead of even trying to conduct a political conversation with his female combatant (Hohmann, 2016). In a comment in the leading Swedish newspaper Dagens Nyheter, Hillary Clinton is described as 'normal' and Trump as 'childish' (Björling, 2016a). In addition, Trump committed another crime against democratic etiquette by saying that he will only recognise the election results if he himself wins, which made an editorial writer call this 'the most shameful statement made by a presidential candidate in a hundred and sixty years'. A year later the infantilisation continues, but now it's Trumps staff that are 


\section{Introduction}

the educators and the White House is being compared to an adult day care centre where the staff treats Trump as an 'undernapped toddler on the verge of a tantrum' (Graham, 2017). Lack of self-discipline, temperament, normal, childish, shameful, undernapped toddler - it is as if the political stage has become a school. In Sweden we have to go back to the beginning of the 1990s and the political party Ny Demokrati (New Democracy) to find even the hint of a political analogue. What the message of the party - 'drag under galoscherna' ('giving it some welly') - meant politically, other than a kind of general expression of populist dissatisfaction directed against an allegedly unwieldy bureaucracy, taxes, and rules for entrepreneurs, was probably not very important. It was the belittling of political culture, the violation of etiquette in itself, that was the message and which on that occasion brought the party into the Swedish Parliament.

It is the same way with Trump: the violation of etiquette is his message, not the content, if there even is one. When Trump commits violations of etiquette in debates on prime-time television, it is possible that they are unplanned, which I find hard to believe, but they become his message when voters who have been hit hard by economic crises and competition for low-income jobs receive it. These voters probably do not put their trust in the traditional political elite but are attracted to 'an otherness' that does not respect the rules that usually, even in times of crisis, regulate political discourse. So Trump does not have to know very much about politics in order to place himself right in 'his' socio-political field. It is enough for him to mutter 'wrong' and accuse Clinton of cheating, threaten to put her in jail, and drag her husband's womanising into the discussion. All this is neither here nor there but that is the very point: Trump's populism means that he displays a lack of respect for the etiquette of politics. The day after the debate in which a presidential candidate had done the most shameful thing in 160 years we heard his supporters review the debate: 'Trump hit exactly the right note. He managed to explain what he wants to do on particular issues' (Björling, 2016b). For those of us who in some sense belong to the system - educated people with jobs and all the things appurtenant to this, and thus with a more or less committed faith in the political system that has to do with acquiring the support of voters for administrating or changing things - this statement is incomprehensible and the right and the left can suddenly be united in their condemnation of Trump's lack of respect for etiquette. 'Chaos is also a system, but it is the system of the others', to borrow the words of Imre Kertész (2015).

Erving Goffman, whose sociology forms the topic of this book, developed a number of concepts in order to understand the order of social interaction. For instance, he made a useful analytic differentiation between various kinds of verbal and corporeal expressions that we communicate with when we interact with other people: expressions given, over which the sender has relatively much control, and expressions given off, over which the receiver has greater control because they are the result of the receiver's interpretations of what the sender communicates. Trump's expressions given 
strike the right chord in certain voters, but it seems to be their interpretation of the expressions given off that provides substance to Trump's message, and the violation of etiquette then acquires great importance. When Trump burns his bridges, socially speaking, not least when he refuses to recognise the metapolitics that secure the regulations and etiquette of politics across party lines, his voters appear to interpret this as his being serious about his politics. After Trump's inauguration as president in 2017, a kind of organised division into two of the expressions was made that makes it possible for Trump to continue violating etiquette in his Twitter messages, while the official presidency is, to a great extent, separated from these. He thus communicates his messages over two different channels, the one being more of a channel for voters and the other more of a channel for the presidency. Once in a while the division between these two is not upheld; e.g., when Trump in March of 2017 refused to shake hands in public with Angela Merkel, but the two channels are mainly kept separate. Role distance, to use another of Goffman's concepts, is thus created - perhaps even a double role distance, where Trump as a populist distances himself in his Twitter messages from the political etiquette of the presidency while as the president he simultaneously assumes the role of a realist politician who, in opposition to his populist messages during the election campaign, bombs Syria and IS in Afghanistan, lowers taxes for high income earners, and celebrates NATO. Five months into his presidency an editorial in The Economist summed it up as follows ('Donald Trump's Washington is Paralysed,' 2017): 'As harmful as what Mr Trump does is the way he does it.' A Swedish columnist adds to this: 'Never before has the United States had a president so utterly devoid of style and dignity, a vulgar, ostentatious billionaire who never reads books and who occasionally encourages his followers to use violence' (Ohlsson, 2017).

But what about Dylan? His violation of etiquette vis-à-vis the Nobel prize institution is his silence, and this seems to upset some people as much as Trump's talk, and also here a kind of pedagogical discourse develops. In a column we can read the following: 'Why the hell doesn't the man say anything? What is it he's brooding over? How hard can it be to pick up the phone and say "YES, PLEASE"...'. And a few paragraphs later: 'Perhaps Bob Dylan is silent because he quite simply hasn't learned how to behave properly. Maybe he just needs some help getting on the right track' (Hilton, 2016). Many other people, soon enough an entire village, wanted to participate in the education of this 75-year-old rascal who was now also described as 'impolite and arrogant' by one of the eighteen members of the Swedish Academy, but the etiquette expert Magdalena Ribbing offers a completely different analysis: 'He's been awarded this prize for being a person of genius, and one has to allow geniuses to have their peculiarities. He may not have been awarded it at all if he had been a well-groomed person in a grey suit who replied to invitations within a week' (Jones, 2016). To return to the expressions given and given off, we never really know what expressions given off really means, and they thus invite interpretation. Perhaps in this case the silence is Dylan's almost inscrutable expression, left to others to interpret. 


\section{Introduction}

\section{What is it that's going on here?}

This introductory exercise shows that Goffman's perspective on social interaction is still useful, in spite of its foundations being laid down in the 1950s. When Goffman in The Presentation of Self in Everyday Life, published in 1959 and partly based on his doctoral dissertation from 1953, develops a dramaturgical perspective on social interaction in organisations and institutions, he justifies this strategy as a complement to four other perspectives used at that time and still found frequently in social science studies: the technical one, which emphasises efficiency; the political one, which largely has to do with the exercise of power; the structural one, which focuses on social status and relationships in networks; and the cultural one, which deals with moral values (Goffman, 1959, p. 239ff). The dramaturgical perspective emphasises what Goffman called impression management, which in part means that both individual and collective actors to a lesser or greater extent attempt to act or make it appear as if they are acting largely in accordance with community and social norms for how actors should be, act, and interact in different contexts, and in part means that actors attempt to influence other people so that they will embrace the actors' own definition of a common social situation. In a way it can be said that a dramaturgical perspective represents a combination of the political and cultural perspectives, because it combines an exercise of power in the form of influence (albeit, on a level of social interaction rather than on a societal level) with values, or, in Goffman's version, norms.

Concretely, the dramaturgical perspective means two things: first, that Goffman strongly emphasises the expressive aspect of social action, by which it should be understood that not only do we act, but we also think about how our actions are perceived by other people, or, in other words, the impressions our actions give rise to in other people. Secondly, it means that Goffman is using quite a few concepts from the world of the theatre in order to emphasise precisely the expressive aspect of action; e.g., role, performance, stage, frontstage, and backstage. This perspective could probably have been perceived as superficial when the book was published, but if we see it as a prophecy it has been extremely successful. Returning to Trump, one may well ask what he is other than a product of a certain setting, not least because he is completely ignorant, politically speaking. His thing is impression management! - not least through the expression 'You're fired!', Trump's stock line in the reality show The Apprentice earlier and which now also appears to have become his stock line in the White House. The dramaturgical perspective has also surfed the neoliberal tsunami of marketisation, which has not only fragmented the only real existing alternative to capitalism as a system, but also, with the help of new public management, transformed almost all the institutions in society that are not actors in the market into actors in politically constructed markets, where they are forced to sell something that previously was not a commodity and thus implement 
impression management. Since 1959 the marketisation of society as a whole has increased, and impression management now describes a completely central aspect of the actions of market actors, whether they are individuals or organisations. Impression management in the form of inflated real estate values and share prices, doped-up performances, and rigged CVs, has thus been entered into the annals of history with names like Fannie Mae, Kaupthing Bank, Justin Gatlin, and Paolo Macchiarini. Goffman's perspective - which in addition consists of so much more than a dramaturgical perspective - is in many ways more alive than ever before.

If by way of introduction I should attempt to summarise my view of Goffman's sociology, I would like to emphasise that Goffman has a kind of generic perspective, which in Chapter 3 is presented as the dynamic relation between ritualisation, vulnerability, and a temporarily working consensus. This is a kind of metaperspective on social interaction that to a great extent decides how Goffman interprets and understands the object of study that links his texts: the social interaction order. Within the framework of this object of study, three themes stand out in Goffman's sociology. First, a theme of politeness and respect, which was expressed clearly in his investigations of rituals in the 1950s and of social interaction in the 1960s. Second, the theme of social illusion, which is pervasive because of Goffman's particular interest in the construction of social illusions that follows from expectations of normality and that is created by us all under the cover of the rituals of everyday life when we engage in impression management but also by social imposters of different kinds, and that is given significant expression in, e.g., the books The Presentation of Self in Everyday Life and Stigma around 1960 and Frame Analysis from the 1970s. Third, and finally, a theme of crisis in the 1970s within whose framework an investigation of the crisis of the social interaction order can be discerned, not least in the books Relations in Public 1971 and Frame Analysis. At the same time that there is a frame analytic continuity in Goffman's studies of the interaction order, we can also, on a different level, see a kind of break that first becomes clear in the book Relations in Public (1971). While the texts preceding this book were to a great extent characterised by assumptions about order and accounts that suggested order, Goffman slips in a dissonant chord in Relations in Public that may be called contingency. Contingency also becomes a powerful theme in the book that followed three years later, Frame Analysis, something that can be illustrated not least by the question that gives meaning to his frame analysis itself: What is it that's going on here? 


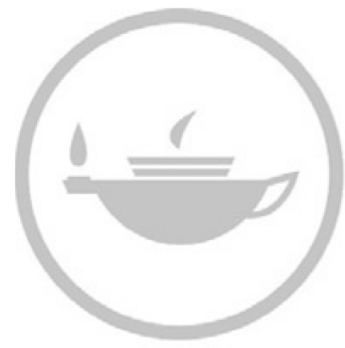

Taylor \& Francis
Taylor \& Francis Group http://taylorandfrancis.com 


\section{Part I}

\section{Goffman and the interaction order}




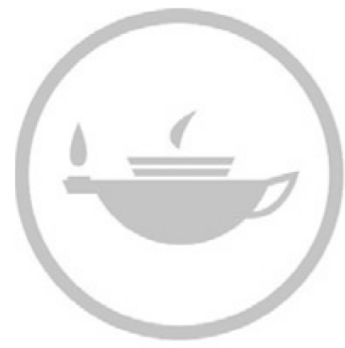

Taylor \& Francis
Taylor \& Francis Group http://taylorandfrancis.com 


\section{Goffman style: Outsider on the inside}

Erving Goffman was born in 1922 into a Russian-Jewish family in Canada. ${ }^{1}$ His parents had immigrated from the Ukraine just before and during World War I and lived at first in the small community of Mannville, where they ran a shop, and later in Dauphin. When Goffman was 15 years old, his family moved to Winnipeg, a city that at this time had around a quarter of a million inhabitants. According to Winkin (2010), Goffman was not particularly good at school, but he was very interested in his chemistry set, with which he experimented when at home. Goffman was described by a classmate from St. John's Technical High School in Winnipeg as being 'in a different world: encapsulated, aloof and remote'. He was one of the gang, but according to Winkin (2010, p. 56f) he was different because Goffman's family differed socially, politically, and culturally to some extent from many other families in the area: they lived in a slightly better area, were not politically active, and did not go to synagogue.

Goffman began his undergraduate studies at the University of Manitoba in Winnipeg in 1939, and his major was chemistry. After a break spent working at the National Film Board of Canada, he continued his studies and graduated from the University of Toronto in 1945 with a major in sociology. In the same year he was admitted as a doctoral student in sociology at the University of Chicago, received his Master's degree from there in 1949, and in 1953 defended his doctoral dissertation 'Communication Conduct in an Island Community', which had its origins in fieldwork conducted on the Shetland island of Unst. He was a teacher at the Department of Social Anthropology at the University of Edinburgh in 1949-51 and worked as a research assistant from 1952 to 1954 at the University of Chicago in two different research projects, whose leaders were Edward A. Shils and E. C. Banfield, respectively. The following year he was employed as a guest researcher at the National Institute of Mental Health in the United States and, among other things, spent one year of participant observation in a mental health institution. In 1958, Herbert Blumer invited Goffman to the Department of Sociology at the University of California, Berkeley, where he became a full professor in 1962. During a period in the 1960s he worked as a blackjack dealer at a casino in Las Vegas, and also advanced to become a 
so-called pit boss. ${ }^{2}$ It is said that his stay at the casino was a participant observation, and it is mentioned in passing in the publications where Goffman writes about gambling (1967 and 1970 [1969]). Goffman often played blackjack in Las Vegas and was reported to the police for card counting in the mid 1960s, something that was also reported to the management of UC Berkeley. Furthermore, Goffman spent the year 1966 at the Harvard Center for International Affairs, and was in 1968 appointed Benjamin Franklin Professor of Anthropology and Sociology at the University of Pennsylvania, the double disciplines perhaps mirroring that he empirically worked as an anthropologist, and theoretically as a sociologist, where he stayed until his death in 1982. In his obituary in Time Magazine (6 December 1982), Goffman is described as an 'unorthodox sociologist whose provocative books [...] developed his somewhat mordant theories of contemporary ritual, based upon the overlooked small print of daily life'.

In a brief memoir, Thomas Schelling (2015), winner of the 2005 Swedish National Bank's Prize in Economic Sciences in Memory of Alfred Nobel and the person who invited Goffman to be a guest researcher at the Harvard Center for International Affair, writes: 'I consider him one of the two or three greatest social scientists of his century. I've often remarked that if there were a Nobel Prize for sociology and/or social psychology he'd deserve to be the first one considered. He was endlessly creative'. Today many people, but far from everyone, agree with Fine and Manning's (2003, p. 58) description of Goffman as

the most significant American social theorist of the twentieth century; his work is widely read and remains capable of redirecting disciplinary thought. His unique ability to generate innovative and apt metaphors, coupled with the ability to name cogent regularities of social behavior, has provided him an important position in the sociological canon. Further, his sardonic, outsider stance has made Goffman a revered figure - an outlaw theorist who came to exemplify the best of the sociological imagination.

As has already been mentioned, Goffman published his first book - The Presentation of Self in Everyday Life - in 1959, and he thereafter published an additional ten books and collections of essays, the last one in 1981 with the title Forms of Talk. At the time of writing, all of Goffman's eleven books are still in print, including Gender Advertisements, which was long out of print and now has a new cover that really illustrates Goffman's words on the last page of the book that advertisers 'make frivolous use of what is already something considerably cut off from contextual controls'. Goffman's first article had the title 'Symbols of Class Status' and was published in the British Journal of Sociology in 1951. In total, he published twenty-three articles in scholarly journals, of which four were reviews and one was an answer to a critical review of his sociology. Goffman published the majority 
of his articles in the journal Psychiatry. He contributed to six anthologies (or similar works), either as an author or with transcripts of oral presentations, comments, and contributions to debates. ${ }^{3}$

\section{An established outsider}

Goffman's sociology has been, and still is, the subject of extensive scholarly discussion, and, in addition, his texts are used by many. ${ }^{4}$ After his death, a minor industry of secondary literature on Goffman appeared, which probably has to do with his exciting sociology but also with the fact that he was a brilliant analyst in terms of scholarship and a special person in social terms, who died relatively young. Lemert (2003) speaks of 'the social power of the enigma' as an explanation for the significant interest in Goffman. The image of Goffman that appears in the secondary literature is the image of a sociologist who is controversial and contradictory and who seems to leave few people indifferent. He was an outsider, in spite of being given access to many of the most desirable domains in sociology. Being an outsider on the inside was in many ways his style.

As a student in Toronto, Goffman found Émile Durkheim, A. R. Radcliffe-Brown, W. Lloyd Warner, Sigmund Freud, and Talcott Parsons to be important sources of inspiration, and at Chicago, Georg Simmel, Herbert Blumer, and Everett Hughes were added to this group (Fine, Manning, \& Smith, 2000). Becker (2003) makes a point of the fact that both sociological and anthropological influences come together in Goffman's sociology: the former from Simmel via Hughes, one of Goffman's teachers in Chicago, and the latter from Durkheim and Radcliffe-Brown via Warner, another of his teachers. Collins (1994) has also emphasised the anthropological aspect of Goffman's sociology, which is expressed in the analysis of social interaction as social rituals. When rereading The Presentation of Self in 2009, Giddens was struck by just how anthropological the book is, referring to its basic approach: 'the sort of man-from-Mars style that Goffman deploys' (Giddens, 2009, p. 290). Burns (1992) points to different sources of inspiration in Goffman's scholarly development, not least the Chicago School of sociology during his years as a doctoral student at the Department of Sociology in Chicago. The First Chicago School had reached its zenith in the 1930s, but continued to inspire sociologists much later. Fine, Manning, and Smith (2000) consider Goffman a central actor in the 'Second Chicago School', and according to Winkin (1999, p. 34f) Goffman responded well to the Chicago habitus, which he describes with the concepts empiricism, humour, and empathy without the ambitions of a social worker. There were also other influences. Burns (1992) suggests that the time spent as a researcher with the National Institute of Mental Health, where Goffman worked with participant observation in mental health institutions, was important for Goffman's scholarly development. Goffman's contacts with the British anthropologist and communication researcher Gregory Bateson, who early on used the 
concept of metacommunication (Ruesch \& Bateson, 1951), was, according to Burns, also important. Finally Burns also mentions Goffman's contacts with language philosopher John Searle at Berkeley and, later, with sociolinguists Dell Hymes and William Labov at the University of Pennsylvania as being important. Among these sources of inspiration we can find the roots of Goffman's urban ethnographic sociology, his preference for participant observation, and his orientation towards ritualised communicative action and behaviour. Goffman allowed these roots to nourish a project that was all his own, which at one and the same time included society as a normative order that limits the freedom of the individual, 'the others' as both audience and those who exert influence, and an active individual who both adapts him- or herself and tries to preserve her or his scope of action, who wishes to be an individual and at the same time receive recognition from the group.

Goffman was an outsider, but a contradictory one. He did not work with any strange or deviant problems, but his studies concerned particularly basic issues in sociology and 'common' occurrences in social interaction i.e., what happens and why what happens happens when people interact with each other and when an individual interacts with unknown others and with the norms of society. Nor was he an outsider in the sense that he was outside the sociological establishment; on the contrary, his works are among some of the most widely read in modern sociology. Even if there was a certain hesitation with respect to sociology, his books received positive reviews early on. Kaspar D. Naegele described Goffman's first version of The Presentation of Self in Everyday Life from 1956 as 'delightful and puzzling', 'brilliant' but also 'precariously suspended between the New Yorker and Stephen Potter'. The reviewer wanted more influential sociologists such as Weber among the references, and objected to Goffman's naive division of the individual into a socialised and a non-socialised self, and concluded that "what we "are" and what we "seem" are both constituted in society" (Naegele, 1956, p. 632). In his review of the same work, social anthropologist Robert N. Rapoport begins by saying that 'Dr. Goffman [...] shows himself to be an European-type universal scholar gone west - a Simmel in Damon Runyon's idiom', and draws the conclusion that the book is worth reading and rereading, "not only for its contributions to sociological perspectives, but as a personally enriching experience, a sometimes forgotten function of sociology' (Rapoport, 1957, p. 28). In another review of the same work, sociologist Gregory P. Stone draws the conclusion that 'the monograph under review impresses one as one of the most trenchant contributions to social psychology in this generation' (Stone, 1957, p. 105). In his review of the 1959 edition of The Presentation of Self, Lloyd Fallers, Professor of Sociology and Anthropology at the University of Chicago, wrote that Goffman's analysis was full of useful concepts, while he at the same time felt that the book was weak when it came to links to other sociological analyses (Fallers, 1962, p. 191). Several other reviews follow approximately the same pattern: commendatory when it comes to the contents, but at the same time hesitant, not least with respect to the possibility of generalisation. 
Goffman was awarded several prizes and honours. In 1961 he received the MacIver Award of the American Sociological Association for his book The Presentation of Self. In 1978 he was awarded the international communication prize In Medias Res, and in the following year the American Sociological Association's Mead Cooley Award in Social Psychology. The Society for the Study of Symbolic Interaction posthumously awarded him The George Herbert Mead Award for Lifetime Achievement in 1983. In 1976 Goffman was appointed an honorary doctor at the University of Manitoba in Canada, and in 1977-78 he received a Guggenheim Fellowship. Finally Goffman was appointed an honorary doctor at the University of Chicago in 1979 with the following motivation: 'Acute analyst of interpersonal transactions, your work has transformed the entire field of microsociology'.

In spite of many good reviews, honours, and the fact that Goffman shortly before his death in 1982 was elected president of the American Sociological Association, it is still possible to say that he was outside the sociological establishment. Even if he perhaps did not want to be included, it seems as though he wanted to reach the top of this establishment. Goffman saw the presidency of the American Sociological Association as a confirmation that he was the foremost sociologist in the United States, at any rate according to Sherri Cavan (2011), one of Goffman's doctoral students in the 1960s. Nevertheless, he did not seem to want to use his position to promote the practice of a certain kind of sociology, and as the president-elect he advertised the contents of the 1982 annual meeting in San Francisco with the following words:

I feel even more that it is unrealistic, and abuses words in a manner we must not allow to become characteristic of us, for a president-elect or anyone else to proclaim what the theme of an annual meeting is to be. There are already enough inflated pronouncements in the world; our job is to dissect such activity, not increase the supply. (Goffman, 1981b, p. 4)

In the same article he instead promoted the value of criticism and analysis:

If we can't uncover processes, mechanisms, structures and variables that cause others to see what they hadn't seen or connect what they hadn't put together, then we have failed critically. So what we need, I feel, is a modest but persistent analyticity: frameworks of the lower range. (Goffman, 1981b, p. 4)

Goffman's contradictory outsidership was not simply a result of his sociology being overseen by certain leading forces within the sociological community, but may also have depended on the fact that Goffman was far too ethnographic to be a theoretician and at the same time far too theoretical to be an ethnographer, to freely quote Fine, Manning and Smith (2000, p. ix). He thus ended up on the sidelines of two of the main orientations. His outsidership may also have been voluntary: 'Goffman seemed to fight all his life a 
battle to remain rooted in the underground, to keep from becoming any kind of Establishment - even a rebellious counter-Establishment', writes Collins (1986, p. 112). Sherri Cavan (2011) feels that Goffman in addition chose to be an outsider in a number of other respects: in his participant observations, in his relationships with colleagues, and with respect to the media and public life. She describes him as 'a lone observer, ${ }^{6}$ which, spontaneously speaking, seems to capture both his way of working and his position. Ulf Hannerz, Professor of Social Anthropology at Stockholm University, says that during a reception in a hotel room, probably in connection with the annual conference of the American Anthropological Association in New York in 1971, Goffman showed up in a 'rather plain sweater of mixed grey shades' and

talked to me and one or another person there, but was mainly parked behind a TV set, making observations. After he had left I pointed out that "that was Goffman who just left", which occasioned some astonishment - some people had apparently believed that he was a TV repairman. ${ }^{7}$

At the same time that Goffman in his sociology appeared to be extraordinarily aware of the relationship between individuals and groups, he himself defied various sociological group affiliations ascribed to him by others. In a letter from 1969 to Everett C. Hughes we can see a glimpse of this affiliation dilemma. The background of Goffman's letter, here quoted by Jaworski (2000, p. 304), was an article in Time about Goffman ('Exploring a Shadow World,' 1969):

That was a very nice letter on Time, time, and left handedness. [...] There is that commitment to the jointly lived life of one's discipline that leads you to write book reviews and letters in the first place. No one insists on it; you can't put the pieces in a bibliography. They are something extra, something that won't get paid for, something to show that even when an official occasion is not in progress, a man should be involving himself in the life that exists between himself and others. They always tell me, those pieces of yours, what I am not that I should be.

Goffman was rather rarely active in collegial contexts and only wrote four reviews during his entire career (Goffman, 1955b, 1955c, 1957c, 1957d), none of which dealt with any central sociological works. He was a discussant during a session on 'public and private opinions' at a conference on public opinion research (Proceedings of the Twelfth Conference on Public Opinion Research, 1957). He had agreed to lead a session on the theme 'Revisions and relations among modern microsociological paradigms' at the World Congress of Sociology in August of 1982, says Helle (1998), but he had to cancel because of his illness and died three months later. Goffman was never the editor of an anthology and was always the sole author of his texts. One exception 
is possibly the text 'Some Dimensions of the Problem' (Goffman, 1957b), where Goffman according to a footnote had written some three pages about patients as normal deviants, but which does not list him as a co-author. Goffman was, finally, a member of the editorial teams for the periodical Sociometry in 1962 (associated editor), the American Journal of Sociology in 1962 (advisory editor), and Theory and Society in 1976-82, where among others the founder of the periodical, Alvin Gouldner, as well as Anthony Giddens, Theda Scocpol, and Charles Lemert were also members. He was also a member of the editorial committee for the sociolinguistic periodical Language in Society from 1974 until his death. Goffman was also the editor of the book series University of Pennsylvania Publications in Conduct and Communication together with Dell Hymes.

\section{Goffman's research style and scientific viewpoint}

Goffman had a particular way of conducting research in practice, a style of research where three 'methods' were combined. First, observation, and second, a contrasting method, which in principle had to do with trying to generate knowledge about a phenomenon by studying or reflecting on its opposite, an approach that is described in this way in Frame Analysis:

Whatever it is that generates sureness is precisely what will be employed by those who want to mislead us. [...] In any case, it turns out that the study of how to uncover deception is also by and large the study of how to build up fabrications. [...] In consequence one can learn how our sense of ordinary reality is produced by examining something that is easier to become conscious of, namely, how reality is mimicked and/or how it is faked. (Goffman, 1974, p. 251)

The third method is conceptualisation, which was used as a tool for systematisation, analysis, and interpretation. According to Susan Birrell (see Williams, 1988, p. 88), Goffman is supposed to have created over 900 concepts, an assertion that suggests that the creation of concepts was an important method for Goffman.

In principle, Goffman was a proponent of the observational method, not least because he had little faith in the interview method on account of its reliance on the actors' own statements. ${ }^{8}$ Goffman used the observational method in order to approach social realities and collect his own empirical material, while at the same time the contrasting method was used in order to break up ingrained ways of thinking about these realities. Conceptualisation - which can also be described as a systematising, analytic, and defining manner of thinking - was the tool that was used to process the collected and critically reflected material. Goffman combined observation, contrastive effect, and conceptualisation in this way; e.g., in his doctoral dissertation and in The Presentation of Self in Everyday Life. 
But Goffman also combined the three methods in another way. Using conceptualisation, an introductory delimitation of a kind of space is initially made, a space that is separated and, in a way, removed from its surrounding context. It thus becomes possible to investigate this space using observation and a continued conceptualisation that identify the parts that are included in the space that is being studied. The parts are shown at work through a number of empirical illustrations, and this chain of events within the delimited space is often called 'dynamics'; e.g., 'the dynamics of the character game' in the essay 'Where the Action Is' (Goffman, 1967, p. 248), 'the dynamics of ratified participation' in the article 'Footing' (Goffman, 1981a, p. 135), and 'the dynamics of shameful differentness' in Stigma (Goffman, 1963b, p. 140). Finally, connections are made between the delimited, investigable space and more comprehensive societal contexts using a contrasting effect, which sometimes represents dramatic changes of levels, from the level of social interaction to a societal level.

This second manner of combining observation, contrastive effect, and concept formation becomes, on the whole, rather apparent in the essay 'Fun in Games' (Goffman, 1961b), where Goffman in the introduction establishes his delimited space using references to everyday life as well as formal definitions of different forms of interaction. This is followed by a plethora of definitions under the heading 'formalizations', whereafter 'dynamics of encounters' are studied, and as a conclusion a contrasting level shift is made, from the commitment of individuals to gambling to a commitment to social interactions in general. Both the first and the second way of combining observation, contrastive effect, and conceptualisation work as critical methods, but the criticism is then not about social criticism, but rather about the fact that the investigations make an epistemological difference that forces us to see social reality in a different way than previously.

Goffman's way of conducting research can also be described in other ways, such as here in a review of one of Goffman's books:

This set of essays shares in the virtues and the defects of Goffman's other works. The well-turned, emotive language comprising the Goffman style goes well with his 'literary' methodology and its results. We find here no theory, but a plausible, loosely-organized frame of reference; little concern with explanation, but masterful descriptions; no accumulation of evidence, but illuminating allusions, impressions, anecdotes, and illustrations; few formulations of empirically testable hypotheses, but numerous provocative insights. We find, also, insufficient use of qualifications and reservations, so that the limits of generalizations are usually not explicitly indicated. (Meltzer, 1968)

Perhaps this might also be appropriate as a description of Goffman's view on scholarship, even if he himself describes it in a completely different way, and the question is whether we should trust Goffman when, in an interview 
(Verhoeven, 1993), he says that he believes himself to be, at bottom, a positivist. And what does it mean for him to be a positivist in this case? It apparently does not mean being a principal proponent of any kind of 'quantitative method', because this is something Goffman distanced himself from, given the phenomena he studied; for instance, when he describes the advantages of 'a naturalistic analysis' in order to understand conversations and states that a 'quantitative analysis', with its focus on, among other things, averages, tends to 'average out some of the significant realities of the interaction' (Goffman, 1971, p. 148).

To Arlene Daniels, one of Goffman's doctoral students, Goffman was a positivist in the sense that he, from an epistemological perspective, was a realist: 'Throughout his work, an underlying belief in positivism appears. Not everything was socially constructed for Goffman. He showed his allegiance to Durkheim in his belief in social facts' (Daniels, 1983, p. 2). But this is probably not the whole story, at least not if one reads the following lines from an epistemological perspective:

A cynical view of everyday performances can be as one-sided as the one that is sponsored by the performer. For many sociological issues it may not even be necessary to decide which is the more real, the fostered impression or the one the performer attempts to prevent the audience from receiving. The crucial sociological consideration [...] is merely that impressions fostered in everyday performances are subject to disruption. We will want to know what kind of impression of reality can shatter the fostered impression of reality, and what reality really is can be left to other students. We will want to ask, 'What are the ways in which a given impression can be discredited?' and that is not quite the same as asking, 'What are the ways in which the given impression is false?'. (Goffman, 1959 , p. 65f)

There is thus no desire to participate in battles over truth or falsehood, and Goffman's words about other people having to work out 'what reality really is' suggests that his potential positivism was of a more limited kind than what is otherwise referred to as positivism. I believe that to him, positivism meant having an empirical rather than a theoretical approach, approximately in accordance with the division Hacking makes in his comparison of Foucault (whose way of working is described as top-down, because most things were seen in the light of comprehensive systems of thought) and Goffman (whose research is designated as bottom-up, because he was 'always concerned with individuals in specific locations entering into or declining social relations with other people') (Hacking, 2004). In an article Sharrock says that his motives for studying Goffman's sociology as a young doctoral student were that it was a sociology everybody could recognise, not theoretically abstracted, but a sociology that concerns itself with a world that is visible to the actor (Sharrock, 1999, p. 121). 
Perhaps Goffman appointed himself a positivist in order to distance himself from a far-reaching social constructivism? In his interview with Verhoeven he says that he differs from the constructivists in that he does not believe that individuals construct reality - something that is also true of the two sociologists so important for the social construction perspective, Berger and Luckmann (1967), who emphasised precisely the social in the social construction of reality. In another context Goffman objects in a pragmatic or empirical way to what is usually called the Thomas theorem - 'if men define situations as real, they are real in their consequences' - by pointing out that the theorem is valid on the condition that the definitions people make are anchored in reality (Goffman, 1971, p. 99). In the same breath that Goffman in the above-mentioned interview says that he believes that he is a positivist, he claims to have been inspired to a great extent by the 'epistemological realism' that Parsons gave expression to in The Structure of Social Action (1937). It is thus likely that Goffman's positivism represented precisely an anchoring in reality and a sober, delimited (as opposed to limitless) social constructivism, similar to the one Hacking wants to capture in the book title The Social Construction of What? (Hacking, 1999). Seen in this way, Goffman combines positivism and constructivism through his view of reality as socially constructed but individually defined, and through his view that both social constructions and individual definitions can be studied empirically with the aim of making statements that in a more or less valid way correspond to the reality that is being studied. Claiming to be positivist can then mean having the ambition to be able to make precisely such statements.

Claiming to be positivist, albeit in a limited sense, was probably very provocative during the politically left-wing radical period when Goffman was active, perhaps in particular if one, like Goffman, was a professor at Berkeley around 1968. At the same time it must be emphasised that 'positivism' can be a very radical thing if placed in an Enlightenment tradition and, for example, used in order to point out injustices in society and how they are upheld by real social institutions. However, for all that, it was probably even more provocative than calling oneself a positivist to say, as Goffman did in the 1960s and 70s, that he did not put his sociology at the disposal of any social transformational force:

The analysis developed does not catch at the differences between the advantaged and disadvantaged classes and can be said to direct attention away from such matters. I think that is true. I can only suggest that he who would combat false consciousness and awaken people to their true interests has much to do, because the sleep is very deep. And I do not intend here to provide a lullaby but merely to sneak in and watch the way the people snore. (Goffman, 1974, p. 14)

That formulation annoyed quite a few people, and that was perhaps precisely what Goffman wanted, something that Collins implies when he writes that 
Goffman was never content to be a "conventional" individualist like everyone else. When everyone else was being a critic and a radical, he set himself up intellectually as a Durkheimian conservative - and yet managed to appear nevertheless as a more radical exposé-artist than almost anyone else. (Collins, 1986, p. 108)

Denzin's reckoning with Goffman, furthermore, begins with a few appreciative words:

He brought a literary sensibility to sociology. He drew on literary sources, and his was a gifted prose that was at once nuanced, ironic, and literary. And he offered a timeless naturalistic, taxonomic sociology; a sociology that seemed to turn human beings into Kafka-esque insects to be studied under a glass. He was the objective observer of human folly. (Denzin, 2002, p. 106f)

However, this essay then continues with what Denzin believes to be the problem itself: that Goffman does not take a stand, and Denzin then in a rather single-minded way supports himself on Becker's article 'Whose Side Are We On?', published in 1967. Becker's analysis of the problem of taking sides can, however, be understood in other ways than Denzin's (see, e.g., Hammersley, 2001). In his article, Becker uses as a point of departure the question, 'When do we accuse ourselves and our fellow sociologists of bias?' (Becker, 1967, p. 240), and the answer he provides is that such accusations are spoken when research supports the subordinated party in a hierarchical relationship. The reason for this lies in what Becker calls 'the hierarchy of credibility':

In any system of ranked groups, participants take it as given that members of the highest group have the right to define the way things really are. In any organization, no matter what the rest of the organization chart shows, the arrows indicating the flow of information point up, thus demonstrating (at least formally) that those at the top have access to a more complete picture of what is going on than anyone else. Members of lower groups will have incomplete information, and their view of reality will be partial and distorted in consequence. Therefore, from the point of view of a well socialized participant in the system, any tale told by those at the top intrinsically deserves to be regarded as the most credible account obtainable of the organizations' workings. (Becker, 1967, p. 241)

That Goffman did not take a position based on the point of view of class, which was so popular in the 1960s and 70s, is obvious. However, as Becker (2003) shows almost forty years after his above-mentioned article, a sociologist can avoid taking sides by developing analyses that break free of the simple perception of reality that is based on the idea that existence always has precisely the two sides that are reproduced in the one or the other 
conflict - analyses, I would like to add, that furthermore, through the effect of contrast, can temporarily break down the 'hierarchy of credibility'. Perhaps it was because of such analyses that Goffman ended up outside the right/left scale: 'To people who were radical, he appeared quite conservative. To people who were conservative he appeared to be some kind of radical rule breaker, an interpersonal anarchist' (Cavan, 2011, p. 26f).

\section{Popular and controversial}

Erving Goffman is in many ways an accessible sociologist. Most of the time he wrote in a very appealing and comprehensible way. Among sociology books, some of his books have been virtual bestsellers. According to Ditton (1980), Goffman's book Stigma had been printed in twenty-six editions up until the year 1980. The book The Presentation of Self in Everyday Life had up until 1980 sold half a million copies after having been almost continuously in print since it was first published in 1959, and in 1980 it was available in ten languages. Considering the interest in Goffman's sociology, which has gradually increased since his death in 1982, his books are undoubtedly still distributed in large numbers. Goffman is thus a widely read sociologist, far outside the limited circle of professional sociologists - 'a layman's sociologist', to quote Posner (1978, p. 68), who also maintains that this popularity partially explains the, at times, strong academic dislike of him. Oromaner criticises this idea, and contends that Goffman has been given a great deal of attention in the scholarly community, and in spite of his colleagues having produced critical analyses of his works 'there are few contemporary sociologists whose work has commanded more interest within the community of social scientists' (Oromaner, 1980, p. 290). As an indication of this, it can be mentioned that Goffman's book Frame Analysis from 1974 up until at least 2006 was one of the most cited works of social science in the Social Science Citation Index, according to Scheff (2006).

But Goffman is not only popular but also controversial, something that Bourdieu captured in his obituary of Goffman:

The guardians of positivist dogmatism assigned Goffman to the 'lunatic fringe' of sociology, among the eccentrics who shunned the rigours of science and preferred the soft option of philosophical meditation or literary description; but he has now become one of the fundamental references for sociologists, and also for psychologists, social psychologists and socio-linguists. (Bourdieu, 1983, p. 112)

With respect to content, Goffman seems to have left few people unaffected, something that the following excerpt from the Oxford Dictionary of Sociology illustrates:

Although Goffman has had many followers he remains unique in the annals of sociology. He broke almost all the rules of conventional 
methodology: his sources were unclear; his fieldwork seems minimal, and he was happier with novels and biography, than with scientific observation; his style was not that of the scientific report but of the essayist; and he was frustratingly unsystematic. Likewise, he is very hard to place in terms of social theory. Sometimes he is seen as developing a distinct school of symbolic interactionism, sometimes as a formalist following in the tradition of Georg Simmel, and sometimes even as a functionalist of the microorder, because of his concern with the functions of rituals (especially talk) in everyday life. He appears to have had a notoriously difficult temperament, which adds to the popular view of him as an intellectual maverick. (Scott \& Marshall, 2005, p. 252)

There is something in Goffman's sociology that alarms people, which is illustrated not least by the last sentence in the quote above. Who would get it into their head to write about the temper of Pierre Bourdieu, Anthony Giddens, or Talcott Parsons in a dictionary of sociology?

According to Posner, there was agreement about one thing in the literature of commentary that she was able to survey at the end of the 1970s:

The picture which Goffman paints of mankind and society is not a very pretty one, nor is it an issue which seems to concern him. This fact alone makes him very unpopular among many of his colleagues, who believe that it is the obligation of sociologists to right the wrongs of the social system they study, or at least to pay lip service to the liberal egalitarian myth. (1978, p. 72)

Goffman's style of research and presentation is also perspectivegenerating, something that can contribute to his readers' beginning to think differently about the phenomena in which Goffman chose to interest himself. According to one of Goffman's students, he had an overarching thesis: 'Don't take the world at face value' (Marx, 1984), which could also possibly be a description of Goffman's style of doing research. At the same time, this thesis is a play on words, because life would be completely intolerable if people did not believe in and take some things for granted, and here there is a difference between social life as it is lived and as it is studied, something that has a certain importance if we want to understand Goffman and sociology. He goes rather far in his questioning of the world as it appears to be, which is clear from an interview with Goffman conducted by the Belgian sociologist Verhoeven in 1980. Verhoeven attempts in different ways to make Goffman characterise, position, and ideologically anchor his sociology, and eventually asks, 'Can I say that in your approach the individual is the most important starting point for sociologists?'. Goffman then answers,

What an individual says he does, or what he likes that he does, has very little bearing very often on what he actually does. [...] So I'm perfectly 
prepared to give you my view on these matters, but I would like to caution you that there is no reason for taking them seriously. (Verhoeven, 1993, p. 322)

Hannerz's conclusion after having discussed different influences on Goffman and Goffman's relationship to different theoretical schools is a pretty good summary: 'Above all, however, Goffman has been his own man' (1980, p. 202).

Since the 1950s, the word 'Goffmanesque' has occasionally been used to characterise Goffman's style of research and presentation, and sometimes the user has not provided the word with an explanation, probably in the conviction that such an explanation would be superfluous (one example is quoted by Burns (1992, p. 1)). In an article published in 2009, Louis Menand, Professor of English at Harvard University, writes the following:

Erving Goffman was a crossover writer. His work, even simply his name, had significance for people who worked in literature, in history, in media studies, in political science, in psychology, in law schools and business schools - and, of course, in anthropology and linguistics. If someone in those fields referred to a situation or an analysis as 'Goffmanesque,' everyone knew what she meant. (Menand, 2009, p. 296) ${ }^{9}$

In spite of Goffman's special style, each person seems to be able to read and use him in their own way. When someone for instance claims that Goffman's sociology is existentialist (J. Lofland, 1980; MacCannell, 1983), it is possible to find another person who claims that 'Goffman's man shows no sorrow, no passion, no love, no hate, no anger. He lacks affect; shows no angst; there is no suffering in his soul. He has no soul' (Psathas, 1977, p. 89). On the other hand, for another researcher this may be a basis for understanding the emotional control that people exercise within, e.g., service professions (Hochschild, 1979). Politically speaking, Goffman in a corresponding way seems to be able to attract as well as repel most people: 'Some view him as a political radical; others view him as a middle-class conservative; while others [...] view him as apolitical', writes Posner (1978, p. 71). In this context can also be mentioned Gouldner's (1971, p. 381) characterisation of Goffman's dramaturgical theory:

The dramaturgical model reflects the new world [...] In this new world there is a keen sense of the irrationality of the relationship between individual achievement and the magnitude of reward, between actual contribution and social reputation.

And when Jenny Diski rereads a few of Goffman's books thirty years later, she writes, 'Reading Goffman now is alarmingly claustrophobic. He presents a world where there is nowhere to run; a perpetual dinner party of 
status seeking, jockeying for position and saving face' (Diski, 2004, p. 10). Denzin expresses something similar:

He gave midcentury academic sociology exactly what it wanted, and what it needed: Men and women in gray flannel suits performing the rites and rituals of a postwar white collar society, a society on the move [...] Goffman's actors did not resist, they conformed to the requirements of a local and global capitalism that erased class, race, and gender in the name of a universal, circumspect human nature. Goffman's moral selves knew their place in the order of things. (Denzin, 2002, p. 107)

However, Goffman himself seemed not to know his place in the interaction order, but challenged it, sometimes in such conspicuous ways that there is now a minor genre consisting of Goffman anecdotes about frame breaks, whereof quite a few can be accessed in the Erving Goffman Archives on the Internet. For instance, in an article in the Winnipeg Free Press Goffman's behaviour is described in connection with his being appointed an honorary doctor at the University of Manitoba in Canada in 1976. He delivered a speech to the newly graduated students, which even today would probably be considered a severe breach of etiquette at such a function. It was reported under the heading 'Aging idiots' gloomy world forecast for grads' (1976), and Goffman felt that students faced a dismal future, governed by ageing idiots in a society whose social forces nobody seemed to understand. On one occasion he stopped speaking to 'shoo away a photographer'. According to the newspaper's comments, he made 'wry observations' on, among other things, outrageous patriotism and recurrences of nationalism in Canada, and observed, 'Not even today have we learned to make democracy safe for the world'. Goffman also encouraged the students 'to remain clearheaded and curious' and said that 'the only worlds left free to you to explore are those of the mind'.

Finally, in the succession of descriptions of Goffman and his sociology, Winkin and Leeds-Hurwitz (2013, p. 59) write about three different Goffmans: the one who describes the world as 'cynically manipulative', the one who sides with the underdog, and the more technical Goffman. It is this last-mentioned Goffman that we will soon see in action in Frame Analysis. But first a few words about Goffman's overarching perspective and interpretational framework.

\section{Notes}

1 Biographical information about Goffman has, if not stated otherwise, been taken from Winkin (1999), Fine and Smith (2000), Treviño (2003), Smith (2006), and Goffman's CV from 1979, which can be found in the Erving Goffman archives at the University of Nevada in Las Vegas, http://www.unlv.edu/centers/ cdclv/ega/documents/eg_resume_79.pdf.

2 Supervisor for a number of dealers. 


\section{Goffman and the interaction order}

3 A complete bibliography can be found at the end of this book.

4 According to an investigation conducted by Times Higher Education in 2009, Goffman was the sixth most quoted writer in the humanities, after Giddens and before Habermas: www.timeshighereducation.com/news/most-cited-authorsof-books-in-the-humanities-2007/405956. article (accessed 28 September 2016).

5 Quoted from the programme for the inaugural ceremony at the University of Chicago on 18 December 1979: http://cdclv.unlv.edu//ega/documents/uchonors. pdf (accessed 30 September 2016).

6 Cavan in e-mail to the present writer on 18 October 2011.

7 Hannerz in e-mail to the present writer on 11 April 2012.

8 For more on this, see Goffman (1989).

9 Goffman was apparently so transgressive that Menand forgets to include Goffman's own subject, sociology, in his list. 


\section{The interaction order is in the balance: The dynamic relation between ritualisation, vulnerability, and working consensus}

Goffman's object of study above all others was social interaction as an ordered activity, or, in other words, the interaction order, as he himself called it in his doctoral dissertation (Goffman, 1953) and in a posthumously published speech written thirty years later in connection with his having been elected chairman of the American Sociological Association (Goffman, 1983b). Goffman tried to understand social interaction using different metaphors, of which ritual is one of the most recurring, since it is found both at the beginning and at the end of his career. Inspired by Durkheim, Goffman interpreted social interaction as rituals built on respect for the individual. What I call the politeness and respect theme in Goffman's sociology is based on such an understanding. It means that individuals help each other maintain a kind of balance and stability in social interactions, thus contributing in a way that was not intended to maintain the social interaction order or the ritual order, as Goffman also called it (it could also be called a frame that regulates how social interaction should be performed). This is where individuals need and develop an ability to interact with others that can vary over time on the basis of person, gender, class, age, culture, society, and situation, but that, according to Goffman, retains certain traits common to these categories:

Societies everywhere, if they are to be societies, must mobilize their members as selfregulating participants in social encounters. One way of mobilizing the individual for this purpose is through ritual; he is taught to be perceptive, to have feelings attached to self and a self expressed through face, to have pride, honor, and dignity, to have considerateness, to have tact and a certain amount of poise. These are some of the elements of behavior which must be built into the person if practical use is to be made of him as an interactant. (Goffman, 1955a, p. 231)

When this works, a kind of balance or equilibrium is created, which Goffman describes as the result of unspoken agreements among the interacting parties and which he calls a temporarily working consensus. But this consensus is vulnerable. A barely perceptible wink noticed by somebody 
other than the person for whom it was intended can, for instance, have devastating consequences for the equilibrium of certain social interactions. It can be re-established, but sometimes it can also collapse completely.

The interaction order is thus characterised as a balancing act. Two 'forces' are at work: on the one hand ritualisation; on the other vulnerability, and the equilibrium between these two can be called a temporarily working consensus. Dichotomies, such as the one between ritualisation and vulnerability, are common sociological tools, and there are a number of classical ones - Gemeinschaft/Gesellschaft, mechanical/organic solidarity, rationalisation/charisma, labour/capital - that have in one way or another inspired sociologists since the nineteenth century. It may be pertinent to mention that Everett Hughes in 1951 published an article where he developed a dichotomy that could be used in comparative studies of work: 'To this end, we seek for the common themes in human work. One such theme is that of routine and emergency' (Hughes, 1951, p. 320). According to Burns (1992, p. 11) the most influential of Goffman's teachers 'was undoubtedly Everett Hughes' and his article was published at the same time that Goffman was finishing his doctoral dissertation. The distance between, on the one hand, routine and emergency and, on the other, between ritual and vulnerability is not particularly great, which is why Hughes's ideas may have inspired Goffman. The difference is that Goffman, using Durkheim's sociology of religion, makes an interpretation of 'routine', which is transformed into 'ritual', while at the same time 'emergency' is reinterpreted from a particular moment of crisis that occurs now and then into a constantly lurking 'vulnerability'. But Goffman did not simply construct a dichotomous tool of interpretation; he also took a step further to focus on the equilibrium of social interaction between ritualisation and vulnerability, asking under what conditions this equilibrium is maintained, broken down, and re-established. Below I will represent how Goffman describes ritualisation, vulnerability, and a temporarily working consensus, concluding by briefly describing the social interaction dynamic created by the interplay between these factors.

\section{Ritualisation}

The literature on ritual and ritualisation is multifaceted and can be found in different disciplines; for instance, anthropology, religious studies, and sociology, each of which in its turn contains several different interdisciplinary schools that use the concept of ritual in order to understand its relationship to, e.g., myth, religion, and society (see also Bell, 1997). The concept of ritual seems to be difficult to define in a comprehensive manner: 'Defining the term "rituals" is a notoriously problematic task. The number of definitions proposed is endless, and no one seems to like the definitions proposed by anyone else' (Snoek, 2006, p. 3). For their part, Brosius and Hüsken (2010) feel that an unambiguous definition of ritual is neither possible nor desirable, 
because ritual quite simply means different things in different contexts. Below I will mention a few definitions of importance for the understanding of Goffman's use of the concept of ritual.

\section{Defining ritual}

Among the attempts to define the concept of ritual can be mentioned Firth's (1972, p. 3) 'symbolic action relating to the sacred'. Enfield's (2009, p. 77f.) differentiation between three ways of using the concept of ritual is also important: (1) 'ritualized communicative behavior', which includes, e.g., human symbolic behaviour and also animal mating behaviour; (2) 'formal ritual', which is defined with reference to the above-mentioned definition by Firth; and (3) 'everyday ritual', such as, for instance, greetings.

After having differentiated between ritual behaviour and ritual action, respectively, Bocock defines ritual as the 'symbolic use of bodily movement and gesture in a social situation to express and articulate meaning' (Bocock, 1974, p. 37). Another definition can be found in Rappaport, who argues that ritual is 'the performance of more or less invariant sequences of formal acts and utterances not entirely coded by the performers' (Rappaport, 1999, p. 24). By 'coded' it is meant that the persons performing the action 'follow, more or less punctiliously, orders established or taken to have been established, by others' (Rappaport, 1999, p. 32). Snoek reproduces the above definition as one of several classical ones, and then breaks these down, in an effort to avoid vagueness, into the following definition: 'A ritual is a prescription (written or otherwise) for a particular ceremony' (Snoek, 2006, p. 14). In this context should also be mentioned Grimes's (2006b, p. 163) differentiation between rite: a sequence of actions given a special meaning because of its stylisation, condensation, or elevation; ritual: actions that are characterised with reference to 'a certain "family" of qualities', such as formalisation, patterning, and condensation, and by their being displayed in a kind of action that can be called performance; and ritualisation: activities that are not normally perceived as, but treated as if they are or could be, rituals; for instance, giving birth, cleaning, and watching TV. In this context can also be mentioned ethologist Eibl-Eibesfeldt, who argues that 'human rituals are [...] basically signals. They signal power, submission, friendship and the like. A very important function of rituals is group cohesion' (Eibl-Eibesfeldt, 1971, p. 54).

A completely different way of relating to rituals is to associate them with the tendency of modern social development to disenchant, through rationalisation, enlightenment, and commodification, many things that had previously been given a sacred meaning - i.e., among other things, rituals in the narrow sense given to them by Firth, but also rituals connected to secular institutions, such as marriage, birth, death, graduation, and the like. 'Ritual has had something of a poor reputation in the contemporary world', writes 
Seligman et al., 'relegated to a form of deviance [...] or extirpated as an empty, external husk, lacking in ultimate spiritual significance, or again, condemned as a form of authoritarian control and dominance' (Seligman, 2008, p. 10). According to these writers, the determined struggle in modern society for sincerity and for establishing 'how things really are' pose a threat to rituals. But in spite of this, Seligman et al. argue that they have recently seen an increase in rituals - both religious and other, more everyday kinds. With reference to Goffman, they claim that social rituals, for instance greetings, create a common social world. Goody, however, objects strongly to any attempt to extend the concept of ritual to include all possible areas, and asks what the point is in calling all manner of things rituals, because this does not actually add anything significant (Goody, 1977).

Thirty-five years later, Knottnerus (2011) claimed that the concept of ritual was underdeveloped and ignored in sociology because sociologists (with brilliant exceptions such as, for instance, Durkheim, Goffman, and Collins) feel that rituals belong in pre-modern societies and live on in modern societies only in the context of religious life. In addition, rituals are often seen as less real and significant than other social processes and structures. The theory developed by Knottnerus - structural ritualisation theory - is based on the idea that everyday life rests on individual and social rituals that contribute to stability in social life. Burke (2005, p. 41) argues that one can see a shift from research on "ritual" as a separate category of human action to the examination of all human behavior as more or less "ritualized".

Grimes, too, rejected Goody's idea that the concept of ritual is unnecessary, and would instead claim that ritual is a useful concept outside what some people see as its principal area, but the prerequisite for this is that the concept is defined and that researchers make clear what they want to use it for. This is because the concept swings between a very narrow usage where ritual is seen as synonymous with religion and sacredness, something that makes its relationship to everyday life obscure - and a far too broad usage that means that ritual is placed on an equal footing with routine, patterns, and formalisation, and that causes the difference between ritual and 'regular' social interaction to disappear (Grimes, 2006b, p. 11). Against this background, Grimes reviews how the concept of ritual has been used over time. At the end of the nineteenth century the concept was used to answer questions about the origins of religion: ritual was seen as a kind of primal religious activity, and what was important then was that ritual was seen as action rather than thought. At the beginning of the twentieth century questions were asked about the functions of rituals, and among the answers mentioned by Grimes are social solidarity (Durkheim) and personal comfort (Freud). In the mid twentieth century rituals were linked to social change, and the interest among some researchers, for example Victor Turner, was focused on how rituals could mobilise forces that could lead to changes in individuals and hierarchies, and to a release of creativity. At present, argues Grimes, research on ritual deals to a great extent with the limits of 
this phenomenon. Ritual is then seen, among other things, as an idealised, controlled, and delimited space - separated from everyday activities - and thus becomes a kind of image of how things should be. That is to say, rituals could show how things could be, and here, argues Grimes, performance, if defined as showing doing, is a kind of ritual tool.

When Schechner (2006, p. 28) asks what to perform means, he relates its different meanings to being, doing, showing doing, and explaining 'showing doing'. Of these four, the ones that are usually related to ritual are doing and showing doing. Grimes demonstrates this through the claim that "whenever ritualists ("people who engage in ritual") enact ("put into force"), they also perform ("show what they are doing")' (Grimes, 2006a, p. 380). It can thus be said that ritual action is not just any action, but an action that particularly underlines and is intended to show that it is being performed precisely in relation to the things the ritual includes. Repetition of sequences of actions, stylisation of the actions, and those actions symbolising something else are tools for showing doing. Goffman's sociological perspective on social interaction emphasises precisely the difference between doing and showing doing, as well as the fact that the showing itself can be and tends to be ritualised. Goffman used the concept of performance in his first book, The Presentation of Self in Everyday Life, in a considerably more narrow manner than it is used today, but the central distinction between doing and showing doing is the message of the book - indeed, it is its primary point. This distinction is perhaps the most important prerequisite for Goffman's attempts to understand social illusions.

\section{The concept and phenomenon of ritual in Goffman's sociology}

When it comes to Goffman's use of the concept of ritual, references are usually given to the essays 'On Face-Work: An Analysis of Ritual Elements in Social Interaction' (Goffman, 1955a) and 'The Nature of Deference and Demeanor' (Goffman, 1956). However, it must be said that Goffman refers to ritual throughout his entire body of works; the central distinction between doing and showing doing is, for instance, dealt with throughout. Most of Goffman's sociology can be related to this distinction. However, I suspect that the early texts (from the 1950s and 60s) make use to a greater extent of religious analogies and metaphors (for instance, religious ceremonies and the sacredness of the self), while the later texts (from the 1970s and 80s) to a greater extent anchor rituals in the routinisation of social interaction. Seen from this perspective, the 1971 book Relations in Public sits on the threshold between these two periods. This becomes apparent by the fact that at least two of its first chapters provide more detailed explanations of earlier aspects of the theme of ritual (e.g., the territories of the self, rituals and ceremonies) and also that two of the later chapters deal more with the ritualisation/routinisation of social interaction (e.g., 'tie-signs' as well as the oscillation 
between 'go about' and 'alarmed' in social interaction in public places). Below I will relate in greater detail how Goffman uses the concept of ritual in his various texts.

The two above-mentioned essays from the mid 1950s have to do with the sacredness of the individual in modern society, and Goffman writes that our secularised world is still religious but in a different way than earlier, in that the individual him- or herself has become a kind of god whose honour is safeguarded through rituals (1956, p. 499). This view of the individual can be linked both to Durkheim (1965 [1912]), who argued that both society as well as the personality of the individual are the subjects of religious rituals, and that the individual has become a kind of sacred object in modern societies, and to Simmel, who argued that

an ideal sphere surrounds every human being, different in various directions and toward different persons; a sphere varying in extent, into which one may not venture to penetrate without disturbing the personal value of the individual. Honor locates such an area. Language indicates very nicely an invasion of this sort by such phrases as 'coming too near'. The radius of that sphere, so to speak, marks the distance which a stranger may not cross without infringing upon another's honor. (Simmel, 1906, p. 453)

Goffman describes in detail how the sacredness, honour, and ideal sphere of an individual affect social interaction in the essay 'On Face-Work', in which the face of the individual, the image of him- or herself that the individual has created in interaction with other people, is studied via the face-work of that individual. Face-work has several aspects: maintaining face, avoiding losing face, saving face if it has been lost, and helping others maintain and/or save face. These are the traffic rules of social interaction, argues Goffman, and they contain what he later called impression management, self-control, avoidance activities engaged in when a person's own face risks being lost, and corrective measures when the rules of order have been transgressed. The latter two are made the subject of in-depth analysis in the book Relations in Public. The order for managing the face of an individual is ritual, argues Goffman, and against this background he describes the 'ritual roles of the self'. One role is, expressed freely, the role of the self as a sacred object. The other role is performed by the individual her- or himself in a ritual game controlled by respect for the individual and the rules of behaviour that control interaction with other people and that, in concrete terms, mean that others are treated in a polite and respectful manner. The first role of the self is thus a kind of abstract vision of the self as worth sanctifying, while the second role of the self is the actual ritual action that real individuals perform. This doubleness can be expressed in the following manner:

When a person is responsible for introducing a threat to another's face, he apparently has a right, within limits, to wriggle out of the difficulty 
by means of self-abasement. When performed voluntarily these indignities do not seem to profane his own image. It is as if he had the right of insulation and could castigate himself qua actor without injuring himself qua object of ultimate worth. (Goffman, 1955a, p. 225)

Goffman creates two definitions of ritual in these early texts. The first one is developed against the backdrop of an argument about a disturbance in social interaction between individuals creating a 'ritual disequilibrium or disgrace', after which the ritual equilibrium must be re-established:

I use the term ritual because I am dealing with acts through whose symbolic component the actor shows how worthy he is of respect or how worthy he feels others are of it. The imagery of equilibrium is apt here because the length and intensity of the corrective effort is nicely adapted to the persistence and intensity of the threat. One's face, then, is a sacred thing, and the expressive order required to sustain it is therefore a ritual one. (Goffman, 1955a, p. 219)

The second definition of ritual is created in connection with an analysis of tokens of respect expressed in, for instance, greetings and apologies. Goffman writes that he uses the term ritual because such secular tokens of respect represent ways in which the individual has to be attentive to and shape the symbolic meanings of his or her actions when she or he is in immediate proximity to an object of particular value (Goffman, 1956, p. 478). Here Goffman views ritual in approximately the same way as does the previously mentioned Firth (1972) - i.e., as 'symbolic action relating to the sacred', where the sacred object is the individual.

We can find many illustrations of this. Not least does it have to do with how we deal with dead people. The ritualised respect for dead people can be seen precisely as respect for the individual in a kind of abstract sense. The things we do in connection with death and the dead may seem hard to understand and even unnecessary from a rationalist perspective. The fact that forensic medical examiners continued to work for years with identifying the victims after the attack on the World Trade Center on 11 September 2001 can of course be seen as a waste of resources, but also as a politicisation of a national trauma, created with the ritualised sacredness of the individual as a central ingredient. Connected to this is of course the fact that certain individuals are more sacred than others, in death as in life, as when Israel in just such a ritualised way released 1,000 Palestinian prisoners in October 2011 in exchange for the Israeli soldier Gilad Shalit. His name was mentioned in the media all around the world, while the freed Palestinians remained a faceless mass.

Goffman often exemplifies the sacredness of the individual with personal actions of respect in the form of greetings and politeness, and warns that these perhaps most often correspond to the interactions of the middle class. The idea of the sacredness of the individual can however also be linked to 
what in sociology and other social sciences is usually called individualisation. Democracy, human rights, and widespread individual choice of most things, all of which were almost unthinkable 200 or 100 years ago, can be seen as illustrations of the strong position held by the individual in late modern societies. When it comes to this, Goffman follows Durkheim's interpretations, based on the sociology of religion, of the position of the individual in secularised modern societies. But Goffman transcends Durkheim's sociology of religion when he demonstrates that social rituals expressing respect and esteem for an individual can be empty shells that only make up a display of respect and esteem for that individual. This can be illustrated by the fact that in parallel with the institutionalisation of the individual's rights, choices, and the like, we can also see an institutionalisation of mechanisms that display just such an image of respect for the individual and that, among other things, are used to deceive the system.

As an example of this can be mentioned codes of ethics found in profit-making businesses. Such codes often contain words of respect about the rights of the individual and these can be seen as just such an example of the sacredness of the individual, until it is revealed that these codes are mostly applied in countries where companies are expected to have such codes, while the same company in other countries exploits child labourers, poisons the environment and conditions of life for individuals, and does not see the rights of their employees as an important issue. The ethics codes are thus displayed globally, but only applied locally. In a corresponding way we can say that where there are democratic institutions there is also a display of democracy. Similar examples can be found in public services, such as schools, where, for instance, it happens that people try to deceive the system by expressing respect for words in ordinances and curricula with regard to, for example, bullying or basic values, while at the same time students and/or personnel are treated disrespectfully.

In his book Relations in Public Goffman defines ritual as 'a perfunctory, conventionalized act through which an individual portrays his respect and regard for some object of ultimate value' (1971, p. 62). This definition corresponds well to the ways of using the concept of ritual mentioned by Enfield, and then in particular the previously mentioned definition by Firth 'symbolic action relating to the sacred' - as well as Goffman's own analysis of the sacred individual in his early texts. At the same time Goffman develops his perspective using Durkheim's distinction between negative and positive rites, which can be defined as two different kinds of rules of behaviour in the interaction with sacred objects. Negative rites are prohibitions, regulations on how to avoid certain things, and the like, while positive rites regulate how to interact with sacred objects. Goffman discusses violations of the negative rites of social interaction under the designation 'remedial interchanges', and this has thus to do with how an individual who has violated rules of behaviour can apologise and again become a respected part of the social interaction order. Remedial interchanges, argues Goffman, are a 
central part of social interaction in public places, an important tool in the organisation of the interaction order in these places. This is because violations of individual territories regularly occur in public places in modern societies (for example, because of crowding), violations that demand that an individual rehabilitate that part of the order that she or he has violated and thereby also him- or herself as a good interactor.

When a person disregards positive rites, that is to say rites that regulate how to interact with sacred objects, in this case the individual, the action is corrected through what Goffman calls supportive interchanges. This type of interchange is described as a gift order with reference to The Gift by Mauss (1954), a connection left out of the two essays from the 1950s but one that Goffman here develops further and modernises. The gift order is described as giving and taking with a display of gratitude. Against this background Goffman summarises as follows:

These two basic interchanges, the supportive and the remedial, are among the most conventionalized and perfunctory things we engage in and traditionally have been treated by students of modern society as part of the dust of social activity, empty and trivial. And yet [...] almost all brief encounters between individuals consist precisely and entirely of one or the other of these two interchanges. In brief, whenever one individual rubs up against another, he is likely to say hello or excuse me. (Goffman, 1971, p. 64)

'Hello' is thus part of the ritual gift order, while 'excuse me' is a minimal remedial action used when that order is violated. Both are often pronounced in a strongly ritualised or routinised, almost automatic, way, and it is usually not until these three little words are left out that their existence becomes apparent as part of a much greater interaction order.

Here it seems to me as though Goffman embarks on a movement that leads in part away from an understanding of the interaction order based more on the sociology of religion: the routinisation of everyday existence is placed at the centre rather than the sacred individual. This becomes apparent also when Goffman discusses the fact that it is possible to violate the basic rules that govern social interaction

as when individuals attack institutional authority by publicly performing obscene gestures. But even here conventions reign. A particular set of understandings is violated, but the means of violation are themselves necessarily drawn from a wider vocabulary of ritual that is common to all. Revolutionaries of decorum must rely on the same idiom as do those who would gently tiptoe through all their social occasions. (1971, p. 237)

The movement away from the sociology of religion continues in Forms of Talk, where Goffman complains about the fact that rituals at one and the same 
time can be both too well-filled and empty, can both signal otherworldliness and automaticity. In this context he also tests various alternative terms that could perhaps replace 'ritual', and his selection is rather interesting: 'ceremonial', 'politeness', and 'expressive'. He immediately rejects the first two of these, but the third he considers interesting, since those actions that are perceived as ritual actions are always expressive because an actor expresses his or her relationship to 'objects of value in their own right' (Goffman, 1981a, p. 17). ${ }^{1}$ In the book Gender Advertisements, which is an analysis of more than 500 advertisements that depict women and women in relation to other women, children, men, and hierarchies, among other things, Goffman plays with the concepts of both frame and ritual in order to get a grasp of what he calls commercial realism: 'the standard transformation employed in contemporary ads, in which the scene is conceivable in all detail as one that could in theory have occurred as pictured, providing us with a simulated slice of life' (1979b, p. 15). The conclusion becomes, among other things, that the characteristic format of rituals - standardisation, exaggeration, and simplification - is developed further within the context of the "commercial realism' of advertisements. Goffman calls this hyper-ritualisation, or, using another term, exaggerated ritualisation:

By and large, advertisers do not create the ritualized expressions they employ; they seem to draw upon the same corpus of displays, the same ritual idiom, that is the resource of all of us who participate in social situations, and to the same end: the rendering of glimpsed action readable. If anything, advertisers conventionalize our conventions, stylize what is already a stylization, make frivolous use of what is already something considerably cut off from contextual controls. Their hype is hyperritualization. (Goffman, 1979b, p. 84)

As I now conclude this survey of the use of the concept of ritual I would like to emphasise that my purpose in using the concept of 'ritualisation' to describe an important part of Goffman's sociological perspective is that it will symbolise things in the social interaction that makes it more stable and predictable. This is not to say that the reality of social interaction is stable, but rather that it is based on certain rules that most people follow when they interact with other people, albeit not rules that have been put to a vote or that lead to incarceration if we violate them. These are vulnerable rules, fragile rules: 'But it is to these flimsy rules, and not to the unshaking character of the external world, that we owe our unshaking sense of realities', writes Goffman (1961b, p. 80f).

\section{Vulnerability}

Analytically it is possible to distinguish between ritualisation and vulnerability, as I do in this chapter in order to show more clearly these two central 
aspects of Goffman's sociology, but in empirically observable social interaction they are connected. Vulnerability in the context of social interaction means, in principle, that social interaction is fragile and liable to collapse unless its different participants singly and together maintain the interaction order - consciously, by mistake, or because they cannot control the impressions of other people well enough. In other words, the interaction order is in the balance and does not become ordered on its own. Concretely, vulnerability means several different things in social interaction:

1 Human beings are vulnerable and can be hurt in their interactions with other people.

2 An individual's own definitions of reality are vulnerable.

3 Shared definitions of reality are vulnerable because they depend on interacting individuals defining reality in roughly the same way.

Why, then, is order vulnerable? Perhaps the most important structural condition for Goffman's studies of social interaction is that the interacting people are in immediate physical proximity to each other. This means that interaction occurs both with expressions given (e.g., verbal and non-verbal expressions over which an interacting individual has a relatively great degree of control) and expressions given off (e.g., verbal and non-verbal expressions over which an interacting person has a lesser degree of control). Because of this, the risk is greater that the interacting individuals transmit contradictory expressions than if they were mainly to use expressions given, which for instance I do when I write this book: as a reader you have no opportunity to decipher my body language, trembling, perspiration, and the like; nor do you have access to all my earlier versions of this text. On the other hand, you as a reader can interpret my choice of expressions, formulations, and other linguistic choices as signs of who I am. During a discussion at a conference, Goffman called visible deficiencies in the self-presentations of individuals 'expressive leakage' (Kelman et al., 1957, p. 429), and, in another context, a lack of 'dramaturgical discipline' (Goffman, 1959, p. 216ff).

Another aspect of the physical proximity between interacting individuals that contributes to vulnerability has to do with a fear of what another person might do; for example, use physical or other forms of violence. Goffman's analysis of fear and the potential for violence in social interactions appears related to Sartre's analysis of the gaze in Being and Nothingness (Sartre, 1966 [1956]), and Sartre's claim that 'Hell is - other people!' could just as well have been Goffman's. This phrase is part of a line towards the end of Sartre's play No Exit (Sartre, 1989 [1946]), a kind of conclusion if one sees the play as an investigation of what Hell is. There are several structural prerequisites for Hell as it is described in the play, for instance the absence of mirrors. In order to see their own reflections, people in Hell have to see their reflections in each other, and another subject thus comes between a person and her or his mirror image. And because they have been unable to choose the people 
with whom they spend their time in Hell, another structural prerequisite, the mirror images often differ from the ones we provide for ourselves: false, distorted, honest, or far too honest. Hell is thus not only 'Others', if we are to believe Sartre, but the particular others that we are forced to spend our time with and reflect ourselves in. The individual is vulnerable in the presence of others, argues Goffman:

When persons come into one another's immediate physical presence, they become accessible to each other in unique ways. There arise the possibilities of physical and sexual assault, of accosting and being dragged into unwanted states of talk, of offending and importuning through the use of words, of transgressing certain territories of the self of the other, of showing disregard and disrespect for the gathering present and the social occasion under whose auspices the gathering is held. (Goffman, 1967, p. 147) ${ }^{2}$

At the same time, the interaction with others is also a stage where we perform in front of others, wash, make ourselves beautiful, try to smell good and dress up, think of how we express ourselves, try to show our best but not our only side, and show ourselves off in ways that allow us to gain advantages. Hell may well be other people, but interacting with them often seems to make us better than had we not met them in the first place. The possibility exists that these efforts are deceptive, since vulnerability and social interaction also include the making of social illusions, of which we are all capable through a greater or lesser degree of impression management. We see it in everything, from the small, manipulated everyday stories that allow us to appear in a better light, to swindlers who know how to take into account the gullibility of other people.

Vulnerability also has to do with the fact that individuals have different life situations that are connected to, for instance, age, gender, class, and culture. In this sense, individuals live in different worlds that can vary immensely and that make it impossible for them to understand each other. Individuals also have different perceptions of reality that are based both on lived conditions of life - e.g., age, gender, culture, class - and on more subjective attitudes. For instance, the alternative facts that are mentioned so often as a consequence of Trump's presidency profit by these differences and the informational uncertainty that through this can be exploited politically.

In this context, language should be mentioned as a creative and multifaceted instrument of communication, which for this precise reason also makes social interaction vulnerable. Everyday language has a rhetorical aspect, which means that the manner in which we express ourselves may sometimes be more important than what we mean, while at the same time we can very well understand the context behind vague turns of phrase. The issue is then not simply to be linguistically correct, but to be situationally correct to an equal degree. In an article with the ambiguous title 'Felicity's Condition', 
Goffman argues that narrow linguistic analyses or detailed transcriptions of sequences of conversation are not adequate tools for understanding conversations. Conversations are normatively and morally regulated, and this, too, controls what we feel is the proper expression and what is appropriately spoken.

Goffman demonstrates this with a simple example, which I summarise freely here. You have been to the cinema and seen a film. The next day you pass a person on the street who is unknown to you, but whom you recognise from the cinema. Then you will probably ask what she or he thought about the film from the previous evening, won't you? Hardly. But if the two of you on the other hand end up in a joint situation that gives reason for a conversation, you can direct the conversation to the point where you can ask that question. Goffman reviews different variations on this theme; for instance, your asking a friend whom you saw at the cinema, but who did not see you, how the film was, which is not simply a question about the film but also demands quite a bit of managing of the fact that you were both there without actually meeting each other (did he or she avoid you, or you her or him?). So the answer to the question of what he or she thought about the film can in that case turn into, 'You were there? Why didn't you say anything?', and then you have to explain why you did not, which suddenly has acquired a moral dimension that has to do with the fact that it is inappropriate not to make one's presence known if one sees a person one knows. A mutual nod at the cinema the evening before would have been enough for you to directly be able to ask, 'What did you think of the film yesterday?' This is because you are then in the same position with respect to information and can openly admit this - unless, Goffman writes mischievously, it was a porn film you had seen the evening before. For this reason, Goffman defines 'Felicity's Condition' - which means the prerequisite for the apt or correct expression - in the following way: 'any arrangement which leads us to judge an individual's verbal acts to be not a manifestation of strangeness. Behind Felicity's Condition is our sense of what it is to be sane' (Goffman, 1983a, p. 27). Conversations are thus both about what is said, about the situation in which it is said, and about normative regulations of conversations. Goffman summarises this in the following way:

Given that you have something that you want to utter to a particular other, how do you go about getting into the circumstances that will allow you appropriately to do so? (Goffman, 1983a, p. 32)

Against this backdrop, our language use is surrounded by a certain degree of caution; to simultaneously have to be linguistically, situationally, and morally correct increases vulnerability in social interactions. We quite simply have multiple opportunities to make mistakes.

Finally, we have the vulnerability that has to do with individuals' resistance, deceptions, humour, mistakes, and actions that violate norms and 
expectations in other ways. Goffman takes up quite a few of these things in his book Frame Analysis, in particular in the chapters about deception and about how to break the framings of situations, and, in the chapter on the vulnerability of experience, Goffman asks, 'how could one go about disorganizing the world?' and answers,

If there is a cognitive organization to the world we are in such that correctives to error, deception, and delusion often emerge, how can these correctives be best offset? One answer, perhaps, is to be found by reexamining the issue of transformation. For, as urged already, the hardest reality is subject to systematic alteration. (1974, p. 493)

The point is that the more convinced we are about our common unity regarding how situations are to be understood, defined, framed, and managed, the more vulnerable we are to the slightest disturbance.

\section{Working consensus}

I will finally focus my attention on the interaction itself, or the dynamic between ritualisation and vulnerability, the process in which the key is the relationship between ritualised action and everything that makes it vulnerable, as well as the balance or equilibrium between them. Goffman calls this balance 'temporarily working consensus' (and similar terms), as well as, in the article 'On Face-Work', 'ritual equilibrium'. It is important to underline that Goffman, when doing this, does not in principle give expression to a consensus perspective in contrast to a conflict perspective, which for instance is made clear in his dissertation, where he describes social interaction 'not as a scene of harmony but as an arrangement for pursuing a cold war' (Goffman, 1953, p. 40). A cold war is a particular kind of peace that is also called a 'terror balance'. In the corresponding way, the temporarily working consensus of social interaction is a consensus for which the alternative is worse, which is why the interacting parties are prepared to go quite far in order to avoid that alternative. Furthermore, Goffman emphasises that the actual content of this consensus varies from situation to situation, and I would like to argue that there are two mechanisms that, to a great extent, create the preconditions for a temporarily working consensus: the already mentioned interaction order, which is based on respect for the individual, as well as the identity values of society - i.e., the normative and institutional regulation of, expectations concerning, and ideas about how individuals should be, act, and look, and what they should do (1963b, p. 128). These control the interaction order, and the identity values to a great extent also determine the content of the social interaction rituals:

Ordinarily the definitions of the situation projected by the several different participants are sufficiently attuned to one another so that open 
contradiction will not occur. I do not mean that there will be the kind of consensus that arises when each individual present candidly expresses feelings of the others present. This kind of harmony is an optimistic ideal and in any case not necessary for the smooth working of society. Rather, each participant is expected to suppress his immediate heartfelt feelings, conveying a view of the situation which he feels the others will be able to find at least temporarily acceptable. The maintenance of this surface of agreement, this veneer of consensus, is facilitated by each participant concealing his own wants behind statements which assert values to which everyone present feels obliged to give lip service. (Goffman, 1959, p. 9) ${ }^{4}$

As can be seen, it is the temporary and superficial unity in itself that is the central thing. This consensus is one of many conceivable social realities:

The whole machinery of self-production is cumbersome, of course, and sometimes breaks down, exposing its separate components: [...] But, well-oiled, impressions will flow from it fast enough to put us in the grips of one of our types of reality - the performance will come off and the firm self accorded each performed character will appear to emanate intrinsically from its performer. (Goffman, 1959, p. 253)

In brief, this has to do with a functioning social interaction in the situation in question. The next time you meet a person who expresses a view that you do not agree with, and you suppress your view because you do not want to or do not have the strength to deal with, or are unable to handle a conflict in the situation in question, then you have experienced creating just such a temporarily working consensus.

But what compels the individual in this situation to want to reach this temporarily working consensus? What is the unity a deviation from? Here I believe we can make use of what Goffman describes as ritual equilibrium in his analysis of different kinds of face-work; for instance, the activities of an individual for maintaining his or her face as well as saving his or her own and other people's faces in social interactions. Face is then defined as 'the positive social value a person effectively claims for himself' (Goffman, 1955a, p. 213). ${ }^{5}$ When face is threatened in social interactions, the individual attempts to save it, and is often helped by other people in order to restore the ritual equilibrium, and this sequence of actions is called 'interchange' (Goffman, 1955a, p. 219). A temporarily working consensus in a situation is the experience of the interacting individuals of a mutual exchange. The advantages to the individuals of the mutual exchange is that the faces of the individuals are not challenged, threatened, or lost. This equilibrium is dependent on each participant and is based on a kind of collective non-decision to 'put up with the situation', ${ }^{6}$ and is for that reason vulnerable. Every actor can therefore, unconsciously or consciously, sabotage the equilibrium 
of social interaction; for instance, by not doing what is expected according to the kind of etiquette that regulates the interaction, by making mistakes, by creatively going against the grain of what is taken for granted, by using humour to shine a different light on everything, or doing other things that disturb or reframe the interaction order.

The relationship between interaction and a temporarily working consensus becomes, in a way, circular, because the temporarily working consensus is a kind of meaning that the interactors give to their mutual exchange, at the same time that this presupposes a temporarily working consensus. A functioning social interaction is, in other words, experienced as good just because it works. In a sense, it is an aim in and of itself. However, as has been said before, it is also vulnerable, and social interaction can therefore quickly turn into something completely different. Such rapid changes are, among other things, what Goffman's concept of frame and framing is about, something that I will show in the following chapters.

\section{Notes}

1 In this context can be mentioned that Album (2010) uses the concept 'expressive-symbolic' instead of 'ceremonial' when he analyses interaction rituals in an emergency room.

2 In the original from 1964 there is a typo that changes the entire meaning of the long, quoted second sentence (Goffman, 1964a, p. 269). The sentence was corrected when the text was republished in the book Interaction Ritual (1967).

3 In this context should be mentioned that Goffman in this text is arguing for a sociological analysis of conversations, an analysis in which it is important to see that interactions between individuals happen both in a situation and in a society, something that is of decisive importance for how we understand and can understand what is being said. He contrasts such an analysis with narrow linguistic and philosophical analyses of conversations, as well as with far too micro-oriented conversational analyses within, e.g., sociology.

4 See also a similar formulation in (Goffman, 1953, p. 350).

5 According to this definition, face is anchored in what Goffman calls social identity, personal identity, and self-identity. In some sense, face is the individual's own, but it is maintained and threatened in social interactions. Face is also a mask (a concept that Goffman, however, does not use), or the role that protects and sometimes hides aspects of the individual. In Ekman and Friesen (2003), face is a mask that can accentuate and hide, e.g., emotions. Knausgård makes an exciting reverse observation: 'In the neck is collected or expressed the fear of everything we cannot see, and if it was once upon a time associated with concrete violence it is nowadays the transferred meaning that is most stressful, the one that is formulated socially, as in being ambushed from behind, covering one's back, having eyes in the back of one's neck, being stabbed in the back' (Knausgård, 2014, p. 9).

6 Or, in other words: 'cooling out' (Goffman, 1952). 


\section{Part II}

\section{Frame and framing}




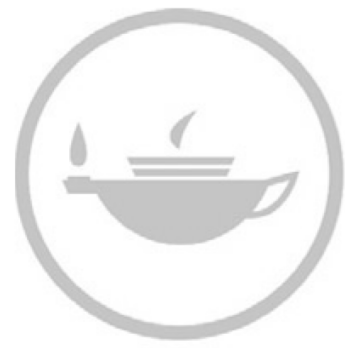

Taylor \& Francis
Taylor \& Francis Group http://taylorandfrancis.com 


\section{Frame Analysis and frame analysis}

The book Frame Analysis was published in 1974 as Goffman's ninth of in total eleven books. It is both a remarkable book and an odd one. It is difficult to understand and a bit wooden, unlike several of Goffman's other books and articles, but in spite of this it is the third most cited in Google Scholar of Goffman's eleven books. ${ }^{1}$ After having read, e.g., Goffman's book Stigma, one understands normality and deviance in quite a different way, one that is not simply about stigmatised people but also about our shared fear of becoming one of the stigmatised, whether because of appearance, aging, illness, clothes, opinions - anything that other people can refer to in their definitions of me. This fear is the driving force behind what Goffman called 'stigma management', which means that individuals attempt to control their presentation of themselves so that the stigma is hidden or made to appear to define them to a lesser extent. This kind of generalisation can be found in several of Goffman's texts, for instance in 'On Cooling the Mark Out', which is about con artists who, after completing their work, are not satisfied with the loot itself but also take pains to cool down their victim's feelings to prevent the victim from reporting the con artist to the police and thus, in some respect, causing the victim to accept his or her own fate. When Goffman lifts his gaze he sees similar coolers in many places in society; e.g., psychotherapists: 'His job is to pacify and reorient the disorganized person; [...] the psychotherapist has the basic task of cooling the mark out' (Goffman, 1952, p. 461).

Frame Analysis does not at all have this heuristic character, and several readers of the book emphasise its tediousness and long-windedness; e.g., Lemert (1997, p. xl): 'Frame Analysis was one of Goffman's intellectually least successful efforts because, at the least, it was, even for him, so extraordinarily messy'. Some readers put up with this because they, in spite of everything, appreciated some of the qualities of the content of the book:

For all its problems and prolixity, I recommend this book strongly. No sociologist since Simmel has tied together so wide a range of apparently disconnected events and activities within a single framework - from natural disasters (mine cave-ins) to verbal disasters (puns). He [Goffman] 
has extended the sociological approach to realms seemingly immune to sociological penetration (hypnosis, possession, insanity, drunkenness, childishness). (Davis, 1975, p. 603)

Others had a completely different opinion:

What have I learned from reading this book: all of its 576 pages of text? Very little and, after the high promise of the opening chapters, I am as much surprised as disappointed. (Swanson, 1976, p. 218)

A present-day reader writes,

Everyone references this book, and I wonder how many have ever read the entire thing. I definitely skimmed a good deal of it and skipped a couple of chapters. This book is unnecessarily long. The point that Goffman makes is not that complex and could be explained in less than 100 pages. I read it, because it's one of those things that you're supposed to read, I guess. However, I found it boring, repetitive, and not so enlightening. Perhaps if I had read this in the 1970s, I would have been more impressed. Who knows? (Kathleen, 2011)

In their article on Frame Analysis - seven years after the publication of the book - Denzin and Keller settle the score with, practically speaking, the totality of Goffman's project, and spare no pains to differentiate it from symbolic interactionism - i.e., their own perspective. ${ }^{2}$ They describe Frame Analysis as 'a structural analysis of selected and [...] peripheral aspects of everyday experience', and conclude that 'his concept of reality is illusive and blurred. [...] His frames catch events that are on the periphery of everyday life' (Denzin \& Keller, 1981, pp. 53, 59). We can find a similar description in Sharron, who in addition describes Goffman's analysis with the expression 'frame paralysis' (Sharron, 2000 [1981]). Zerubavel, who has been strongly inspired by Frame Analysis, does not share this view, and instead describes the book as 'a masterful study of our experiential partitioning of reality' (1991, p. xi).

There are, consequently, many ways of understanding Goffman's sociology, and when it comes to texts on Frame Analysis it is in many cases the writer's expectations of what a Goffman text is supposed to contain that determines to a great extent her or his assessment of that text. For instance, Frame Analysis is much more tedious than earlier books - i.e., the reader in question had expected a book that was like the earlier, more stimulating, books. Frame Analysis is not symbolic interactionist but structuralist, or the other way around. Frame Analysis is not about common reality. It does not have a class perspective. All these assessments are quite possibly reasonable, but the energy of these claims does not come so much from Frame Analysis as from expectations that have been either disappointed or fulfilled. 
The reading of Frame Analysis is probably also influenced by the fact that the book has an object of study that differentiates it somewhat from Goffman's other books, which focus on the interaction order and thus on social interaction in many different contexts and forms, such as, e.g., institutions, public places, roles, norms, gender, everyday life, routines, rituals, and conversations. All these are usually experienced as central sociological areas. In Frame Analysis Goffman has two other goals in that he partly wants to illustrate what 'frame analysis' is, partly show that 'reality' can be made the subject of framing because it is not as solid as is sometimes claimed. Therefore, Goffman follows two tracks in Frame Analysis: a methodological track (How does one conduct frame analysis), and an ontological track (How can the fragility of reality be constituted?). The latter track causes the object of study in Frame Analysis, and thus the entire book, to be experienced as considerably more sociologically peripheral than Goffman's earlier and later objects of study.

\section{A general statement of what?}

The reading of Frame Analysis also appears to vary in accordance with how the reader understands what Goffman means when he writes that Frame Analysis is 'a general statement' (Goffman, 1974, p. 14). The way I understand it, 'a general statement' can mean two completely different things in light of the content of Frame Analysis. The question then becomes in what respect Frame Analysis is general and what it is that is being generalised. In the same paragraph in which we find the expression 'a general statement', Goffman writes, 'I deal again in this book with what I have dealt with in others - another go at analyzing fraud, deceit, con games, shows of various kinds'. When I read this I get the impression that Frame Analysis aims to be 'a general statement' regarding precisely the above-mentioned parts of Goffman's sociology. The following sentence contains, among other things, these words: 'much repetition of other things I've written'. If we presume that it relates to the things Goffman enumerates in the previous sentence, then 'a general statement' refers to what he has written about fraud, con games, impression management, shows, etc. and not to everything he has written. This is confirmed to some degree by the fact that Goffman in the same sentence mentions a list of his own books that he refers to in Frame Analysis and which contains six books (1961b, 1963a, 1963b, 1967, 1970 [1969], 1971) out of his eight previous ones (1974, unpaginated page after p. xviii). ${ }^{3}$ It is then interesting to note that the two books left out are his perhaps best-known books: The Presentation of Self in Everyday Life (1959) and Asylums (1961a). The former is probably Goffman's most widely read book, and in it, as has been mentioned previously, is introduced a dramaturgical perspective on social interaction. For its part, Asylums gave Goffman a certain degree of notoriety in the United States, because the book was interpreted as a political contribution to the debate on total institutions, rather than merely a 
series of studies of what coercion does to people when they attempt to cope in such institutions. ${ }^{4}$ I cannot fully assess the significance of these 'exclusions' that Goffman made of his two best-known books (if they indeed were exclusions), but if Frame Analysis is 'a general statement' regarding his entire oeuvre, surely the two excluded books should have been included. On the other hand, if Frame Analysis is 'a general statement' on fraud, con games, shows, etc., surely the two excluded books should also in this case have been included, since they to a great extent refer to these things through the analysis of 'impression management' in The Presentation of Self and 'secondary adjustment' in Asylums.

Apart from these conjectures, it is in reality con games, frauds, and shows that Goffman discusses in Frame Analysis and not his general sociological perspective. Goffman makes general statements about his sociological perspective in his speech as the newly elected president of the American Sociological Association, the speech he could not deliver because of his illness and that was published posthumously with the title 'The Interaction Order' (Goffman, 1983b), in which he talks about the social interaction order. For this reason, I believe that this text is Goffman's 'general statement' on his sociological project. In addition, it is perfectly possible to connect Frame Analysis to the general perspective on social interaction in Goffman's sociology that was presented in the preceding chapter: the dynamic relationship between ritualisation, vulnerability, and working consensus. Not least the vulnerability of social reality is frequently discussed in Frame Analysis.

If Goffman's 'general statement' in Frame Analysis is interpreted as a general statement on fraud etc., the idea presents itself immediately that he refers to Schütz's enumeration of the many lifeworlds (or provinces of meaning): 'All these worlds - the world of dreams, of imageries and phantasms, especially the world of art, the world of religious experience, the world of scientific contemplation, the play world of the child, and the world of the insane' (Schütz, 1945, p. 553). Goffman discusses Schütz in the introduction to Frame Analysis, and I believe that Goffman quite simply complements Schütz's list with one additional lifeworld, which could be called the world of social illusion and social illusion-making.

\section{What kind of book is Frame Analysis?}

In addition to asking what kind of 'general statement' Frame Analysis represents, one should also ask what kind of book Frame Analysis is. Ergo: How should Frame Analysis be framed? Is it a research report? Or a theory book? Or a book on methodology? It is a little of each, but the understanding of it - at least my understanding - is simplified if it is recognised above all as a book on methodology. The method presented and practically illustrated in Frame Analysis is, then, frame analysis. ${ }^{5}$ Goffman himself writes the following about this: "My phrase "frame analysis" is a slogan to refer to the examination [...] of the organization of experience' (Goffman, 1974, p. 11). The 
presentation is, at times, rather hard to understand and long-winded, but it is not particularly difficult to understand that frame analysis, considered as a method, has to do with understanding social interaction, partly by contextualising it, partly by connecting it to the sets of norms, rules, conventions, etc. that define, control, and frame interaction. If Frame Analysis is framed as a book on methodology one can, in addition, lower one's expectations with respect to its literary qualities - who would ever entertain the idea that a book on survey methods, conversational analysis, or multivariate analysis would have to be good literature? - and evaluate it in accordance with the standard usually employed for assessing books on methodology: its practical usefulness.

I thus believe that Goffman in Frame Analysis describes how he felt he was working when analysing social interaction. Frame analysis is sometimes described in such a way that the reader - at any rate the present reader cannot completely put his or her finger on what it means; the description is, in a way, elusive. But at times Goffman concretises in a clarifying manner what frame analysis can be. For instance, he writes about 'engrossables', which means that an individual can be swept off his or her feet, become enraptured, or lose her or his head, and Goffman mentions the following three examples: 'King Arthur has just unsheathed his sword and is about to defend Guenevere', 'The little otter is about to attack his mother', and 'His bishop is about to threaten my knight' (Goffman, 1974, p. 46). Goffman writes that one way of relating to these three representations is to understand them within the framework of the respective meaningful context of each one, but then continues to argue that one could also relate to them using a common-sense version of frame analysis: 'In the Scott novel, the writer has the character Ivanhoe do all kinds of strange things', 'The otters are not really fighting', and 'The men seem to be playing some kind of board game'. In a way, one assumes a position outside the situations into which the three descriptions invite one, the situations that provide meaning and that take possession of one, and this step makes possible a kind of metareflection that can provide answers to the question Goffman claims that frame analysis should answer: What is it that's going on here? We understand what is happening if we can contextualise the events and understand the norms and rules that control the interaction: a novel, a mock fight, and a game three different frames.

\section{Notes}

1 Frame Analysis had 23,285 citations, coming after Stigma with 29,313 and The Presentation of Self in Everyday Life with 49, 581 citations (accessed 19 July 2017).

2 Which is something Goffman surely would not object to, not least because he seemed to be sceptical of dividing sociology into different schools (see, e.g., Zerubavel, 2008). Placing Goffman in or outside symbolic interactionism of course also depends on how this is defined. Helle (1998) answers in the affirmative to the question of whether Goffman was a symbolic interactionist, however 
on condition that symbolic interactionism be defined in the very broad way that Rose (1962) does: a kind of sociology of understanding à la Weber, which has been given its primary American expression via George Herbert Mead. If, however, symbolic interactionism is defined in the manner of Blumer (1986), Goffman is not a symbolic interactionist, according to Helle.

3 I have, however, only found references in Frame Analysis to five of Goffman's earlier books. He also refers once each to his Master's thesis (1949) and his doctoral dissertation (1953). In Frame Analysis, the most frequently cited of his earlier books is Relations in Public, with ten references.

4 This politicisation of Asylums was probably the reason for the only two 'political' commissions that Goffman, to my knowledge, received. The first was in 1970, when he, together with Thomas Szasz and George Alexander, founded the organisation The American Association for the Abolition of Involuntary Mental Hospitalization. The second came in 1971-75, when he was an expert on a committee of inquiry under the management of Senator Charles E. Goodell. The committee had the name The Committee for the Study of Incarceration and presented a number of suggestions based on criticism of incarceration as punishment and argued for time limits on punishments. During the four years that the inquiry was active it had twenty working meetings, and Andrew von Hirsch summarised the result of these in the book Doing Justice (Hirsch, 1976). In Goffman's obituary in the University of Pennsylvania journal Almanac ('Deaths of Four Faculty Members: Dr. Erving Goffman,' 1982, p. 1), this expert commission is emphasised. However, Goffman does not mention this commission in his CV and does not seem to have been particularly active in the committee work itself; at least there is nothing written about this. In the committee report there are special statements from four of the fourteen specially appointed experts of the committee, but nothing by Goffman. Whereas von Hirsch's book is frequently cited, one of the few references to the committee's actual work can be found in a Spanish book on criminal policy and punishment systems: 'Many of the disagreements within the committee, which are perhaps forgotten today, were reflections of different opinions and political-intellectual tensions that existed among the members of the committee' (Beiras \& Almeda, 2005, p. 268).

5 Hazelrigg (1992, p. 241) argues in a similar vein in an article on Frame Analysis. 


\section{The development of Goffman's interactional and situational frame concept}

Goffman's sociology derives its character from two existential prerequisites: (1) individuals always share a social situation with other individuals, and (2) individuals lack fully reliable knowledge about the individuals with whom they share this social situation. Goffman transforms these existential prerequisites into two knowledge problems: defining the situation and gather social information about others respectively. The definition of the situation is a concept that has to do with how individuals try to understand and handle situations they share with other people, while gathering social information is a crucial tool when individuals, quickly and often based on a weak foundation of knowledge, need to 'read' both the situation and the individuals they are interacting with. These existential prerequisites form the basis of Goffman's frame concept.

In Frame Analysis Goffman is primarily interested in the tacit understandings of reality constructed by individuals in social interaction. Goffman calls these 'frames'. Inspired by William James (1950 [1890]), Gregory Bateson (2000 [1955]), and Alfred Schütz (1945), Goffman developed the frame concept further by emphasising its simultaneously cognitive, social interactive, and situational aspects. How these work together in an actual social interaction can be made visible by posing Goffman's question, 'What is it that's going on here?' in a social interaction context. The idea of posing precisely that question is that the answer is often not a given in situations where two or more individuals interact. The interaction has to be contextualised seen in the light of its context - and what happens can then turn out to be something other than what appears to be happening, and can sometimes also quickly be transformed into something else, illustrating the vulnerability of social interaction. This vulnerability, however, is difficult to understand if we do not simultaneously understand the ritualised and routinised character of social interaction. The ritualisation makes the interaction fixed and repetitive in character by way of its being anchored in the interacting individuals' experiences of social interaction. For this reason, social interaction is at one and the same time ritualised and vulnerable, and the frame concept captures precisely this doubleness. 


\section{The frame concept}

Goffman defines 'frame' as a situational definition that follows certain principles of organisation, and as such it controls both the events and the subjective commitment of the individual within the situation in question (Goffman, 1974, p. 10f). Frame is a context that can be something else depending on how we define what is included in this context. Most obviously, what is seemingly one and the same thing can be different depending on whether what happens is, for instance, in earnest or for fun, 'for real' or make-believe, if it happens when awake or in a dream, or if it is experienced in one's memory or at the current point in time. Variations in the framing turn one thing into something else, a bit like when a terrified person is chased by a murderer, then wakes up to find with relief that it was a dream, even though not all transitions between frames are as dramatic as this one. Goffman illustrates this in his analysis of holding hands, which he sees as a tie sign. Because holding hands can also have other meanings; e.g., getting a manicure, Goffman uses the concept of frame in order to frame the differences between different meanings of holding hands, and a frame is then described as 'a different scheme of interpretation for the meaning of an act' (1971, p. 231). This demonstrates that the concept of frame is not very useful if the definition of a phenomenon is more or less unambiguous, but that it is the variations that make it useful - that is to say, when different actions and interactions appear to mean the same thing but do not.

In Goffman's version, frames appear in two forms that can be called non-transforming and transforming, respectively. Goffman calls the former primary frameworks, and subdivides these into two categories: natural and social. These should be considered as inert background perceptions about human existence. Natural primary frameworks identify

occurrences seen as undirected, unoriented, unanimated, unguided, 'purely physical.' Such unguided events are ones understood to be due totally [...] to 'natural' determinants. It is seen that no willful agency causally and intentionally interferes, that no actor continuously guides the outcome. [...] Full determinism and determinateness prevail. (Goffman, 1974, p. 22)

On the other hand, social primary frameworks include mechanisms controlled by human volition, such as laws, rules, norms, habits, power, culture, institutions, and organisations. Human volition is in control, but in a rather abstracted, mediated, and indirect way. In addition, control often occurs in a temporally dislocated way, in that individual human wills that are now active are controlled by those previously active, which have been crystallised as, among other things, the above-mentioned mechanisms. To take only two examples of social primary frameworks, we can think of how people in a relatively short time have been trained to envision space and time. For example, boundaries between nations or parts of cities are perceived as things that are practically independent of our wills. Or to put it in Zerubavel's words (1991, p. 6), 
The perception of supposedly insular chunks of space is probably the most fundamental manifestation of how we divide reality into islands of meaning. Examining how we partition space, therefore, is an ideal way to start exploring how we partition our social world. [...] Despite the fact that Egypt and Libya or Chinatown and Little Italy are actually contiguous, we nevertheless treat them as if they were discrete.

Time and how it is perceived by human subjects is another such institution that seems to control the will of individuals, to the degree that many of us experience hunger at socially appropriate times that are called breakfast, lunch, and dinner.

The concept of frame illustrates how people simultaneously create inertia and variability, and are capable of quickly shifting between these two. In Goffman's texts this ability is sometimes transformed into a human perception that presents human beings as principled when it suits them and indulgent towards deviations from principles when this is considered appropriate. Under the headline 'A Simultaneous Multiplicity of Selves' in the essay 'Role Distance', Goffman writes,

It should be noted that face-to-face interaction provides an admirable context for executing a double stance - the individual's task actions unrebelliously adhere to the official definition of the situation, while gestural activity that can be sustained simultaneously and yet noninterferingly shows that he has not agreed to having all of himself defined by what is officially in progress. (1961b, p. 133)

Goffman goes on to conclude the following, a few pages further on:

I have argued that the individual does not embrace the situated role that he finds available to him while holding all his other selves in abeyance. I have argued that a situated activity system provides an arena for conduct and that in this arena the individual constantly twists, turns, and squirms, even while allowing himself to be carried along by the controlling definition of the situation. The image that emerges of the individual is that of a juggler and synthesizer, an accommodator and appeaser, who fulfils one function while he is apparently engaged in another; he stands guard at the door of the tent but lets all his friends and relatives crawl in under the flap. (1961b, p. 139)

In the terminology established in the preceding chapter, one could say that the individual described above is busy managing an interaction order that balances between ritualisation and vulnerability.

If natural and social primary frameworks are frames that to a lesser extent are subject to transformations in the form of human situational definitions, there are also frames that are characterised by being more or less 


\section{Frame and framing}

easily transformable. Such keys or nuances represent transformations of well-known action and interaction patterns, and Goffman assigns them to two different families: one where one or more of the people involved do not know the code controlling the interactions, and another where the actors involved are familiar with the code. The first category is called 'fabrications' and is characterised by asymmetry in the sense that at least one of the actors involved in the situation is unaware of the transformation. Examples of fabrications are practical jokes and cons. The second category is called 'keyed frames' and is characterised by the fact that all the actors involved in the sequence of activities are aware of the transformation it represents. Examples of such keys are 'make-believe', 'contests', and 'ceremonies'. Keyings such as these can be imagined as horizontal transformations because they can, as it were, be placed side by side with one another. But keyings can also be transformed vertically by new layers of transformations; e.g., 'make-believe', being added on top of the earlier ones, something that Goffman calls laminations (see, e.g., 1974, pp. 156-157).

Keying thus describes a new nuance shift; for example, from 'for real' to 'make-believe', and means that something is transformed from something into something else. Goffman describes such transformations as 'the set of conventions by which a given activity, one already meaningful in terms of some primary framework, is transformed into something patterned on this activity but seen by the participants to be something quite else' (Goffman, 1974, p. 43f). ${ }^{1}$ The new nuance shift results in an established frame leading the action in another direction, and 'performs a crucial role in determining what it is we think is really going on' (Goffman, 1974, p. 45).

\section{The frame phenomenon and the spatiality of Goffman's sociology}

A frame demarcates something from something else. Within the frame exists or is created a certain meaning. One might think of the frame of a painting that frames and thus emphasises one thing and excludes other things. We become aware of this if we imagine an empty frame hanging on a white wall. In this case, the frame itself causes the white inside of it and the white outside of it to acquire different meanings, in spite of the whiteness being something that has the same appearance in both cases.

A framed nothing

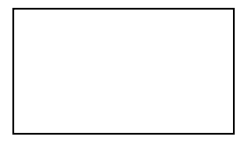

is more than nothing. ${ }^{2}$

If, on the other hand, the frame frames a canvas painted white and hung on a white wall in an exhibition, what is framed acquires a different meaning. We can then say that the artist has an intention with the framed whiteness, 
which does not have to be the case with the empty frame that frames a part of a white wall. A painting can, incidentally, have two frames: the frame that the canvas is stretched across and that is not visible for a viewer at, for example, an exhibition, and the frame that frames the picture and is seen and makes visible the content inside the frame. One frame is the invisible skeleton that holds the painting. together, and the visible frame is intended to emphasise the work of art. One is functional and the other is expressive.

We can use this concrete concept of frame, which is thus only one aspect of the concept of frame, in order to actualise the spatiality that characterises Goffman's sociology. The space, the place, the region, the framed space are both empirical observations and analytical tools for Goffman, which, among other things, delimit the objects of knowledge in which he is interested. Already in his doctoral dissertation (Goffman, 1953), his choice of studying the social life on an island, physically delimited as it is, seems to confirm this. ${ }^{3}$ In addition, we can see spatiality at work in The Presentation of Self in Everyday Life (1959) when it comes to the differentiation between front and back region as well as the outside. The perceptional barriers that constitute these regions are also spatial concepts. Furthermore, in Stigma Goffman (1963b) describes the world of the individual as being divided into different regions of importance for the management of social and personal identity. Similarly, a total institution is a place separated from other places, but the boundary between the total institution and its surroundings is considerably more coercive than the perceptual barriers that separate the front from the back regions. The mental hospital as a total institution is described in Asylums as a storage space for inmates, but the title of the book is, spatially speaking, ambiguous: asylum can mean both a care facility and a place of sanctuary. It is, however, not a place of sanctuary but nevertheless a space that Goffman describes in his article 'The Insanity of Place' when he says that mental hospitals are

hopeless storage dumps trimmed in psychiatric paper. They have served to remove the patient from the scene of his symptomatic behavior, which in itself can be constructive, but this function has been performed by fences, not doctors. (1969, p. 357)

In his analysis of the places of mental hospitals, Goffman distinguishes between 'space out of bounds', 'surveillance space' where the patient is subject to the control of the institution, and 'free places' (Goffman, 1961a, p. 227ff). Goffman often used a division into three categories, of which we have seen two examples here, when the character of a phenomenon was to be determined. Some things are immediately relevant, other things are different, and finally there are things that do not quite belong. Frames are also determined in this way: frame, breaking frame, and out of frame. This spatiality is not simply a division of the world, but also a non-totalitarian attitude to human existence.

Goffman's analysis of social interaction in public places is another example of spatiality, and in his book Relations in Public he imports territorial 
analysis from ethology and applies it to social interaction. Concepts such as reservation, territory, markers that designate territories (a coat placed over the back of a chair in a restaurant, for instance), respect and the lack of respect for the territories of others, and the assertion of one's own territory are examples of concepts that Goffman uses in his analysis of the preserves or territories of the self. Finally, the analysis of action in the essay 'Where the Action Is' (included in Goffman, 1967) is also based on spatial delimitation of Las Vegas, no less, where Goffman, in a letter to Everett Hughes, claimed to study 'the frayed edges of American civilization' (quoted in Pettit, 2011, p. 145). In the epilogue to this book ('Framed boundlessness - Action and everyday life in Las Vegas'), I reflect on the framed boundlessness of Las Vegas and the special form of action for which this boundlessness creates the prerequisites.

However, a frame does not have to refer to a particular concrete context, but may be liberated from it and made able to frame another context, which is just exactly what we see in the transition from the above-mentioned concrete spatial concept to the more abstract frame concept. ${ }^{4}$ An example of this more abstract framing is bracketing, that is - to put something within parentheses and thus create a space in the text and in thought. Quotation marks are used in a similar way, both in texts, where they can express the fact that someone else has written what is being quoted and that it consequently has been taken from another context, and in speech, where one can signal quotation marks in the air with one's fingers while one is talking and thus indicate that one is quoting, is ironic, and will not quite stand by what one has said, distancing oneself, and similar things. ${ }^{5}$ In such cases, the frame is not as concrete as the frame of a painting, and its framing function is maintained in a different way. To begin with, we can illustrate this with reference to William James and the kind of frame he describes as an 'image in the mind' - surrounded by a 'fringe - and with every such image goes'

the sense of its relations, near and remote, the dying echo of whence it came to us, the dawning sense of whither it is to lead. The significance, the value, of the image is all in this halo or penumbra that surrounds and escorts it, - or rather that is fused into one with it and has become bone of its bone and flesh of its flesh; leaving it, it is true, an image of the same thing it was before, but making it an image of that thing newly taken and freshly understood. (James, 1948 [1892], p. 165f)

'Frame' is here something that can define and redefine a context, and Goffman further develops James's cognitive concept of frame, strongly inspired by Gregory Bateson's communicative concept of frame. Metacommunication is central for Bateson, which in this particular case is manifested in the fact that animals and people can do things and at the same time communicate that what they are doing is to be understood in a different way than the literal interpretation that the action suggests. The point of departure is an observation Bateson made of monkeys play-fighting and his interpretation 
of their play - i.e., that in order to be involved in this game the monkeys had to be able to metacommunicate the message that 'this is play' in order to avoid a serious and dangerous fight (Bateson, 2000 [1955], p. 179). Play-fighting is a rather complex phenomenon communicatively speaking, because those who are involved in it must be able to communicate to each other that 'these actions, in which we now engage, do not denote what would be denoted by those actions which these actions denote', or in other words, more concretely, 'The playful nip denotes the bite, but it does not denote what would be denoted by the bite' (Bateson, 2000 [1955], p. 180). Play is, according to Bateson, a frame, which he defines as a context within which both communication and actions are given a particular meaning. As examples of frames he mentions, apart from play, also films, interviews, work, and several others. Bateson claims that play presupposes that one must be able to differentiate between the terrain and the map, between what he calls mood-signs and simulated mood-signs. Play is not the only activity where this differentiation is important; it is also a prerequisite for threats, betrayal, theatre performances, and for the social illusion-making that Goffman was often interested in.

The concept of frame is, in other words, connected to metacommunication. What characterises this communication is that it concerns the frame of reference, more precisely communication about the communication that is going on (Watzlawick, Bavelas, \& Jackson, 2011 [1967]). Against this background it can be said that Goffman's sociological project involves an investigation of metacommunication in social interaction. This is manifested in concepts such as impression management and his expressive concept of role (Goffman, 1959), ritual (Goffman, 1967), role distance (Goffman, 1961b), secondary adjustment (Goffman, 1961a), and passing and information control (Goffman, 1963b). Also his analysis of the difference between the practices and the admirable aims of total institutions that deal with people is an example of a kind of communication regarding institutional practices at the metalevel. ${ }^{6}$ In this sense, the development and use of the frame concept entails a framing of his earlier sociology in a partially new light, and a general emphasis on the metalevel of social interaction that was not equally apparent earlier. This meta-activity is captured well by Czarniawska (2006, p. 1667) when she writes that Goffman 'wanted to see what made social interactions happen, not what they meant; or rather, how did they mean what they meant'.

\section{Frame as the social dynamics of the situation}

Goffman's account regarding frames, framing, and the analysis of frames has several aspects, and in what follows I will investigate three of them more closely: the cognitive, the interactive, and the situational aspects. Against this background, I will provide an interpretation of the frame concept that suggests that Goffman's version of the frame concept intends to describe the social dynamics of the situation. 


\section{The cognitive aspect: social information and the organisation of experience}

An individual knows things about her- or himself that nobody else needs to find out, on condition that the individual him- or herself does not reveal these things (I disregard here coercive methods for making an individual involuntarily reveal things about her- or himself). This does not mean that the image the individual has of him- or herself is true and/or consistent, or that the individual is fully aware of how she or he appears to other people, but only that the individual knows or has the capacity to know things about him- or herself that no one else knows; for example, things that may be stigmatising. This is a completely central existential prerequisite for interaction among people. On this prerequisite rests, in a way, also what sociological system theorists have called 'double contingency' (Parsons, 1966 [1951]) - i.e., the lack of certainty experienced by interacting actors because they know that the other actor knows that they could act differently than they actually do (Vanderstraeten, 2002). Goffman's sociology is based on the idea that individuals not only know that a different course of action is possible, but that they actually act differently than they say they do, and talk about their interaction in ways that do not always correspond to what they are doing. This special, potentially socially illusory symbolic interaction is more than anything else Goffman's province in sociology, and already in his dissertation he compares social interaction with a model of social order (Goffman, 1953, pp. 33-41) that is based in part on Parsons's above-mentioned work and in part on Barnard (1938), and that I will describe in greater detail in the following chapter. One of his conclusions from this comparison goes as follows:

It is interesting to note that a desire to maintain a working acceptance is, paradoxically enough, one of the few general bases of real consensus between persons. Individuals regularly act on the assumption that others are the sort of persons who would attempt to maintain a working acceptance, and this imputation of an attribute is usually justified by consequent behavior. Persons, on the whole, can be relied upon to make every effort to avoid a 'scene.' In this context it may be added that many so-called empty gestures seem to serve primarily as signs that the sender is 'responsible' and can be counted upon to play the social game of maintaining a surface agreement with and an acceptance of the others. The very general tendency for persons to maintain a working acceptance during immediate communication must not lead us to make narrow assumptions concerning the motivation of this behavior. An actor may attempt to maintain the appearance of agreement in order to save the situation and minimize embarrassment, or in order to be genuinely indulgent to the offender, or in order to exploit the offender in some way. (Goffman, 1953, p. 40f) 
Goffman calls the set of facts about an individual that he or she can choose not to reveal to others the 'individual information preserve' (Goffman, 1971, p. 38f). The possibility of hiding things from other people and having control over what to show of oneself to other people is a central and recurring theme in Goffman's sociology.

At the same time that the individual exists in an information preserve where she or he to a greater extent than outside this preserve can control information about him- or herself, cover up, and make her- or himself unavailable for others, the individual is most of the time in constant contact with, aware of, curious about, and interested in other people, which means that he or she finds out and will try to find out what other individuals do, believe, think, and feel. In this way the individual's control over her or his own information preserve diminishes. This can be seen in a ritualised form when two strangers encounter each other in passing in a public place and employ what Goffman (1963a, p. 84) calls 'civil inattention'. The individuals then give each other enough attention that the other one knows that he or she has been seen, and at the same time little enough attention that the other does not feel she or he is the subject of any particular interest. In most cases these are ritual gestures that signal a certain meaning, but the background for such a ritual having developed can be that strangers who have encountered one another have wanted (and sometimes and in some places still want) to find out whether the other is dangerous or deviates from what is perceived as normal in the situation in question, and if their attention therefore has to be intensified, which Goffman calls 'becoming alarmed', or if he or she can continue doing what he or she was doing prior to the encounter - 'going about his or her business' (Goffman, 1971, p. 238). Against this background, individual normality can be defined: 'normal' individuals are people who allow us to continue with (go about) our business and do not force us to be on alert (be alarmed).

In his analysis of interacting individuals, Goffman $(1959$, p. 2) differentiates between expressions given and expressions given off, where the former are described as communication in the traditional sense, while the latter rather have to do with the meaning that other people can give to an individual's actions on the basis of other information than, for example, the individual's claims expressed about her- or himself. In the same way that the individual is interested in what other individuals are doing, she or he is interested in what really happens in situations that he or she shares with other people. In order to find out what happens in a situation, several information strategies can be applied; one is to try and read expressions given off and other aspects of the situation that say something about its meaning. Goffman describes this in the following way:

Underlying all social interaction there seems to be a fundamental dialectic. When one individual enters the presence of others, he will want to discover the facts of the situation. Were he to possess this information, 
he could know, and make allowances for, what will come to happen and he could give the others present as much of their due as is consistent with his enlightened self-interest. [...] Full information of this order is rarely available; in its absence, the individual tends to employ substitutes - cues, tests, hints, expressive gestures, status symbols, etc. as predictive devices. In short, since the reality that the individual is concerned with is unperceivable at the moment, appearances must be relied upon in its stead. (Goffman, 1959, p. 249)

The information that is referred to here is social information and it is conveyed by the very person it is about, and conveyed through bodily expression in the immediate presence of those who receive the expression' (Goffman, 1963b, p. 43).

In the article 'The Interaction Order' (1983b), Goffman describes two ways of identifying a person that both present analytically scientific as well as everyday aspects. A categorical identification of an individual means that the individual is understood in relation to social categories. Four such categories are particularly useful: age, sex, class, and race, ${ }^{7}$ and all individuals can be identified with reference to these. Individual identification, on the other hand, has to do with the special characteristics and the special combination of characteristics that an individual possesses. It can have to do with appearance, dialect, scent, etc. ${ }^{8}$ Categorical and individual identification are important features in urban environments, where the number of encounters with strangers is great and thus also the need for social information. In Frame Analysis Goffman takes social information as his point of departure by using the question 'What is it that's going on here?', which the individual tries to answer when she or he enters a situation by reading the chain of events, who the other people are, and their actions. The information state of the individual, a concept Goffman takes from game theory, is crucial for how the situation can be handled, and refers to an individual's knowledge of a chain of events, the intentions of the other people involved, probable outcomes of his or her own and other people's actions, and other similar things (Goffman, 1974, p. 133f). When I am soon to leave for the vernissage of an exhibition, I believe that I know from experience roughly how this will turn out; I also know some things about the friends and acquaintances I will encounter there. On the other hand, I do not know how the individuals who attend but are unknown to me will behave and what the unique situation in itself holds in store. For the most part, such social interpretations of situations do not have to do with creating completely new definitions, but rather with transferring the things one knows from similar situations to the current situation. The perspective on social definition that Goffman uses in his book Frame Analysis is thus strongly anchored in the experiences of the individual, and here he supports himself to a great extent on William James and Alfred Schütz. The subtitle of Goffman's book, An Essay on the Organization of Experience, points to the central role Goffman gives to 
experience. He also emphasises that the book has to do with an organisation of experiences and not an organisation of society, with the structure of individual experiences and not social structure (Goffman, 1974, p. 13). Experience is 'something that an individual actor can take into his mind', writes Goffman, and thus demonstrates that the organisation of experiences is not simply about organising what is immediately experienced, but also about organising what has been experienced earlier. Here a very concrete temporal perspective with respect to the situation is thus introduced.

Goffman's perspective is manifestly cognitive, and he does not enter deeply into the emotional aspects of social interaction. An uncontrolled emotional commitment is seen rather as something that can lead to individuals not acting in accordance with the framework that regulates actions in particular situations. This suggests that the emotional commitment also has its framework, which Goffman tries to demonstrate by pointing to the idea that a framing of activities not only has to do with creating meaning through actions but also with commitment. But the very degree of commitment is framed:

All frames involve expectations of a normative kind as to how deeply and fully the individual is to be carried into the activity organized by the frames. Of course, frames differ quite widely in the involvement prescribed for participants sustaining them. Some, like traffic systems, are properly sustained as an off-and-on focus of attention whose claim upon the participant is deep only when there is sudden trouble to avoid. Other frames, like that in which sexual intercourse is understood, prescribe involvement that is literally and figuratively embracing. In all cases, however, understood limits will be established, a definition concerning what is insufficient involvement and what is too much. (Goffman, 1974, p. 345)

Against this backdrop, Goffman discusses in passing how we can partially unconsciously become both emotionally and cognitively absorbed by activities, and thus sometimes violate the frames that regulate actions.

\section{The interactive aspect: definition of the situation and shared concept of reality}

'What is it that's going on here?' is thus the question that an individual attempts to answer in order to be able to act in accordance with the framing of the situation. It can be answered wholly or partially by making an inventory of one's own experiences, by reading how other people act in the situation in question, and by collecting the available social information about individuals on the basis of what they say and how they act, their appearances, clothes, dialects, and other things. These various bits of information can be used by an individual in order to define a situation, something that can 
be decisive for action and thus for interaction with other people in that situation. Goffman therefore sees the individual as an everyday explorer of a world that is shared with other people.

According to Goffman, it is, in addition, in an individual's interest to gain control of the actions of other people in situations that are shared, and this is done mainly by influencing other people's definition of the situation (1959, p. 3f). This influencing is, to a great degree, accomplished through what is called impression management, which can be more or less conscious. Most of the time many people attempt to control impressions in order to present themselves in the best possible light on the basis of the norms, rules, conventions, and institutions that regulate how we are expected to be as people and actors in situations. Sometimes impression management can also be a kind of exercise of power:

If one individual attempts to direct the activity of others by means of example, enlightenment, persuasion, exchange, manipulation, authority, threat, punishment, or coercion, it will be necessary, regardless of his power position, to convey effectively what he wants done, what he is prepared to do to get it done and what he will do if it is not done. Power of any kind must be clothed in effective means of displaying it, and will have different effects depending upon how it is dramatized. [...] Thus the most objective form of naked power, i.e., physical coercion, is often neither objective nor naked but rather functions as a display for persuading the audience; it is often a means of communication, not merely a means of action. (Goffman, 1959, p. 241)

According to Goffman, interacting individuals have, as has already been mentioned, an interest in creating a temporarily working consensus, which can consist of a kind of tacit agreement about how the shared situation should be defined. The driving impetus behind this is the interest of individuals in avoiding, for instance, open conflict, feelings of shame, and losing face.

In Frame Analysis Goffman takes as his point of departure the Thomas theorem when he discusses what a 'definition of the situation' is. The theorem is as follows: 'If men define situations as real, they are real in their consequences' (Merton, 1968 [1949], 1995; Thomas, 1923; Thomas \& Thomas, 1928), and Goffman's comment is quite simply that the theorem is 'true as it reads but false as it is taken', which roughly means that the theorem can be spoken but hardly performed. Why is this? It quite simply has to do with whether the Thomas theorem is understood literally - i.e., that all situations always and by everyone can be defined however that person pleases, or in a more limited way. Goffman's objections have to do precisely with the limitations of the theorem, and these objections are based on a Durkheimian view. It is true that social facts, or with another word, institutions, of different kinds do not prevent us from imagining reality whichever way we please, but we cannot expect reality to become the way we want only on the basis of our conception of it. 
Goffman also objects that the individual most of the time does not create a definition of the situation, but rather reads and interprets the situation and what it requires. Furthermore, events that are 'new' are often inserted into everyday routines that are already applied, whereafter their news value is reduced. The course of events that produces a definition of the situation can thus hardly be described using a rational flowchart; instead, the timing is of a different kind:

True, we personally negotiate aspects of all the arrangements under which we live, but often once these are negotiated, we continue on mechanically as though the matter had always been settled. So, too, there are occasions when we must wait until things are almost over before discovering what has been occurring and occasions of our own activity when we can considerably put off deciding what to claim we have been doing. (Goffman, 1974, p. 2)

In a review of Frame Analysis, Davis (1975) points out that what Goffman, by means of this book, above all proves himself to be is a social constructivist, and I can agree with this if it means that the societies and social worlds we inhabit are just that, socially constructed - not given by nature or individually constructed. Many aspects of our societies are historical and social constructions that today's individuals have to relate to as though they were 'social facts', such as norms, laws, habits, languages, different forms of durable collective associations (for instance school) and other institutions, as well as Goffman's 'own' institutions, the interaction order and the identity values of society. The institutions can be changed, but it often takes a long time, and for this reason they constitute constraints that limit the actions of individuals and can lead to resistance. Social constructions are also an expression of the exercise of power, and depending on the differences in available resources, different individuals have varying opportunities for influencing how their existence is constructed; for instance, through their or others' choice of school, education, work, living arrangements, etc.

What Goffman does with his critical commentary on the Thomas theorem is to warn of a far too voluntaristic interpretation of the theorem. We can illustrate this by differentiating between three kinds of situational definitions whose individual construction processes differ in scope: (1) societal social constructions, or institutions that emerge gradually and that to a varying extent design how individuals should define situations and act within their framework, (2) individual social definitions, which are those that are described by a Thomas theorem interpreted literally, and (3) individual social interpretations of situations, of which individuals are active constituents. Goffman turns the first and third categories against the second in an attempt to show the limitations of the applicability of the Thomas theorem. In this respect his line of reasoning is similar to Hacking's (1999) critical 
scrutiny of boundless social construction perspectives that do not clarify what a social construction actually constructs.

Goffman also develops the concept of 'definition of the situation' by clarifying what the above-mentioned third kind of situational definition means. He does this by investigating the conditions for the vulnerability of frames, and finds, for instance, that they are vulnerable when information is scarce and the interacting individuals become dependent on such information, that someone can make money from manipulating frames, and that con artists deliberately exploit frames in order to promote their own interests. However, these special cases also say something about how individuals deal with frames in situations when fraud, a profit motive, or a scarcity of information do not have a strong influence, in situations that are more 'normal' but where 'an individual's notion of what is going on can become shaky, and, in reverse, what an individual can do to undermine the frame employed by another' (Goffman, 1974, p. 486). This thus has to do with situations where individuals, you or I, begin to doubt that what is going on actually should be defined in the way that it has hitherto been defined. In order for a frame to function, this doubt has to be removed, and by functioning is then meant that the frame enables several individuals to define the situation in approximately the same way, as in this example:

To be 'natural', then, is not merely to seem at ease, but to be acting in such a way as to convince others that the apparent frame is in fact the actual one. That is what is meant, functionally speaking, by sincerity and spontaneity. When we deal with an incompetent person and find it difficult not to smile, or deal with a mad one and find it difficult not to show fear, or deal with the police and find it difficult not to show guilt, what we are tending to give away is not a person, ourselves, but a frame, one that we had been maintaining. These affects and responses are only incidentally of persons; they are primarily about frames, and it is only in frame terms that one can make sense of the concern shown in regard to them. (Goffman, 1974, p. 487)

A frame is thus the situational definition or perception of reality we share with other people. It can be an answer to William James's question: 'Under what circumstances do we think things are real?' (James, 1950 [1890], p. 287). To Goffman, James's 'we' literally means we because a social situation implies co-presence. ${ }^{9}$ Frames can therefore also be types of social worlds, illustrated for instance by Fine's (1983) application of the frame concept in an analysis of different social worlds in role-playing games. Another example is Goffman's play with the language of different social worlds when he lets British historian and writer of the book Diplomacy, Sir Harold Nicolson, advise a diplomat to exercise self-control in street language: 'Baby, don't blow your cool' (Goffman, 1967, p. 227). 


\section{The situational aspect: the situation as a shared frame and its social dynamics}

The question 'What is it that's going on here?' is, as previously stated, the point of departure for Goffman's book Frame Analysis, and the answer to this question can claim to be a general theory about how individuals orient themselves in situations they share with other people. The answer is, in summary, that an individual through her or his experiences gains an interpretational competence on the basis of which he or she reads and gives meaning to the context of situations. Goffman calls the pattern of such contexts a 'frame'.

In a few texts that were published before Frame Analysis, Goffman defines the frame concept in different ways; e.g., as a 'scheme of interpretation for the meaning of an act' (Goffman, 1971, p. 231). In his essay 'Fun in Games', Goffman writes the following about the frame concept as it was used by Bateson:

In Bateson's apt term, games place a 'frame' around a spate of immediate events, determining the type of 'sense' that will be accorded everything within the frame. (Goffman, 1961b, p. 20)

But the framing can also be seen as a kind of code, a linguistic code and/or a behavioural code:

Given a well-received, easily understandable message, what light is the message to be seen in, what systematic, word-by-word rereading is to be given it? Is the sender engaged in what he appears to be doing, namely, sending a serious, reliable message? Or is he merely practicing his sending, or engaging in a joke, or sending a false message because he is now working for the other side, or sending a message at the point of a gun [...]? (Goffman, 1970 [1969], p. 141)

It is, however, also possible to place additional emphasis on the contextualising characteristic of the frame, and then the doubleness of the frame concept will, in addition, appear: both a reading of the context of an act and an anchoring of an act in a context. Both Weick (1995) and Scheff $(2005,2006)$ define frame as 'the structure of context'. Weick links the concept to the individual creation of meaning in the sense of sense-making, while Scheff deals instead with the analytical side of the frame concept when it has to do with understanding, as a researcher, situations within which an act takes place. The contextual structure can be attributed to both a subjective and an intersubjective (shared) context as well as to social facts (Scheff, 2006, p. 73), and can be compared with Aronsson's description of frame as 'the conditions of social interaction' (Aronsson, 2002, p. 68). The definition of frame as 'the structure of context' has its merits, not least a concreteness that makes it easy to observe, empirically speaking. Goffman also gives context a central role when he writes, 
It is obvious that a given appearance can on different occasions have different meanings. He who cleans off his dinner plate can be seen as starved, polite, gluttonous, or frugal. But usually the context, as we say, rules out wrong interpretations and rules in the right one. (Indeed, context can be defined as immediately available events which are compatible with one frame understanding and incompatible with others.) And when the context might not suffice, participants take care to act out requisite evidence, here, as it were, helping nature to be herself. (Goffman, 1974, p. 440f)

The limitation of defining frame only as 'the structure of context' is thus not the strong emphasis on context, but the fact that the active, socially defining, information-gathering, and experience-organising individual ends up much too far in the background. Emphasis is thus placed on the result of the activity of the individual and not on the actual process and the dynamics of the chain of events, which I feel is a central trait in Goffman's definition of frame - i.e., a situational definition that follows certain organisational principles and that, as such, controls both the events and the subjective commitment of the individual in the situation in question (Goffman, 1974, p. 10f), and, it can be added, in Goffman's sociology as a whole. There is reason to connect the frame to the situation, because the situation is a kind of linchpin of Goffman's understanding of social interaction. He defined 'situation' as a context in which two or more individuals are in each other's immediate proximity and are accessible to each other's influence (1964b, p. 135), or as 'any environment of mutual monitoring possibilities that lasts during the time two or more individuals find themselves in one another's immediate physical presence' (1967, p. 167), or, as in the article 'Footing', 'the full physical arena in which persons present are in sight and sound of one another' (1981a, p. 136). In one of his last texts Goffman writes,

It is social situations that provide the natural theater in which all bodily displays are enacted and in which all bodily displays are read. Thus the warrant for employing the social situation as the basic working unit in the study of the interaction order. And thus, incidentally, a warrant for claiming that our experience of the world has a confrontational character. (Goffman, 1983b, p. 4)

Goffman adds that this emphasis on social situations does not mean that what happens in situations are opening night performances, but that in the situation new experiences are mixed with things an individual brings with him or her from other contexts; for instance, experiences of social interaction and cultural ideas and assumptions. In this way, Goffman merges situation and frame, and the situation then becomes a framing in an immediately interactive, cognitive, and social sense. Against this background, I want to capture the meaning of the frame concept through the expression "the social 
dynamics of the situation'. ${ }^{10}$ In Frame Analysis, Goffman emphasises that his perspective is situational, and his analysis is focused on sequences of events (so-called 'strips') in situations that include one or more individuals. The situation is, in a manner of speaking, the spatially cohesive frame of social interaction, while the cognitive frame in the situation can be called 'code' or 'sense'. The interactions among individuals make up the dynamic element of the situation, and can result in frames being confirmed, ignored, changed, transgressed, or broken down. Situation, code, sense, and interaction together make up the frame that creates the prerequisites for the social dynamics of the situation.

Even if the perspective is situational, society is constantly present in Goffman's analyses, and among other things it takes the form of a continuous pressure on the individual for adaptation, a social constraint that the individual contributes to maintaining by adapting to it, but that he or she sometimes tries to resist and sometimes feigns having adapted to. It is precisely this multidimensionality that is characteristic of Goffman's perspective, and we can find many descriptions of this in his texts; for example, where Goffman describes individuals as constantly actively turning situational definitions to their advantage by 'twists, turns, and squirms' (Goffman, 1961b, p. 139).

The situational dynamics have both a more objective aspect in the form of the contextual structure that characterises the situation and a more subjective aspect in the form of the experiences of the individual acting in the situation, how he or she chooses to organise these in the given situation, and how she or he against the background of a situational definition chooses to orient his or her actions in the situation. Goffman calls the latter 'footing' (Goffman, 1981a). That is to say, a frame can be understood as a shared definition of a situation, while footing is instead the orientation or positioning of an individual (Davies \& Harré, 1990) in the situation. The individual can change her or his orientation in a situation (e.g., resisting the shared definition of the situation) without the situation itself necessarily changing as a result. Against that background, the idea that the concept of frame is either structural or interactionist (Gonos, 1977) appears less relevant. I would rather like to see the frame concept as both: structural in given situations, while it at the same time directs actions and interactions, which in their turn can influence the structure of the situation.

The Goffman frame concept is a development of the concept 'definition of the situation', which can be made visible by rephrasing Goffman's question 'What is it that's going on here?' into three questions: 'How do I usually act in such a situation?', 'What do other people expect from me in this situation?', and 'How should one act in situations such as this?' Thus, frame does not simply answer the question 'What is it that's going on here?' but also the question 'What applies here?' and can be connected to what Goffman in other contexts calls 'situational proprieties' (Goffman, 1963a, p. 24), which are defined as a code that is normative for the situation in question. 
In this sense, frame corresponds both to the individual's own experience, other people's expectations, and the norms of society (and similar directors of actions, such as different kinds of institutions and cultures). Goffman also talks about the particular 'sense' that is ascribed to everything within a frame (Goffman, 1961b, p. 20). Furthermore, he describes a fundamental dialectic that exists in all social interaction and that expresses itself in that the individual wants to know the purpose of the interaction but is rarely completely successful in doing so and therefore has to 'employ substitutes cues, tests, hints, expressive gestures, status symbols, etc. - as predictive devices' (Goffman, 1959, p. 249). All this is embedded in the situation. The situations described by Goffman are therefore never static but in constant movement, or, with another word, dynamic. The movement is explained by different forces influencing each other; it can be individuals who try to realise different interests and end up in conflict with one another, or the exercise of power and resistance, or the interaction and tensions between ritualisation and vulnerability, which was illustrated earlier. The aim of my concept 'the social dynamics of the situation' is precisely to capture this interplay between forces within the social situation, and where the individuals' own and their mutual framings of the situation are decisive.

\section{Notes}

1 There could be a point in imagining Goffman's presentation of the interaction between frames and keys in the light of what in physics is called states of aggregation, which refers to the different states in which a substance can exist, such as in the case of water: gas, liquid, and solid state. Theoretically speaking it is the same substance, but in the different states of aggregation the substance in question varies when it comes to its retention of shape.

2 The recently opened "Dubai Frame" may exemplify this: http://www.thedubaiframe. $\mathrm{com} /$

3 The island was the isolated Shetland isle of Unst, called Dixon in the dissertation.

4 In his review of Frame Analysis, Jameson (1976) also discusses spatiality and, among other things, the transition from a more concrete to a more abstract spatial concept in Goffman's analyses.

5 Many Swedish speakers erroneously say situationstecken ('situation mark') instead of the correct citationstecken ('citation mark'). This error is interesting in the context of frames, because it illustrates precisely that quotation marks sometimes can frame a situation.

6 This is possibly a precursor of the concepts that, from the 1970s and onwards, came to be among the main concepts of institutional organisational theory: loose coupling (Weick, 1976) and decoupling (Bromley \& Powell, 2012).

7 'Race' in its special American framing refers primarily to skin colour, which means that it can be read in close physical interactions between unknown people. 'Race' is thus not the same thing as ethnicity, which also refers to cultural categories - e.g., religious and other customs, languages, food, and clothes which in many cases, if the interacting person so desires, can be concealed in social interactions.

8 When you describe a person to another person you can use these individual identifiers, but there are differences among them. Describing someone with 
identifiers such as eye colour, height, and hair colour is probably perceived by most people as less highly charged than if a person's scent is involved. Body odour seems to be perceived as a more intimate identifier, which probably has to do with the fact that in most cases one has to be physically close to a person in order to perceive their body odour, and if one does not, this also says something about that person. Another reason can be that body odour is sometimes perceived as a moral indicator: 'Much of the moral symbolism relevant to interaction is expressed in terms of olfactory imagery. An untrustworthy person may be described as a "stinker", a "stinkoe", or a "stinkpot". In contrast, a holy or ritually pure person may be metaphorically described as emitting the 'odor of sanctity' (see Wright 1967, pp. 23-24). At the same time, groups may be termed "smelly and slovenly" or, on the other hand, "clean and orderly" (Largey \& Watson, 1972, p. 1021f). Or to put it in a different way: 'It is said "we are what we eat" - but it is also true that we are what we smell like: fragrant or foul, good or bad' (Synnott, 1991, p. 446).

9 'By definition, an individual's activities must occur either in social situations or solitary' (Goffman, 1967, p. 167).

10 Incidentally, Collins (2004) describes his and Goffman's analytical strategy in the study of interactional rituals with the words 'the dynamics of situations'. 


\section{Continuities and cracks in Goffman's frame analysis}

As has been shown above, Erving Goffman was simultaneously a controversial and popular sociologist, and it is possible that the reason for this was the very way in which he presented his studies of social interaction. The studies are often written in an accessible manner, and they most of the time lack scholarly methodological and theoretical jargon. In addition, they take up topical subjects, among which can be mentioned social trust and illusion, which are always topical but were perhaps particularly so in the American Cold War society in which Goffman was active. Game theory, to which Goffman devoted a couple of texts, can be said to have been topical for the same reason. Other particularly topical themes to which Goffman devoted his time were; e.g., everyday life, roles, stigma, identity, the politics of identity, total institutions, diagnostics of mental illness, talk, and gender. Towards the end of 1960s his view on social interaction in public places came to be influenced by increasing social tensions in American society following the civil rights movement, the Vietnam War, and the student revolt.

When it comes to the book Frame Analysis opinions differ greatly, as has already been made apparent. This could have to do with it being unclear what the book really is about. Therefore, it is of great importance how one as a reader chooses to frame Frame Analysis. I personally feel that Frame Analysis can be seen as a book on methodology, where frame analysis as a method is discussed and exemplified. The examples are often made with reference to social illusions - i.e., things that widen our register of social reality without for this reason changing our basic, scientifically based perception of reality; e.g., 'fraud, deceit, con games, shows of various kinds' (Goffman, 1974, p. 14). Or, to put it differently: Goffman is using a social constructionist perspective that is aware of its own limits. It can thus provide a highly reasonable answer to Hacking's (1999) question, 'social construction of what?', that is to say, social construction at a level where human definitions of reality have a practical ontological meaning. Social illusions are based on both the belief of social actors that everything is normal and the vulnerability that arises when it turns out that normal can be something other than what it appears to be. It is here - in the social dynamics between 
everyday ritual and vulnerability - that Goffman places his frame analytic method:

My aim is to try to isolate some of the basic frameworks of understanding available in our society for making sense out of events and to analyze the special vulnerabilities to which these frames of reference are subject. I start with the fact that from an individual's particular point of view, while one thing may momentarily appear to be what is really going on, in fact what is actually happening is plainly a joke, or a dream, or an accident, or a mistake, or a misunderstanding, or a deception, or a theatrical performance, and so forth. And attention will be directed to what it is about our sense of what is going on that makes it so vulnerable to the need for these various rereadings. (Goffman, 1974, p. 10)

It is, however, also important for the understanding of Frame Analysis to see how the frame analytic method that is illustrated therein is related to Goffman's entire oeuvre. In the present chapter I will therefore demonstrate both continuity and cracks in Goffman's frame perspective.

\section{Continuities}

Goffman rarely helped his readers see the continuity in his own sociological research by himself representing it as accumulative. It is true that Goffman referred back to his own works, but at the same time he constantly defined new concepts that pointed to new aspects of often well-known phenomena. Usually, he did not relate his research other than superficially to sociological or other schools. He rarely placed his work in any theoretical, methodological or philosophy of science context. The metascientific reflections on his own work were thus poorly developed, and therefore one can also question its continuity, something that has also been done.

There are, however, exceptions, and two will be mentioned here. The description of his research interests that Goffman provided in 1957 in an elevenline 'autobiographical sketch' could be said to be valid for his entire project:

I have been interested in social encounters, in the moments during which people come into and remain in one another's immediate presence, [...] I am interested in how an individual must act to communicate that he is a member in good standing in a situation, in a conversation, or in an occupation, and I have been pursuing this interest for the past year as an observer in a State-type mental hospital. (Goffman, 1957a, p. 12)

The key point here is not that Goffman claims to be interested in social interaction, but that he at the same time applies a metaperspective that points to norms, rules, expectations, etc. that control an interacting individual or define any resistance to this control. This is still undeveloped frame thinking. 
Another exception is 'The Interaction Order', the address that his illness prevented him from delivering in 1982 as the new chairman of the American Sociological Association and which was published posthumously in 1983. There he emphasised the continuity of his own research.

\section{The interaction order}

Why do we try to control other people's impressions of ourselves and attempt to make them accept our definition of situations we share? Why do we create, using audience segregation, separate regions where we can act in quite varying and sometimes contradictory ways in front of different audiences? Why do we help other people save face when they risk losing it? Why are women and men displayed in gender stereotypical ways in advertisements? Goffman answers these and many other questions regarding social interaction by referring to a kind of interaction order that in some sense controls how individuals act when they are in immediate proximity to each other. $\mathrm{He}$ only mentions this interaction order explicitly in his doctoral dissertation from 1953 and in the above-mentioned article 'The Interaction Order' from 1983. One can, if one wishes, say that a long series of analyses of social interaction over thirty years is framed by a number of more theoretical deliberations about an order that is sometimes presented as interindividual and sometimes as supraindividual and sometimes as both or as something else. ${ }^{1}$ The existence of such an interaction order makes the interaction between individuals appear not completely random, and it can therefore, to a certain extent, be systematised, which Goffman may have been on his way to doing by using the over 900 concepts he created.

In one of the opening chapters in his doctoral dissertation, 'Communication Conduct in an Island Community', Goffman describes the relationship between social order and social interaction. With the benefit of hindsight one can, if one wishes, see these ten pages as a framework for his thirty-year project that followed. In these pages, a model of the social order is constructed based on Parsons's book The Social System (1951) and Barnard's The Functions of the Executive (1938), almost an ideal type that is used as an analytic tool in order to compare how 'conversational interaction', or the interaction order, corresponds to and deviates from the model of social order. This model says the following, according to Goffman (1953, pp. 33-41):

1 Social order is found where the differentiated activity of different actors is integrated to a single whole, allowing thereby for the conscious or unconscious realization of certain overall ends and functions.

2 The contribution of an actor is a legitimate expectation for other actors; they are able to know beforehand within what limits the actor is likely to behave, and they have a moral right to expect him to behave within these limits. Correspondingly, he ought to behave in the way that is expected of him because he feels that this is a morally desirable way of behaving and not merely an expeditious way of behaving. 
3 Proper contribution from participants is assured or 'motivated' by means of a set of positive sanctions or rewards and negative sanctions or punishments. These sanctions grant or withdraw immediately expressed social approval and goods of a more instrumental kind. These sanctions support and help to delineate social rules that are both prescriptive and proscriptive, enjoining certain activity and forbidding other activity.

4 Any concrete social order must occur in a wider social context. [...]

5 When the rules are not adhered to, or when no rules seem applicable, participants cease to know how to behave or what to expect from others. [...]

6 A person who breaks rules is an offender; his breaking of them is an offense. He who breaks rules continuously is a deviant.

7 When a rule is broken, the offender ought to feel guilty or remorseful, and the offended ought to feel righteously indignant.

8 An offense to or infraction of the social order calls forth emergency correctives which reestablish the threatened order, compensating for the damage done to it. [...]

9 Given the rules of the social order, we find that individual participants develop ruses and tricks for achieving private ends that are proscribed by the rules, in such a way as not to break the rules.

This model contains both system and individual levels. On the former level the system is contrasted with chaos, while on the individual level morality is contrasted with anomie. Order can break down through development towards chaos and anomie, and be built up through development towards a system and morality. The individual can manage the system and morality in different ways, through, among other things, adaptation and tricks.

In connection with each point in the model, Goffman describes how 'conversational interaction' corresponds to or deviates from the ideal type of social order. Some important anomalies concern point 3 about sanctions, where Goffman states that the sanctions that exist within the interaction order are moral approval or disapproval rather than rewards and punishments. When it comes to point 5 and the dissolution of rules, such things as embarrassment is experienced within the interaction order. With respect to point 7, guilt is experienced as shame in the interaction order. When it comes to breaking rules and restoring order after rules have been broken (point 8), attempts to re-establish the interaction order after the breaking of rules can lead to the breakdown of order, and for this reason interacting individuals often overlook breaches of rules or attempt to draw attention to them in tactful ways. In a large number of ways the interaction order or 'conversational interaction' thus deviates from a conventional sociological systems model of social order that was valid at the time. From this, Goffman concludes the following:

In conversational interaction, as opposed to many other kinds of social order, offense is quite common; hence, forbearance is almost a constant requirement. The dissensus that forbearance conceals, [...] should be 


\section{Frame and framing}

considered as part of the model for conversational interaction and not as something which occurs as a deviation from the model. For example, the exercise of gain strategies is so common a thing that it is often better to conceive of interaction not as a scene of harmony but as an arrangement for pursuing a cold war. A working acceptance may thus be likened to a temporary truce, a modus vivendi for carrying on negotiations and vital business. (Goffman, 1953, p. 40)

The result of a comparison of the interaction order with the conventional sociological model of social order is thus that the interaction order is ordered without having to consist of as much order as the model of the social order. As has been demonstrated earlier, the interaction order is vulnerable and breaches of norms are more common, as is pretended adaptation.

In the article 'The Nature of Deference and Demeanor' (1956) Goffman analyses social interaction as a kind of ritual, as was mentioned above. The point of departure is Durkheim's (1965 [1912]) classic sociological analyses, where it is maintained that both society and the personality of the individual are the subject of religious rites and that the individual has become a kind of sacred object, or, as Durkheim expresses it in his study of suicide,

But today he [the individual] has acquired a kind of dignity which places him above himself as well as above society. So long as his conduct has not caused him to forfeit the title of man, he seems to us to share in some degree in that quality sui generis ascribed by every religion to its gods which renders them inviolable by everything mortal. He has become tinged with religious value; man has become a god for men. Therefore, any attempt against his life suggests sacrilege. Suicide is such an attempt. No matter who strikes the blow, it causes scandal by violation of the sacrosanct quality within us which we must respect in ourselves as well as in others. (1952 [1897], p. 299)

In modernised societies with democratic states there is often strong, judicial protection for the integrity of the individual that can be seen as an illustration of the sacredness of the individual, while at the same time these laws in reality can also regularly be circumvented by different actors, for instance when individuals end up in conflict or when power is exercised by authorities, businesses, and organisations. As was made clear in Chapter 3, Goffman claims that this sacredness of the individual is confirmed through symbolic actions in a social interaction where we show deference for the individual in an all but ritualised way with our behaviour. We can thus say that Goffman by 'interaction order' means the respect that individuals in part show each other in social interaction, in part show the order by allowing their behaviour to be controlled by it. Included in the interaction order is also how we correct our own and other people's behaviour when it lacks respect. Goffman sees this order in all interactions among people, even in 
such microscopic interactions as when somebody asks a stranger for the time (1981a, p. 15ff). Goffman sometimes expresses himself in such a way that the concept of the interaction order can be interpreted to mean a kind of supraindividual ritual order that individuals follow unconsciously. But at the same time, Goffman's previously mentioned discussion of alternative words for 'ritual' shows that he was dissatisfied with such interpretations: 'The term "ritual" is not particularly satisfactory because of connotations of otherworldliness and automaticity' Goffman, 1981a, p. 17). However, Goffman sometimes also expresses himself in ways that make it possible to interpret the interaction order as an interpersonal order, a kind of symbolic system of exchange where an individual, by respecting other people, can also expect to be respected by them. Goffman writes the following in his last text:

The modern nation state, almost as a means of defining itself into existence, claims final authority for the control of hazard and threat to life, limb, and property throughout its territorial jurisdiction. Always in theory, and often in practice, the state provides stand-by arrangements for stepping in when local mechanisms of social control fail to keep breakdowns of interaction order within certain limits. Particularly in public places but not restricted thereto. To be sure, the interaction order prevailing even in the most public places is not a creation of the apparatus of a state. Certainly most of this order comes into being and is sustained from below as it were, in some cases in spite of overarching authority not because of it. Nonetheless the state has effectively established legitimacy and priority here, monopolizing the use of heavy arms and militarily disciplined cadres as an ultimate sanction. (Goffman, 1983b, p. 6)

Goffman chose to study the interaction order through the rules of behaviour that exist in society and that in different ways control how individuals interact with each other. He analysed the rules in detail and made three important distinctions. First, rules of behaviour are manifested in two different ways: as obligations, which through moral constraint establish how individuals should behave, and as expectations, which express consideration for others. Second, Goffman differentiated between symmetric and asymmetric rules of behaviour: symmetric rules control behaviour by being applicable to everyone; asymmetric rules of behaviour regulate deviations from the general order (e.g., in hierarchical systems there can be different rules of behaviour depending on where in the hierarchy individuals are placed). Third, Goffman differentiated between rules of content and ceremonial rules of behaviour; the former are laws, morals, and ethics, while the latter can be called etiquette.

Most rules of behaviour control us habitually without our usually thinking about it, and often it is not until we have broken the rules that they make themselves known: as reprimands from the people around us and as feelings of guilt. In particular, feelings of guilt in connection with 'making fools of ourselves' are a very strong corrective force in social interactions. 


\section{Frame and framing}

However, it is not only the person who breaks the rules that risks being affected by feelings of guilt and a loss of reputation or face in connection with breaking a rule, but also other people involved in the interaction: the person who broke the rules should have followed the rules, and the other people should not have allowed the rules to be broken in the first place. According to Goffman, we all have an interest in maintaining a 'temporarily working consensus' in social interaction, or, in other words, in avoiding a 'scene' (Goffman, 1953, p. 40f). Conversely, this is confirmed when a disturbance or a 'scene' cannot be avoided and the façade cracks: feelings overflow and the conflict can then escalate to an unanticipated degree, independent of how trifling the source of the conflict may seem to be. This can concern feuds between neighbours about placing a fence $25 \mathrm{~cm}$ in one direction or the other, or 'pointless' quarrels between spouses about trifles. Conflicts in traffic can also develop into veritable social drama.

\section{Five illustrations of frame analysis before Frame Analysis}

By relating the interaction order to his earlier studies mentioned in his 1983 article, Goffman emphasised the continuity of his sociological project and perspective. But how does this continuity relate to Goffman's frame perspective? I will deal with this question below by studying Goffman's methods of analysis in five different texts that precede Frame Analysis.

Goffman's frame perspective is a metareflexive perspective. The question 'What is it that's going on here?' requires reflection on one's own experiences, one's own and other people's interactions, and the social norms, rules, conventions, traditions, institutions, etc. that regulate the interactions of individuals in general as well as in specific situations. It can be rather difficult not to know what happens in a situation, both because strong social sanctions can be developed against the person who acts in the wrong way, and because of feelings of shame over not knowing what applies and/or not daring to ask. There is therefore reason to reflect on how an individual in fact and in practice finds out which frames govern a situation. Because it is difficult for many people, but not everyone, to ask straight out in front of other people what is happening in a situation, individuals can pose direct questions to other individuals, pose indirect questions whose answers can possibly say something about the situation, and observe the events in the situation to find out what is going on. But individuals can also make 'moves' in the situation in order to be able to read other people's countermoves, and thus also possibly get an answer to the question 'What is it that's going on here?'. This interaction in order to obtain answers to what an interaction is about, and which frame (or frames) governs it, can be called metasociality. ${ }^{2}$

When a situation or the frame that controls the situation is difficult to understand, it can become filled with friction, something that can be illustrated by my experiences of a queuing system that is difficult to understand at the tyre company were I twice a year change the tyres on my car. ${ }^{3}$ The first time 
I visited the company there were a fair number of people there for the same reason as I, and there was a room assigned for those waiting their turn. But there was no queuing system, no obvious queue, no queue number tickets, and neither was there staff organising everything. For someone uninitiated it was a room filled with standing and sitting people, although everyone there knew that in spite of everything this was a kind of queue, something that was at least made visible when someone tried to jump the 'queue' or someone claimed that someone else was jumping the 'queue'. Every time a new customer came into the room there was a certain amount of unrest and people's alertness level was elevated, which it can be assumed had to do with the fact that the situation did not have a frame that was common for all those who waited. What is it that's going on here?

At my second visit, six months later, I knew what to expect and was not in particularly good spirits. When I got there I decided to try and find out who was last in this difficult-to-define queue. I tactfully enquired of a few people whether they were last in line, and finally one of them answered that she thought she was among the last because nobody had come into the waiting room between me and her. After that I kept my eyes on that person and made sure I got into the workshop immediately after her. Now I had, on the basis of my experiences from the previous visit, framed the situation in such a way that I could handle it fairly well. On my third visit I took additional steps and loudly enquired who was last in the queue when I got into the room, and then followed my routine from the second visit. Now I had contributed to a shared frame among the waiting. This way of organising a queue has also been described by other people when it comes to bank queues in Moscow, queues in Latvia, and taxi queues in Cuba. An interesting thing in this context is that the tyre company had previously had a queueing system with queue number tickets, and the manager told me that when an infringement of that system had resulted in a fight between two customers, the company decided to get rid of this queuing system and leave it to the customers themselves to organise their waiting.

As has been made clear, Goffman's socially interactive frame perspective is based on William James's cognitive and Gregory Bateson's communicative frame concepts. Goffman's frame concept is presented as an analytic tool through an emphasis on the question 'What is it that's going on here?', which researchers as well as interacting individuals are understood to ask themselves when they attempt to find out which definition or definitions of the situation apply. Here there is reason to differentiate between practical framing, which is applied by the people interacting in a situation, and analytic framing, which is used by the researcher. ${ }^{4}$ Practical framing can advantageously make use of Vollmer's definition: 'Framing is the process during which participants come to terms with actual occasions through producing context for events and activities' (Vollmer, 2013, p. 67). Goffman's analytic framing is presented below, and within its frame, albeit unspoken, appears the additional question, 'Why do the things that are happening here happen?', because Goffman also looked for the mechanisms that control the actions of individuals. 


\section{Frame and framing}

Below I will illustrate analytic framing using five of Goffman's studies of social interaction, which were all completed before the publication of Frame Analysis. The choice of texts includes one article, three books, and one essay, all central and well-known texts, and represents a distribution over time from 1955 to 1963, a period of high activity in Goffman's authorship when he, among other things, published five of his eleven books. This selection is representative of Goffman's texts published before Frame Analysis. It reflects two of the three themes I feel can be found in Goffman's texts: the theme of politeness and respect, as well as the theme of social illusion. Finally, they all reflect the social interaction dynamics between ritualisation, vulnerability, and temporarily working consensus.

In the following five examples I emphasise in particular four recurring characteristics in Goffman's analyses of social interaction in their different contexts:

1 governing mechanisms, which is here an umbrella term for rules, norms, normative expectations, conventions, routines, rituals, regularities, institutions, orders, etc. that are or can be action- and interaction-regulating and that affect the degrees of liberty of the actions of individuals in situations where they interact with others,

2 the situation or, in other words, the spatial delimitation of the interaction,

3 the performance of the interaction, and

4 the dynamics of the interaction and the situation, and with 'dynamics' is then meant a kind of theory of force concerning how entities in a unified space influence each other in a number of different ways; e.g., cooperate, end up in tension and conflict, exist side by side but are indifferent to one another, are involved in coordinated cooperation that can give rise to both intended and unintended consequences, etc. The dynamics of the interactional context is the sense or, put differently, the actual frame that becomes a consequence of the meeting between governing mechanisms and the actual carrying out of the interaction in the situation at hand.

\section{1 'On Face-Work' (1955) - framing the expressive order of face activity}

In the article 'On Face-Work' Goffman investigates the moral regulation of social interaction within whose frame the individual is made into a sacred object and the interaction assumes ritual traits. This means that society mobilises its members as

self-regulating participants in social encounters. One way of mobilizing the individual for this purpose is through ritual; he is taught to be perceptive, to have feelings attached to self and a self expressed through face, to have pride, honor, and dignity, to have considerateness, to have tact and a certain amount of poise. These are some of the elements of 
behavior which must be built into the person if practical use is to be made of him as an interactant, and it is these elements that are referred to in part when one speaks of universal human nature. (Goffman, 1955a, p. 231)

But, continues Goffman,

universal nature is not a very human thing. By acquiring it, the person becomes a kind of construct, built up not from inner psychic propensities but from moral rules that are impressed upon him from without.

The object of study in this text is the face and the face-work of interacting individuals. Goffman argues that when studying this, one studies 'the traffic rules of social interaction' (1955a, p. 216) or, in other words, the interaction order.

It is in the nature of things that face activity in social interaction presupposes face-to-face meetings. For this reason, Goffman does not make much of an effort to determine face activity spatially to a greater extent than this.

Face-work is the activity that is being investigated, and face is defined 'as the positive social value a person effectively claims for himself by the line others assume he has taken during a particular contact' (Goffman, 1955a, p. 213). Face-work is everything the individual does in order to make sure that his or her own actions correspond with her or his face, but also with norms etc. that regulate his or her actions. The individual can maintain, lose, save, and give face.

Goffman describes the dynamics of face-work as a "viable system of interaction', which is at the same time individual, social, and societal, and is represented as follows:

While his social face can be his most personal possession and the center of his security and pleasure, it is only on loan to him from society; it will be withdrawn unless he conducts himself in a way that is worthy of it. Approved attributes and their relation to face make of every man his own jailer; this is a fundamental social constraint even though each man may like his cell. (Goffman, 1955a, p. 215)

The system of interaction makes up a special ritual expression order that regulates the individual maintenance of face, but also the cooperation between individuals that makes sure that most faces are saved and restored.

\section{The Presentation of Self in Everyday Life (1959) - framing expressive control and impression management}

In this book Goffman develops a dramaturgical perspective on social interaction and points to two sets of norms that are of great importance for 


\section{Frame and framing}

how individuals choose to interact with each other. The first set consists of norms of politeness and decency that regulate how individuals are expected to treat the people with whom they interact. These norms occur generally, with cultural and social variations, and individuals are expected to follow them if they want to be defined by others as individuals that are decent, etc. The second set of rules is a result of Goffman's dramaturgical analysis, and is presented under the heading 'The arts of impression management' in the following way:

In order to prevent the occurrence of incidents and the embarrassment consequent upon them, it will be necessary for all the participants in the interaction, as well as those who do not participate, to possess certain attributes and to express these attributes in practices employed for saving the show. [...] the defensive measures used by performers to save their own show; the protective measures used by audience and outsiders to assist the performers in saving the performers' show; and, finally, the measures the performers must take in order to make it possible for the audience and outsiders to employ protective measures on the performers' behalf. (Goffman, 1959, p. 212)

Goffman calls these three measures, whose purpose is to rescue a performance, 'dramaturgical loyalty', 'dramaturgicaldiscipline', and 'dramaturgical circumspection'. Goffman applies these primarily to group performance, but they can in principle also be applied to individual performance, with the additional note that dramaturgical loyalty then means being consistent with and loyal to one's own performance. The art of managing impressions can be seen as an unusually clear description of framing social interaction.

The prerequisites for Goffman's dramaturgical theory are, first, that individuals in some sense gain something by demonstrating that they subordinate themselves to the norms of politeness and decency, and, second, that this demonstration does not reflect how the individual always acts. For this reason it here becomes central to imagine the movement of individuals between different spaces, or, as Goffman calls them, regions. In the front region the interaction with or performance in front of others takes place. Here it is important to maintain a front, but behind it - in the back region - the individual can act in ways that do not at all correspond with the front displayed. In order to make this spatial determination of interaction complete, Goffman also talks about the outside, a residual category made up of places that are neither the front nor the back region at the time of the individual's performance. It should be emphasised that the three regions that Goffman invents are entirely relative to the ongoing social interaction and to each other.

When it comes to the performance of interaction framed in this way, this is to a great extent characterised by a risk of being exposed or found out when a person is the kind of person or does the kind of thing that does not correspond with the front that is being displayed. This characterises 
Goffman's entire analysis but comes to its most pregnant expression in the difference between expressions given and expressions given off. Expressions given are expressions the individual consciously transmits in order to convey particular information determined by her- or himself. The individual has, relatively speaking, a great deal of control over expressions given. The opposite is true of expressions given off, and the reason for this is explained by Goffman in the following way: 'Performers can stop giving expressions but cannot stop giving them off' (Goffman, 1959, p. 108). The control over expressions given off lies to a greater extent with the people with whom the individual interacts, because they interpret the impressions transmitted by the individual and compare them with the expressions that are being sent out. A poignant literary illustration of the different expressions is provided by Pär Lagerkvist in his novel The Dwarf. Maestro Bernardo has arrived at the court in order to paint the Prince's portrait, but also wants to depict the dwarf working at court naked in a full-length portrait. At first, the dwarf believes this concerns a portrait of his face, but not even then does he want to make himself the object of Bernardo's gaze. Why not? asks Bernardo. The dwarf answers, "II wish to possess my own face." He [Bernardo] thought this strange, smiled somewhat, but then admitted that there was something in what I said. But, even when unreproduced, one's face is the property of many, in fact of all who look upon it' (Lagerkvist, 1958 [1944], p. 44).

The dynamics that characterise the interaction context when interpreted in a dramaturgical fashion can be called the dynamics of expression control and impression management. By trying to control the expressions given and given off, the interacting parties also try to control other people's impressions of themselves. In the context of such a perspective, interacting individuals try to present themselves before other people as in the performance of a part on a stage, and, as on the theatre stage, the audience contributes to creating the performance.

The interacting parties are thus dependent on each other in a kind of mutual production of the self, a production that is very vulnerable if the interacting parties choose to violate or by mistake violate norms of politeness and decency or stop observing dramaturgical loyalty, discipline, and circumspection.

\section{3 'Fun in Games' (1961) - framing out the irrelevant}

In the essay 'Fun in Games', published in Encounters (Goffman, 1961b), social interaction in and in connection with games is investigated. The context of the game is spatially delimited and is called a gaming encounter, which encompasses the game - the specific rules of the game in question - and gaming - the concrete interaction context in which the gaming takes place. The game, writes Goffman, is 'codifiable and clean', while gaming is 'very sticky'. There can thus be a significant difference between the game itself and the activity that develops during the gaming. It is the social interaction 
among the players that makes the difference, in particular their human ability to spontaneously engage in interaction with other people:

By this spontaneous involvement in the joint activity, the individual becomes an integral part of the situation, lodged in it and exposed to it, infusing himself into the encounter in a manner quite different from the way an ideally rational player commits his side to a position in an ideally abstract game. As already considered, a game move is one thing; self-mobilization through which this move is executed during a gaming encounter is quite another. Game rules govern the one, the structure of gaming encounters governs the others. (Goffman, 1961b, p. 38)

Two sets of rules frame the interaction context in which the game is embedded: the rules of the game, and the norms that regulate the interaction itself; for instance, that respect should be shown to other people and that one should be available for interaction when together with people one knows.

But there is an additional set of rules: rules that ensure that the game can continue in spite of the above-mentioned interaction obligations. Goffman calls these rules 'rules of irrelevance', and they regulate spontaneous social interaction so that the game can continue in accordance with its rules:

The elegance and strength of this structure of inattention to most things of the world is a great tribute to the social organization of human propensities. Witness the fugue-like manner in which deeply engrossed chess players are willing to help each other reposition a piece that has been brushed aside by a sleeve, dissociating this event from relevant reality and providing us with a clear example of a fundamental process, the sustaining of a subordinate side-encounter simultaneously with a main one that has been accorded the accent of reality. (Goffman, 1961b, p. 20)

Goffman then refers to Bateson's frame concept in order to capture the kind of sense 'that will be accorded everything within the frame'. Anything else is 'out of frame' because the gamers regard it as irrelevant. The things irrelevant to the game are placed out of the frame of the situation.

The dynamics in gaming encounters can be described as a show of force between, on the one hand, the gamers' focus on the game, which makes everything else in the gaming encounter appear irrelevant, and on the other hand the tendency of the gamers to spontaneously engage in social interaction that has nothing to do with the game itself. Goffman imagines that the participants in the gaming encounter manage this show of force by using 'transformation rules' to separate things from 'the world outside' that are allowed to come into the gaming encounter from those that are to be kept outside. But these rules are not sufficient, and Goffman also imagines that things irrelevant for the game that, in spite of everything, come into the gaming encounter have to pass through a symbolic interaction membrane 
that regulates how things that are allowed to come in from the world outside may be expressed inside the gaming encounter:

If we think of an encounter as having a metaphorical membrane around it, we can bring our concerns into focus. We can see that the dynamics of an encounter will be tied to the functioning of the boundarymaintaining mechanisms that cut the encounter off selectively from wider worlds. (Goffman, 1961b, p. 66)

Here, Goffman thus uses a frame concept that emphasises the sense that characterises the situation, and he imagines a kind of framing filter that separates things relevant to the situation from things that are not. The sense that is particular to the gaming encounter has to be ensured by the interacting parties' framing the social interaction in ways that will enable disturbances of the game to be kept outside the gaming encounter, and by disturbances that nevertheless come in also being reframed in order to fit the sense that determines the gaming encounter.

\section{Behavior in Public Places (1963) - framing the management of personal front}

In this book, Goffman studies social interaction in public places, and a number of different rules are described. First, moral norms that regulate how individuals are expected to behave in order to reach their goals; second, rules of behaviour that prescribe that individuals should strive to fit into the order that exists; and, third, social norms that individuals in close proximity to one another are expected to respect. In addition, he also mentions situational proprieties, which are regulated by a moral code that in its mode of operation can be likened to, e.g., an honour code or a professional code.

Several spatial delimitations are made. Public places are defined as 'any regions in a community freely accessible to members of that community' (Goffman, 1963a, p. 9). Gatherings of people - Goffman's specific object of study in this context - are defined as 'any set of two or more individuals whose members include all and only those who are at the moment in one another's immediate presence'. In connection with this, 'situation' is defined as 'the full spatial environment anywhere within which an entering person becomes a member of the gathering that is (or does then become) present'. Finally, social occasions such as, e.g., a party, a day at work, or an opera visit, are defined as activities that

provides the structuring social context in which many situations and their gatherings are likely to form, dissolve, and re-form, while a pattern of conduct tends to be recognized as the appropriate and (often) official or intended one. [...] Each class of such occasions possesses a distinctive ethos, a spirit, an emotional structure, that must be properly 
created, sustained, and laid to rest, the participant finding that he is obliged to become caught up in the occasion, whatever his personal feelings. (Goffman, 1963a, pp. 18-19)

The social interaction in public places is of a rather special kind because it consists of a mixture of what Goffman calls focused and unfocused interaction. The former is characterised by the interacting individuals having a mutual interactive focus, such as, for instance, in a conversation. The unfocused type is characterised by fleeting, quickly emerging, and transitory encounters in places that are not shared because of, rather than in spite of, other people. At the same time, these forms of interaction can morph into one another when individuals meet acquaintances in a public place, and an island of focused interaction is then formed in the stream of unfocused interaction. It is the unfocused interaction in which Goffman is interested, and it is described by, among other things, the concept of 'civil inattention': 'that one gives to another enough visual notice to demonstrate that one appreciates that the other is present (and that one admits openly to having seen him), while at the next moment withdrawing one's attention from him so as to express that he does not constitute a target of special curiosity or design' (Goffman, 1963a, p. 84). Civil inattention, writes Lofland (1998, p. 30), 'makes possible copresence without commingling, awareness without engrossment, courtesy without conversation'.

The dynamics that are made visible in Goffman's analysis of social interaction in public places has to do with a mixture of, on one hand, fleeting encounters with unknown people, and, on the other, encounters with known others. It is here, as in other interaction contexts, Goffman argues, that individuals that are situationally present display themselves 'through the disciplined management of [...] "personal front" (Goffman, 1963a, p. 25). This performance ensures a kind of superficial consensus, but at the same time many things happen under the surface that suggest the opposite:

Situational requirements are of a moral character: the individual is obliged to maintain them; he is expected to desire to do so; and if he fails, some kind of public cognizance is taken of his failure. But once this character of situational obligations is granted, we must see that a study of them leads off in many different directions. We may expect to find many different motives for complying with them, many different reasons for breaking them, many different ways of concealing or excusing infractions, many different ways of dealing with offenders. We may also expect to find that rules maintained or broken before one audience will not be handled in the same way by the same person when he is before another audience. And, of course, we find that an involvement ruling upheld in one community will not be honored in the next. One theme of this study, then, is that a moral rule is not something that can be used as a means of dichotomizing the world into upholders and offenders. (Goffman, 1963a, p. 240f) 
The soluble structure of moral obligations in interaction situations thus creates the prerequisites for a multiplicity of motives for adapting to and violating moral rules.

\section{Stigma (1963) - framing the interaction between the identity values in society, the discredited, and the discreditable}

The stigma phenomenon, the way Goffman describes it in the book Stigma, has to do with an individual's lack of social recognition because of an inability to conform to the identity values that are valued in society. The constant in this stigma concept is social recognition, because this is generally sought after, while the variables are the identity values and the opportunities individuals have to conform to and/or conceal their stigmas. This creates prerequisites for the social game that has to do with hiding one's own stigma but also with not showing that one is aware of those of other people. The rules that are foregrounded in Goffman's analysis of stigma are normative and institutional regulations for expectations concerning, and ideas about how individuals should be, behave, and appear, and what they should do. In this context, individuals in a society can be comprehensively defined as either discredited or discreditable. Their actual social identities can always be compared to virtual social identities that are anchored in identity values. Goffman emphasises that stigmatisation has nothing to do with characteristics, but is about relations between, on the one hand, different types of collective patterns - perhaps we can call them norms - and, on the other hand, individuals.

Spatially, Goffman delimits the analysis of stigma to 'mixed contacts': '[...] the moments when stigmatized and normal are in the same "social situation", that is, in one another's immediate physical presence, whether in a conversation-like encounter or in the mere co-presence of an unfocused gathering' (Goffman, 1963b, p. 12). Because the analyses of Goffman and other researchers have successively undermined the use of the word 'normal', it is seldom used in current research on 'stigma'. I therefore wish to emphasise that 'normal' in Goffman's usage is not a concept describing a fixed state but one that should rather be understood to include the people who at the time are not discredited (but who, like everyone else, risk being discredited). Another spatial aspect of the analysis of stigma that Goffman draws attention to is the idea that the world of a stigmatised individual is divided into different regions - 'forbidden, civil, and back places' (Goffman, 1963b, p. 82) - that require different ways of handling the stigma. Spatially speaking, the stigmatised individual thus reads his or her world differently than an individual who is not stigmatised.

The actions that Goffman foregrounds are called techniques of information control and have to do with how individuals - discredited and discreditable ones - handle social information about themselves with the aim of passing. But here Goffman also assumes another position by pointing to 
examples of people who no longer feel the need to hide their stigma, and they then reach a kind of turning point in their moral careers:

I want to suggest now that the stigmatized individual can come to feel that he should be above passing, that if he accepts himself and respects himself he will feel no need to conceal his failing. After laboriously learning to conceal, then, the individual may go on to unlearn this concealment. It is here that voluntary disclosure fits into the moral career, a sign of one of its phases. It should be added that in the published autobiographies of stigmatized individuals, this phase in the moral career is typically described as the final, mature, well-adjusted one - a state of grace [...] (Goffman, 1963b, p. 101f)

Goffman calls the dynamics into which the mechanisms, spaces, and actions can be incorporated 'the dynamics of shameful differentness' (Goffman, $1963 b$, p. 140). These dynamics are, to a great extent, controlled by the individual's feeling of being seen by other people, her or his will to take control of what should be displayed to other people, and the opportunities for passing as 'normal'. This does not merely have to do with stigmatised people but with everyone in a society where social recognition is important: 'The general identity-values of a society may be fully entrenched nowhere, and yet they can cast some kind of shadow on the encounters encountered everywhere in daily living' (Goffman, 1963b, p. 128f).

\section{Metasociality}

The pattern I see in the five analyses that have been presented here can be said to demonstrate how Goffman worked with frame analysis as a method of analysis long before publishing the book Frame Analysis. ${ }^{5}$ If we want an answer to the question 'What is it that's going on here?' in social interaction contexts, we must thus make visible and systematically study mechanisms governing the interaction, the situation in which the interaction takes place, how the interaction is in fact performed, and the social interaction dynamics that manifest themselves through this.

By this kind of analysis is constructed what can be called a metasocial perspective. The concept of metasociality has not been used much and only gets a handful of hits on Google (12 hits) and Google Scholar ( 3 hits), ${ }^{6}$ which is virtually nothing compared to the amount of hits one usually gets when searching the Internet. There are very few accounts of the concept in the research literature, but when used the concept has several different meanings. In a biological study of bees, for example, the concept of metasociality means a higher level of sociality (Minckley, 1987), and in an anthropological study it means 'a collective representation of a collective state' (Schram, 2009, p. 106). In a social psychology study, on the other hand, the researchers are trying to measure the difference between people who 'have' high and low 
degrees of metasociality, the former meaning that they have rich friendships and are considered trustworthy by others (Ray, Mackie, Smith, \& Terman, 2012). In a study on mathematical problem-solving skills the author defines metasociality as 'the individual's awareness of their social skills, ability to regulate these social skills, perceptions and beliefs and emotions with respect to another person, and the ways these beliefs and emotions affected social behavior in a dyadic problem-solving situation' (Sherzer, 1995, p. 1).

The above-mentioned uses represent definitions of metasociality that differ considerably from each other and from my way of using the concept. There are, however, other 'meta' concepts: metacommunication, or, communication about the ongoing communication (Watzlawick, Bavelas, \& Jackson, 2011 [1967]); metacognition - i.e., thinking about thinking (Beran, 2013); metareflection - i.e., reflection on reflection (for example, Clark, 2009) ${ }^{7}$; metamodernism, a 'discourse, oscillating between a modern enthusiasm and a postmodern irony' (Vermeulen \& van den Akker, 2010); and, not least, what Geertz in a concluding description of the function of the Balinese cockfight in Balinese culture calls 'a metasocial commentary', meaning 'a Balinese reading of Balinese experience, a story they tell themselves about themselves' (Geertz, 2000 [1973], p. 448). By metasociality I mean a similar loop-like movement as those demonstrated above, but one that covers both the interacting actors' reflections on the ongoing social interaction and social interactive moves that represent ways of illuminating and/or examining the frame or framing of the ongoing social interaction. The latter meaning signifies that an actor does something that receives an answer or perhaps rather a consequence that can possibly say something about what happens in the shared situation. In this context, making moves in social situations then means doing this in order to acquire more information through other people's countermoves.

During the conference 'Strategic Interaction and Conflict', where Goffman, incidentally, sat on the planning committee, a session was devoted to 'The vocabulary of basic moves', which was opened by Thomas Schelling and in which Goffman during the discussions said,

Communication and move-making, I would argue, are two quite different things, and the whole virtue of the game theory for the sociologist is that it drives a wedge between communication and strategic interaction. What is going on in the game is not communication, but an exchange where each move alters the objective, environmental, concrete, existential situation of the other player, whether he knows it or not. (Goffman, 1966, p. 161)

Goffman investigates this game theoretical effort in greater detail in the essay 'Expression Games', and provides an analysis of moves within intelligence activities that does not need to be outlined here. The point is that move-making is not only based on one's own definition of the situation, but can be used in order to acquire information about the situation that is 
shared with other people. The reason why such moves are made seems to be that to many individuals it seems more difficult to ask straight out what is going on here than to elicit countermoves that can be read in the belief that they will provide information about what is going on in the situation.

Metasociality can thus make itself known on the level of interaction in the form of the actors' practical investigation of what is going on in a situation, which consequently allows them to find out which frame(s) governs the situation. Different methods can then be used, for instance observation of the events and also conversations ('interviews') with the other people involved. A third method for finding an answer to the question 'What is it that's going on here?' can be active actions within the situation with the aim of acquiring information about it by making moves and reading countermoves.

\section{Cracks}

Goffman claimed that there was continuity in his sociology because it dealt with the interaction order and its different aspects. But here, as in everything else, there are cracks. One of these cracks can be linked to Frame Analysis and is expressed, depending on how it is framed, in the question 'What is it that's going on here?'. If we frame the question on a 'microsocial' level it rather smoothly ties in with Goffman's interaction order and can be answered through the kind of analysis that I have demonstrated in the five examples above, which also show that Goffman worked in a frame analytic manner long before Frame Analysis. In addition, Frame Analysis can then be seen as a methodology book in which Goffman tries to describe - in the dry, technical way that is characteristic of many books on methodology - what he himself believed he was doing and how a frame analysis can be conducted. On the other hand, if the question 'What is it that's going on here?' is framed on a 'macrosocial' level, cracks appear in Goffman's perspective. In the following, I will demonstrate this by complementing Goffman's frame analysis with a temporal perspective and reflecting on the crisis in the interaction order that can be discerned in Goffman's texts from the beginning of the 1970s.

\section{Frame as space, framing as time and space}

Goffman's account in Frame Analysis - and in general - has, as has been previously stated, a very strongly spatial or situational character. Space is a central analytic category in Goffman's sociology. Below I will show that, in addition, it has a weak temporal character. The situationality that characterises Goffman's sociology does this to such a great extent that when he occasionally brings up time, it is also described as a kind of situation, something that is illustrated by this often-quoted expression where 'moments' appear to mean points in time rather than a flow of time, or perhaps a 'juncture', which means both a point in time and a situation: 'Not, then, men and their moments. Rather moments and their men' (Goffman, 1967, p. 3). 
This statement can be interpreted in different ways, and Emirbayer (1997, p. 296) describes its meaning as follows: 'The study of face-to-face encounters thereupon becomes a matter of locating regularities across such transactional processes, of specifying recurrent mechanisms, patterns, and sequences in meso-level "occasions". 8 Another interpretation of Goffman's statement can be found in Donati (2013, p. 150):

In this statement, engagement effectively comes to be a pure event "without a subject", in the sense that the event defines the Self and not vice versa. Having the human person depend on the "situational moment" is tantamount to dissolving him or her.

Emirbayer thus sees Goffman's words as an epistemological statement about how to study an individual in a particular situation, while Donati interprets the statement ontologically in that he thinks it implies, above all, a certain idea about the relationship between an individual and his or her surroundings. With the exception of Donati's rather extreme final point I believe that both interpretations are correct, even if I would rather summarise Goffman's statement in one word: contextualisation, which can be seen clearly in action in the articles 'The Neglected Situation' (Goffman, 1964b) and 'Footing' (Goffman, 1979a), and which in Frame Analysis is described as an 'anchoring of activity':

Given their understanding of what it is that is going on, individuals fit their actions to this understanding and ordinarily find that the ongoing world supports this fitting. These organizational premises - sustained both in the mind and in activity - I call the frame of the activity. (Goffman, 1974, p. 247)

This definition of frame emphasises the correspondence between experience and ongoing activity. The role of the temporal dimension has been downplayed, and it appears in part in terms of experience and in part in terms of so-called 'strips'. The experiences of individuals are more or less taken for granted, seem stable, and are not problematised, but appear in Frame Analysis as a kind of individual depository of knowledge that can be organised in order to suit the action in situations that vary according to the frame. Temporality therefore exists only prior to a situation, not during it; nor do frames appear to be situationally transgressive in Goffman's version other than in the form of experiences stored by individuals. The brief interaction sequences - strips - do have a temporal dimension, but this dimension does not transgress a situation either, but instead constitutes it. ${ }^{9}$

Experience is defined extremely briefly as 'something that an individual actor can take into his mind' (Goffman, 1974, p. 13). Is experience really everything that is taken into one's mind? Even, for instance, things that are forgotten? Does experience not have to be processed in some way other than 
taking it in for it to become an experience? Experiences are hardly constant simply because they have been taken into the mind, because memory is not always a reliable companion. Whatever the case, experience to Goffman consists of such things that an individual, consciously or unconsciously, has assimilated from outside the situation in question. That is to say, experience has to be organised during exchanges of situations. In a situation, experiences are organised in order to answer the question 'What is it that's going on here?' and thereby link themselves to the strips, the brief interaction sequences. On the whole, this is all that Goffman has to say when it comes to the temporal dimension, and it works because he is interested in frame analysis as a method. For the researcher the key element of the method is, as I have shown previously, to connect the actions and interactions of individuals inside a situation to different governing mechanisms; for example, norms and rules. Against this backdrop, frame becomes a kind of snapshot, unlike framing, which can be understood as a process where frames are continuously adjusted and transformed.

If one wants to study framing as this more dynamic chain of events in situations, a somewhat more developed temporal dimension is necessary. Such a more developed dimension is offered by German historian of concepts Reinhart Koselleck through his metahistorical temporal categories, and below I will attempt to complement Goffman's frame perspective with Koselleck's temporal perspective. At the same time, this attempt reveals, it will turn out, a crack in Goffman's sociological perspective.

Experience is a completely central category in Goffman's frame perspective, but it only means something that exists inside the heads of individuals. For his part, Koselleck transforms both experience and expectations into analytic categories and calls them the 'space of experience' and the 'horizon of expectation', respectively. The purpose of these is

the outlining and establishment of the conditions of possible histories, and not this history itself. This then is a matter of epistemological categories which assist in the foundation of the possibility of a history. Put differently, there is no history which could be constituted independently of the experiences and expectations of active human agents. With this, however, nothing is yet said about a given concrete past, present, or future history. (Koselleck, 2004 [1979], p. 256)

If we connect the concepts of space of experience and horizon of expectation to Goffman's frame concept, a kind of situational time is created. This time concerns both the interacting individuals and their shared situation. If we imagine that the individuals enter the situation and ask 'What is it that's going on here?', they can answer this question by, as Goffman writes, organising their experiences. The question is then reformulated as 'What happened in similar situations that I have experienced?', and the answer to that question then constitutes the space of experience where possible 
previous events and interpretations of them can be replayed and compared with the situation at hand. Because future events are always more or less uncertain, individuals reasonably also have to reflect on questions such as these: 'What might happen here?', 'What do I want to happen here?', 'What do other people want to happen here?', 'What mustn't happen here?', and similar questions that thus constitute the horizon of expectation for the situation. This creates an extension in time of the situation, not only backwards with reference to experiences but also forwards with reference to expectations. Goffman touches on expectations mainly in passing, such as, for example, when he in his analysis of 'the theatrical frame' with reference to game theory defines what he calls an 'information state', but he does this using the same words as Koselleck:

By an 'information state' I mean the knowledge an individual has of why events have happened as they have, what the current forces are, what the properties and intents of the relevant persons are, and what the outcome is likely to be. In brief, each character at each moment is accorded an orientation, a temporal perspective, a 'horizon'. (Goffman, 1974, p. 133f)

The purpose of Koselleck's use of the concepts of space of experience and horizon of expectation is to allow the past and the future to connect with each other in order to thus 'thematise historical time' (Koselleck, 1979, p. 353) ${ }^{10}$ and create temporal connections that are 'beyond mere chronology' (Koselleck, 2004 [1979], p. 258). When these two concepts are linked, experience is defined in part as something that has happened, in part as something that can be taken out and, e.g., be narrated. One might imagine that Goffman's 'organisation of experiences' corresponds to these two aspects of experience.

But Koselleck also uses the two concepts as metahistorical categories for investigating the relationship between experience and expectation in the development of history, and here there is another and, in my opinion, exciting link to be made to Goffman's sociology. Koselleck's thesis is that the distance between experience and expectation becomes ever greater during the Modern period (Neuzeit), which is characterised by enlightenment, revolution, and faith in progress. He speaks of 'a potential utopian surplus', and writes that '[expectation] no longer can [...] be satisfactorily deduced from previous experience' (Koselleck, 2004 [1979], p. 268). This undeniably puts a finger on a problem in Goffman's frame perspective, and the question is whether this shaky relationship between experience and expectations that Koselleck imagines does not better describe Goffman's frame concept than Goffman's continual reference to the organisation of experiences in order to understand what is happening in a situation. Goffman's question 'What is it that's going on here?', the answer to which interacting actors always seem to have in their experiences, can with Koselleck's help be made to reflect the kind of contingency that in many ways otherwise characterises Goffman's 
analysis and which I have previously described as the dynamic relationship between ritualisation and vulnerability. This relationship can most often be found at a 'micro-level' in Goffman's sociology, and vulnerability can be contingency at the interaction level, on condition that the interacting individuals are aware of it/have experienced it. When it comes to Goffman's later analyses of social interaction in public places, however, connections are also made to contingency at a societal level.

\section{Contingency: the social climate of public places and the transformation of the gaze}

Contingency, certainty, ontological uncertainty, security, fear, risk, and trust are all frequent themes in late modern sociology and are usually connected to the modernisation of society and, in its wake, to, for example, individualisation, globalisation, rationalisation, commodification (see, e.g., Bauman, 1989, 2006, 2007; Beck, 1992 [1986]; Giddens, 1990). Goffman did not contribute to this particular sociological theorising - he died before the above-mentioned sociologists came to dominate the stage. But at the beginning of the 1970s a kind of contingency theme appears in his texts, e.g., in the chapter 'Normal Appearances' in his book Relations in Public, and then as a problematisation of the atmosphere of interaction in public places that connects 'micro'- and 'macro'-sociological perspectives. In this chapter, vulnerability is made up of a contingency at the 'micro-level' that is charged by chains of events from different places in society, such as plane hijackings, gang wars, and street violence, and that affects interaction - not least eye work - in public places.

The gaze has a special role when it comes to interaction in public places or places where strangers meet. One of the best-known historical works that deals with this theme is Norbert Elias's study of the gradual civilising process of Western society during the most recent half millennium, where he argues that what has determined the civilising development of the West is people's growing mutual dependence on each other combined with violence being largely removed from everyday social interplay. The growing mutual dependence, then, refers precisely to individuals who do not have close relationships with one another. When it comes to violence, argues Elias (1982, p. 238), this has been confined to barracks and only intervenes in the life of the individual in emergency situations. A social mechanism thus comes into existence, he writes, 'in which the constraints between people are lastingly transformed into self-constraints' (Elias, 1982, p. 242f). The mechanism is portrayed as more coercive than human will or reason, but Elias does not quite explain what happens when mutual dependence results in social interaction free of violence, and violence in the form of self-discipline is transferred inside human beings. Is this a mechanism in a person's psychological equipment or in the social structure or both?

Those familiar with Elias's descriptions of how sociological research should be conducted may find reason to answer that the civilising process is 
an order in both directions. This is because Elias considered the sociological object of study to be the mutual dependence between individual and society, while he at the same time criticised both structuralist sociology for reifying the social structure, and individualist sociology as naïvely egocentric (Elias, 1978). However, when it comes to the study of the civilising process, Elias is not always faithful to his sociological ideal, and he cannot quite hold onto a description of the civilising process as a slowly progressing anonymous change of the form taken by the mutual dependence between individual and society. In part, this has to do with Elias's capturing his object of study with a psychoanalytically tinged conceptual apparatus, and portraying the civilising process as a kind of psychological change. This change is supposed to be a result of coercive changes in social structure. For instance, Elias argues that the state's monopolisation of violence forces individuals to be self-controlled, and speaks of a 'superego' that represses affect in the spirit of social structure. It is therefore possible, without being far too unfaithful to Elias's account, to interpret the civilising process as a psychological change brought about by changes in social structure - a kind of psychological process of evolution.

Duerr has based his in many ways convincing criticism of Elias's work on such a reading, and he has tried to find deviations from the pattern Elias calls 'the raising of the shame threshold'. Duerr tries to show empirically that the shame threshold in certain respects has been lowered, and he therefore writes about 'the myth of the civilising process'. He summarises his criticism in the following way: 'I have not claimed that nothing has changed in history, but that these changes - when taking a long view - cannot be described using an evolutionary curve' (Duerr, 1996, p. 17). Furthermore, Duerr claims that modernisation means a weakening or even a dissolution of social control that increases the opportunities for acting with impunity in an uncivilised manner:

It is difficult to see why the levelling of power relations should lead to shame thresholds being raised and not lowered. Because before whom should people feel ashamed when there no longer tends to be anyone controlling them or exercising power over them? (Duerr 1998, p. 13f)

With reference to the widespread anonymity and alienation in modern society he also claims that "the eye of the village" is a much more perfect instrument of surveillance than the "thousand eyes" of the great anonymous society' (Duerr, 1998, p. 20f). In summary, it can be said that Elias and Duerr each emphasises his own aspect of the two that Durkheim (1964) argued were linked to the increasing differentiation in the modern development of society: simultaneous social solidarity and anomie. Elias argues that the organic solidarity following from differentiation has a civilising effect, while Duerr rather is of the opinion that differentiation leads to a kind of anomie and moral laxness which makes the individual invisible as a moral subject. 


\section{Frame and framing}

Here there is reason to refer to Goffman's studies of social interaction in public places, and above all to the 'eye work' of civil inattention and to changes of this in times of contingency. In a public place strangers meet in passing, which is the central characteristic of this kind of encounter, and in general these people are going somewhere else and have different aims than meeting strangers in that public place. Because all the others are, in some sense, obstacles in one another's paths, interaction in a public place has to do with avoiding others in a smooth and easy way and, in general, avoiding ending up in a conflict with someone.

At the same time one has to ask what it means to see others. If we are to believe Sartre, it means primarily seeing the Other as an object and then becoming aware of that Other as a subject because the Other also sees me (Sartre, 1966[1956], p. 340ff). The gaze that, according to Goffman, is at work in public places both sees the other person in order to show that he or she exists, and does not see her or him out of respect. Civil inattention is the concept Goffman uses in order to describe how we act when we simultaneously see and do not see another person. When I, for instance, pass a stranger on the pavement I show him or her civil inattention by first quickly scanning her or him with my gaze to show the other person that he or she has been seen, only to thereafter look down, thus showing the other person that she or he is not the subject of any special interest (Goffman, 1963a, p. 84f). In the book Relations in Public the analysis of the interaction order of civil inattention is developed further by linking it to the normality of one's behaviour in public places, and the other person's normal performance means 'that it is safe and sound to continue on with the activity at hand with only peripheral attention given to checking up on the stability of the environment' (Goffman, 1971, p. 239). Civil inattention is thus both something one can expect from other people if one behaves normally, and something oneself gives to other people that behave normally. It thus has the character of a kind of symbolic gift exchange. On the other hand, a person who behaves abnormally can expect other people to either stare intently or become temporarily blind.

Goffman defines normality in public places with reference to individual activity consisting of two simultaneous aspects: 'going about one's business' and 'becoming alarmed'. Depending on the situation and the situational definition, 'going about one's business' or 'becoming alarmed' come to the fore. When individuals go about doing something, they simultaneously survey their surroundings using their senses in order to reassure themselves that there is no reason to be alarmed. Other unknown people in the surroundings are always an element of uncertainty, and an individual's surveillance of other people has to do with assuring her- or himself that anything other than initial attention is superfluous. Consequently, normality consists of things to which we have no reason to give other than fleeting attention. This is an extremely elastic definition of normality which in its actual content varies over time, between different cultures, societies, generations, people, and in 
other ways. Civil inattention can also be expressed in the kind of actions that Goffman captures with the words, 'when bodies are naked, glances are clothed' (Goffman, 1971, p. 46), and in this lies a kind of respect towards the, at least for the moment, deviant, ${ }^{11}$ but also a mutual work to maintain order in interaction. This mutual work can also include different remedial activities after the interaction order has been violated. This consists of things such as apologies, exclamations ('Whoops!'), and attempts to save the situation and thus the face of the violator of the norm: 'When an interactional offense occurs, everyone directly involved may be ready to assume guilt and to offer reparation' (Goffman, 1971, p. 108).

This far, Goffman's analysis stays within the frame of the theme of politeness and respect that characterised especially his texts from the 1950s on face-work and respectful behaviour. But in Relations in Public Goffman is nevertheless more interested than previously in deviations from the social interaction of civil inattention. He begins by stating that interaction in public places is a neglected area when it comes to research, but that at the end of the 1960s it was given attention because of the 'unsafety and incivility of our city streets', and, furthermore, that these streets have developed from being an exemplary area for social interaction into a battlefield. From this Goffman draws the following conclusion: 'It would seem a good time to develop the interaction ethology needed if we are to study this domain naturalistically' (Goffman, 1971, p. xii). The driving force here seems to be a lack of recognition, and the description of the decline of public places is not difficult to recognise today:

The vulnerability of public life is what we are coming more and more to see, if only because we are becoming more aware of the areas and intricacies of mutual trust presupposed in public order. Certainly circumstances can arise which undermine the ease that individuals have within their Umwelt. Some of these circumstances are currently found in the semi-public places within slum housing developments and slum neighborhoods, and there is no intrinsic reason why some of these sources of alarm (as well as some additional ones) cannot come to be found in the residential community of the respectable classes, causing the fragile character of domestic settings to be evident there, too. Certainly the great public forums of our society, the downtown areas of our cities, can come to be uneasy places. Militantly sustained antagonisms between diffusely intermingled major population segments young and old, male and female, white and black, impoverished and well-off - can cause those in public gatherings to distrust (and to fear they are distrusted by) the persons standing next to them. The forms of civil inattention, of persons circumspectly treating one another with polite and glancing concern while each goes about his own separate business, may be maintained, but behind these normal appearances individuals can come to be at the ready, poised to flee or to fight back if 
necessary. And in place of unconcern there can be alarm - until, that is, the streets are redefined as naturally precarious places, and a high level of risk becomes routine. (Goffman, 1971, p. 331f)

The mechanisms that create social unrest and contingency may very well be events on a completely different level than the interaction order, which is, as it were, charged at a distance and creates prerequisites for different transformations of and departures from the order. Much later Bauman described how the state, as an answer to the increasingly risky western societies, is trying to legitimise its existence by phasing out the welfare state and replacing it with a kind of 'personal safety state' (Bauman, 2007, p. 15).

Goffman also refers to changes in the public interaction order that have led to 'citizens at large having learned the sociological lesson that their easefulness had been dependent all along on the self-restraint sustained by potential offenders' (Goffman, 1971, p. 290). Civil inattention could thus be exploited by people who no longer feel the pressure or need to submit to the self-discipline that the public interaction order presumes. Civil inattention is then transformed into something that replaces interventions or escape, and becomes the shell within which fearful individuals can continue to contribute to the maintenance of the interaction order. The politely downcast eyes change their meaning: I am here but I do not present a challenge. The interaction order is suddenly more akin to the one Elijah Anderson calls 'the code of the street' than to Goffman's:

Many people, particularly those who see themselves as more economically privileged than others in the community, are careful not to let their eyes stray, in order to avoid an uncomfortable situation. As they walk down the street they pretend not to see other pedestrians. (Anderson, 1990, p. 220)

Consequently, the gaze of which Sartre spoke changes meaning: the reluctance to be seen as a subject makes me blind to the Other, and turns that Other and thus myself into objects. Because it is as a subject that I might end up in situations where I am challenged or threatened, and through a kind of self-objectification I can avoid such situations and at the same time be present. Civil inattention is thereby framed as fearful inattention. Obviously, counter-forces arise, and Elijah Anderson has described how in an ever more hostile social climate in certain public places - charged with 'macrosocial' events such as unemployment, social exclusion, increasing competition in every possible area, increasing violence among hostile groups, and public places being abandoned by individuals who could serve as counter-forces the kind of islands that Anderson calls 'cosmopolitan canopies' are created amongst the contingency. His most prominent empirical illustration is the Reading Terminal in Philadelphia: 'This is a calm environment of equivalent, symmetrical relationships - a respite from the streets outside'. And he 
describes its social atmosphere: 'The mass of pedestrians moves about, seeing but not seeing, paying what Erving Goffman called "civil inattention"“ (Anderson, 2011, pp. 33, 11). Moreover, I like to add, framing the Reading Terminal as a peaceful place.

\section{Frame and framing}

The feeling of contingency that we find in Relations in Public from 1971 (and to which Goffman later refers in 'The Interaction Order' from 1983) also characterises Frame Analysis. It is true that the key question of the book, 'What is it that's going on here?', is reserved for individuals' readings of interaction situations, but it can also be seen as a reflection of contingency on the eve of current changes in society and the interaction order that affect interaction situations. ${ }^{12}$ It is worth repeating Koselleck's words: 'no longer can expectation be satisfactorily deduced from previous experience'. If this is the case, which subsequently has been indicated by the strong emphasis in sociological research on the contingency in late modern societies, there is reason to downplay 'frame' somewhat as the organisation of experiences, because it is not quite sufficient for capturing the sense of contemporary times, and to instead emphasise 'framing'. The less frames can be connected to experience, the more need for framing. Framing then means the active, socially interactive doing of temporary situational frames that govern social interaction, and thus the framing of social interaction can reflect changes in society. Due to lack of space, I can here only point to some general similarities between Goffman's frame perspective and Latour's Actor-NetworkTheory in his book Reassembling the Social. (This fascinating title could in some ways work as a description of framing.) Both claim that the social (Latour) and social interaction (Goffman) can be studied in its own right. Moreover, Latour criticises sharply, and sometimes kind of rigidly, some sociologists' tendency to reduce the social to the societal and writes:

If connections are established between sites, it should be done through more descriptions, not by suddenly taking a free ride through all-terrain entities like Society, Capitalism, Empire, Norms, Individualism, Fields, and so on. [...]The name of the game is not reduction, but irreduction. (Latour, 2007 [2005], p. 137)

Goffman probably wouldn't completely agree with Latour, but as a newly elected chair of the American Sociological Association, he pointed out that his colleagues hadn't been enthusiastic of his claim of a 'face-to-face domain' as an empirical category that could be studied in its own right (Goffman, 1983b, p. 2).

One reason why Frame Analysis has not elicited and does not elicit as much fascination as several other books by Goffman may be that it is, to a rather great extent, expressed in terms of nouns rather than verbs; in other 
words, it focuses more on frame than on framing, more on conditions than on processes in the making. Several of Goffman's other books often deal with and strongly emphasise something that is just about to happen. Several of the concepts he invented mirror that: e.g., impression management (Goffman, 1959), primary and secondary adjustments (Goffman, 1961a), gaming (Goffman, 1961b), stigma management, fitting in (Goffman, 1963b), social gathering (Goffman, 1963a), action (Goffman, 1967), going about one's business and becoming alarmed (Goffman, 1971), gender displays (Goffman, 1979b), and footing (Goffman, 1979a). Goffman was perhaps aware of this difference when he in the opening chapter of Frame Analysis ironically, but no less fairly, criticises his own book:

There are lots of good grounds for doubting the kind of analysis about to be presented. I would do so myself if it weren't my own. It is too bookish, too general, too removed from fieldwork to have a good chance of being anything more than another mentalistic adumbration. [...] Nonetheless, some of the things in this world seem to urge the analysis I am here attempting, and the compulsion is strong to try to outline the framework that will perform this job, even if this means some other tasks get handled badly. (Goffman, 1974, p. 13)

In this context there is a point in also emphasising the difference between analysis and the object of the analysis - i.e., frame analysis and frame. Presented in this manner, the book Frame Analysis, as has already been mentioned, deals with the actual form of analysis that makes apparent the frame or frames that govern situations in which individuals interact with each other. There are, however, exceptions: in particular Chapter 10, 'Breaking Frame', and Chapter 11, 'The Vulnerabilities of Experience', which are more about framing. It is true that the question that is completely central in Frame Analysis - What is it that's going on here? - can be answered with reference to one or another frame, but the very dynamics of the situation shared by the actors are lost if we do not simultaneously imagine how the actors construct and reconstruct the situation by defining it in relation to their experiences and to other people, make tacit agreements, adapt to the moment, withhold their own opinions in order to save the situation, leave it in protest, and many, many other things. In some sense they construct the frame when they apply it in agreement with other people, but then the frame simultaneously develops and is transformed by being adapted to the situation. Again, it is of great importance how a reader chooses to frame Frame Analysis.

Some of the stilted impressions given by Frame Analysis would possibly disappear if one in parallel to frame were to speak about framing, in a way similar to that in which Goffman differentiates between game and gaming, where the former represents the rules of the game and the latter playing the game in its social context. In Frame Analysis Goffman talks about keying in approximately the way I here argue that one could talk about framing, but 
the problem is that Goffman reserves the concept of keying for what can be called an open code shift of the situation, and thereby differentiates it from so-called fabrications, where one or more people are unaware of the code shift. This differentiation is probably important in the systematising phase of an analysis - and Goffman was very systematic in his analyses ${ }^{13}$ - but when the concept of keying refers exclusively to a single aspect of the transformation of frames it cannot replace framing.

Framing has to do with transforming social situations or preventing them from being transformed, and could be exemplified with several of Goffman's own more process-related and dynamic concepts. Remedial work is such a concept, and this can form a model for framing. This concept describes the remedial work that interacting individuals perform when norms have been violated: 'The function of remedial work is to change the meaning that otherwise might be given to an act, transforming what could be seen as offensive into what can be seen as acceptable' (Goffman, 1971, p. 109). This description captures the very idea of framing. In Frame Analysis the dynamics of framing can also be glimpsed occasionally; for instance, here, in the chapter 'Breaking Frame':

when an individual misframes events, his subsequent action will break the frame [...]. He cannot rely on an unmanaged relationship between his own behavior and the scene in which it occurs, since the mutual consistency which ordinarily comes without apparent effort must now be consciously achieved and consciously sustained. (1974, p. 348)

I want to get at and emphasise the process-oriented in Goffman's frame perspective, where frame is transformed into framing - as in the quote above. In the following three chapters I present three of my own studies, where I attempt in different ways to apply framing in analyses of social media, online chess, and the exercise of power.

\section{Notes}

1 Kim (2003) provides an overview of these different positions.

2 Metareflection and metasociality can be seen as two different methods for finding out what is happening in a situation. Metasociality is related to Garfinkel's ideas about how to consciously violate the sense of the situation for the purpose of 'making commonplace scenes visible' (Garfinkel, 1967, p. 36f).

3 The reason for this is the Swedish law that says that between 1 December and 31 March and whenever there are wintry conditions on the roads, your car must be equipped with winter tyres. This creates a certain yearly rhythm in changing wheels and tyres and in the flow to and from the workshops that perform this work.

4 This distinction is reminiscent of the one that Lemert (C. C. Lemert, 1997) makes between, on the one hand, a layperson's sociology that deals with an actual and practised ability to interact, and, on the other hand, a professional sociology that scientifically describes, analyses, reflects on, and interprets the ability to interact socially. 
5 When it comes to continuity in Goffman's sociology, researchers have often tried to subsume it under some earlier great sociologist and/or theoretical school. The most recent study of Goffman's sociological perspective up to now, Deciphering Goffman by Ramon Vargas Maseda (2017), is partly doing that by connecting Goffman's work to pragmatism and symbolic interactionism, but principally also shares the same ambition as I have here: to show continuity in Goffman's work.

6 The searches were made on 11 July 2017.

7 Here one can also mention Bourdieu's (1990, p. 382) argument about scholastic fallacies, which means that researchers do not assume a metaperspective with respect to their own activities or to scientific activities in general (but they do to other people's activities if these are the object of study). Bourdieu called these epistemic doxa: 'thinkers leave in a state of unthought [...] the presuppositions of their thought [...] which are acquired through an academic or scholastic experience, often inscribed in prolongation of an originary (bourgeois) experience of distance from the world and from the urgency of necessity'.

8 Incidentally, Emirbayer writes in his article 'Manifesto for a Relational Sociology' (1997, p. 296) that Goffman's statement 'could well serve as an epigraph for this entire manifesto'.

9 There are exciting exceptions to this relative timelessness in what Goffman calls social sabotage (1974, p. 426ff), which he describes with reference to the creative sabotages carried out by activist Abbie Hoffman, surrealist André Breton, the Female Moral Reform Society, and theatre director and professor Richard Schechner's 'The Performance Group', the aim of whom was both cognitive and social transgression. Calling their acts sabotage seems to define them as exceptions.

10 This expression cannot be found in the English edition and has therefore been translated into English by the present author from the German original edition.

11 Here there is again reason to actualise the lack of - or possibly only the implicitness of - a temporal perspective in Goffman's analysis. If one were to ask, 'How long are glances clothed when bodies are naked?', the drawback of exclusively applying a spatial perspective - which is what Goffman does here by focusing on the corporeal encounter - is made apparent.

12 Goffman was good at linking his sociology to the spirit of the times, and when it comes to the above-mentioned question it had been posed in popular culture by, among others, Bob Dylan in 'Ballad of a Thin Man' from 1965 ('Something is happening here but you don't know what it is. Do you, Mr. Jones?'), and by Stephen Stills in 'For What It's Worth' from 1966 ('There's something happening here, but what it is ain't exactly clear').

13 When Denzin and Keller (1981, p. 56), with reference to systematics and classification, call Goffman 'a Linnaean structural biologist', Goffman answers (1981c, p. 67) that this is nothing to be ashamed of. 


\section{Part III}

Framing social media, online chess, and power 


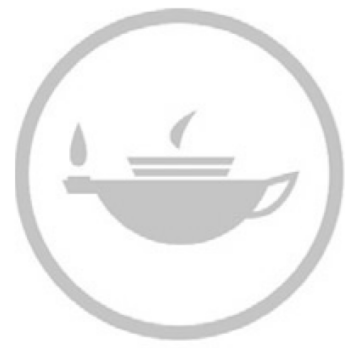

Taylor \& Francis
Taylor \& Francis Group http://taylorandfrancis.com 


\section{A new interaction order? - framing interaction in social media}

I have just checkmated my opponent in a game of online chess and get the following message via chat: 'I will rape your mom ok?', and three seconds later a mail: "hey my friend - I will rape your mom and after that, kill her!'. This does not happen very often because most people on Lichess are mainly interested in chess, but when it does happen I always think a bit dramatically that on the Internet there are no obstacles to a kind of 'dark force' that lies in wait to spread its crude message. On the chess site the players are anonymous, and it 'costs' them very little to threaten my mother's life (who incidentally has been dead for twenty years). However, on a closed site with around 15,000 members where higher education is discussed by, in many cases, named individuals who work in universities and university colleges, this dark force also lies in wait. When things go south there, the tone is not as rough as at the chess site, but it is very often destructive, conspiratorial, and impossible to, even with the best of wills, perceive as a bad joke. There always seem to be people here who cannot stomach constructive conversations and who lie in wait with negative comments, often without having any other basis for their statements than their own experiences. In connection with one of the doctoral students at my department defending his thesis, the contents of the thesis were presented in a press release from the University and shared on this higher education site. The thesis, existing on the borderland between the humanities and social sciences and, among other things, based on a significant amount of archival material, with articles from newspapers and periodicals whose discourse is analysed, was immediately dragged through the mud, with comments, mainly from men, coming thick and fast in a kind of self-generating downward spiral. Far-reaching conclusions about the thesis were presented, and most of the comments were loose and evasive - of the kind that do not need substantiation. There seemed to be no constructive intention, nor any curiosity: someone has written a thesis I haven't read but for some unclear reason don't like, come on guys let's destroy the damn thing!

Because the thesis was available in full text online, and a link was provided in the press release that had been shared, I could not help asking whether any of those who commented on the thesis also had read it. There was silence and the atmosphere soured in spite of it already being at the bottom, but then one person answered that he had read very little of the thesis. 
Another had skimmed it and added that nobody does anything else today not even the people in the examination committee. I asked, 'So you mean that skimming is enough of a basis for your claim that the thesis is "a dyedin-the-wool pseudo analysis in the spirit of post-modernism?"'. 'Yes,' answered the named man, who claimed to be a professor of a technical subject and who completely lacks the expertise in the subject required to act as a member of the examination committee.

These are only two recent examples that I have experienced myself, but it seems that one could make an almost endless list of examples like these if one listens to the ongoing public conversation about harassment and personal integrity in social media. The scope of and reasons for this phenomenon are under discussion. What is, for example, the driving force of men who in groups attack women online? Many have themselves experienced harassment online, but how serious should this be in order for us to be able to talk about trolling? In Sweden a 650-page public enquiry has suggested a number of new penalties in order to increase protection for people's integrity online and counteract harassment, illicit threats, and defamation (Integritet och straffskydd (SOU 2016:7) [Integrity and Protection Provided by Criminal Law], 2016). Quite a lot of research is being done on this topic, and one of the latest articles is summarised as follows by the researchers:

In online communities, antisocial behavior such as trolling disrupts constructive discussion. While prior work suggests that trolling behavior is confined to a vocal and antisocial minority, we demonstrate that ordinary people can engage in such behavior as well. We propose two primary trigger mechanisms: the individual's mood, and the surrounding context of a discussion (e.g., exposure to prior trolling behavior). (Cheng, Bernstein, Danescu-Niculescu-Mizil, \& Leskovec, 2017)

In The Wall Street Journal the results of these researchers were presented under the heading, 'We're All Internet Trolls (Sometimes)' (Mims, 2017). The researchers undeniably have a point in that it is not exclusively an 'antisocial minority' but also 'ordinary people' who engage in harassment online. That everyone at some time or another is an Internet troll is, however, a significant overstatement that will have to be attributed to the media. Perhaps the writer of the headline meant that everyone could become Internet trolls under the right circumstances? In any case, that is what this chapter is about: the interactive frame that seems to create prerequisites for a new interaction order on the Internet. In this and in the following chapter I will compare social interaction face-to-face with interaction in social media based in part on my own participant observations and in part on Goffman's frame perspective.

\section{Broad and narrow transmission of expressions}

Goffman's studies focus on interaction among people who are in immediate physical proximity to one another, so close that they can see, hear, and 
touch each other and smell each other's scents. Along with speech, a person's face is the single most important element in such interactions. It is our faces we turn towards the person we interact and communicate with, in order to be able to perceive the other person and assure ourselves that the other person also perceives us. To Goffman the face-work of the individual is therefore of vital importance, and he defines it as 'the actions taken by a person to make whatever he is doing consistent with face' (1955a, p. 216).

The social information that an individual can acquire about another individual in face-to-face encounters is conveyed, as has been mentioned earlier, through two different kinds of expressions. Expressions given are verbal and symbolic, which the individual controls to a rather high degree and uses in order to express information. Expressions given off are verbal and symbolic, which can be interpreted and to a greater extent controlled by other people precisely as symptomatic or non-symptomatic expressions of the individual who transmits them. Expressions given off can be a dialect, the choice of words, slips of the tongue, and quite a few of the things that the body does - perspires, laughs, shakes, cries, rumbles, farts, blushes, and looks - sometimes against our will, and that we for that precise reason try to control. These expressions can in a particular interaction be interpreted by others as symptomatic of one thing or another. We can probably all recall when we, for instance, have been unable to avoid bursting out into uncontrolled laughter or have tried to 'correct' our dialects.

Goffman writes that the very acts of existence produce expressions: 'Individuals [...] exude expressions' (1970 [1969], p. 5) and in another context he writes: 'Performers can stop giving expressions but cannot stop giving them off' (1959, p. 108). Even silence can be an expression given off in cases where choosing between speaking and silence is essential. The richest interaction in terms of expressions given off is interaction face-to-face (f2f), since all the senses are (or can be) acted upon during the interaction. This is one frame for social interaction and in what follows I will compare the f2f frame with interaction in social media, which I call interaction persona-to-persona (p2p). ${ }^{2}$

In his article 'Replies and Responses' Goffman offers a detailed analysis of the conditions that prevail in a face-to-face conversation, which I will use as an instrument to compare interaction face-to-face with persona-topersona. He chooses to view the conversation as a system whose function requires that the following conditions be met:

1 A two-way capability for transceiving acoustically adequate and readily interpretable messages.

2 Back-channel feedback capabilities for informing on reception while it is occurring.

3 Contact signals: means of announcing the seeking of a channeled connection, means of ratifying that the sought-for channel is now open, means of closing off a theretofore open channel. Included here, identification-authentication signs. 
4 Turnover signals: means to indicate ending of a message and the taking over of the sending role by next speaker. [...]

5 Preemption signals: means of inducing a rerun, holding off channel requests, interrupting a talker in progress.

6 Framing capabilities: cues distinguishing special readings to apply across strips of bracketed communication, recasting otherwise conventional sense, as in making ironic asides, quoting another, joking, and so forth; and hearer signals that the resulting transformation has been followed.

7 Norms obliging respondents to reply honestly with whatever they know that is relevant and no more.

8 Non-participant constraints regarding eavesdropping, competing noises, and the blocking of pathways for eye-to-eye signals. (Goffman, 1976, pp. $264-265$ )

Goffman describes the conversation here in a highly technical manner, ${ }^{3}$ which is done for analytical purposes so that we can see the component elements as clearly as possible. We can use this description as a coarse tool to compare face-to-face-interaction (f2f) on the one hand and persona-topersona interaction ( $\mathrm{p} 2 \mathrm{p}$ ) as it occurs in social media on the other:

Table 7.1 Comparison of $\mathrm{f} 2 \mathrm{f}$ and $\mathrm{p} 2 \mathrm{p}$

\begin{tabular}{|c|c|c|}
\hline $\begin{array}{l}\text { System requirements for talk as a } \\
\text { communication system }\end{array}$ & $F 2 F$ & $P 2 P$ (as it occurs in social media) \\
\hline $\begin{array}{l}1 \text { two-way transceiving } \\
\text { capability }\end{array}$ & Yes & Yes \\
\hline $\begin{array}{l}2 \text { back-channel feedback } \\
\text { capabilities }\end{array}$ & Yes & $\begin{array}{l}\text { Limited, since the interacting } \\
\text { individuals are not in one another's } \\
\text { physical presence. }\end{array}$ \\
\hline 3 contact signals & Yes & Yes \\
\hline 4 turnover signals & Yes & $\begin{array}{l}\text { Yes, but the turn-taking will work } \\
\text { mechanically due to technical } \\
\text { limitations. }\end{array}$ \\
\hline 5 preemption signals & Yes & $\begin{array}{l}\text { Yes, but it is not, for instance, possible } \\
\text { to interrupt anyone in the middle } \\
\text { of their 'speech', and interruptions } \\
\text { can occur only after the post has } \\
\text { been completed. The character of } \\
\text { the interruption is different because } \\
\text { it has to be indicated by a change in } \\
\text { subject or the interactant actually } \\
\text { states that there is going to be an } \\
\text { interruption. }\end{array}$ \\
\hline 6 framing capabilities & Yes & $\begin{array}{l}\text { Limited, but present with the help of } \\
\text { emoticons and emojis. }\end{array}$ \\
\hline 7 norms obliging honesty & Yes & $\begin{array}{l}\text { Yes, but more difficult to monitor } \\
\text { compliance, given the minimal social } \\
\text { information. }\end{array}$ \\
\hline 8 non-participant constraints & Yes & $\begin{array}{l}\text { Yes, with the help of various technical } \\
\text { solutions. }\end{array}$ \\
\hline
\end{tabular}


Both $\mathrm{f} 2 \mathrm{f}$ and $\mathrm{p} 2 \mathrm{p}$ correspond to the system requirements formulated by Goffman with regard to conversation as a communication system, although $\mathrm{p} 2 \mathrm{p}$ is limited in various respects.

The overall differences can generally be reflected using two metaphors: f2 $\mathrm{f}$ may be described as an encounter between two flows of different types of expressions - given and given off - while $\mathrm{p} 2 \mathrm{p}$ can be likened to a pingpong communication model in which the technical limitations on the flows of expression make the transitions in terms of turn-taking, framing, and back-channel cues highly distinct and mechanical. The flow from one person to another in f2f actually consists of two parallel streams that can have the same or contradictory messages. Metacommunication (communication about the ongoing communication) is also possible in that one person involved in $\mathrm{f} 2 \mathrm{f}$ can, so to speak, comment on one stream of expression with the help of the other stream. To conclude: $f 2 f$ and $p 2 p$ are very different communicative situations - they are two different frames for interaction. In conversations between people who are in physical proximity to one another, everything flows into each other and is held together by the situation being shared by the conversationalists. Take, for instance, the apparently trivial question 'What's the time?' and the answer 'Five'. This conversational sequence requires a specific context, a particular situation that is shared by the actors. To illustrate this, I posted the question 'What's the time?' on Twitter and Facebook and did not get the implicied response, but rather mostly silence and in some cases, reflections on how we organise time, such as 'It's five o'clock here, don't know what time it is by you' or 'As I read your e-mail the time is six o'clock, but I see that you sent it at five' (see also Castells, 1996, ch. 7). Also the seemingly trivial question of what time it is presupposes a mutual spatial framing in order to be meaningful. Like everything else, the framing must thus be re-created linguistically in $\mathrm{p} 2 \mathrm{p}$ interactions.

Differences between $\mathrm{f} 2 \mathrm{f}$ and $\mathrm{p} 2 \mathrm{p}$ in terms of the capacity to send and transmit expressions have a major impact on the communicative situation of the interacting individuals. We can speak of two interaction frames: first broad transmission, in the sense that, face-to-face, we share the situation and thus transmit a large volume of expressions to one another, and second the less expression-rich interactions in social media: narrow transmission, which is narrow in the sense that it consists to a greater extent of expressions given and to a lesser extent of expressions given off.

\section{Oversharing: connecting backstage regions frontstage}

In an earlier study I have shown that the boundary between the private and the public - in other words front- and backstage - tends to be drawn in a different way in $\mathrm{p} 2 \mathrm{p}$ than in $\mathrm{f} 2 \mathrm{f}$ (Persson, 2012a). The communicative situation in social media might be likened to a situation in which individuals in an apartment complex sit inside their own apartments and communicate with one another by calling out through windows that are 
open onto a common area. Any location can serve as a node in a social online network, given the technical options. The node is often located in the user's home, and that very circumstance should have a bearing on how the user communicates, specifically in that the user is often present in a private backstage area, communicating with others in the same situation. However, the communication may also be experienced by others in a manner akin to the situation in the apartment complex above, and in that sense the user is frontstage. One might say that social media often connect back regions in the front region. But there are ways to prevent transgression of the boundary between private and public in some social media; e.g. Facebook, where there are possibilities to exclude and include persons from your flow.

The interaction order - at least in its polite and respectful Goffman version - is being subjected to a change pressure in social media. In $\mathrm{f} 2 \mathrm{f}$ interaction, the interactors can transmit information to one another through body language, and such information can enforce norms and make it known that certain behaviours are inappropriate; for example, through glances, facial expressions, and bodily movements, and this can occur at the same time as verbal expressions are being sent. The ping-pong model of interaction in the context of social media entails the interactor writing something (give expressions) before other interactors can in turn write back. There is, as shown, very little opportunity for the parallel sending and transmission of expressions, and thus little or no opportunity for back-channel cues. First of all, this means that the one party must send out (write) too much before it becomes possible to make adjustments, and it may be that the boundary between front- and backstage has already been overstepped. In other words there are no mechanisms in social media to correct wrongdoings while doing them. Second, the efforts of others to make adjustments cannot occur until after the limits of what is deemed proper have already been overstepped, with the result that the person overstepping the border will likely lose face, and thus must choose between apology and defence, rather than between 'will I say/write this?' and 'will I not?'. In the context of this discussion, the forms of interaction that are peculiar to social media lead, in theory, to a rapid escalation of conflict, thereby creating special conditions for civil inattention. Such interactions are wordless and require physical proximity, and it remains to be determined whether civil inattention can be exercised in social media and, if so, how. I would imagine that some form of civil inattention occurs in social media through 'silence' - that is, one interactor choosing not to try to rectify transgressions of the boundary between front- and backstage. It is, however, possible that such an attempt at informative silence could be interpreted as approval of the transgression. This may be due in part to the fact that informative silence in $\mathrm{f} 2 \mathrm{f}$ is never just silence, because the verbal silence is instead supported by expressions given off. The body is thus not silent when it is in physical proximity to other bodies. Nor is the body 
silent in social media, but there is no one else who can 'hear' or scan it, with the result that silence in $\mathrm{p} 2 \mathrm{p}$ interaction is probably not an informative but an actual silence.

\section{Unsignificant others and ratified participants}

Like the rest of society, social media can be divided into places that are more private or more public, where people thus meet known and unknown others. Like so many other things in late modern societies, the individual chooses whether he or she wants to participate in social media communication or not. It is possible to remain outside, but others can choose to, e.g., publish a picture on Instagram of a person who has chosen to remain outside - but social media is, in spite of this, more selective than f2 $\mathrm{f}$ interactions. Social media that are more private can be likened to families, associations, and organisations, to which access is more or less regulated. For instance, Facebook has a number of choices that its users can make that regulate who has access to the user's own Facebook space. Social media can also be completely open, and can then be likened to public places, to which 'everyone' has access. There are intermediate forms, such as, e.g., a closed group with 20,000 members where all of the users are naturally not acquainted with one another. It thus appears to be just as complicated to comprehensively define what a public or private place is in $f 2 f$ as in $p 2 p$, because there are intermediate forms with regard to the relationships of the individuals involved. As Goffman was studying social interaction in public places, his results - concepts and definitions - can be used to some extent in order to understand social interaction in social media, in spite of his studies being conducted forty to seventy years ago.

When Goffman in the chapter 'Normal Appearances' describes interaction in public places, he says that George Herbert Mead 'must be our guide', and continues,

What the individual is for himself is not something that he invented. It is what his significant others have come to see he should be, what they have come to treat him as being, and what, in consequence, he must treat himself as being if he is to deal with their dealings with him. Mead was wrong only in thinking that the only relevant others are ones who are concerned to give sustained and pointed attention to the individual. There are other others, namely, those who are concerned to find in him someone unalarming whom they can disattend in order to be free to get on with other matters. So what the individual in part must come to be for himself is someone whose appearances are ones his others can see as normal. (Goffman, 1971, p. 279)

What kind of people are these other others that Goffman mentions? They are people we encounter in public places, and to whom we have an objective 
relationship, because we equate them with things such as bicycles, lamp posts, and other things over which we have to have a certain degree of control when we move about in such places. In a way, they are a kind of nonpersons, because we generally do not want anything with respect to them other than fleetingly and in passing noticing them, and they generally do not want anything else with respect to us either. In this sense there is an unspoken mutuality that expresses itself in civil inattention, avoidance, and non-seeing. At the same time, this objective relationship in a public place can be turned into social interaction.

We can determine the individuals in public places on the basis of Mead's differentiation between the significant other and the generalised other. Significant others are people who have a particular significance to us in our role-taking, as positive and/or negative role models. Mead describes the generalised other, on the other hand, as 'the attitude of the whole community', in which an individual also has to mirror her- or himself, and it is 'in this form that the social process or community enters as a determining factor into the individual's thinking' (Mead, 1962 [1934], pp. 154, 155). The difference between significant and generalised other is, to put it simply, like the difference between a model and a set of norms. What Goffman says in the quote above is that there is an additional other that we relate to, very fleetingly and in passing in public places. He does not give these persons any other name than 'other others', but I believe that she or he can be called the unsignificant other.

What characterises the unsignificant other is that he or she is a person who most of the time does not appear as a person to us but who can do so - a potential - which is the reason why I have not chosen the designation insignificant but instead call this figure, who can oscillate between unimportant and important, unsignificant. Unsignificant others are part of the flow of people we meet in public places. According to Goffman (1971, p. 154), these strangers appear indifferent, but can be transformed into an audience and are then also transformed into a kind of significant others, before which there is reason to mould one's behaviour in accordance with the general norms that are captured precisely by the concept of the generalised other. The unsignificant other is an outsider - the one who in the interactional context neither performs nor is the audience. The interaction with unsignificant others has, to a great extent, to do with body-to-body interaction, rather than face-toface interaction. The unsignificant other is a person without a face and a personality, a body we perhaps bump into when we get on the bus or whose body heat we can sense when we sit in the free seat recently abandoned by the other. Unsignificant others affect us, just as we affect them, through their presence in a mutual space or a mutual situation, where we are in each other's immediate physical proximity. They are individuals oscillating between being non-persons and persons, with whom one can develop some sort of relationship. 
As has been mentioned previously, Goffman uses the concepts focused and unfocused interaction in order to describe the difference between various degrees of commitment in interactions; e.g., in a public place where unfocused interaction implies dealing with a shared presence, a nonencounter. Focused interaction, on the other hand, is an f2f meeting between people. This is developed further in the article 'Footing', where Goffman, among other things, analyses the difference between ratified participants in conversations and bystanders, and how the latter can participate in conversations - that, e.g., take place in a public place - by eavesdropping or happening to overhear what is being said. Here p2p differs from $f 2 f$, because in social media either everyone is a ratified participant (in open social media), or there are no bystanders (in closed social media). The somewhat mechanical character of conversations in social media is thereby confirmed.

\section{Framing social media}

In Chapter 6 I pointed to four common elements in Goffman's frame analysis, and here I will by way of summary structure the interaction order in social media using these elements.

Governing mechanisms are rules and norms etc. that are action-directing in social interactions. Interaction $\mathrm{f} 2 \mathrm{f}$ and $\mathrm{p} 2 \mathrm{p}$ can be seen as two different frames that differ in part with respect to governing mechanisms. In social media, rules and norms etc. that the people interacting have learned in $\mathrm{f} 2 \mathrm{f}$ are mixed with special norms and rules that apply to $\mathrm{p} 2 \mathrm{p}$. Among the latter can be mentioned ethical rules and netiquette; e.g., Facebook's community standards:

People use Facebook to share their experiences and to raise awareness about issues that are important to them. This means that you may encounter opinions that are different from yours, which we believe can lead to important conversations about difficult topics. To help balance the needs, safety, and interests of a diverse community, however, we may remove certain kinds of sensitive content or limit the audience that sees it. (Facebook community standards, https://www.facebook.com/ communitystandards, accessed 30 July 2017)

Sensitive content is, e.g., nudity, hate speech, bullying, harassment, threats, depictions of violence, etc. In closed groups there are, in addition, regulations. For instance, in the closed Swedish Facebook group 'Högskoleläckan' ['University leaks'], the following rules of behaviour apply:

1 We stick to the subject - issues relating to university and university college activities.

2 We strive to maintain a good tone and show good manners towards other debaters. This means that we (a) stick to the subject of the thread 
of the original poster, (b) are allowed to criticise severely, but in a civilised and objective fashion, (c) do not discriminate among people - it is what is written, not who does it, that counts.

3 We do not publicly shame individual people or incite hatred against groups.

4 We respect other research orientations by not categorically dismissing things we do not agree with or creating insinuating posts without clear issues.

5 We do not distribute commercial advertisements even if they are on topic.

6 We respect the decisions of the moderators. Report posts that violate any of the rules. All members can report posts that deviate from the rules of behaviour. Moderators give reprimands and delete inappropriate posts. (accessed 30 July 2017)

As in f2f interaction, rules are rarely completely effective when it comes to preventing harassment etc. in $\mathrm{p} 2 \mathrm{p}$ interaction. However, the situation within which the interaction takes place in $\mathrm{f} 2 \mathrm{f}$ differs quite a lot from that in $\mathrm{p} 2 \mathrm{p}$. In $\mathrm{f} 2 \mathrm{f}$ the interacting parties are in a shared situation at the same time, while the situation in $\mathrm{p} 2 \mathrm{p}$ to a great extent is influenced by the fact that the parties are in a shared computer network in which the time can vary, because the interacting parties may be in any conceivable location while they are interacting. Because users in $\mathrm{p} 2 \mathrm{p}$ are physically found in locations that to a great extent are backstage (enclosed in themselves with a computer or mobile phone) while at the same time they are connected to a network which is frontstage to a considerably greater degree, this can lead to oversharing of information that would not have been shared $\mathrm{f} 2 \mathrm{f}$.

The performance of the interaction is, largely, affected by the conditions for expression transmission in $\mathrm{f} 2 \mathrm{f}$ and $\mathrm{p} 2 \mathrm{p}$. In the former, interaction framing, mainly verbal language and body language are used, and thus there is a broad transmission of expressions given and expressions given off. In $\mathrm{p} 2 \mathrm{p}$ interaction the interaction is performed using written language and symbols i.e., a narrow transmission mainly of expressions given. A wholly central difference is also that the interaction $\mathrm{f} 2 \mathrm{f}$ to a great extent takes place between individuals known to one another, while the interaction $\mathrm{p} 2 \mathrm{p}$ consists to a greater extent of a mixture of known others and unsignificant others.

The dynamics of the interaction and the situation in $\mathrm{p} 2 \mathrm{p}$ interaction have, as has been shown by way of comparing Goffman's description of conversations $\mathrm{f} 2 \mathrm{f}$ as a communication system to $\mathrm{p} 2 \mathrm{p}$ interaction, the character of a ping-pong interaction model that appears mechanical with respect to taking turns, reframing the interaction, and feedback hints.

To conclude, the communicative situation of the user in social media is paradoxical compared to f2f interaction. On the one hand, the user has much greater opportunity to edit the expressions he or she sends out, because of the physical separation of the interactors, thereby enabling 
highly controlled self-presentations that are - if illusory - hard for the other to control. In the physically proximate face-to-face interactions, it is possible to compare other people's self-presentations against the highly bodylanguage-based social information that can be gathered about the person with whom one is interacting. Self-presentations are thus less vulnerable in $\mathrm{p} 2 \mathrm{p}$, as the interactors are separated in space. On the other hand, the risk appears to be greater that the user will send out overly unconsidered expressions, think out loud, say too much, and become indiscreet because he or she is unable to benefit from the expressions given off that we constantly receive from (and give to) the others involved in $\mathrm{f} 2 \mathrm{f}$ interaction. The amount of regulating social feedback decreases markedly in social media, thereby increasing the tendency to overshare information and make ill-considered comments.

The difference between the communicative situation in interaction faceto-face and social media is a difference in the way expressions given and expressions given off have to be combined. Face-to-face, these different kinds of expressions are intertwined because of the physical proximity of the interactors, while interaction $\mathrm{p} 2 \mathrm{p}$, in comparison, is characterised by oversharing of expressions given and undersharing of expressions given off. This tends to create a special information state ${ }^{4}$ in $\mathrm{p} 2 \mathrm{p}$ that differs in certain ways from that in $\mathrm{f} 2 \mathrm{f}$ and can be likened to intelligence activities, which Goffman refers to as a frame described as follows:

Given a well-received, easily understandable message, what light is the message to be seen in, what systematic, word-by-word rereading is to be given it? Is the sender engaged in what he appears to be doing, namely, sending a serious, reliable message. Or is he merely practicing his sending, or engaging in a joke, or sending a false message because he is now working for the other side, or sending a message at the point of a gun. (Goffman, 1970 [1969], p. 141)

The comparison made in this chapter points to the communicative frame that is applied in social media being in several ways similar to intelligence activities, and the reason for this is that it is based on a narrow transmission of impressions. Further, and less dramatic, this frame also resembles Goffman's description, in his doctoral dissertation, of classroom behaviour, which:

seems a useful area for study because in a classroom children can be observed who have not yet learned to keep themselves in control or respect others and yet are sensitive to the fact that they ought to conduct themselves in a mannerly way. (Goffman, 1953, p. 361)

The knowledge among the users of social media is unevenly distributed and, consequently, also the possibilities to frame the interaction correctly. 
112 Framing social media, online chess, and power

\section{Notes}

1 Chat and mails at the chess site Lichess, 15 July 2017.

2 Persona is here defined as a created or an assigned representation of an individual; e.g., a username, a chosen identity, a picture etc.

3 He writes: 'We would thus be dealing with talk as a communications engineer might, someone optimistic about the possibility of culture-free formulations' (Goffman, 1976, p. 264).

4 Goffman (1974, p. 133f) defines 'information state' as '[...] the knowledge an individual has of why events have happened as they have, what the current forces are, what the properties and intents of the relevant persons are, and what the outcome is likely to be'. 


\section{Frame disputes in online chess and chat interaction}

Chess is frequently perceived to be a silent and courteous, even chivalrous, game. The emergence of the game of chess stretches back at least to seventh-century India and it is considered to have been known throughout Europe since the eleventh century. ${ }^{1}$ Its diffusion in Europe therefore coincided with the emergence of feudal society after the fall of the Western Roman Empire, and the game indeed reflects - in many ways - the class and power structure of early feudal society with its three estates: nobility, priesthood, and peasantry, together with its royal power. Chess shows great stability over time when it comes to rules, moves, and pieces, but does it also stay stable when played online? In this chapter I will answer this question based on results from several years of playing at two different online chess sites. During this time I've made participant observations focusing on differences between face-to-face chess and online chess, and I draw on the same basic differences between face-to-face and persona-to-persona interaction that was established in the previous chapter.

In order to grasp different aspects of the game, I have used Goffman's (1961) concept of gaming encounter and, within this concept, the difference between gaming and game respectively. Goffman describes, as already mentioned, the difference between these two in terms of gaming being sticky, whereas game is clean and possible to subject to rules. Goffman's view, based on game theory, is thus only rationalistic in respect of the game itself, but not in respect of the playing of the game and it is precisely here that questions can be asked where online chess is concerned. The game chess with all its rules - is the same when it is played face-to-face and online. But does this apply also to the actual playing of chess?

\section{The identity of chess}

Chess has a firm identity but has also changed over time and been sensitive to cultural and societal influences. No one has interpreted its many-sided character more inspiring than Stefan Zweig:

ancient and yet eternally new, mechanically constituted and yet an activity of the imagination alone, limited to a fixed geometric area but 
unlimited in its permutations, constantly evolving and yet sterile, a cogitation producing nothing, a mathematics calculating nothing, an art without an artwork, an architecture without substance and yet demonstrably more durable in its essence and actual form than all books and works, the only game that belongs to all peoples and all eras. (2005 [1942], p. 15)

As an example can be mentioned the development of the queen. That piece was from the beginning called the "vizier' and was a weak piece, but during the period from the year 1,000 to the end of the fifteenth century it became the most powerful piece of the game and was called the 'queen'. The chain of events that made this transformation possible have been discussed in a few texts: a bit fancifully on psychoanalytic grounds by Colby (1953), and with reference to many different sequences of events that enabled this change, among other things gender struggles, by Yalom (2004). But during the latest two centuries chess has, in the view of Eales (1985, p. 195), demonstrated an extraordinary stability. The rules of the game and the pieces have remained unchanged since the nineteenth century and, since then the game has come to be institutionalised with clubs, competitions, ranking systems, and national and world championships. In the 1970s the chess world went through a transformation, according to Swedish chess journalist and player Lars Grahn. In his book on the World Championship qualification game in 1968 between Russian grandmaster and later world champion Boris Spasskij and Danish grandmaster Bent Larsen, he writes about the modest conditions that were offered on site in Malmö in Sweden:

No one had got the idea to cover the shabby table with a cloth. It stood there naked in all its frailness and since long stripped of the varnish. It was the kind of table where you fold out the rickety legs and fasten them with wing nuts. It was four years before Spasskij and Fischer played in Reykjavik at a specially designed mahogany table with padded armrests of leather and a chessboard sunken in the table top. Four years before the revolution in the chess world. (Grahn, 2014, p. 20)

The entry of the computer into the world of chess was one of the twentieth century's great innovations so far as the game was concerned. When the chess computer Deep Blue, after three trials, defeated the then world champion Garry Kasparov in 1997, a possible peak in the rationalisation process of chess was achieved. Quite possibly the chess world has still not recovered, even if it has been said that chess has been reenchanted again with the victory of Magnus Carlsen, the young Norwegian with his special creative and less rationalistic playing style, in the World Chess Championship in 2013 (Hall, 2014).

Chess, regarded as a game, is commonly described as being wholly dependent on the skill of the players and as lacking the luck element that exists in many other games. Chess, in fact, is strictly governed by rules and the 
rules cannot be influenced by the players, either through negotiation or by them bending the rules; all such behaviour is regarded as cheating. A kind of respectful silence is also associated with the game. Everyone who has played chess knows that it is expected that one is silent during the course of the game, since chess is played with the players' complete concentration and any talk can thus be disturbing. There are, in fact, just a few occasions when the players may break this silence; for instance, when one of the players threatens the other's king and is then expected to utter a warning by saying 'check!' and when a player offers a draw or resigns. Thus talking, like the game itself, is strictly regulated.

For the last fifteen years I have played online chess on occasions, mostly under the cloak of anonymity, and I have, therefore, had good reason to think about similarities and differences between chess played face-to-face (f2f) and chess played persona-to-persona (p2p). In comparing the two I use the same instrument that was used in the previous chapter, based on Goffman's article 'Replies and Responses'; namely, the two interaction frames called broad and narrow transmission of expressions. How is, then, the social interaction in online chess framed compared to chess being played face-to-face?

\section{Framing social interaction in chess face-to-face and persona-to-persona}

F2f and $p 2 p$ represents, as shown, very different communicative situations: on the one hand a more or less undifferentiated flow of expressions, and on the other hand a ping-pong like way of interaction. What form do these differences take when firstly the game of chess is concerned, and secondly the playing of chess is focused? In general terms, one could assume that since f $2 \mathrm{f}$ chess is a case of $\mathrm{f} 2 \mathrm{f}$ interaction and $\mathrm{p} 2 \mathrm{p}$ chess a case of $\mathrm{p} 2 \mathrm{p}$ interaction, the differences between them are the same as those presented above, but that does not appear to be the case.

As mentioned, Goffman differentiates between, on the one hand, gaming - the interactive context that exists in playing and which is described as sticky - and, on the other hand, game, the game itself, which is pure and is possible to make into a regular activity that does not differ in playing terms from one occasion to another. The similarities between chess f2f and $p 2 p$ considered as game are great: the board is the same, the moves are the same, the pieces and the game rules likewise.

\section{Chess etiquette and frame disputes}

Studying social interaction in online chess is, among other things, studying frame disputes. ${ }^{3}$ The disputes have to do with the different ways that chess can be played f $2 \mathrm{f}$ and $\mathrm{p} 2 \mathrm{p}$ and, also, how players frame online chess: some players frame online chess as if it is the same as chess face-to-face, while 
others are developing a different kind of chess online. One of the online chess sites where I have played had three pre-composed text messages which were used when a player wants to offer and accept a draw, to abort the game right at the opening, and resign respectively. Superficially, these correspond to $\mathrm{f} 2 \mathrm{f}$ chess equivalences but the offer of a draw may be used to impose stress on the opponent through the text message being sent again and again; indeed, twenty times is not uncommon. The equivalent in $\mathrm{f} 2 \mathrm{f}$ chess would be the opponent saying 'shall we agree on a draw?' twenty times, one after another! It is almost inconceivable. Likewise in another online chess site where you have the possibility to ask your opponent to allow you to do a takeback, a possibility unfamiliar to formal $\mathrm{f} 2 \mathrm{f}$ chess but not in more informal situations. Here the frame dispute is very obvious because the wish to do a takeback can have several different meanings; e.g., when a grown-up helping a child to play chess, chess practice, psyching the opponent (in cases where the takeback question is being asked over and over again), and when the takeback question is asked after a fatal mistake that would end the game and means 'it would be nice/interesting to continue playing with you'.

Another characteristic in $\mathrm{p} 2 \mathrm{p}$ chess is that it appears to be easier to continue playing in hopeless situations. It also happens that when a player is subject to this, he or she quite simply gives up, despite having won, and thus feels sure that the time-wasting opponent learns the lesson that respect for the other player is more important than a match won or lost. In a chat on a chess site there is a line of reasoning as follows concerning when one should really give up in a chess game online when one has already lost:

A 'I was just wondering, is it generally considered rude to drag out a losing online game instead of resigning? I' ve been getting a lot of that lately. I think it's kind of rude. [...]'

B '[...] I never resign no matter what. [...]'

C 'Perhaps they are simply hoping for a miracle :] And to answer your question: Yes, it is a bit rude. But you need to be aware that some people don't know the etiquette ... and others just prefer to give their opponents as hard of a time as possible.' ('Resignation Etiquette, '2012)

Chess as a game may thus undergo change somewhat when it is played $\mathrm{p} 2 \mathrm{p}$; the moves are the same but the manner of handling offers of a draw, takebacks, and not resigning respectively, differ from $\mathrm{f} 2 \mathrm{f}$.

As mentioned already, the game of chess $\mathrm{f} 2 \mathrm{f}$ has a very clear identity and, moreover, in overall terms an indisputable etiquette. The World Chess Federation (FIDE), in particular, gives expression to this in its 'Laws of Chess'. Everything concerning chess as a game is regulated there in a highly rationalistic way. Under the heading 'Basic rules of play' it is stated, for example, 'The objective of each player is to place the opponent's king "under attack" in such a way that the opponent has no legal move' (FIDE, 2014). 
As has already been evident and will be illustrated further, this goal for the game of chess is not always shared by all players who play online. At the same time, FIDE's laws of chess state that there is awareness that not everything can be regulated beforehand. Nevertheless, the laws of chess do not contain any chess etiquette; the only thing that is said on this matter is as follows: 'The players shall take no action that will bring the game of chess into disrepute' (FIDE, 2014). This may be due to the fact that chess etiquette mainly regulates the chess gaming itself, since the moves and rules of chess are undisputed and strongly institutionalised. The etiquette mainly concerns the social interaction that gaming necessarily comprises and is embedded in, and which may be harder to rationalise in the same way as the game.

Chess organisations which are closer to club level than FIDE nevertheless publish texts that describe chess etiquette. The Illinois Chess Association in the US has, for example, produced a text on etiquette that is directed at chess-playing children and their parents. This describes just how the game of chess is embedded in social interaction, which must be regulated in different ways in order not to interfere negatively in the game itself; here, once more, there is reason to mention Goffman's description of the game as clean and gaming as sticky. Another example is Clatskanie Chess Club in the US, which has a setup of rules and norms which are also directed at children, but which have a slightly more general character and emphasise honesty, consideration, and humility in a chess milieu ('Chess Etiquette,' 2014).

In professional $\mathrm{f} 2 \mathrm{f}$ chess, psyching may occur in the form of, e.g., intensive staring at the opposing player, grimacing, and slamming the pieces down when they are moved, writes King, and continues:

The board shaker may be [...] irritating. It's hard to concentrate properly when the chess pieces are vibrating! Tigran Petrosian used this tactic against Viktor Korchnoi in 1977. Korchnoi asked him to stop, but Petrosian's riposte was to switch off his hearing aid. Then Korchnoi retaliated with a fast kick under the table. For the next game a partition was set up under the table. (King, 2002, p. 50)

In these circumstances, the efforts, honour, and prizes that are at stake are relatively high, and chess, in such cases, is therefore less play and more serious. The presence of so-called skittles, meaning disorderly and nonsense chess, at major chess tournaments also confirms this. In the breaks from the serious matter of the tournament, and in forms that deviate sharply from the 'normal' chess game and playing of the game, the playfulness of the game is recaptured: "All forms of skittles are symbolically "noisy" in contrast to the rule of silence during serious play [...], and all of them suspend one or more rules of standard chess to define their non-serious status' (Aycock, 1988, p. 132). 


\section{Comparison of the gaming conditions in $f 2 f$ and $p 2 p$ chess}

To continue now to similarities and differences between the gaming conditions in chess played face-to-face (f2f) and persona-to-persona ( $22 p$ ) including chat - I will start with a general comparison in Table 8.1.

Table 8.1 Game and gaming conditions in $\mathrm{f} 2 \mathrm{f}$ and $\mathrm{p} 2 \mathrm{p}$ chess

\begin{tabular}{|c|c|c|}
\hline & $f 2 f$ chess & $p 2 p$ chess + chat \\
\hline The other's presence & As a human being. & As text and persona. \\
\hline Communication forms & $\begin{array}{l}\text { The game as such, speech, } \\
\text { body language, all strictly } \\
\text { regulated by rules and } \\
\text { etiquette. }\end{array}$ & $\begin{array}{l}\text { The game as such, } \\
\text { automated text } \\
\text { messages related to the } \\
\text { game, chat. }\end{array}$ \\
\hline Meeting place & $\begin{array}{l}\text { Often neutral ground (chess } \\
\text { club). Can also be played } \\
\text { more informally in the } \\
\text { home or school. }\end{array}$ & $\begin{array}{l}\text { Often the players own } \\
\text { territory; e.g., at home } \\
\text { and own computer. }\end{array}$ \\
\hline $\begin{array}{l}\text { Definition of the } \\
\text { other's playing } \\
\text { strength }\end{array}$ & $\begin{array}{l}\text { Can most often be carried } \\
\text { out in advance when } \\
\text { the players play in the } \\
\text { same club or competition } \\
\text { through ranking system. } \\
\text { Private game: playing } \\
\text { strength can only be } \\
\text { assessed after the game. }\end{array}$ & $\begin{array}{l}\text { The player can choose if } \\
\text { he/she wishes to show } \\
\text { his/her ranking, given } \\
\text { that the chess site } \\
\text { permits this possibility. }\end{array}$ \\
\hline Offer of draw & Oral, ritualised. & Text message. \\
\hline $\begin{array}{l}\text { End of game (apart } \\
\text { from draw) }\end{array}$ & $\begin{array}{l}\text { Checkmate, resignation, loss } \\
\text { on time. }\end{array}$ & $\begin{array}{l}\text { Checkmate, resignation } \\
\text { through automated text } \\
\text { message, loss on time, } \\
\text { loss through one of the } \\
\text { players stopping play } \\
\text { without resigning, loss } \\
\text { through logging out of } \\
\text { the chess site. }\end{array}$ \\
\hline $\begin{array}{l}\text { When to continue to } \\
\text { play and when to } \\
\text { resign }\end{array}$ & $\begin{array}{l}\text { Dependent on the game but } \\
\text { adjusted through norms } \\
\text { for when and how players } \\
\text { are expected to resign. }\end{array}$ & $\begin{array}{l}\text { Easy to resign and easy } \\
\text { to continue playing in } \\
\text { hopeless situations. }\end{array}$ \\
\hline $\begin{array}{l}\text { Game's social } \\
\text { character }\end{array}$ & $\begin{array}{l}\text { Silent respectfulness, } \\
\text { concentrated focus on } \\
\text { the game, very limited } \\
\text { possibilities for side } \\
\text { activities. }\end{array}$ & $\begin{array}{l}\text { May differ from the } \\
\text { same as f } 2 \mathrm{f} \text { chess to } \\
\text { the opposite: noisy } \\
\text { chat, attention divided } \\
\text { between game and } \\
\text { other activities. }\end{array}$ \\
\hline $\begin{array}{l}\text { Relation between game } \\
\text { and gaming }\end{array}$ & $\begin{array}{l}\text { Gaming is often close to game } \\
\text { and therefore the activity } \\
\text { can often be described } \\
\text { solely with reference to the } \\
\text { game as such. }\end{array}$ & $\begin{array}{l}\text { Gaming may deviate } \\
\text { strongly from game. }\end{array}$ \\
\hline
\end{tabular}


While one plays p2p chess on the sites I refer to here, one can chat at the same time as the game is in progress, which is kind of foreign to the character of chess as we know it in the f2f version, since the chatting would correspond to conversation during the chess game and such activity is not part of the conditions of $\mathrm{f} 2 \mathrm{f}$ play. There are different chat possibilities depending on what kind of subscription one has. When playing for free on one of the sites, several years ago, there was a rudimentary chat with fixed lines. During the time I used the site the lines were as follows:

\begin{tabular}{ll}
\hline 1 Hello & 11 Good game \\
2 Let's go for another & 12 Are you still there? \\
3 OK for a last game & 13 Yes \\
4 No thanks & 14 No \\
5 :-) & 15 Thanks \\
6 :-( & 16 Played well! \\
7 You play very well & 17 Another game? \\
8 Bye & 18 Have a nice day (added April 2013) \\
9 I can't answer you, I'm still in 7 & 19 Oooops! (removed April 2013) \\
$\begin{array}{l}\text { days trying period } \\
10 \text { Good evening }\end{array}$ & 20 Ouch! (removed April 2013) \\
\hline
\end{tabular}

Compared to a chat where the words flow freely, this type of chat with fixed lines seemed a bit vapid. On the other hand, the actual use of such vapid chat illustrates that even a minimal interaction situation can be reframed to something quite different, as shown below.

Most of the chat lines are friendly or neutral. Indeed, the selection of just such lines as the site's organiser has carried out metacommunicate that the players are supposed to uphold a friendly tone. However, symbolic interaction often does not allow itself to be enclosed in such neat frames, and consequently different reframings of the recommended frame can be made and were actually made. Some of the lines may therefore be used in wholly different ways than intended. Situation, context, and timing, in combination with the creativity of human actors, may alter the meaning of the lines, as set out below.

Line no. 5-an emoticon that represents a smiling face-may express pleasure over an opponent's good play but it may also express malicious pleasure where it is used after the opponent has made a poor move. Line no. 4 - No thanks - may be used wholly without charge like a confirmation that the player concerned does not wish - or is not able - to play more, but when the player, on the other hand, has lost a game because of very poor play and wishes to play a new one, then the line may be perceived as a kind of review of the previous game. Lines no. 7, 11, and 16 may be used in a friendly way, as intended, but also ironically and sardonically, whereas line no. 17 may be used as an encouragement to the opponent to resign. Line no. 12 may be a way of attempting to hasten the opponent's moves and sometimes leads to the opponent making a move or terminating the game, especially where the player 
has taken a long time since the last move and has possibly spent time doing something else - maybe writing email, answering the phone, fetching coffee. The question: 'Are you still there?' - with a kind of situational emphasis on you as a consequence of the long waiting time - seems to be framing the other player as a responsible actor. Oooops! and Ouch! may be used to indicate that one's own bad move does not meet one's own expectation; the lines set the bad move within a form of brackets and separates it from what the opponent may believe to be his/her normal playing strength. But these two lines can also be used to regret the other's mistakes. They may also, nevertheless, be used sardonically/scornfully; for example, if one of the players is superior in the game and puts the other player in situations where he/she is forced to make bad moves and the superior player comments on each move with an Oooops!

In the conversation on social media, attention is often given to unpleasant comments and, e.g., oversharing of personal, often intimate information, which is not really in accord either with the interaction order that, according to Goffman, frames social interaction, or indeed accepted etiquette. Also the tone of social interaction may, as we can see, be changed when the respectful and silent chess game is played online. Here it becomes evident that we are not always being helpful in upholding a friendly and smooth interaction order and in this connection it can be mentioned that Billig (2005) states that we are not always friendly and considerate in social interaction but sometimes rather cruel and criticises what he calls Goffman's 'nice guy view'.

In the examples above - where friendly chat lines are sometimes reframed into malevolence - I believe that differences in the framing of social interaction in $\mathrm{f} 2 \mathrm{f}$ and $\mathrm{p} 2 \mathrm{p}$ chess respectively can explain this transformation. In particular, the anonymity in $\mathrm{p} 2 \mathrm{p}$ chess means that players can set aside respect for the other person, transform him/her into an object for whom there exists no relation of responsibility. One can neither hold oneself nor anyone else responsible. This can break down the self-censorship of individuals where malevolence is concerned. This is, nevertheless, only one difference between $\mathrm{f} 2 \mathrm{f}$ and $\mathrm{p} 2 \mathrm{p}$ chess. There are also other differences that influence the game itself and the gaming conditions.

\section{Engrossment and distance}

Social interaction is being enacted under different levels of involvement, and typologically we can imagine a continuum that may be described as follows:

Table 8.2 Engrossment and distance

\begin{tabular}{lll}
\hline engrossment & $\begin{array}{c}\text { alternating between } \\
\text { engrossment and } \\
\text { distance }\end{array}$ & distance \\
\hline
\end{tabular}


Engrossment or intense involvement means that individuals are engaged to such an extent that the sense of distance may be wholly lost, whereas distance may be difficult to reconcile with an engrossing commitment. An intermediate stage may also be envisaged where alternation take place between engrossment and distance. An analytical and strongly simplified figure, as above, cannot accurately capture the fact that transitions between the different positions take place gradually. Nonetheless, the figure can tell us a lot about social interaction in principle.

When it comes to the alternation between engrossment and distance, this accords fairly well with what Goffman imagined people do when they go in and out of situations which they share with others: they attempt to find out about and define or interactionally construct the frame which organises the activities within the situation and, in order to do this, they may ask a distancing question: 'What is it that's going on here?' (Goffman, 1974, p. 8). Framing often - probably always - consists of alternating between engrossment and distance, between involvement in the interaction and, at the same time, reflection upon it. Against this background I will continue the comparison between f2f and $p 2 p$ chess and also ask three questions to f2f and p2p chess respectively: Who am I interacting and playing with?; What is allowed to disturb a game?; and, How can a player tell what the actions of the other player mean?

\section{Who am I nteracting and playing with?}

As mentioned, social interaction according to Goffman (1961b, p. 7, 1963a, p. 24) may be of two different kinds: unfocused and focused. Unfocused interaction occurs as soon as individuals are in one another's proximity and in some way influence one another; for example, two strangers who share a seat in a bus and control their respective behaviour in order not to touch the other person in an inappropriate way. Focused interaction means instead that two or more individuals have a shared focus; for instance, when they converse or play chess. Unfocused interaction is about presence in shared situations, while focused interaction is about a mutual and shared involvement.

Perhaps the most fundamental difference between $\mathrm{f} 2 \mathrm{f}$ and $\mathrm{p} 2 \mathrm{p}$ chess is that in the latter case one cannot be sure whom one is playing with and, consequently, whom one is sharing the situation and the involvement with. Behind the persona 'guestmaeb', which the chess site generated randomly when I just logged in, there may be found a chess amateur like myself, a world champion, or a chess computer, a man or woman, Swede or Kenyan, old or young, but as a player on the site, I cannot find this out. If one wishes to try to read one's opponent one has to satisfy oneself with the game itself and the chat. In the article 'On the Internet nobody knows if you're Bobby Fischer', there is a tale of how Nigel Short, a grandmaster in chess who in 1988-89 was ranked number three in the world, made public how he believed that he was playing chess online with the former grandmaster Bobby Fischer as late as the year 2000, when Fischer had, in fact, long retired. The player who Short actually met was anonymous, and he and many 
others could only attempt to find out who it was by analysing the game itself and chat conversations. One of the designers of the chess programme Fritz, Frederic Friedel, did just this and his attempt is described thus:

Next, Friedel dissected 'Fischer's' approach to the game. The Bobby Fischer of lore, Friedel suggested, would never use the ridiculous openings Short had described - they were sick, rude, uncouth maneuvers that any top-level player would find odious; Fischer, by contrast, had always been a courtly player. On this point, many disagree. [...] grandmaster Fischer always did what he had to to win. He didn't have a signature style so much as a will, a ferocity, and fresh ideas that could seem like mistakes until he proved them otherwise. (Wieners, 2002, p. 75)

In the discussion that followed on Friedel's website, a certain 'Jason L., a person who posed as a chess cheater, wrote as follows:

Hi I'd just like to say that I guarantee Bobby is not on the internet playing chess. Why? Cuz I am the best chess cheat on the internet and the situation is very familiar to me. In the last year, I have played thousands of games cheating and have yet to ever come close to losing even one game. [...] I have written an autoplayer program [...] I just start up a one min[ute] game and sit back and watch my program play by itself [...] No, I am not the Fischer character in the web. Yes, cheating is fun. I get so much satisfaction laying a GM [grandmaster] in a 2 min game and watching him resign after 25 moves, and then urging him to take up checkers. (Wieners, 2002, p. 75)

Then somebody who called her- or himself Bobby Fischer began playing top class chess on a chess site and the questions mounted up: 'Was this Short's Fischer, a copycat Fischer, Fischer himself, or even Jason L.?' (Wieners, 2002, p. 75). The fact that the question 'Who am I playing with?' cannot be answered with any degree of certainty is an essential difference between $\mathrm{f} 2 \mathrm{f}$ and $\mathrm{p} 2 \mathrm{p}$ chess. And here one can think of Goffman's shrewd class analysis of English aristocratic politeness: 'In the classic phrase of England's gentry, "Anyone for tennis?" did not quite mean anyone; [...]' (Goffman, 1961b, p. 29), and still surely does not mean 'anyone'. When, however, anonymous online chess is concerned, the invitation 'Anyone for chess?' may mean literally this. So the answer to the question 'Who am I interacting and playing with?' when $\mathrm{p} 2 \mathrm{p}$ chess is concerned is, therefore, 'anyone'.

\section{What is allowed to disturb a game?}

The level of involvement, as mentioned above, may be different in social interaction; this is evident from the difference between focused and unfocused interaction, but also within the category of focused interaction. 
Focused interaction may be so engrossing that the interacting individuals are wholly screened from their surroundings and Goffman meant that such interaction is regulated by 'rules of irrelevance'. This total engrossment in, and targeted attention on, some part of the reality and simultaneous definition of other things as irrelevant is an obvious picture of chess. It resembles Coser's 'greedy institutions', which create the conditions for 'total commitment', which in its turn '[...] reduce[s] the anxieties that spring from competing role-demands and the pull of differing loyalties and allegiances' (Coser, 1974, p. 18). Puddephat (2008) obtains support from Coser when he puts forward the view that 'the chess world', with its 'devoted participation', may be perceived as a kind of greedy institution.

The screening that is a consequence of the rules of irrelevance finally has effects that resemble what Csíkszentmihályi calls flow:

Because of the structure of the game, the primary rewards people derive from it are autotelic. [...] Like climbers, dancers, or surgeons, chess players shift into a common mode of experience when they become absorbed in their activity. This mode is characterized by a narrowing of the focus of awareness, so that irrelevant perceptions and thoughts are filtered out; by loss of self-consciousness; by a responsiveness to clear goals and unambiguous feedback; and by a sense of control over the environment. These are the salient features of that modality of experience we have called 'flow'. (Csíkszentmihályi, 2000[1975], p. 72)

Chess players are presented here as deeply engrossed, enthusiastic participants involved in their activity. Does this apply to all chess? Hardly. These descriptions presuppose that special conditions of play are in place and that the framing of social interaction can create the special sense that allows almost total involvement and makes much else irrelevant for the time being. These conditions of play and such framing are in place during chess tournaments and surely in chess clubs and possibly also sometimes in the case of 'private chess'.

Where online chess is concerned, other conditions apply too. Online chess is open to anyone, anywhere, is available anytime (assuming Internet access), and appears to be subject to preconceived notions by the players involved which strongly deviate from the chess world that is institutionalised. Given that the Internet players - assuming that they are people and not chess computers, which we cannot know for sure - are mostly in their homes, where there is much else to attract their attention (e.g., at their computer, which invites other activity while waiting for the other player's move), other rules of irrelevance may apply. The framing of online chess seems not to result in the same level of engrossment as $\mathrm{f} 2 \mathrm{f}$ chess. 
My own experience and observations of online chess, which is all that I can currently base these statements on, show that much else is allowed to disturb the chess game when this takes place on the conditions described above. The phone rings and the opponent then has to wait, in which case it is easier that our relationship is anonymous. One of the children needs help with homework and then the opponent gives up the chess game in progress or just lets the time tick on. Occasionally, nevertheless, engrossment can also occur. The answer to the question 'what is allowed to disturb a game?' varies with the gaming conditions: from almost nothing in tournament chess f2f to almost everything in online chess.

\section{How can a player tell what the actions of the other player mean?}

Social interaction implies not only that people meet one another and converse, do something together, play games, or whatever the case may be; they also read or decode the expressions that the others give and give off. Why does he have a strained crease on his brow when we speak to one another? Why does her eye wander? Why is he sweating so profusely just now? Why did she say this - what did she mean really? In f2f interaction, the flow of expressions is extensive and the interpretation of expressions likewise offers many different possibilities before they are translated into distinct impressions. In $\mathrm{p} 2 \mathrm{p}$ interaction, as we have seen, the flow is narrower. This does not mean that attempts at interpretation cease, rather attempts at interpretation may become even more intensive. How can, for example, a player in $\mathrm{p} 2 \mathrm{p}$ chess find out the meaning of what the other player does?

One way of finding out the implications of the opponent's game is to store experiences from other players. This is what a ranking system does, but here I am thinking of making mental notes of how others play, how strong they are as players, and such like. This presupposes that the players use the same persona over a longer period. At the site where I play at this moment, every game is being stored in a database open to other players. However, if one plays as Anonymous then each game represents a new start; one is without ranking and reputation.

If we only take the game itself into consideration, then the players are spatially separated from each other. Consequently, players can only read their opponent through expressions by way of the game. Moves can suggest how proficient the player is; the use of time can also express something; the circumstances under which a player offers a draw may be significant. Equally, when the opponent resigns, some resign at the very same time they end up in any situation of disadvantage; others prolong things as far as possible. During my observations I carried out an experiment to try to find out the significance that can be interpreted from the use of time right at the very start of the game. I challenged an opponent to play a five-minute game but then made no opening move. I did this twenty-five times with different 
players. Seventeen of the players gave up after 20 seconds or less, the quickest after only 2 seconds. Eight of the players gave up after more than 20 seconds; the one who waited longest did so in 66 seconds. This gives the impression that the players frame a five-minute game as a very fast game: if it has not started after 20 seconds then most give up. But this is also determined by the fact that it is exceptionally easy to initiate a new game: many players wish to play.

My participant observation has been carried out on a chess site where there is the possibility to chat at the same time as one plays. This occurs on a series of different chess sites and, in itself, is a rather notable innovation. It is perhaps more a concession to the format that applies to many other social networking sites online than a contribution to the development of chess. Chatting is hardly a substitute for talking during the course of a chess game, as speech is strictly regulated in $\mathrm{f} 2 \mathrm{f}$ chess. But sometimes chatting helps inform a player as to what the actions of the other mean.

\section{Conclusions}

Chess as game is chess regardless of whether it is played face-to-face or persona to persona. In this case I mean chess considered as game as such. The playing of chess may, nevertheless, vary depending on differences in playing conditions between these two forms of chess, as shown in the present text. The differences are so large that one can talk about two different game frames that set their stamp on the game. In its main features, f2 $\mathrm{f}$ chess may be described as a silent game despite the fact that talk is possible, whereas $\mathrm{p} 2 \mathrm{p}$ chess is a silent game since talk is impossible. The communication between the players in $\mathrm{f} 2 \mathrm{f}$ chess takes place through three channels: the game itself, sharply limited talk, and body language. In $\mathrm{p} 2 \mathrm{p}$ chess, on the other hand, the communication takes place through one channel: the game itself. However, there is often scope for online chat at the same time as the game is in progress, and in that case and by will of the players the communication is expanded with a further channel. In those cases where chat is used, the difference between $\mathrm{f} 2 \mathrm{f}$ and $\mathrm{p} 2 \mathrm{p}$ chess increases, since players are not expected to converse with one another when playing chess. The chat facility is a replacement for the loss of talk online. When it is used with chess, the game tends to change, since the talk, in principle, is already removed from the game in its $\mathrm{f} 2 \mathrm{f}$ frame.

Even a very limited chat, like the one I have studied here and which comprises some twenty fixed lines, may be used in ambiguous ways, as indicated above. The silent respectfulness that characterises the game of chess may be sustained with the aid of friendly and polite chat. Players that lack respect for the game, and for the other player, appear to have greater scope, under the playing conditions that characterise $\mathrm{p} 2 \mathrm{p}$ chess, to transform chess from silent respectfulness to a loud-mouthed ego trip and from honourable civility to petty pinpricks. And, last but not least, players who 
126 Framing social media, online chess, and power

are anonymous and not in physical proximity have limited possibilities to maintain the etiquette of chess should anyone choose to break it. Frame disputes - in the players' minds, chat, or game - are more frequent in $\mathrm{p} 2 \mathrm{p}$ than in $\mathrm{f} 2 \mathrm{f}$ chess.

\section{Notes}

1 Historical and technical information on the game of chess, throughout, has been obtained from King (2000) and Hall (2014).

2 The vizier - adviser - was in ancient times a high-placed official in Muslim countries.

3 For the term 'frame disputes', see (Goffman, 1974, p. 322ff). 


\section{Interactional power - influencing others by framing social interaction}

Goffman was definitely no theorist of power, but because social interaction is a recurring theme in his sociology, so is people's influence on each other, and influence can be seen as a kind of exercise of power. On one occasion Goffman touched upon the relationship between state authority and interactional power, and he then said the following:

The modern nation state, almost as a means of defining itself into existence, claims final authority for the control of hazard and threat to life, limb, and property throughout its territorial jurisdiction. Always in theory, and often in practice, the state provides stand-by arrangements for stepping in when local mechanisms of social control fail to keep breakdowns of interaction order within certain limits. Particularly in public places but not restricted thereto. To be sure, the interaction order prevailing even in the most public places is not a creation of the apparatus of a state. Certainly most of this order comes into being and is sustained from below as it were, in some cases in spite of overarching authority not because of it. Nonetheless the state has effectively established legitimacy and priority here, monopolizing the use of heavy arms and militarily disciplined cadres as an ultimate sanction. (Goffman, 1983b, p. 6)

In an article from the 1950s we can read what can be understood as just such a description of the establishment of the order 'from below' mentioned in the above quotation: 'societies everywhere, if they are to be societies, must mobilize their members as selfregulating participants in social encounters' (Goffman, 1955a, p. 231). Even if Hacking excludes power from his comparison of Goffman and Foucault in favour of a description of the positioning of each of them in relation to their objects of study, his description of their approaches as bottom-up and top-down, respectively, also has quite a bit to say about power:

But Goffman was not reporting individual exchanges for their own sake. One of his projects was to understand how people were constituted, defined themselves and were understood by others, in terms of 
exactly such interactions. I call this 'bottom-up' because we start with individual face-to-face exchanges, and develop an account of how such exchanges constitute lives. I call Foucault top-down because he starts with a mass of sentences at a time and place, dissociated from the human beings who spoke them, and uses them as the data upon which to characterize a system of thought, or rather, its verbal incarnation, a discursive formation. (Hacking, 2004, p. 278)

The difference between Foucault's top-down perspective on power and Goffman's bottom-up perspective can be illustrated with the help of Foucault's expression 'conduct-of-conduct' (Dean, 2010 [1999], p. 177f; Foucault, 1982, pp. 220-221). Authorities conduct the conduct of the citizens. Goffman instead kept the authorities behind the scenes in a state of alert and focused more - that's bottom-up - on interacting individuals' conduct (without using that particular word). The individuals are presented as self-regulating actors inside an interaction order supervised by the authorities. Foucault's reference to the authorities/the state is detailed and well informed, while Goffman's is coarse and uninterested. At the same time, Foucault's emphasis on 'apparatuses of security' (Foucault, 2007, p. 208) looks a bit like Goffman's 'standby arrangement' in the citation above.

Unlike Foucault's top-down perspective, Goffman's bottom-up perspective was rarely defined as a power perspective by his contemporaries, but that connection has sometimes been made later. In what follows I will present Goffman's perspective as a power perspective based on interactional power, where influence through the framing of social interaction is a central part. First a few words about power theory.

\section{How, when, and where is power exercised?}

Power is a central concept in the social sciences, something to which already Bertrand Russell (1938, p. 10) drew attention when he wrote that 'the fundamental concept in social science is Power, in the same sense in which Energy is the fundamental concept in physics'. Clegg and Haugaard begin their comprehensive overview of the concept of power by stating the same thing, while at the same time they say that the concept of power 'is arguably one of the most difficult concepts to make sense of within the social sciences' (2013 [2009]b, p. 1). What does it mean that the concept of power is fundamental within the social sciences? First, that there is a constant discussion of the concept of power because it is an 'essentially contested concept' (Gallie, 1955; Lukes, 1974, 2005). Second, the concept of power is used to study processes and mechanisms that both build up, change, and tear down societies and institutions over time, processes and mechanisms that develop the force that can be called power. The concept of power is perhaps mainly used in studies at the societal and institutional levels, but societies and institutions are created by individuals through social interaction, which is why 
the concept of power can also be used on the interactional level. Against this background I will here briefly summarise research on power by looking for answers to the questions 'how, when, and where is power exercised?' in a few central theoretical works on power.

Research on how power is exercised has generated a number of different results. It has, for instance, been said that power is exercised through decisions (Dahl, 1961), decisions and non-decisions (Bachrach \& Baratz, 1970), socialisation (e.g., Lukes, 1974), sanctions (e.g., Blau, 1964), and power resources that can be used in order to reward and punish (Korpi, 1983). Theoreticians of power have, in addition, created theoretical systems that contain principally different, but in practice complementary, ways of exercising power. Weber (1968a, p. 53), for example, differentiated between 'power' - the probability to carry out one's will despite resistance - and 'domination' - the will of a superior actor realised because the will to obey is stronger than the will to resist. Russell (1938) separated physical power, reward/punishment, and the influencing of opinion. Galbraith (1983) filled his system of the exercise of power with compulsion, compensation, and conditioning; and Etzioni (1975) focused on violence, norms, and symbols.

It is of course extremely relevant to reflect on how power is exercised, but the discussion on power is made considerably more stringent if one also considers the temporal aspect of the exercise of power - i.e., when it is being exercised. This is perhaps best illustrated by what can be called an individual's gradual growing into society from birth and forward, and thus his or her habituation to concrete existing social and societal conditions. Such processes can be designated in different ways and accorded different meanings, but here I am after the socialisation of the individual (Berger \& Luckmann, 1967) and a critique of far too mechanistic perspectives on socialisation (Freud, 1962 [1930]; Wrong, 1961), as well as similar perspectives that are designated in other ways; e.g., habitus (Bourdieu, 1977) and the emphasis in American 'sociology of everyday life' on the routinisation/ritualisation of social interaction; e.g., Garfinkel (1967) and Goffman (1967) (see also Chapter 3). When the above-mentioned Lukes criticises Dahl and Bachrach and Baratz he is trying to do precisely this: place the exercise of power in a temporal context. He says that the subjective interests of an individual who is subject to the exercise of power may have been shaped so that these subjective interests deviate from the objective interests of that individual, and that this may explain the lack of conflict and thus the absence of power in the sense of Dahl and Bachrach and Baratz. That is to say, Lukes's criticism takes as its starting point the biographical aspect of the temporal context in which the exercise of power is located, and then emphasises the importance of socialisation.

The different answers to the question of when power is exercised makes topical a third question - that is to say, where power is exercised. If the study of power is focused on moments of influence, it becomes easier to delimit the spatial exercise of power, something that, on the other hand, becomes more 
difficult if the exercise of power is studied biographically or historically. The question of where power is exercised has therefore also been answered in different ways. Some researchers argue that power has a centre; others that power is everywhere. The idea that power has a centre or a small number of centres has been claimed in political theory by theoreticians of elites; e.g., Pareto (1968 [1901]) and Mills (1956). The pluralists; e.g., Dahl (1961), believe that power is exercised in several competing centres of power. Unlike these attempts to spatially delimit power, it has also been pointed out that power does not have one or several centres, but is exercised in many different places in society, perhaps everywhere. For instance, Barnes (1988) believes that power is embedded in society as a whole, and Elias (1978) describes power as a structural characteristic of human relations. Foucault says that power relations are imminent in other types of relationships (Foucault, 1979; Foucault \& Kritzman, 1988).

\section{Foucault and Goffman}

There is reason to dwell on Foucault because his influence has been great in the field of power theory during the last forty years, but in this case also because there are certain similarities to Goffman's perspective. In Foucault, discipline represents a special form of exercise of power that results in power being made invisible, while at the same time the individuals who are subject to the exercise of power are made visible. This kind of discipline constitutes a break with an earlier, more expressive exercise of power that made power visible as something so constant and stable that it appeared almost meaningless and dangerous to challenge it, a kind of exercise of power that I believe can be said to live on in the authoritarian regimes of the twentieth century and the present day. However, in many places in modern societies, changes have occurred that have resulted in power becoming less clear and visible. It is then no longer a function of the visible, but of the invisible, exercise of power.

The spirit of discipline can, against this background, be said to be economic, because it constitutes an exercise of power that is economical with physical violence, while at the same time it is also economic in the sense that it attempts to increase the usefulness of the disciplined individuals. Discipline 'made possible the meticulous control of the operations of the body, which assured the constant subjection of its forces and imposed upon them a relation of docility-utility', states Foucault, and continues,

But in the course of the seventeenth and eighteenth centuries the disciplines became general formulas of domination. They were different from slavery because they were not based on a relation of appropriation of bodies; indeed, the elegance of the discipline lay in the fact that it could dispense with this costly and violent relation by obtaining effects of utility at least as great. [...] The historical moment of the disciplines 
was the moment when an art of the human body was born, which was directed not only at the growth of its skills, nor at the intensification of its subjection, but at the formation of a relation that in the mechanism itself makes it more obedient as it becomes more useful, and conversely. What was then being formed was a policy of coercions that act upon the body, a calculated manipulation of its elements, its gestures, its behaviour. The human body was entering a machinery of power that explores it, breaks it down and rearranges it. [...] Thus discipline produces subjected and practised bodies, 'docile' bodies. Discipline increases the forces of the body (in economic terms of utility) and diminishes these same forces (in political terms of obedience). In short, it dissociates power from the body; on the one hand, it turns it into an 'aptitude', a 'capacity', which it seeks to increase; on the other hand, it reverses the course of the energy, the power that might result from it, and turns it into a relation of strict subjection. (Foucault, 1979 [1975], p. 137f)

The point of Foucault's concept of discipline, unlike, for instance, that of Weber (1968a, p. 53) - which is based on the idea that discipline is defined as the 'methodically prepared and exact execution of the received order, in which all personal criticism is unconditionally suspended' (Weber, 1968b, p. 1149) - is thus not unquestioning obedience, but the combination of obedience and the economising of force that turns the subordinate into a conscious and will-governed instrument. Foucault's version of discipline does not create slaves or robots, but instead seems to be a process that is eventually characterised by the self-control of the individual. 'One is,' Foucault (1979 [1975], p. 153) writes, 'as far as possible from those forms of subjection that demanded of the body only signs or products, forms of expression or the result of labour'. Discipline's form of submission means instead that

the efficiency of power, its constraining force have, in a sense, passed over to the other side - to the side of its surface of application. He who is subjected to a field of visibility, and who knows it, assumes responsibility for the constraints of power; he makes them play spontaneously upon himself; he inscribes in himself the power relation in which he simultaneously plays both roles; he becomes the principle of his own subjection. By this very fact, the external power may throw off its physical weight; it tends to the non-corporal; and, the more it approaches this limit, the more constant, profound and permanent are its effects: it is a perpetual victory that avoids any physical confrontation and which is always decided in advance. (Foucault, 1979 [1975], p. 202f)

In the long term, discipline thus seems to be a question of developing a soul that can control the body. Successful development 'makes invisible' the exercise of power by concealing or denying the connections between outer 
influence and individual action. The disciplined human being can against this background be defined as a person who controls and governs him- or herself - to the advantage of other people and perhaps also her- or himself. The subordinate is thus transformed from an object of the exercise of power into a subject that contributes to the exercise of power. Foucault called the whole complex of ideas and practices that generate this kind of power, which in modern societal development is increasingly built into people, governmentality:

First, by 'governmentality' I understand the ensemble formed by institutions, procedures, analyses and reflections, calculations, and tactics that allow the exercise of this very specific, albeit very complex, power that has the population as its target, political economy as its major form of knowledge, and apparatuses of security as its essential technical instrument. Second, by 'governmentality' I understand the tendency, the line of force, that for a long time, and throughout the West, has constantly led towards pre-eminence over all other types of power sovereignty, discipline, and so on - of the type of power that we can call 'government' and which has led to the development of a series of governmental apparatuses (appareils) on the one hand, [and, on the other,] to the development of a series of knowledges (savoirs). Finally, by 'governmentality' I think we should understand the process, or rather, the result of the process by which the state of justice of the Middle Ages became the administrative state in the fifteenth and sixteenth centuries and was gradually 'governmentalized'. (Foucault, 2007, p. 108f)

In a way, governmentality poses the question: How does one govern a population of free individuals? Apart from all efforts to 'shape, guide, direct the conduct of others' - i.e., the 'conduct of conduct' (Dean, 2010 [1999], p. 17ff; Foucault, 2007, p. 192f), this form of control also has to do with creating 'governable subjects' (N. Rose, 1999, pp. 3, 40ff). This means that free individuals are formed with the help of different mechanisms that, e.g., make them ever more dependent on wage labour, on education, on money in order to be able to consume, and other similar things that help individuals both govern themselves and not define governance as control but as calculated adaptation to the conditions such as they appear in the individuals' own lives. Concomitantly to this transformation of the exercise of power, an increase in efficiency occurs: governance stops engaging in symbolic demonstrations of strength and instead becomes, in a manner of speaking, goal-oriented. From such a perspective of efficiency, the social background, sexual orientation, age, skin colour, or gender of the individual who governs her- or himself in order to, for instance, be as efficient a bricklayer or professor as possible, or as good a citizen as possible, makes little difference as long as the efficiency goals are reached. To govern, in this sense, Foucault writes, '[...] is to structure the possible field of action of others' (Foucault, 1982, p. 221). 
In this way there emerges what at first glance may appear to be a paradox: hand in hand with the transformation of power that can be called governmentality comes a kind of individual liberation in a number of areas. This development is, as ever, uneven, and as a consequence of this kind of modernised exercise of power another kind of modernisation emerges that is turned against power itself, and that becomes visible when, e.g., a person resists discrimination because of his or her skin colour. A kind of liberation on the individual level modernises the exercise of power, while at the same time this modernised exercise of power draws individuals out of their collective designations by way of individualisation: if, for instance, it turns out that a young person in school or at university has problems reading, the staff may determine that this has to do with his or her social or cultural background, and that there is a set of individual measures of assistance that can be taken in order to enable the individual to fulfil the requirements of the school or university. This emphasis in the exercise of power on the resources and problems of an individual against the background of efficiency requirements tends to first make visible and then separate the exercise of power from that individual's social and collective designations.

How does this relate to Goffman's sociology? Goffman did not claim that power was a central category in his studies of social interaction. He hardly mentions power at all. But one of his texts comes pretty close to a more traditional perception of power: his book Asylums. In this book, events inside total institutions are analysed, and it would have been possible for me to use it as one of the examples of Goffman's manner of conducting frame analysis. As mentioned in Chapter 6 frame analysis is sensitive to four certain aspects:

- governing mechanisms, which are far more coercive in total institutions.

- the situation, which is spatially much clearer.

- the performance of interactions, which is more hierarchically differentiated in a total institution.

- the dynamics of the interaction in the situation, that often consist of conflict-filled social dynamics between, in particular, the staff and the inmates, which to a great extent are based on what Goffman calls 'the privilege system', which regulates rights, order, rewards, and punishments, with the aim of breaking down the personality of the inmate and constructing another, more suitable one. ${ }^{1}$

But the precise fact that this has to do with total institutions, which are less contradictory than many other types of institutions, also makes the power that is being exercised stand out more clearly than in other institutions. Although it is not an unequivocal exercise of power, Goffman portrays the power that is exercised in a total institution as a mixture of coercive power and self-discipline. 
Coercive power is characteristic of the more obvious total institutions prisons, military training, and mental hospitals - and Goffman describes how it is exercised already during the admission procedure, where a process of mortification immediately begins in order to 'kill' the identities and the roles the inmate brings with him- or herself from the outside. Then the inmate is initiated into the privilege system, which aims to adapt the inmates to the total institution, and they gradually develop different ways of adapting to the coercion of the institution. Primary adaptation means that the inmate or client in a total institution does as she or he is told - cooperates - while secondary adaptation means 'any habitual arrangement by which a member of an organization employs unauthorized means, or obtains unauthorized ends, or both, thus getting around the organization's assumptions as to what he should do and get and hence what he should be' (Goffman, 1961a, p. 172). This is to say that Goffman here sees a space for social illusion-making, where the inmates can pretend to be adapted in a large number of different ways, and thus resist the exercise of power within the institution by demonstrating to themselves that they are not completely defined by the institution. So when Foucault (1979 [1975], p. 138) writes, 'Thus discipline produces subjected and practised bodies, "docile" bodies', Goffman would perhaps ask how subjected the disciplined bodies really are, and issue a warning that the docility of the bodies may be a social illusion, not least because of the fact that there also is and has to be another form of power in the coercive power of the total institutions: self-discipline. Because in spite of the inmates' being convicted of crimes and having diagnoses that result in their being seen as not accountable for their actions, they are expected to be able to control themselves within the total institution:

Inmates must be caused to self-direct themselves in a manageable way, and, for this to be promoted, both desired and undesired conduct must be defined as springing from the personal will and character of the individual inmate himself, and defined as something he can himself do something about. (Goffman, 1961a, p. 83)

Here we see, with reference to Hacking, how Goffman's situational, interactionist sociology and Foucault's archaeological discourse analysis can be made to complement each other. What Foucault in his top-down perspective represents as a temporal sequence of events where coercive power is partially sidelined by governmentality for hundreds of years, Goffman in his bottom-up perspective sees as two factors in action side by side in the total institution: the how, when, and where of the exercise of power, on the one hand seen as a development over time and on the other hand framed in the special social dynamics of the total institution.

\section{Power as influence and resisting influence}

The few researchers who have tried to define Goffman's perspective as relevant within research on power argue with reference to the fact that his 
studies on social interaction are also about influence. Both appear as soon as people are in each other's proximity and are also played out by individuals in a kind of inner dialogue before, during, and after interacting with other people. Goffman links this continual influence and reflection on influence to the interaction order, which is maintained by those who interact without really aiming to do so. It can be said that the interaction order is an unintended consequence of how individuals consciously and subconsciously influence other people and avoid being influenced by them.

Goffman's studies of influence were made at a time when sociologists instead used the concept of power to understand events at the level of social structure, at governmental, and international levels, and, to some extent, at the organisational level. All of Goffman's active time as a sociologist came to be characterised by such a 'macrounderstanding' of power resulting from, among other things, the Cold War between East and West, and by students and, in some places, workers revolting against an unfair societal and world order.

Researching etiquette in interaction between people or what it means to hold hands in public places provoked some critics, even more so perhaps when it turned out that Goffman's texts garnered great attention. Many of his critics felt that Goffman turned his back on the complex of problems relating to class and power. One of the most persistent ones was Denzin, who twenty years after Goffman's death wrote that Goffman

gave midcentury academic sociology exactly what it wanted, and what it needed: Men and women in gray flannel suits performing the rites and rituals of a postwar white collar society, [...]. Goffman's actors did not resist, they conformed to the requirements of a local and global capitalism that erased class, race, and gender in the name of a universal, circumspect human nature. Goffman's moral selves knew their place in the order of things. (Denzin, 2002, p. 107)

Furthermore, Kemper (2011, p. 81), from a completely different point of departure, felt that one of Goffman's largest mistakes was 'omitting the power dimension as one of his major conceptual foci'. On the whole, this criticism is fair: Goffman was no radical class theorist; he did not study race but on the other hand he did study gender and, as has previously been mentioned, power was not a concept Goffman used in a theoretically foundational manner. At the same time, it probably would have been difficult for Goffman to use the kind of status-power model developed by Kemper, because in this model power is defined as 'involuntary compliance' and status as 'voluntary compliance' (Kemper, 2011, p. 13). This division is hardly useful if power is to be connected to the kind of socially interactive influence studied by Goffman.

There are also those who see Goffman's sociology as relevant in the study of power. In an article, Rogers describes her purpose in studying Goffman's significant but unexpected contribution to the study of power 
in this manner: "to illustrate the utility of looking to "nonpower" scholars for insights relevant to the refinement of this central sociological concept' (Rogers, 1977, p. 88). Further, in an in-depth text, she finds that Goffman provides a number of significant but implicit contributions regarding power, which she summarises as follows: 'Goffman's strategy is rather to indicate the determinative and general influences of social orders, including public order, and "social establishments" on behavior in everyday life' (Rogers, 1980, p. 128). Jenkins tries to develop this perspective on Goffman's 'view on power' and writes:

Power, in this view, is not confined to warfare, politics or economic exploitation. It is, rather, a mundane matter of everyday relationships between ends, on the one hand, and ways and means, on the other. While recognizing the ubiquity of power in the everyday human world - in the sense that a greater or lesser degree of efficacy is fundamental to all human endeavours - by situating power within the practicalities of what people do, I attempt to avoid the problems inherent in abstracting 'totalising' theories of power. [...] (Jenkins, 2008, p. 159)

Goffman's contribution then concerns primarily the influence of interacting actors on each other, while they simultaneously are influenced by the more collective order that Goffman calls the interaction order.

Influence is usually not seen as power unless there is an intention behind it, and Weber's definition of power illustrates this: 'the probability to carry out one's will despite resistance'. In order to specify exactly Goffman's view on power it is important to differentiate between influence and intentional influence, even if this can be difficult.

Goffman studies influence in all of his texts because influence is a kind of default value in social interaction - in other words, social interaction is hardly possible without mutual influence, even if the degree of influence can vary greatly. (In contrast, influence can be imagined without social interaction.) However, the forms of this socially interactive influence vary with the situation. The smooth manoeuvring of an individual through the flow of people in a public place, where it is impossible to avoid influence, but which to a great extent has to do with being influenced and influencing to the least possible extent, is one example. Goffman calls this form of influence unfocused interaction, and it exists as soon as individuals are in each other's proximity. Focused interaction, on the other hand, implies a mutual presence in a situation where the interacting individuals have a common focus and mutually influence each other; e.g. a conversation. A third form of interaction can be exemplified by the gaming encounter, as has previously been mentioned. It is a form of interaction where the main activity - the game that follows set rules and makes the interaction predictable - can be threatened by a secondary activity - the interactional context in which gaming is embedded and whose influence means that attention is drawn away 
from the game itself. As has been mentioned earlier, Goffman believes that the participants have managed this show of force between two realities - the game and the gaming - by using 'transformation rules' to separate things from 'the world outside' that are allowed to come into the gaming encounter from those that are to be kept outside. This is then an example of a more intentional influence.

We also find such influence in what I have previously called social illusion-making. One example is stigma management, which means hiding one's own drawbacks because they risk leading to stigmatisation - singling out and exclusion because of the dynamics of shameful differentness where shame is 'a basic social coin, with awe on one side and shame on the other' (Goffman, 1959, p. 70). Another example is impression management, which has to do with controlling how other people perceive a person and the shared situation. Impression management is a very commonplace and 'normal' form of social illusion-making - so commonplace that most of the time it is completely frictionlessly integrated into the social interaction and not at all as 'acted' as, for example, a lonely hearts racket and fraud and Goffman develops his analysis of this more than is the case with other forms of illusion-making in which he is interested, and presents the results under the heading 'The arts of impression management'. This art consists, as has been mentioned previously, of three main activities, and concerns the impression management of groups, but can just as well be applied to individuals, and communication within the impression-managing group is then replaced with the inner dialogue of the individual. The first activity is called dramaturgical loyalty, and means that the interacting individuals or groups, in order to succeed with the performance, have to be loyal to the impression of themselves or to the situation that is communicated to the person or persons with whom the individuals or groups interact. The second activity is called dramaturgical discipline, and it means that the interacting individuals must retain control so that the performance is successful even when they are carried away by their own enthusiasm for the interaction with other people. Goffman calls the third activity dramaturgical circumspection, and this means that the interacting individuals must protect their impression management both before and after the interaction; e.g., not give information to outsiders that is in conflict with the impression management. Another part of the art of controlling impressions is the maintenance of the boundary between front- and backstage, because the insights of other people backstage can disrupt the impression management, as well as the setting and the personal front that both support the performance.

There is also reason to mention the fact that the opportunity to influence and avoid influencing varies according to structural differences in different forms of interactions. Such a difference becomes visible in the comparison I have made in the two preceding chapters between social interaction face-toface and persona-to-persona: the difference between a broad and a narrow transmission of expressions. On condition that an interacting individual can 
maintain the discipline of influence that Goffman calls the art of managing impressions, this management entails assuming as much control as possible over both expressions given and expressions given off. The maintenance of this control is more difficult when it comes to a broad transmission of expressions, but more efficient from a power perspective if this control is successful. In the case of a narrow transmission of expressions - in, e.g., social media - the power of influence is limited when it comes to the expression flows themselves, and this might be considered to explain how it is that wars of words escalate so quickly in certain social media. The will to influence is not in parity with the actual opportunities to influence.

To return to the art of impression management, the final element in this performative influence or exercise of power is the audience - the persons with whom the interacting individual interacts, whether individuals or groups - in other words, the persons who, with the aid of impression management, are to be convinced that the performance is real. The audience can of course resist the impressions the performers transmit, but more often the audience assists and displays what Goffman in this text calls 'tactful inattention'2 and overlooks mistakes and slips of the tongue:

When performers make a slip of some kind, clearly exhibiting a discrepancy between the fostered impression and a disclosed reality, the audience may tactfully 'not see' the slip or readily accept the excuse that is offered for it. And at moments of crisis for the performers, the whole audience may come into tacit collusion with them in order to help them out. [...] Similarly, at times of inspection, whether in school, in barracks, in the hospital, or at home, the audience is likely to behave itself in a model way so that the performers who are being inspected may put on an exemplary show. (Goffman, 1959, p. 231f)

The influence and avoidance of influence is a kind of keynote throughout Goffman's entire oeuvre, and one can, if one so desires, relate this to the questions posed earlier about how, when, and where power is exercised. The answer to the question 'How is power exercised?' would then be 'by way of different kinds of influence and avoidance of influence in social interaction', while the other two questions about when and where power is exercised would be answered with 'just about always', and 'in principle everywhere'. Such an understanding of power could in addition be seen as an illustration of the transformation of the exercise of power described in Foucault's claim that power relations are immanent in other types of relations.

In order to summarise Goffman's implicit power perspective, it can be said to deal with influence and avoidance of influence in different forms, degrees of intensity, and frequency, with the exercise of power being conscious and unconscious, physical and psychological. Impression management is a clear example of influence, while civil inattention is an example of avoidance 
of anything other than superficial influence. The power to influence is completely integrated into what Goffman calls the interaction order in two ways:

1 To influence and be influenced by unknown others to the smallest degree possible.

2 To influence known others and (if to a lesser degree) unknown others in accordance with norms for interaction regarding respect, regulation of distance, apologies - in short: social etiquette.

\section{Framing social interaction as exercise of power}

There is, however, also another understanding of power in Goffman's works, and it rather constitutes an answer to the question 'Why is power exercised?' and is connected to framing. Goffman argues that it is in an individual's interest to gain control over the actions of other people in situations that are shared, and this is done by influencing other people's definition of the situation:

Regardless of the particular objective which the individual has in mind and of his motive for having this objective, it will be in his interests to control the conduct of the others, especially their responsive treatment of him. This control is achieved largely by influencing the definition of the situation which the others come to formulate, and he can influence this definition by expressing himself in such a way as to give them the kind of impression that will lead them to act voluntarily in accordance with his own plan. (Goffman, 1959, p. 3f) ${ }^{3}$

It is this theme of influence that is developed further in Goffman's version of the frame concept, and it constitutes the most important difference in comparison to James's cognitive and Bateson's communicative concept of frame. As has already been mentioned, Goffman's interactive frame concept has, to a great extent, to do with creating mutual definitions in situations shared by other individuals:

At work, I think, is the possibility that every definition of the situation, every continued application of a wonted frame, seems to presuppose and bank on an array of motivational forces, and through certain extreme measures any such balance seems to be disruptable. To be able to alter this balance sharply at will is to exert power: that is one meaning of the term. (Goffman, 1974, p. 447)

Here it is thus not simply a matter of influencing other people's definition of oneself through a definition of the situation, as was expressed in the above quote from The Presentation of Self, but about influencing other people's definitions of the shared situation. The exercise of power thus lies in the 
common framing - either the reproduced one or the altered one - of the situation. This somewhat takes the sting out of the otherwise reasonable criticism directed by Denzin and Keller (1981, p. 59) at Goffman's occasionally rather one-dimensional use of the frame concept, at least in the opening chapter of Frame Analysis. They nevertheless exaggerate when they, in the same breath, claim that 'There is no interaction in Frame Analysis'. It is true that some parts of the book focus more on the individual than on the interaction, something that Goffman himself notes in the (from the perspective of the power of influence) highly interesting chapter 'Breaking Frame':

It has been argued that the individual's framing of activity establishes its meaningfulness for him. Frame, however, organizes more than meaning; it also organizes involvement. During any spate of activity, participants will ordinarily not only obtain a sense of what is going on but will also (in some degree) become spontaneously engrossed, caught up, enthralled. All frames involve expectations of a normative kind as to how deeply and fully the individual is to be carried into the activity organized by the frames. (Goffman, 1974, p. 345)

Goffman also describes how framing constitutes a kind of instrument of influence - indeed, even a tool for the exercise of power - that the individual nevertheless can also consciously resist and unconsciously violate. He writes that 'involvement is an interlocking obligation', which means that individuals in a commonly framed situation are linked and dependent on each other, and therefore have an interest in adjusting not only their own but also other people's actions according to the requirements of the framing. At the same time he says, completely in line with the dynamic relationship between ritualisation, vulnerability, and temporarily working consensus that I have previously described, that all social activity appears vulnerable to violations of the framing. Goffman describes unconscious violations of the framing, which he calls 'flooding out', and which can be exemplified with breaking out into uncontrolled laughter, and shifts of nuance in the framing that lead to actions that violate the frame. Goffman describes breaking the frame in words that in a contrasting manner make me, at least, think about power: 'the unmanageable might occur, [...], with resulting bewilderment and chagrin', 'a break can occur in the applicability of the frame, a break in its governance', 'back into control by the frame', 'becoming interactionally disorganized'.

Goffman's way of looking at power corresponds well with what Haugaard and Clegg (2013 [2009], p. 3) believe has characterised the development of the concept of power since the 1980s: 'perceptions of power that see it as more generally constitutive of reality'. They also discuss the fact that Goffman's perspective, like ethnomethodology, was for a long time not recognised as a perspective that could contribute to the theory of power. The reason for this, they believe, may be that Goffman's sociology has been perceived as 'micro' 
while power has been defined as 'macro' (Clegg \& Haugaard, 2013 [2009] a, p. 450). My contribution in this chapter, when it comes to the exercise of power according to Goffman's perspective, is that the exercise of power is constructed from below through the constitution of the mutual definitions of reality of interacting actors in shared situations. This is what framing social interaction is about.

\section{Notes}

1 Goffman's analysis of and way of understanding a total institution is, to a great extent, based on observational studies of social life in closed mental hospitals, in spite of this being only one of the different kinds of institutions that Goffman regards as total institutions. Mental hospitals together with prisons are obvious examples of such institutions, convents/monasteries and boarding schools are not too far-fetched, while ships and 'large mansions from the point of view of those who live in the servants' quarters' are more surprising examples (see, in addition, Goffman, 1961a, p. 16).

2 In a later text Goffman calls a similar phenomenon in the interaction in public places 'civil inattention' (Goffman, 1963a, p. 84).

3 In a footnote in connection with this excerpt from the text, Goffman refers to an unpublished paper by Tom Burns where Burns argues for the idea that in all interaction there is an underlying theme: 'the desire of each participant to guide and control the responses made by the others present'. 


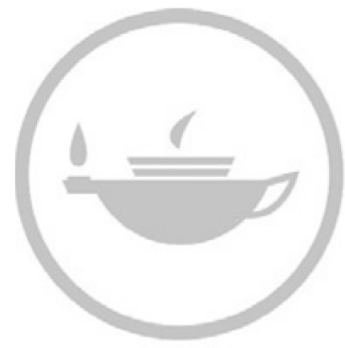

Taylor \& Francis
Taylor \& Francis Group http://taylorandfrancis.com 


\section{Part IV}

Conclusions 


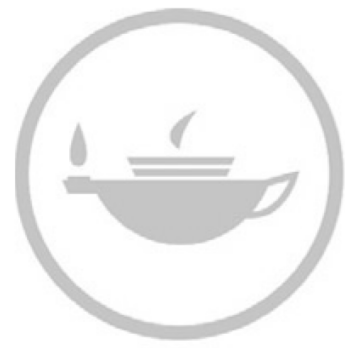

Taylor \& Francis
Taylor \& Francis Group http://taylorandfrancis.com 


\section{Concluding remarks}

Erving Goffman drew a radical line right across the social interaction existence on the one side what is presented and what is or is made visible in the interaction with others (frontstage), and on the other side what is not presented or remains hidden (backstage). When the idea of such a boundary has been established, it is hardly possible to experience one side without thinking about the other. Is he or she really the way she or he represents him- or herself? Do the ethical guidelines at my place of work truly reflect what is happening there? Are the state representatives' talk about democracy supported in concrete actions by democratic institutions and practices? This is a very basic and radical metaperspective because we - individual or collective actors - continually relate how we imagine we are and should be, and want to be perceived how (we believe that) other people perceive us. What distinguishes Goffman's sociology is precisely this continuously present metaperspective that is expressed in Frame Analysis, but that I have shown also characterises his substantial analyses of social interaction. Goffman's approach was frame analytic long before he wrote the book on frame analysis as a method.

For some reason I imagine that assuming a metaperspective was not as common in Goffman's day as it is today. I believe this has to do with faith; that there was faith in science, in the state, in society, authorities, media, and many other things that are distrusted today. Goffman rarely expressed such faith, but seemed to be constantly critical in a typically scholarly manner, and almost always regarded his objects of study from a metaperspective. This perspective is per definition critical because it demonstrates that other perspectives are possible. It may seem that the person who adopts a metaperspective does not share the common perspectives that everybody is assumed or even expected to adopt. I believe this was more pronounced in Goffman's day; today it is in many cases implied and is only made apparent when somebody is considered to have violated views that everybody is assumed to need to share. At the same time, one cannot disregard the fact that our time can be perceived as precisely a time of metaperspectives, whether they are analytic-scientific, cynical, experience-based, mediating, selling, persuasive, and probably additional 
other kinds. I was given an indication of this recently, when two Jehovah's Witnesses rang the doorbell. After explaining in an overly friendly way that I wasn't interested, they handed me a leaflet where it said that god will improve the world. For some reason I read the leaflet, which towards the end poses the question, 'Can one really believe in this?', and my conviction that blind faith excludes metareflection was at first given a proper challenge. Then I understood that this was a metareflexively persuasive question that aims at trying to convince non-believers such as myself. So if our time is a time of metaperspectives, it is also a time when we have to reflect on metaperspectives. That is what I have tried to do in this book when it comes to Goffman's metaperspective.

Goffman was programmatically 'meta', and his overriding thesis is said to have been 'don't take the world at face value'. This is a good scholarly point of departure, but it does not work particularly well in social interaction, because there trust seems to be more important than doubt. In order to study social interaction, critical metaperspectives are needed; in order to perform social interaction, these are often a scourge. The framing of social interaction, the way I have tried to present it in this book, is both a scientific approach to social interaction as an object of study, and a practice that people use in order to create shared realities in social interaction.

My motive in writing this book has been to create a better understanding of Goffman's frame perspective for myself. I think I have succeeded in doing this, and my hope is that the reader who has got this far in the text shares this perception, or at any rate has been given tools for critically reflecting further on Goffman's metaperspective.

My contribution can be summarised as follows:

1 Goffman's object of study was the interaction order, and, within that framework, three themes regarding social interaction: politeness/respect, social illusions, and - to a lesser degree - crisis in the interaction order.

2 I have throughout described Goffman's overarching perspective and interpretational framework as the dynamic relationship between ritualisation, vulnerability, and temporarily working consensus.

3 Goffman's method of analysis was frame analysis, and I like to frame the book Frame Analysis as a book on methodology where this method of analysis is presented and discussed.

4 I have shown that there was continuity in Goffman's way of working. His work was frame analytic long before the book Frame Analysis was published. However, there were also cracks; e.g., the fact that time is, to a great extent, absent in Goffman's frame analysis and that this method of analysis for that reason may well be complemented with a temporal perspective. I attempt to show that Koselleck's combination of the metahistorical categories of space of experience and horizon of expectation can provide that temporal perspective. 
5 Another crack is the crisis in the interaction order that Goffman sporadically mentions, beginning in his book Relations in Public from 1971 and forwards. As I have shown, vulnerability can be found throughout in Goffman's texts, but from the above-mentioned book and forwards, vulnerability can be connected to contingency the way it was later represented by leading sociologists; e.g., Giddens and Bauman. By placing emphasis on a crisis in the interaction order, it is also possible to link Goffman's microsociological question, 'What is it that's going on here?', to increasing experiences of uncertainty in society.

6 I describe frame as the social dynamics of the situation, not least because Goffman often tried to describe precisely the dynamic character of framing, both in Frame Analysis and in earlier studies. These dynamics are a result of the combination of governing mechanisms, the unifying situation, and the actual performance of the interaction by the actors themselves.

7 The frame concept gives a somewhat rigid impression while at the same time it is a result of variation; it has the character of a frozen moment in a variable social existence. The concept of framing is, to my mind, better suited for capturing the essentially dynamic transformations that are about to occur when individuals interact with each other and that flash by in Goffman's analysis of social interaction.

8 I see social media as a new interaction order. This consists, at bottom, of the same basic elements as the face-to-face interaction order, but these can be framed in various ways in social media such as Facebook, online chess, and chat interaction, due to completely different interaction conditions. The most important difference in interaction conditions has to do with dissimilarities in the transmission of expressions: a broad transmission face-to-face and a narrow one in social media. One indication of that we here have to do with a new interaction order, is that frame disputes are more common in social media; for example, in online chess and chat, than in face-to-face interaction.

9 Goffman's entire project has to do with influencing others and avoiding influence from others. I attempt to show that Goffman has quite a bit to add to research on power if power is defined as influence and resistance to influence.

Four pages from the end of Frame Analysis Goffman asks, 'And at the heart of it?', and I urge my readers to read these pages themselves, but I can nevertheless not resist quoting a few memorable lines:

There is a relation between persons and role. But the relationship answers to the interactive system - to the frame - in which the role is 


\section{Conclusions}

performed and the self of the performer is glimpsed. Self, then, is not an entity half-concealed behind events, but a changeable formula for managing oneself during them. (1974, p. 573)

If one wants to experience what Goffman expresses here one should visit Las Vegas - which we will soon do in our imaginations - where boundlessness itself is framed. 


\title{
Epilogue
}

\section{Framed boundlessness - action and everyday life in Las Vegas}

\begin{abstract}
We fly over the Rocky Mountains from the northeast, and there in the night she lies, bathing in her own neon light - 'that great whore on the other side of the desert', as French sociologist Jean Baudrillard (1988 [1986], p. 3) once called Las Vegas seen from the horizon of Salt Lake City. On the ground an unusually efficient machine takes care of us, and after a moment we cruise in an airport shuttle along the Strip - the broad, $7 \mathrm{~km}$-long street whose infinite multiplicity of commercial glitter is the main attraction of Las Vegas. This was what professor of architecture Robert Venturi et al. (1972) wanted us to see as a communication system where symbol is more dominant than place. The Strip is bordered by hotels that in many cases are copies of other things: they symbolise tourist attractions such as Venice, the skyline of New York, Paris, a pyramid in Egypt, a casino in Monte Carlo, and film versions of Camelot and Treasure Island. The idea of the Strip is well captured in the ads for the hotel Paris Las Vegas with its 2,900 rooms, spa facilities, and casino:
\end{abstract}

You can hit the highlights in no time. As part of its architecture, the resort has detailed replicas of the Arc de Triomphe, Louvre façade, Paris Opera House and Hotel de Ville. And you certainly can't miss the 50 -story, half-scale replica of the Eiffel Tower, now one of Las Vegas' most famous landmarks.

On the plane from Chicago I speak to a woman who is visiting Las Vegas for the fourth time. It is the luxury, the glamour, the strolling among the boutiques, and the posh hotel with its pool area that attract her. 'Everything is right here,' she says, and continues, 'You don't have to go to Paris, Venice, Cairo; every thing is here in Las Vegas!' It is madly postmodern - authenticity, so what! - a burlesque fast-forwarding of the world's tourist magnets, swell places, and television sagas as Disneyfied American mythology. This is not a place that is ashamed of being a copy.

However, the hotels are not simply copies; they also have their own identities by being among the biggest in the world. In 2007, fifteen of the world's twenty largest hotels were located in Las Vegas. In the same year there were 
151,000 hotel rooms there and another 11,000 in hotels under construction, which can be compared to around 80,000 hotel rooms in New York at the same time (Rivlin, 2007). During the last fifty years, growth in Las Vegas has time and again passed the limit of what was believed possible. Up until 2007 Las Vegas had the most rapid increase in population of any metropolitan area in the US since 1969. During the period 2000-7 the population of Las Vegas increased by $31 \%$ from one and a half million to over two million people (Lang, Sarzynski, \& Muro, 2008). Of the more than 5,000 people who moved to Las Vegas every month during the above-mentioned period, many bought properties with borrowed funds, and several ended up in trouble when the financial crisis broke out in 2008, which is why Las Vegas now also attracts people with its low property prices due to compulsory auctions. When we visit the city in $2011^{1}$ the number of hotel rooms has decreased to 148,000 (according to Las Vegas Convention and Visitors Authority) and many people talk about the crisis, but it is hard to discover any sort of crisis in the shimmering glitter. We don't know whether to interpret this as a successful recovery from the crisis or as us dancing on a grave. We arrive at midnight and everything is happening as though it were daytime and perhaps also as though nothing has changed. In the hotel room we hear planes land and take off; this in fact happens 1,400 times a day, and forty million passengers per year are transported to and from Las Vegas via McCarran Airport (statistics for the year 2009 according to ACI 2011). Many people also come in cars from Los Angeles, a 'metropolis of the West' to which Nils Runeby (2003) also counts Las Vegas. What are they after?

\section{Action!}

In Las Vegas hardly any cars or other industrial products are manufactured; here it is experiences that are produced, and not just any experiences but action, to express it in the words of Erving Goffman. In the 1960s he was a professor at the University of California at Berkeley, and among much else made covert observations in casinos in Las Vegas, both as a skilfully card-counting gambler and undercover as an employed blackjack dealer. His goal was to study both service relationships and 'the frayed edges of American civilization' in Las Vegas, as he wrote in a letter from 1960 to Everett Hughes (quoted in Pettit, 2011, p. 145). Few people have described the fleeting character of Las Vegas as Goffman did in his essay 'Where the Action Is':

Not only are money gambles made available, this type of action is overlaid with the consumption kind. A brief penetration into high living is laid on. Attendant-parked limousines are cluttered at the entrance. Beyond the entrance, the setting is luxurious. Liquor is served at the tables, often at no cost to the consumer. A quality buffet may be provided, allowing for discriminative gorging. A gratuity system is 
encouraged that elevates its users and provides scantily clad waitresses, selected for their looks, cause to be somewhat accessible. A 'pit' operated signal system enables these girls to deliver drinks, cigarettes and aspirin anywhere on the premises upon request. [...] Table contact is facilitated with the nationally known and with big spenders. Proximity to what some might consider the gangster element is also provided. Easy access to nationally famous entertainment is assured, and even some physical closeness to the entertainers themselves. The lounge bar is 'dressed' with chorus girls clothed in their off-stage costumes. Female customers feel they can experiment with sports high-fashion, claiming an age and style they might be too modest to try out at home. In brief, the opportunity for ephemeral ennoblement abounds. However, should the consumer want to sit down during this ennoblement, he will very likely have to sit at a gaming table. There is a rich ambience, then, but each minute of it is likely to cost the risking of considerable money. (Goffman, 1967, p. 198f)

Action, according to Goffman, is the word that describes the special social dynamics that characterise both games of chance and other activities where 'the individual knowingly takes consequential chances perceived as avoidable' (Goffman, 1967, p. 194) - or, it should be added, where these individuals are in proximity to or in environments in which other people take such risks. Extreme sports, wild partying, and fast cars are other examples of this. When Tony Soprano in the television series Sopranos visits Las Vegas it becomes a break even from his everyday existence as a Mafioso: sex with his mistress in the luxurious hotel room, mescaline from the peyote cactus, and games of chance. Action is living fast, partying, risk-taking, and whatever is 'in'. We find all this in Las Vegas, at any rate if one leaves the run-down Riviera Hotel where the symposium I am visiting takes place. This hotel was built in 1955 in a 'grand European style', and was the first high-rise hotel (nine floors) on the Strip, since when, it is true, it has added up to around twenty floors, but is nevertheless dwarfed by the sixty-eightfloor high Fontainebleau, which is located just next door. There is not a lot of action going on at the Riviera any longer. ${ }^{2}$ The erstwhile glamour of the Hotel Riviera has vanished, even the Lonely Planet guidebook informs us; the visitors in the shabby casino are as old as the hills, and 'outside the front entrance, a bawdy bronzed statue of the Riv's showgirls is fondly fondled by drunk tourists' (Benson, 2009, p. 68). But there is action to be found in many other places in Las Vegas: in hundreds of casinos, in lots of bars where serious partying is going on, in queer bars, in the many clubs with exciting music and shows with well-known artists. There is a rollercoaster and bungee jumping at the top of the 350-metre high tower the Stratosphere, and many other things. One begins to understand what Hunter S. Thompson (Thompson, 2005 [1972], p. 47) meant when he in 1971 wrote, 'this is not a good town for psychedelic drugs. Reality itself is too twisted'. 
The reason why Las Vegas took the step from a group of farms to a city was that the railway between Los Angeles and Salt Lake City opened in 1905. Bars and gambling clubs sprouted up along Fremont Street, situated close to the railway station in what is today the old centre of Las Vegas. With the opening of the Golden Nugget in 1945, which was then the largest casino in Las Vegas, competition increased. Other casinos were modernised, and Fremont Street became known as the Glitter Gulch (McCracken, 1997). A few years earlier gambling and hotel businesses had started up along what later came to be called the Strip, which is now the centre point of Las Vegas. In the 1940s the Mafioso Bugsy Siegel decided to invest large sums of dirty money in Las Vegas, and in 1940 he built the casino hotel the Flamingo, which was claimed to connect Monte Carlo stylistically to Miami Beach, and which is today the oldest hotel on the Strip. Many other hotels followed, were renovated, added to, and torn down, from 1993, in the form of controlled demolitions before an audience on-site and on the Internet. The ways of attracting tourists have gradually become ever more studied, and the casino hotels have developed into ever more luxurious and grandiose variants; such as, for instance, Caesar's Palace, built in 1966, which was then followed by theme hotels that depict Paris, the New York skyline, an Egyptian pyramid, and many, many other things.

The latest wave consists of so-called mega-resorts, enormous indoor landscapes where casinos are mixed with luxury restaurants, pool areas, spa facilities, bars, boutiques, and shows where naked bodies are intermingled with top artists. All this is now part of what even the guidebook calls reinvention, a continuous reimagination or maybe reconstruction, in small things as in great, of the very idea of Las Vegas: attracting people with constantly new attractions that are bigger, riskier, more sinful - in short, attracting people with more action. This leads to many things that exist today in Las Vegas being something other than what they previously were: 'Long-time residents still refer to the Palace Station as the Bingo Palace, to Hoover Dam as Boulder Dam, to Las Vegas Boulevard as the Boulevard rather than The Strip, and to local restaurants by their name from three to five incarnations ago', write Gottdiener, Dickens, and Collins (1999, p. 197f). If one reads a historical reflection on Las Vegas as a hotel and casino town (e.g., McCracken, 1997), and at the same time tries to identify the hotels and casinos that are mentioned on a contemporary map, one finds that there are many that no longer exist. Gottdiener et al. argue that one important reason for this reinvention is 'the "est" philosophy: Newest, Biggest, Fastest, Costliest, Loudest, Tallest'. Action in the above-mentioned and many other forms is an important part of what some call the experience economy (e.g., Boswijk, Thijssen, \& Peelen, 2007), which occasionally becomes a kind of event economy, and Las Vegas is perhaps its most spectacular manifestation. This is where municipal councillors from Sweden come to be inspired when they try to transform an industrial economy into one of experiences and events, a transformation that we can later see illustrated in ads; for example, when 
the shop Lager 157 is about to open a branch in a small town: ' 5 days to go [...] Opening soon [...] Design Outlet [...] a 3,500 sqm ceramics factory has become 3,500 sqm of fashion and experiences'. On Twitter came the addition, 'Nothing will ever be the same'.

\section{Framed boundlessness}

In Las Vegas the motor of the dynamics of the experience economy is probably primarily action that transgresses moral and habitual limits, or, in other words, a framed boundlessness that makes action possible. Las Vegas is a kind of free zone that in principle can be likened to phenomena such as economic free zones, freed from, for instance, taxes, rules, and unions, free schools that are freed from municipal regulations and bureaucracy, and tax havens that are often situated on islands or in Switzerland with its bank secrecy. These all involve a kind of framed boundlessness - authorities draw a line and decide that within this boundary other rules and conditions shall apply than outside it. In the same way, in Las Vegas it is decisions by the authorities that create differentiated conditions on the one or the other side of a stipulated boundary. For example, entrepreneurs used the differences created by politically decided tax boundaries and began to build hotels on a site outside the Las Vegas city limits because of the lower taxes there. That place is today called the Strip.

In Las Vegas gambling was given sanctuary from 1931, but also other things that were or are forbidden in the rest of the United States are permitted either in the city of Las Vegas or in the state of Nevada. Quick marriages came to be an aspect of the free zone when Nevada kept their liberal marital laws while other states passed more restrictive ones. 'How far in advance do you have to know if we decide to get married?', my wife Titti and I asked the wedding organiser outside our hotel chapel, which was decorated wholly in plastic. 'Give me two hours,' she answered. Quick divorces became legal in Nevada in 1911, and became well-known after Hollywood celebrities such as Clark Gable and his wife later took advantage of the opportunity to get an express divorce in Las Vegas (McCracken, 1997). Finally, as the only state in the United States, Nevada permits brothels, albeit not in cities with more than 400,000 citizens, which means that brothels are not allowed in the actual city of Las Vegas. But within an hour's drive from the city one can find Mabel's Whorehouse and The Chicken Ranch, and in these and eleven other brothels researchers from the University of Nevada, Las Vegas, have conducted ethnographic studies over a period of ten years (Brents, Jackson, \& Hausbeck, 2010). They have primarily been interested in prostitution as work and the working conditions of the prostitutes, not at all issues that seem to engage many people in Sweden - i.e., whether prostitution should be seen as oppression or not. They show that legal brothels are far from a matter of course in Nevada. It is true that Nevada has 'built a tourist industry on turning deviance into leisure' (ibid., p. 2), but not deviance strong 
enough to appear abnormal, and there are different opinions concerning where the boundaries of normality should be drawn. The casino industry opposes legal brothels, continue Brents et al., while its own marketing at the same time makes use of sexual innuendo. In the guidebook we can read about striptease clubs: 'Vegas is the original adult Disneyland. Prostitution may be illegal, but there are plenty of places offering the illusion of sex on demand' (Benson, 2009, p. 152).

Las Vegas Convention and Visitors Authority (a so-called quasi-authority, established by the state, tax-financed by Clark County, and governed by an autonomous board whose task it is to market southern Nevada) has made a series of commercials under the motto 'What happens in Vegas, stays in Vegas'. It is both an invitation and an assurance that it is permissible to do things one perhaps would not do at home. In one of the films we can see a female physician tear off her white working clothes at the hospital, and in the next moment she is in Las Vegas wearing pumps, a push-up bra, and string tanga, busily testing the limits of her identity. Men's identity experiments in the commercials from the quasi-authority are about, among other things, assuming a professional title with high status and power, and then going out onto the street and negotiating with prostitutes. ${ }^{3}$ In spite of the commersexual licentiousness in the Strip and the Glitter Gulch, the commercials portray the possible roles of men and women in an extraordinarily limited and traditionally sexualised way: she chooses to be a sex object in her identity experiment; he becomes a wealthy and powerful party who controls her. The identity experiments have to do with becoming something other than what one is at present, and in that respect they are similar to Las Vegas's own reinvention.

Global tourism, from which the casino industry makes money, often means, according to Brents et al. (2010), the promotion of prostitution in different forms. The economic dynamics that characterise Las Vegas have, to a great extent, to do with managing boundaries: other people's maintenance of moral boundaries in other locations and the transgression of moral boundaries in Las Vegas. The difference between these two forms the foundation of many business ideas in Las Vegas. Such differences made it possible in the 1950s to turn a loss into a profit by including a strip show, as was the case with the casino hotel the Dunes (Gottdiener et al., 1999).

Today it is other moral boundaries that are maintained and transgressed. Maintaining boundaries can, for instance, be a route that leads to differentiation of the clientele. The new hotels on the Strip are veritable luxury hotels that cater to a certain category of customers. The Wynn (built in 2005) and its sister hotel, the Encore (built in 2008), for instance, leave sordidness and a moral balancing act behind them. The idea is, instead, elegance, exclusivity, and respectability. For this reason, the boutiques in the Wynn's lovely ground floor mall display brands such as Dior, Rolex, Cartier, Gaultier, and Chanel, while the food in the restaurants is designed by prizewinning chefs and drinks are consumed with a view over an artificial waterfall. The owner, 
Steve Wynn, has a long Las Vegas history behind him, and during recent decades this history seems to have developed under the aegis of respectability. When in 1993 he replaced the Mafia-associated 1950s hotel the Dunes with the glamorous Bellagio, the Las Vegas Mafia era is said to have come to an end. And this was accomplished in a symbolically significant way: the Dunes was blown up before an audience of 200,000 people, and this demolition can be seen on a special web page featuring demolitions of Las Vegas hotels. ${ }^{4}$

Against this background one can ask if it is a coincidence that the two sister hotels, the Wynn and the Encore, are constructed like a kind of reversed brackets, seen from above, like this:

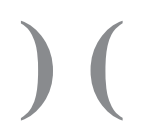

- albeit in reality somewhat displaced laterally. Las Vegas is a place where brackets have been put around many things that otherwise characterise American society. Consequently, free reign has been given to licentiousness in a number of different respects: legal games of chance, quick marriages and divorces, partying, round-the-clock opening hours, and legal brothels in the vicinity. Many things, in other words, of what Elvis Presley in the film and song Viva Las Vegas (Presley, 1964) complains are impossible to have the time to experience during the far too short twenty-four-hour day. Bracketing has been an especially good deal - the question is if respectability, which of course is a kind of de-bracketing in Las Vegas, is also a good deal. The financial crisis in 2008 created serious problems in the city, and when Deutsche Bank wanted to sell the Cosmopolitan, the four billiondollar casino hotel in Las Vegas, it also turned out that the casino hotel did not turn a profit. In Las Vegas it is cheap to stay in a hotel because a hotel's casino is the moneymaking machine. Oldenburg (1999 [1989], p. 224) writes that in Las Vegas a casino-goer can lose 100,000 dollars without complaining but gripe that a can of Coca-Cola is too expensive. The extraordinary bar of the Cosmopolitan is, however, an attraction for young people, although the hotel does not consider them people from whom enough money can be made, since they hang out in the bar rather than gamble away their money in the casino, according to the New York Times (Craig, 2011), which also reveals the scoop that a drunken person threw up in the line to the nightclub at the so far respectable Cosmopolitan.

There are tensions in the framed boundlessness. The tension between sexual licentiousness and contempt for women is, for example, given an everyday but extremely clear expression when we see a man display a T-shirt in a shop to another man. On the T-shirt there are two women: 
'my wife', who is an extremely overweight woman, and 'my girl', who is exceedingly curvaceous. In the street we see large numbers of both extremely overweight women (and men) and, in some cases, 'my girls' in the form of prostitutes that totter about in extremely high-heeled shoes while 'their' pimps stand on street corners like watchful vultures, with their upper bodies bent forward and their wits about them. Here there is also tension between commercial licentiousness and the carnivalesque. Everything is commodified and commercialised in Sin City, the name Las Vegas is sometimes given. At the same time this seems to promote another kind of licentiousness, which may perhaps be described as the carnivalesque. For a brief time people free themselves from the grip power has on their everyday routines, just as in mediaeval carnivals (Bachtin, 1968), and we can illustrate this using Tom Wolfe's article from the 1960s on Las Vegas, republished in a book with the amazing title The Kandy-Kolored Tangerine-Flake Streamline Baby (Wolfe, 1971). In this article, Wolfe refers to a meeting with four senior citizens who do not want go to bed, and he is struck by the realisation that Las Vegas is there for old people who shake loose. Out of the closet he then pulls all the everyday Protestant taboos that the senior citizens try to violate by drinking, having fun, playing games of chance, being out late, getting up late, wasting their time, idling about, and moseying around town in capri pants. This licentiousness does not cost a lot of money; above all it requires time. Here the framing of the licentiousness and the expression 'What happens in Vegas stays in Vegas' now gets a new meaning, when also the rebellious side of the carnival stays in Las Vegas, thereby being kept within its prescribed frame. The humdrum everyday existence, which is often programmed by different power-wielders, is challenged for a limited time, by both suckers and escapists, to quote an article by Findlay (1990).

\section{Everyday life in Las Vegas}

When Goffman describes casino activities in Nevada, he sees people with lively and daring attitudes to life, who, in the hope of winning, sometimes put their families, their assets, house and home, future education, and present work at stake in the casino. Goffman wants to explain this daring liveliness with reference to Nevada's special social organisation, or rather the social dynamics to which the special framing of Las Vegas gives rise:

The relative ease of divorce and marriage; the presence of a very large number of persons who have failed occupationally or maritally; a frontier tradition of asking no questions about a person's history or current livelihood; the clear possibility of getting an equivalent job across the street after being fired; the high visibility of a large number of casino employees known to have worked recently in better jobs in other casinos; the fact that sporadic bouts of big play mean sporadic realization 
of the ideal experience of a culture, such that however long and lean the days between bouts, this use of one's money may be the best that Nevada can offer. (Goffman, 1967, p. 194)

When Goffman wrote this in the mid 1960s, Las Vegas (including the rest of Clark County) had around 150,000 inhabitants, and was probably mainly a gambling den, and people's everyday existence was characterised by this. Since then the population has increased to over two million inhabitants, and Las Vegas has become one of the primary tourist resorts in the world. The gambling den has become a tourist industry. All kinds of infrastructure is needed in a city of over a million inhabitants: drains, water, communication, schools, hospitals, universities, and everything else that belongs to everyday life instead of to the action of the casinos and the event economy. Roads are needed so that people who work nights can transport themselves to their residences in the suburbs, and so that the people who work days can get from the suburbs to their jobs.

One might wonder what kind of everyday life people live in the Las Vegas of the tourist industry. For instance, how is it to have children there? How can one express the difference between how one reacts as a parent when one's teenager calls out, 'Bye, I'm going into town!' if one lives in Stockholm, Iowa City, Ystad, or Las Vegas? I asked my colleagues in Las Vegas about their everyday lives, and a person who had not lived there very long answered that everyday life was a bit tricky and that it is probably okay as long as one does not have children. Another person who had lived there for a long time had moved up into the nearby mountains.

Everyday life is what one has become accustomed to, and the way in which one has adapted to the social organisation and dynamics that characterise life in one's surroundings. Las Vegas is, to an extreme extent, a city organised for tourism, and tourists there (like in other places) are probably more interested in getting away from their own everyday existence than in engaging themselves other than fleetingly with the everyday lives of the locals. The two characteristics I have pointed to earlier, reinvention and boundlessness, exist in a tense relationship to everyday existence. Reinvention seems to mean constant change to maintain what is characteristic of Las Vegas, and perhaps this affects the everyday existence of the locals most, because they experience the changes entailed by construction, new attractions, and so on. The inhabitants are said to joke that the building crane is the city bird of Las Vegas. With 5,000 or more people moving in per month, as was the case during the 1990s, one must, for instance, construct a new school every month (Gottdiener et al., 1999). The boundlessness, on the other hand, is consciously exploited in order to challenge the everyday existence of the tourist in many different ways, and to constantly challenge the boundaries between the back and front regions of individuals. Everyday existence has, to a great extent, to do with maintaining the boundary between these regions in a special way and often in great agreement with other people, and 
be, do, and say what is appropriate in the respective region. Licentious sexuality, partying, gambling, and play instead of work and everyday existence challenge this division into regions. To express it in words borrowed from a person who at a public enquiry philosophised about how to lure more tourists to Nevada:

Let's talk about gaming, 24-hour availability of liquor, quickie divorces, all the things we do here in Nevada. We have been very successful at this because we recognize one overriding issue, and that is that one man's morality is another man's pleasure [...] I've been asked many times [...] 'What can we do here [...] to bring more tourism in?' [...] you have to offer people something that they can't get at home. (quoted in Brents et al., 2010, p. 1)

What tourists get in Las Vegas they in part take home with them, and this tends to change their everyday existence. It is this routinisation of difference that leads to what we perceive as a need for action to continually be developed. Action cannot become everyday existence. When the tourists take action home and begin to drink umbrella drinks while they barbecue an ordinary pork chop, play roulette on the Internet, and in different ways try to adopt less mundane lifestyles, then everyday existence changes. Thus, everything that happens in Las Vegas does not stay in Las Vegas. This dispersal of action from Las Vegas to other places also happens in other ways; for example, games of chance are today allowed in all US states except two, instead of only in Nevada, and the Internet has also become a gambling den. Some people feel that because of this, Las Vegas has become more of a pioneer than a deviant. The city's new face is more respectability and less sin, more games than gambling, more family tourism than sex tourism. As has been made clear, backstage there are also other things.

Three tension-filled social dynamics characterise this strange city. First, the framed boundlessness that gives Las Vegas its distinctive character, at the same time that it is distributed outside of its boundaries, is diluted, and therefore must be constantly reinvented in new forms so as not to lose out in the sharp competition of the event economy. Second, folksiness, which is a prerequisite for the extreme mass tourism on which Las Vegas supports itself, and the simultaneous striving for upper-class respectability that underlies the new mega-hotels that manage impressions using luxury, money, and class. Third, and finally, the increasing normalisation and conventionalisation of the city of Las Vegas and its dependence on, and exploitation of, the 'abnormal' and deviant. All these things are there at the same time; one is not more real than the other.

We decide to walk to the Arts District that is situated halfway between the Strip and the old city core of Las Vegas. We pass the Fontainebleau, three quarters finished, Sahara Avenue and the 350-metre tower the Stratosphere, and then the neighbourhoods become increasingly seedy. When we see 
small wedding chapels and shabby motels adjacent to them with signs bearing the text Adult Movies we can truly imagine the sequence of activities the newlyweds go through ... Then we get to the Arts District, and after a while to blocks where we are the only white people on the street. Our bodies scream whiteness and our shorts are clear tourist signs. In the street there are groups of black men, someone shouts at us from a motel balcony. A black man stops in front of us, smiles his kind, toothless smile, and says, 'Welcome to the real Las Vegas!'

\section{Notes}

1 This text was originally written in 2012 and is based on data up to that same year.

2 Nor at the Fontainebleau, which was only $70 \%$ complete before the financial crisis hit in 2008 and transformed its ' 25 acres of prime Strip-front real estate' (Illia, 2011) into a construction site completely without action, and this is also how it can be described in April 2017 (Gillan, 2017). When it comes to the Riviera, it was closed in 2015 and in 2016 it became one in a long line of Las Vegas hotels to be subject to controlled demolition shown live and on YouTube: https://www. youtube.com/watch? $\mathrm{v}=\mathrm{P} 2$-vq9Co3yk

3 These commercials were analysed in the Couch-Stone symposium in Las Vegas in 2011 by Brooke Wagner (2011), a sociologist at the University of Nevada.

4 www.vegas.com/lounge/implosions.html 


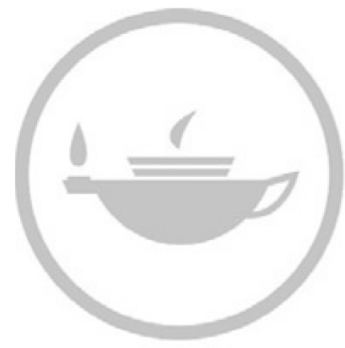

Taylor \& Francis
Taylor \& Francis Group http://taylorandfrancis.com 


\section{Complete bibliography \\ Erving Goffman's writings}

1. Goffman, Erving M. (1949), Some characteristics of response to depicted experience. (Unpublished Master dissertation.) Chicago: Department of Sociology, University of Chicago. ${ }^{1}$

2. Goffman, Erving (1951), "Symbols of class status". The British Journal of Sociology, 2 (4) (Dec.): 294-304.

3. Goffman, Erving (1952), "On cooling the mark out: Some aspects of adaptation to failure". Psychiatry, 15 (4): 451-463.

4. Goffman, Erving (1953), Communication conduct in an island community. (Unpublished PhD dissertation.) Chicago: Department of Sociology, University of Chicago.

5. Goffman, Erving (1953), The service station dealer: The man and his work. (Prepared for The American Petroleum Institute.) Chicago: Social Research, Inc. $^{2}$

6. Goffman, Erving (1955), "On face-work: An analysis of ritual elements in social interaction”. Psychiatry, 18 (3) (Aug.): 213-231.

7. Goffman, Erving (1955), "Review of Children's humor: A psychological analysis by Martha Wolfenstein 1954". The American Journal of Sociology, 61 (3) (Nov.): $283-284 .^{3}$

8. Goffman, Erving (1955), "Review of Tobati: Paraguyan Town by Elman R. Service \& Helen S. Service 1954". The American Journal of Sociology, 61 (2) (Sep.): 186-187.

9. Goffman, Erving (1956), The presentation of self in everyday life. (Monograph No. 2). Edinburgh: University of Edinburgh, Social Sciences Research Centre.

10. Goffman, Erving (1956), "The nature of deference and demeanor". American Anthropologist, 58 (3) (Jun.): 473-502.

11. Goffman, Erving (1956), "Embarrassment and social organization". The American Journal of Sociology, 62 (3) (Nov.): 264-271.

12. Goffman, Erving (1957), "Review of Human problems of a state mental hospital by Ivan Belknap 1956”. Administrative Science Quarterly, 2 (1) (Jun.): 120-121.

13. Goffman, Erving (1957), "Review of Other people's money by Donald R. Cressey 1953”. Psychiatry, 20 (3): 321-326.

14. Goffman, Erving (1957), "A sociologist's view (On some convergences of sociology and psychiatry)". Psychiatry, 20 (3): 201-203.

15. Goffman, Erving (1957), "Interpersonal persuasion". In: Bertram Schaffner (ed.), Group processes. (Transactions of the Third Conference, October 7, 8, 9 and 10, 1956, Princeton, NJ.) New York: Josiah Macy, Jr. Foundation. 
16. Goffman, Erving (1957), "Alienation from interaction". Human Relations, 10 (1): 47-59.

17. Goffman, Erving (1957), "The patient as a 'normal deviant': Problems of stigma and isolation" (pp. 507-510 in Milton Greenblatt \& Theodore Lidz, "Some dimensions of the problem"). In: Milton Greenblatt, Daniel J. Levinson \& Richard H. Williams (ed.), The patient and the mental hospital. Glencoe, IL: The Free Press.

18. Goffman, Erving (1958), "Characteristics of total institutions". In: Symposium on preventive and social psychiatry, 1958. Washington, D.C.: Walter Reed Army Institute of Research.

19. Goffman, Erving (1959), The presentation of self in everyday life. New York: Anchor Books.

20. Goffman, Erving (1959), "The moral career of the mental patient". Psychiatry, 22 (2): 123-142.

21. Goffman, Erving (1961), Asylums: Essays on the social situation of mental patients and other inmates. Garden City, NY: Anchor Books, Doubleday \& Co.

22. Goffman, Erving (1961), Encounters: Two studies in the sociology of interaction. Indianapolis: The Bobbs-Merrill Company, Inc.

23. Goffman, Erving (1961), "On the characteristics of total institutions: The inmate world". In: Donald R. Cressey (ed.), The prison: Studies in institutional organization and change. New York: Holt, Rineheart and Winston, Inc.

24. Goffman, Erving (1961), "On the characteristics of total institutions: Staff-inmate relations”. In: Donald R. Cressey (ed.), The prison: Studies in institutional organization and change. New York: Holt, Rineheart and Winston, Inc.

25. Goffman, Erving (1963), Behavior in public places: Notes on the social organization of gatherings. New York: The Free Press.

26. Goffman, Erving (1963), Stigma: Notes on the management of spoiled identity. Englewood Cliffs: Prentice-Hall.

27. Goffman, Erving (1964), "Mental symptoms and public order". In: David McK. Rioch \& Edwin A. Weinstein (ed.), Disorders of communication. (Proceedings of the Association, December 7 and 8, 1962, New York.) Baltimore: The Williams \& Wilkins Company.

28. Goffman, Erving (1964), "The neglected situation". American Anthropologist, 66 (6) (Dec.): 133-136.

29. Goffman, Erving (1966), "Communication and enforcement systems". In: Kathleen Archibald (ed.), Strategic interaction and conflict: Original papers and discussion. Berkeley: Institute of International Studies, University of California.

30. Goffman, Erving (1967), Interaction ritual: Essays on face-to-face behavior. New York: Anchor Books.

31. Goffman, Erving (1969), Strategic interaction. Philadelphia: University of Pennsylvania.

32. Goffman, Erving (1969), "The insanity of place". Psychiatry, 32 (4) (Nov.): 357-388.

33. Goffman, Erving (1971), Relations in public: Microstudies of the public order. New York: Basic Books.

34. Goffman, Erving (1974), Frame analysis: An essay on the organization of experience. New York: Harper and Row. 
35. Goffman, Erving (1976), "Gender advertisements". Studies in the Anthropology of Visual Communication, 3 (2) (Fall): 65-154.

36. Goffman, Erving (1976), "Replies and responses". Language and Society, 5 (3) (Dec.): 257-313.

37. Goffman, Erving (1977), "Genderisms". Psychology Today (Aug.): 60-63.

38. Goffman, Erving (1977), "The arrangement between the sexes". Theory and Society, 4 (3): 301-331.

39. Goffman, Erving (1978), "Response cries". Language, 54 (4) (Dec.): 787-815.

40. Goffman, Erving (1979), Gender advertisements. New York: Harper \& Row.

41. Goffman, Erving (1979), "Footing". Semiotica, 25 (1/2): 1-29.

42. Goffman, Erving (1981), Forms of talk. Philadelphia: University of Pennsylvania Press.

43. Goffman, Erving (1981), "A reply to Denzin and Keller". Contemporary Sociology, 10 (1): 60-68.

44. Goffman, Erving (1981), "Program committee encourages papers on range of methodologies". ASA Footnotes, 9 (6) (Aug.): 4.

45. Goffman, Erving (1983), "The interaction order". American Sociological Review, 48 (1): 1-17.

46. Goffman, Erving (1983), "Felicity's condition". American Journal of Sociology, 89 (1) (Jul.): 1-53.

47. Goffman, Erving (1983), "Microsociologie et histoire". In: Philippe Fritsch (ed.), Le sens de l'ordinaire. Paris: Editions du Centre National de la Recherche Scientifique. ${ }^{4}$

48. Goffman, Erving (1989), "On fieldwork". (Transcribed and edited by Lyn H. Lofland.) Journal of Contemporary Ethnography, 18 (2) (Jul.): 123-132.

\section{Notes}

1 As far as I know this is the only time that Goffman uses the initial M. in his author's name. His full name was Erving Manual Goffman.

2 This report hasn't been publicly available since at least the end of the nineties, but is now available in the Erving Goffman Archives:

3 This review doesn't appear in the bibliographies in Smith and Chaput Waksler (1989), "The published works of Erving Goffman". Human Studies, 12 (1-2) and Lemert and Branaman (ed.) (1997), The Goffman reader. Oxford: Blackwell.

4 This text is an edited transcription of a simultaneously interpreted address that Goffman gave at the conference 'Quotidienneté et Historicité, at l'Université Lyon II, May 13-14, 1982. 


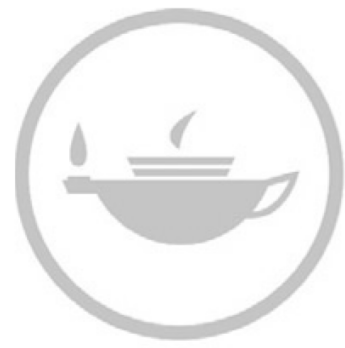

Taylor \& Francis
Taylor \& Francis Group http://taylorandfrancis.com 


\section{References}

Aging idiots' gloomy world forecast for grads. Editorial. (1976, 27-05-1976). Winnipeg Free Press, p. 83. Retrieved from https://newspaperarchive.com/winnipeg-freepress-may-27-1976-p-83/, http://cdclv.unlv.edu/ega/news/agingidiots_76.pdf

Album, D. (2010). Close Strangers. In M. H. Jacobsen (Ed.), The contemporary Goffman (pp. 352-373). London: Routledge.

Anderson, E. (1990). Streetwise: race, class, and change in an urban community. Chicago: University of Chicago Press.

Anderson, E. (2011). The cosmopolitan canopy: race and civility in everyday life. New York: W.W. Norton \& Co.

Aronsson, K. (2002). Goffman, vetandet och den allvarsamma leken [Goffman, knowing and serious play]. In P. Linell \& K. Aronsson (Eds.), Jagen och rösterna: Goffman, Viveka och samtalet (pp. 63-74). Linköping: Tema Kommunikation, Linköpings universitet.

Aycock, D. A. (1988). 'Gens una sumus': play as metaculture. Play \& Culture, (1), 124-137.

Bachrach, P., \& Baratz, M. S. (1970). Power and poverty: theory and practice. New York: Oxford University Press.

Bachtin, M. (1968). Rabelais and his world. Cambridge, MA: MIT Press.

Barnard, C. I. (1938). The functions of the executive. Cambridge, MA: Harvard University Press.

Barnes, B. (1988). The nature of power. Cambridge: Polity.

Bateson, G. (2000 [1955]). A theory of play and fantasy. In G. Bateson (Ed.), Steps to an ecology of mind (pp. 177-193). Chicago: University of Chicago Press.

Baudrillard, J. (1988 [1986]). America. London: Verso.

Bauman, Z. (1989). Modernity and the holocaust. Cambridge: Polity.

Bauman, Z. (2006). Liquid fear. Cambridge: Polity Press.

Bauman, Z. (2007). Liquid times: living in an age of uncertainty. Cambridge: Polity.

Beck, U. (1992 [1986]). Risk society: towards a new modernity. London: Sage.

Becker, H. S. (1967). Whose side are we on? Social Problems, 14(3), 239-247.

Becker, H. S. (2003). The politics of presentation: Goffman and total institutions. Symbolic Interaction, 26(4), 659-669.

Beiras, I. R., \& Almeda, E. (2005). Politica criminal y sistema penal: viejas y nuevas racionalidades punitivas. Barcelona: Anthropos.

Bell, C. M. (1997). Ritual: perspectives and dimensions. New York: Oxford University Press.

Benson, S. (2009). Las Vegas encounter. Footscray: Lonely Planet. 
Beran, M. J. (2013). Foundations of metacognition. Oxford: Oxford University Press.

Berger, P. L., \& Luckmann, T. (1967). The social construction of reality: a treatise in the sociology of knowledge. New York: Anchor Books.

Billig, M. (2005). Laughter and ridicule: towards a social critique of humour. London: Sage.

Björling, S. T. (2016a, 21-10-2016). Hon lyckades få Trump att framstå som barnslig [She managed to get Trump to appear childish]. Dagens Nyheter, p. 18.

Björling, S. T. (2016b, 21-10-2016). Trumps tvivel riskerar skada demokratin [Democracy at risk by Trump's doubt]. Dagens Nyheter, pp. 18-19.

Blau, P. M. (1964). Exchange and power in social life. New York: Wiley.

Blumer, H. (1986). Symbolic interactionism: perspective and method. Berkeley: University of California Press.

Bocock, R. (1974). Ritual in industrial society: a sociological analysis of ritualism in modern England. London: Allen \& Unwin.

Boswijk, A., Thijssen, T., \& Peelen, E. (2007). The experience economy: a new perspective. [Amsterdam]: Pearson Prentice Hall.

Bourdieu, P. (1977). Outline of a theory of practice. Cambridge: Cambridge University Press.

Bourdieu, P. (1983). Erving Goffman: discoverer of the infinitely small. Theory, Culture and Society, 2(1), 112-113.

Bourdieu, P. (1990). The scholastic point of view. Cultural Anthropology, 5(4), 380-391.

Brents, B. G., Jackson, C. A., \& Hausbeck, K. (2010). The state of sex: tourism, sex, and sin in the new American heartland. New York: Routledge.

Bromley, P., \& Powell, W. W. (2012). From smoke and mirrors to walking the talk: decoupling in the contemporary world. The Academy of Management Annals, 6(1), 483-530.

Brosius, C., \& Hüsken, U. (2010). Change and stability of rituals. In C. Brosius \& U. Hüsken (Eds.), Ritual matters: dynamic dimensions in practice (pp. 1-25). London: Routledge.

Burke, P. (2005). Performing history: the importance of occasions. Rethinking History, 9(1), 35-52.

Burns, T. (1992). Erving Goffman. London: Routledge.

Castells, M. (1996). The information age: economy, society and culture. Vol. 1, The rise of the network society. Malden, MA: Blackwell.

Cavan, S. (2011). When Erving Goffman was a Boy. Retrieved from http://cdclv. unlv.edu/ega/articles/cavan_eg_boyhood.pdf

Cheng, J., Bernstein, M., Danescu-Niculescu-Mizil, C., \& Leskovec, J. (2017). Anyone can become a troll: causes of trolling behavior in online discussions. Paper presented at the Proceedings of the 2017 ACM Conference on Computer Supported Cooperative Work and Social Computing, Portland, Oregon, US.

Chess Etiquette. (2014). Retrieved from http://clatskaniechessclub.tripod.com/id37. html

Clark, P. G. (2009). Reflecting on reflection in interprofessional education: implications for theory and practice. Journal of Interprofessional Care, 23(3), 213-223.

Clegg, S. R., \& Haugaard, M. (2013 [2009]a). Discourse of power. In S. R. Clegg \& M. Haugaard (Eds.), The SAGE handbook of power (pp. 400-465). London: Sage.

Clegg, S. R., \& Haugaard, M. (2013 [2009]b). The SAGE handbook of power. London: Sage. 
Colby, K. M. (1953). Gentlemen, the Queen. The Psychoanalytic Review, 40, 144-148.

Collins, R. (1986). The passing of intellectual generations: reflections on the death of Erving Goffman. Sociological Theory, 4(1), 106-113.

Collins, R. (1994). Four sociological traditions. New York: Oxford University Press.

Collins, R. (2004). Interaction ritual chains. Princeton, NJ: Princeton University Press.

Coser, L. A. (1974). Greedy institutions: patterns of undivided commitment. New York: Free Press.

Craig, S. (2011, 18-04-2011). Deutsche Bank's \$4 billion Las Vegas bet. New York Times.

Csíkszentmihályi, M. (2000 [1975]). Beyond boredom and anxiety. San Francisco: Jossey-Bass Publishers.

Czarniawska, B. (2006). A golden braid: Allport, Goffman, Weick. Organization Studies, 27(11), 1661-1674.

Dahl, R. A. (1961). Who governs?: democracy and power in an American city. New Haven, CN: Yale University Press.

Daniels, A. K. (1983, January). A tribute to Erving Goffman. ASA Footnotes, 11.

Davies, B., \& Harré, R. (1990). Positioning: the discursive production of selves. Journal for the Theory of Social Behaviour, 20(1), 43-63.

Davis, M. S. (1975). Review of Frame analysis: an essay on the organization of experience by Erving Goffman. Contemporary Sociology, 4(6), 599-603.

Dean, M. (2010 [1999]). Governmentality: power and rule in modern society (Second ed.). Thousand Oaks, CA: Sage.

Deaths of Four Faculty Members: Dr. Erving Goffman. (1982). Almanac, 29(13), 1.

Denzin, N. K. (2002). Much ado about Goffman. The American Sociologist, 33(2), 105-117.

Denzin, N. K., \& Keller, C. M. (1981). Frame analysis reconsidered. Contemporary Sociology, 10, 52-60.

Diski, J. (2004). Think of Mrs. Darling. London Review of Books, 26(5), 10-11.

Ditton, J. (1980). Editor's introduction: a bibliographic exegesis of Goffman's sociology. In J. Ditton (Ed.), The view from Goffman (pp. 1-23). London: Springer.

Donald Trump's Washington is Paralysed. (2017, 01-07-2017). The Economist. Retrieved from www.economist.com/news/leaders/21724392-and-man-ovaloffice-making-bad-situation-worse-donald-trumps-washington

Donati, P. (2013). Engagement as a social relation: a leap into trans-modernity. In M. S. Archer \& A. M. Maccarini (Eds.), Engaging with the world: agency, institutions, historical formations. New York: Routledge.

Duerr, H. P. (1996). Myten om civilisationsprocessen. Bd 2, Intimitet [The myth of the civilizing process, 2. Intimacy]. Stockholm: Symposion.

Duerr, H. P. (1998). Myten om civilisationsprocessen. Bd 3, Obscenitet och våld [The myth of the civilizing process, 3. Obscenity and violence]. Stockholm: Symposion.

Durkheim, E. (1952 [1897]). Suicide: a study in sociology. London: Routledge \& Kegan Paul.

Durkheim, E. (1964). The division of labor in society. New York: Free Press.

Durkheim, E. (1965 [1912]). The elementary forms of the religious life. New York: Free Press.

Eales, R. (1985). Chess: the history of a game. London: Batsford.

Eibl-Eibesfeldt, I. (1971). Love and hate: on the natural history of basic behaviour patterns. London: Methuen \& Co. 
Ekman, P., \& Friesen, W. V. (2003). Unmasking the face: a guide to recognizing emotions from facial clues. Cambridge, MA: Malor.

Elias, N. (1978). What is sociology? New York: Columbia University Press.

Elias, N. (1982). The civilizing process. Vol. 2, State formation and civilization. Oxford: Blackwell.

Emirbayer, M. (1997). Manifesto for a relational sociology. American Journal of Sociology, 103(2), 281-317.

Enfield, N. J. (2009). Everyday ritual in the residential world. In G. Senft, \& E. B. Basso (Eds.), Ritual communication (pp. 51-80). Oxford: Berg.

Etzioni, A. (1975). A comparative analysis of complex organizations: on power, involvement, and their correlates. New York: The Free Press.

Exploring a Shadow World. (1969, 10-01-1969). Time.

Fallers, L. (1962). The presentation of self in everyday life by Erving Goffman. American Anthropologist, 64(1), 190-191.

FIDE. (2014). Laws of chess. Retrieved from www.fide.com/component/ handbook/?id=171\&view=article

Findlay, J. (1990). Suckers and escapists? Interpreting Las Vegas and postwar America. Nevada Historical Society Quarterly, 33(1), 1-15.

Fine, G. A. (1983). Shared fantasy: role-playing games as social worlds. Chicago: University of Chicago Press.

Fine, G. A., \& Manning, P. (2003). "Erving Goffman”. In: George Ritzer (ed.), The Blackwell companion to major contemporary social theorists. (Blackwell Reference Online). Oxford: Blackwell Publishing.

Fine, G. A., Manning, P., \& Smith, G. W. H. (2000). Introduction. In G. A. Fine \& G. W. H. Smith (Eds.), Erving Goffman, Vol. 1 (pp. IX-XLIV). London: Sage.

Fine, G. A., \& Smith, G. W. H. (2000). Erving Goffman. Vol. 1-4. London: Sage.

Firth, R. (1972). Verbal and bodily rituals of greeting and parting. In J. S. La Fontaine (Ed.), The interpretation of ritual (pp. 1-38). London: Tavistock Publications.

Foucault, M. (1979 [1975]). Discipline and punish: the birth of the prison. New York: Vintage Books.

Foucault, M. (1979). The history of sexuality. Vol. 1, An introduction. London: Allen Lane.

Foucault, M. (1982). The subject and power. In H. L. Dreyfus \& P. Rabinow (Eds.), Michel Foucault: beyond structuralism and hermeneutics (pp. 208-226). Brighton: Harvester.

Foucault, M. (2007). Security, territory, population: lectures at the Collège de France, 1977-1978. Basingstoke, Hampshire: Palgrave Macmillan.

Foucault, M., \& Kritzman, L. D. (1988). Politics, philosophy, culture: interviews and other writings, 1977-1984. New York: Routledge.

Freud, S. (1962 [1930]). Civilization and its discontents. New York: W. W. Norton.

Galbraith, J. K. (1983). The anatomy of power. Boston: Houghton Mifflin.

Gallie, W. B. (1955). Essentially contested concepts. Paper presented at the Proceedings of the Aristotelian society.

Garfinkel, H.(1967). Studies in ethnomethodology. Englewood Cliffs, NJ: Prentice-Hall.

Geertz, C. (2000 [1973]). The interpretation of cultures: selected essays. New York: Basic Books.

Giddens, A. (1990). The consequences of modernity. Cambridge: Polity Press.

Giddens, A. (2009). On rereading The presentation of self: some reflections. Social Psychology Quarterly, 72(4), 290-295. 
Gillan, J. (2017). It's a wrap: Fontainebleau gets a makeover. Retrieved from http:// news3lv.com/news/local/its-a-wrap-fontainebleau-gets-a-makeover

Goffman, E. (1949). Some characteristics of response to depicted experience (Master's Thesis). Chicago: Department of Sociology, University of Chicago.

Goffman, E. (1952). On cooling the mark out. Psychiatry, 15(4), 451-463.

Goffman, E. (1953). Communication conduct in an island community (PhD Thesis). Chicago: Department of Sociology, University of Chicago.

Goffman, E. (1955a). On face-work: an analysis of ritual elements in social interaction. Psychiatry, 18(3), 213-231.

Goffman, E. (1955b). Review of Children's humor: a psychological analysis by Martha Wolfenstein 1954. American Journal of Sociology, 61(3), 283-284.

Goffman, E. (1955c). Review of Tobatí: Paraguayan town by Elman R. Service \& Helen S. Service 1954. American Journal of Sociology, 61(2), 186-187.

Goffman, E. (1956). The nature of deference and demeanor. American Anthropologist, 58(3), 473-502.

Goffman, Erving (1957), "The patient as a 'normal deviant': Problems of stigma and isolation" (pp. 507-510 in Milton Greenblatt \& Theodore Lidz, "Some dimensions of the problem"). In: Milton Greenblatt, Daniel J. Levinson \& Richard H. Williams (ed.), The patient and the mental hospital. Glencoe, IL: The Free Press.

Goffman, E. (1957a). Autobiographical sketch. In B. Schaffner (Ed.), Group Processes (p. 12). New York: Josiah Macy, Jr. foundation.

Goffman, E. (1957c). Review of Human problems of a state mental hospital by Ivan Belknap 1956. Administrative Science Quarterly, 2(1), 120-121.

Goffman, E. (1957d). Review of Other people's money by Donald R. Cressey 1953. Psychiatry, 20(3), 321-326.

Goffman, E. (1959). The presentation of self in everyday life. New York: Anchor books.

Goffman, E. (1961a). Asylums: essays on the social situation of mental patients and other inmates. Garden City, NY: Anchor Books, Doubleday \& Co.

Goffman, E. (1961b). Encounters: two studies in the sociology of interaction. Indianapolis, IN: The Bobbs-Merrill Company, Inc.

Goffman, E. (1963a). Behavior in public places: notes on the social organization of gatherings. New York: The Free Press.

Goffman, E. (1963b). Stigma: notes on the management of spoiled identity. Englewood Cliffs, NJ: Prentice-Hall.

Goffman, E. (1964a). Mental symptoms and public order. In D. M. R. E. A. Weinstein (Ed.), Disorders of communication. (Proceedings of the Association, December 7 and 8, 1962, New York.) Baltimore: The Williams \& Wilkins Company.

Goffman, E. (1964b). The neglected situation. American Anthropologist, 66(6), 133-136.

Goffman, E. (1966). Communication and enforcement systems. In K. Archibald (Ed.), Strategic interaction and conflict: original papers and discussion. Berkeley: Institute of International Studies, University of California.

Goffman, E. (1967). Interaction ritual: essays on face-to-face behavior. New York: Anchor Books.

Goffman, E. (1969). The insanity of place. Psychiatry, 32(4), 357-388.

Goffman, E. (1970 [1969]). Strategic interaction. Oxford: Basil Blackwell.

Goffman, E. (1971). Relations in public: microstudies of the public order. New York: Basic Books.

Goffman, E. (1974). Frame analysis: an essay on the organization of experience. New York: Harper and Row. 
Goffman, E. (1976). Replies and responses. Language in Society, 5(3), 257-313.

Goffman, E. (1979a). Footing. Semiotica, 25(1-2), 1-29.

Goffman, E. (1979b). Gender advertisements. New York: Harper and Row.

Goffman, E. (1981a). Forms of talk. Philadelphia: University of Pennsylvania.

Goffman, E. (1981b). Program committee encourages papers on range of methodologies. ASA Footnotes, 9(6), 4.

Goffman, E. (1981c). A reply to Denzin and Keller. Contemporary Sociology, 10(1), $60-68$.

Goffman, E. (1983a). Felicity's condition. American Journal of Sociology, 89(1), 1-53.

Goffman, E. (1983b). The interaction order: American Sociological Association, 1982 Presidential Address. American Sociological Review, 48(1), 1-17.

Goffman, E. (1989). On fieldwork. (Transcribed and edited by Lyn H. Lofland.) Journal of Contemporary Ethnography, 18(2), 123-132.

Gonos, G. (1977). "Situation" versus "frame": The "interactionist" and the "structuralist" analyses of everyday life. American Sociological Review, 42, 854-867.

Goody, J. (1977). Against 'ritual'. In S. F. Moore \& B. G. Myerhoff (Eds.), Secular ritual. Assen: Van Gorcum.

Gottdiener, M., Dickens, D. R., \& Collins, C. C. (1999). Las Vegas: the social production of an all-American city. Cambridge, MA: Blackwell.

Gouldner, A. W. (1971). The coming crisis of western sociology. London: Heinemann.

Graham, D. A. (2017, 11-10-2017). The infantilization of the president. The Atlantic.

Grahn, L. (2014). När Bent mötte Boris och sista dansen med Lizzie [When Boris met Bent and the last dance with Lizzie]. Malmö: Lalimo förlag.

Grimes, R. L. (2006a). Performance. In J. Kreinath, J. Snoek \& M. Stausberg (Eds.), Theorizing rituals: issues, topics, approaches, concepts (pp. 379-394). Leiden: Brill.

Grimes, R. L. (2006b). Rite out of place: ritual, media, and the arts. Oxford: Oxford University Press.

Hacking, I. (1999). The social construction of what? Cambridge, MA: Harvard University Press.

Hacking, I. (2004). Between Michel Foucault and Erving Goffman: between discourse in the abstract and face-to-face interaction. Economy and Society, 33(3), 277-302.

Hall, J. (2014). Från krigsövning till folkkär hjärngympa [From war training to mental gymnastics]. Svenska Dagbladet 2014-05-16 [Swedish Daily News].

Hammersley, M. (2001). Which side was Becker on? Questioning political and epistemological radicalism. Qualitative Research, 1(1), 91-110.

Hannerz, U. (1980). Exploring the city: inquiries toward an urban anthropology. New York: Columbia University Press.

Haugaard, M., \& Clegg, S. R. (2013 [2009]). Introduction: why power is the central concept of the social sciences. In S. R. Clegg \& M. Haugaard (Eds.), The SAGE handbook of power (pp. 1-24). London: Sage.

Hazelrigg, L. (1992). Reading Goffman's framing as provocation of a discipline. Human Studies, 15, 239-264.

Helle, H. J. (1998). Erving Goffman: a symbolic interactionist? In L. Tomasi (Ed.), The tradition of the Chicago school of sociology. Aldershot: Ashgate.

Hilton, J. (2016, 19-10-2016). Den Dylandska tystnaden ter sig alltmer som en ren provokation [Dylan's silence more and more like a provocation]. Dagens Nyheter, p. 2.

Hirsch, A. v. (1976). Doing justice: the choice of punishments: report of the committee for the study of incarceration. New York: Hill and Wang. 
Hochschild, A. R. (1979). Emotion work, feeling rules, and social structure. American Journal of Sociology, 85(3), 551-575.

Hohmann, J. (2016, 20-10-2016). The Daily 202: Trump's lack of self-control allows Clinton to sweep the debates. The Washington Post. Retrieved from www. washingtonpost.com/news/powerpost/paloma/daily-202/2016/10/20/daily-202trump-s-lack-of-self-control-allows-clinton-to-sweep-the-debates/5807e456e9b69b640f54c6a9/?wpisrc=nl_daily202\&wpmm $=1$

Hughes, E. C. (1951). Mistakes at work. The Canadian Journal of Economics and Political Science, 17(3), 320-327.

Illia, T. (2011). No luck for stalled Fointaineblesu Las Vegas. Architectural Record, 44(1).

Integritet och straffskydd (SOU 2016:7) [Integrity and Protection Provided by Criminal Law]. (2016). Stockholm: Regeringskansliet/Wolters Kluwers.

James, W. (1948 [1892]). Psychology. Cleveland, OH: World Publishing Co.

James, W. (1950 [1890]). The principles of psychology, vol. 2. New York: Dover.

Jameson, F. (1976). On Goffman's frame analysis. Theory and Society, 3(1), 119-133.

Jaworski, G. D. (2000). Erving Goffman: the reluctant apprentice. Symbolic Interaction, 23(3), 299-308.

Jenkins, R. (2008). Erving Goffman: a major theorist of power? Journal of Power, l(2), 157-168.

Jones, E. (2016, 10-10-2016). Svenska Akademien har slutat försöka nå tigande Dylan [The Swedish Academy has stopped trying to reach silent Dylan]. Dagens Nyheter, p. 3.

Kathleen. (2011). Review of frame analysis. Retrieved from www.goodreads.com/ review/show/200174617?book_show_action=true\&from_review_page=1

Kelman, H. C., Getzels, J. W., Perry, S. E., Brehm, J. W., Schein, E. H., Goffman, E., \& Baldwin, J. C. (1957). Public and private opinions. Public Opinion Quarterly, 21(3), 427-429.

Kemper, T. D. (2011). Status, power and ritual interaction [e-book]: a relational reading of Durkheim, Goffman, and Collins. Farnham, Surrey, England: Ashgate.

Kertész, I. (2015). Den sista tillfykten: en dagboksroman [The last refuge]. Stockholm: Weyler.

Kim, K.-k. (2003). Order and agency in modernity: Talcott Parsons, Erving Goffman, and Harold Garfinkel. Albany: SUNY Press.

King, D. (2000). Chess: from first moves to check mate. New York: Kingfisher.

King, D. (2002). Schack: från de första dragen till schack matt. Stockholm: B. Wahlströms.

Knausgård, K. O. (2014, 19-08-2014). Ansiktets baksida [The back of the face]. Svenska Dagbladet Kultur, 8-11.

Knottnerus, J. D. (2011). Ritual as a missing link: sociology, structural ritualization theory, and research. Boulder: Paradigm Publishers.

Korpi, W. (1983). The democratic class struggle. London: Routledge \& Kegan Paul.

Koselleck, R. (1979). Vergangene Zukunft: zur Semantik geschichtlicher Zeiten. Frankfurt am Main: Suhrkamp.

Koselleck, R. (2004 [1979]). Futures past: on the semantics of historical time. New York: Columbia University Press.

Lagerkvist, P. (1958 [1944]). The dwarf. New York: Hill and Wang.

Lang, R. E., Sarzynski, A., \& Muro, M. (2008). Mountain megas: America's newest metropolitan places and a federal leadership to help them prosper. Retrieved from http://digitalscholarship.unlv.edu/brookings_pubs/3/. 


\section{References}

Largey, G. P., \& Watson, D. R. (1972). The sociology of odors. American Journal of Sociology, 1021-1034.

Latour, B. (2007 [2005]). Reassembling the social: an introduction to actor-networktheory. Oxford: Oxford University Press.

Lemert, C. (1997). "Goffman”. In C. Lemert \& A. Branaman (Eds.), The Goffman reader. Malden, MA: Blackwell.

Lemert, C. (2003). Goffman's enigma. In A. J. Treviño (Ed.), Goffman's legacy (pp. xi-xvii). Lanham: Rowman \& Littlefield.

Lemert, C. C. (1997). Social things: an introduction to the sociological life. Oxford: Rowman \& Littlefield.

Lofland, J. (1980). Early Goffman: style, structure, substance, soul. In J. Ditton (Ed.), The view from Goffman (pp. 24-51). London: Macmillan.

Lofland, L. H. (1998). The public realm: exploring the city's quintessential social territory. Hawthorne, New York: Aldine de Gruyter.

Lukes, S. (1974). Power: a radical view. London: Macmillan.

Lukes, S. (2005). Power: a radical view (2. expanded ed.). Basingstoke: Palgrave Macmillan.

MacCannell, D. (1983). Erving Goffman (1922-1982). Semiotica, 45(1-2), 1-34.

Marx, G. T. (1984). Role models and role distance. Theory and Society, 13(5), 649-662.

Maseda, R. V. (2017). Deciphering Goffman - the structure of his sociological theory revisited. London: Routledge.

Mauss, M. (1954). The gift: forms and functions of exchange in archaic societies. Glencoe, IL: Free Press.

McCracken, R. D. (1997). Las Vegas: the great American playground. Reno: University of Nevada Press.

Mead, G. H. (1962 [1934]). Mind, self and society: from the standpoint of a social behaviorist. Chicago: University of Chicago Press.

Meltzer, B. N. (1968). Review of Interaction ritual: essays in face-to-face behavior. Social Forces, 47(1), 110-111.

Menand, L. (2009). Some frames for Goffman. Social Psychology Quarterly, 72(4), 296-299.

Merton, R. K. (1968 [1949]). Social theory and social structure. New York: The Free Press.

Merton, R. K. (1995). The Thomas theorem and the Matthew effect. Social Forces, 75(2), 379-422.

Mills, C. W. (1956). The power elite. New York: Oxford University Press.

Mims, C. (2017, 05-03-2017). We're all internet trolls (sometimes). The Wall Street Journal. Retrieved from www.wsj.com/articles/were-all-internet-trollssometimes-1488718803.

Minckley, R. L. (1987). Aspects of the reproductive biology of two carpenter bees (genus Xylocopa) in southern Arizona (M.S. Thesis). University of Arizona, Tucson. Retrieved from http://arizona.openrepository.com/arizona/handle/10150/276573

Naegele, K. D. (1956). Review of The presentation of self in everyday life (book). American Sociological Review, 21(5), 631-632.

Ohlsson, P. T. (2017, 09-07-2017). När midnatt råder [When midnight prevails]. Sydsvenska Dagbladet.

Oldenburg, R. (1999 [1989]). The great good place: cafés, coffee shops, bookstores, bars, hair salons, and other hangouts at the heart of a community. Philadelphia: Da Capo Press. 
Oromaner, M. (1980). Erving Goffman and the academic community. Philosophy of the Social Sciences, 10(3), 287-291.

Pareto, V. (1968 [1901]). The rise and fall of the elites: An application of theoretical sociology. Totowa, NJ: The Bedminster Press.

Parsons, T. (1937). The structure of social action. New York: McGraw-Hill.

Parsons, T. (1951). The social system. Glencoe, IL: Free Press.

Parsons, T. (1966 [1951]). The social system. New York: The Free Press.

Persson, A. (2012a). Front- and backstage in social media. Language, Discourse \& Society, 1 (2), 11-31.

Persson, A. (2012b). Ritualisering och sårbarhet: ansikte mot ansikte med Goffmans perspektiv på social interaktion [Ritualization and vulnerability -face-to-face with Goffman's perspective on social interaction]. Malmö: Liber.

Persson, A. (2015). Online schack och chatt interaktion. In H. Rahm (Ed.), Vetenskapssocieteten i Lund. Arsbok 2015 (pp. 65-83). Lund: Vetenskapssocieteten i Lund.

Pettit, M. (2011). The con man as model organism: the methodological roots of Erving Goffman's dramaturgical self. History of the Human Sciences, 24(2), 138-154.

Posner, J. (1978). Erving Goffman: his presentation of self. Philosophy of the Social Sciences, 8(1), 67-78.

Presley, E. (1964). Viva Las Vegas!

Proceedings of the Twelfth Conference on Public Opinion Research. (1957).

Psathas, G. (1977). Goffman's image of man. Humanity and Society, 1(1), 84-94.

Puddephatt, A. J. (2008). Incorporating ritual into greedy institution theory: The case of devotion in amateur chess. Sociological Quarterly, 49(1), 155-180.

Rapoport, R. N. (1957). The presentation of self in everyday life. By Erving Goffman. Man, February, 28.

Rappaport, R. A. (1999). Ritual and religion in the making of humanity. Cambridge: Cambridge University Press.

Ray, D. G., Mackie, D. M., Smith, E. R., \& Terman, A. W. (2012). Discrete emotions elucidate the effects of crossed-categorization on prejudice. Journal of Experimental Social Psychology, 48(1), 55-69.

Resignation Etiquette??? (2012). Retrieved from www.chess.com/forum/view/ community/resignation-etiquette

Rivlin, G. (2007, 24-04-2007). In Las Vegas, too many hotels are never enough. The New York Times. www.nytimes.com/2007/04/24/business/24vegas. htm 1 ? rref $=$ collection $\% 2$ Fbyline $\% 2$ Fgary-rivlin \&action $=$ click \&content Collection $=$ undefined $\&$ region $=$ stream $\&$ module $=$ stream_unit $\&$ version $=$ latest $\&$ contentPlacement $=29 \&$ pgtype $=$ collection.

Rogers, M. F. (1977). Goffman on power. The American Sociologist, 12, 88-95.

Rogers, M. F. (1980). Goffman on power, hierarchy, and status. In J. Ditton (Ed.), The view from Goffman (pp. 100-133). London: Macmillan.

Rose, A. M. (1962). A systematic summary of symbolic interaction theory. In A. M. Rose (Ed.), Human behavior and social processes: an interactionist approach. London: Routledge \& Kegan Paul.

Rose, N. (1999). Powers of freedom: reframing political thought. Cambridge: Cambridge University Press.

Ruesch, J., \& Bateson, G. (1951). Communication: the social matrix of psychiatry. New York: Norton. 
Runeby, N. (2003). Los Angeles - västerns Metropolis [Los Angeles - the metropolis of the west]. In E. Sellberg (Ed.), Den skapande staden: idéhistoriska miljöer Stockholm: Carlssons.

Russell, B. (1938). Power: a new social analysis. London: Allen \& Unwin.

Sartre, J.-P. (1966 [1956]). Being and nothingness: a phenomenological essay on ontology. New York: Pocket Books.

Sartre, J.-P. (1989 [1946]). No exit, and three other plays. New York: Vintage International.

Schechner, R. (2006). Performance studies: an introduction (Second ed.). New York: Routledge.

Scheff, T. J. (2005). The structure of context: deciphering frame analysis. Sociological theory, 23(4), 368-385.

Scheff, T. J. (2006). Goffman unbound!: a new paradigm for social science. Boulder, CO: Paradigm Publishers.

Schelling, T. (2015). If there were a Nobel Prize for sociology and/or social psychology Goffman would deserve to be the first one considered. The Erving Goffman Archives. Retrieved from http://cdclv.unlv.edu//archives/interactionism/goffman/ schelling_15.html

Schram, R. (2009). Feast of water: Christianity and the economic transformation of a Melanesian society (PhD Thesis). University of California, San Diego. Retrieved from http://escholarship.org/uc/item/31b8t37q\#

Schütz, A. (1945). On multiple realities. Philosophy and Phenomenological Research, 5(4), 533-576.

Scott, J., \& Marshall, G. (2005). Oxford dictionary of sociology. New York: Oxford University Press.

Seligman, A. B. e. a. (2008). Ritual and its consequences: an essay on the limits of sincerity. Oxford: Oxford University Press.

Sharrock, W. (1999). The omnipotence of the actor: Erving Goffman on 'the definition of the situation'. In G. Smith (Ed.), Goffman and social organization: studies in a sociological legacy (pp. 119-137). London: Routledge.

Sharron, A. (2000 [1981]). Frame paralysis: when time stands still. In G. A. Fine \& G. W. H. Smith (Eds.), Erving Goffman (Vol. III, pp. 94-108). London: Sage.

Sherzer, M. (1995). The effects of metacognitive and metasocial processes on mathematical problem solving skills. Northern Illinois University, DeKalb. Retrieved from https://books.google.se/books?id=PLxYNwAACAAJ

Simmel, G. (1906). The sociology of secrecy and of secret societies. American Journal of Sociology, 11(4), 441-498.

Smith, G. W. H. (2006). Erving Goffman. London: Routledge.

Smith, G. W. H., \& Waksler, F. C. (1989). The published works of Erving Goffman. Human Studies, 12 (1-2).

Snoek, J. A. M. (2006). Defining 'Rituals'. In J. Kreinath, J. Snoek \& M. Stausberg (Eds.), Theorizing Rituals. Leiden: Brill.

Stone, G. P. (1957). The presentation of self in everyday life. By Erving Goffman. The American Journal of Sociology, 63(1), 105.

Swanson, G. E. (1976). Review of Erving Goffman's frame analysis. Annals of the American Academy of Political and Social Science, 420, 218-220.

Synnott, A. (1991). A sociology of smell. Canadian Review of Sociology/Revue canadienne de sociologie, 28(4), 437-459. 
Thomas, W. I. (1923). The unadjusted girl: with cases and standpoint for behavior analysis. Boston: Little, Brown, and Co.

Thomas, W. I., \& Thomas, D. S. (1928). The child in America: Behavior problems and programs. New York: Knopf.

Thompson, H. S. (2005 [1972]). Fear and loathing in Las Vegas: a savage journey to the heart of the American dream. New York: Harper Perennial.

Treviño, A. J. (Ed.) (2003). Goffman's legacy. Lanham, MD: Rowman \& Littlefield.

Vanderstraeten, R. (2002). Parsons, Luhmann and the theorem of double contingency. Journal of Classical Sociology, 2(1), 77-92.

Venturi, R., Scott Brown, D., \& Izenour, S. (1972). Learning from Las Vegas. Cambridge, MA: MIT Press.

Verhoeven, J. C. (1993). An interview with Erving Goffman, 1980. Research on Language and Social Interaction, 26(3), 317-348.

Vermeulen, T., \& van den Akker, R. (2010). Notes on metamodernism. Journal of Aesthetics \& Culture, 2, 1-14. doi:10.3402/jac.v2i0.5677

Vollmer, H. (2013). The sociology of disruption, disaster and social change. Punctuated cooperation. Cambridge: Cambridge University Press.

Wagner, B. (2011). What happens in Vegas? The symbolic use of sex and identity in the marketing of Las Vegas. Paper presented at the 2011 Couch-Stone Symposium, Las Vegas.

Watzlawick, P., Bavelas, J. B., \& Jackson, D. D. (2011 [1967]). Pragmatics of human communication: a study of interactional patterns, pathologies, and paradoxes. New York: Norton.

Weber, M. (1968a). Economy and society: an outline of interpretive sociology. Vol. 1. New York: Bedminster Press.

Weber, M. (1968b). Economy and society: an outline of interpretive sociology. Vol. 3. New York: Bedminster Press.

Weick, K. E. (1976). Educational organizations as loosely coupled systems. Administrative Science Quarterly, 1-19.

Weick, K. E. (1995). Sensemaking in organizations. Thousand Oaks, California: Sage.

Wieners, B. (2002). On the internet, nobody knows if you're Bobby Fischer. Yahoo! Internet Life, 8(1), 72-77.

Williams, R. (1988). Understanding Goffman's methods. In P. Drew \& A. Wootton (Eds.), Erving Goffman. Exploring the Interaction Order (pp. 64-88). Cambridge: Polity Press.

Winkin, Y. (1999). Erving Goffman: What is a life? The uneasy making of an intellectual biography. In G. Smith (Ed.), Goffman and social organization: studies in a sociological legacy. (pp. 19-41). London: Routledge.

Winkin, Y. (2010). Goffman's greenings. In M. H. Jacobsen (Ed.), The contemporary Goffman (pp. 51-63). New York: Routledge.

Winkin, Y., \& Leeds-Hurwitz, W. (2013). Erving Goffman: a critical introduction to media and communication theory. New York: Peter Lang.

Wolfe, T. (1971). The kandy-kolored tangerine-flake streamline baby. New York: Pocket Books.

Wright, L. (1967). Clean and decent: the fascinating history of the bathroom \& the water closet and of sundry habits, fashions \& accessories of the toilet principally in Great Britain, France \& America. Toronto: University of Toronto Press.

Wrong, D. H. (1961). The oversocialized conception of man in modern sociology. American Sociological Review, 183-193. 


\section{References}

Yalom, M. (2004). The birth of the chess queen: how her majesty transformed the game. New York: Harper Collins Publishers.

Zerubavel, E. (1991). The fine line: making distinctions in everyday life. New York: Free Press.

Zerubavel, E. (2008). Remembering Erving Goffman: studying with Erving Goffman. The Erving Goffman Archives. http://cdclv.unlv.edu//archives/interactionism/goffman/zerubavel_08.html.

Zweig, S. (2005 [1942]). Chess Story. New York: New York Review Books. 


\section{Index}

'absence of power' (Dahl and Bachrach and Baratz) 129

action 1, 4-5, 27-9, 33-4, 52, 54-6, 58-61, 65-6, 75-7, 83-4, 87-8, 96-7, 124-5, 139-40, 149-53, 157-8; concrete 145; and everyday life in Las Vegas 149; of individuals where they interact with others 76,132 ; and interaction patterns 52 ; and interactions of individuals 88 activities 39, 43, 52, 55, 59-61, 64, 71, 75-7, 79, 81, 87, 118-19, 121, 123, 136-7, 140; differentiated 70; high 76; individual 92; joint 80; ongoing 87; regular 115 ; secondary 136

actors $4,15,17,31,34,39,50,52,56,60$, $70,72,85-6,96,105,147$; collective 4, 145 ; human 119 ; responsible 120 ; selfregulating 128; social 68; superior 129 advertisements 34, 70

American Anthropological Association 14 American Journal of Sociology 15

American Sociological Association 13

Anderson, Elijah 94-5

antisocial behavior 102

antisocial minorities 102

articles 10-11, 43, 87, 101-2; 'Exploring a Shadow World' 14; 'Footing' 16, 64-5, 87, 96, 109; 'The Neglected Situation' 87; 'Symbols of Class Status' 10

Asylums 45-6, 53, 133

audiences 12, 17, 60, 70, 78-9, 82, 108-9, 138,155 ; on-site 152 ; and outsiders 78 ; segregation of 70

Bachrach, P. 129

'back into control by the frame' 140

Baratz, M. S. 129
Bateson, Gregory 49, 54-5, 63, 75, 80, 139

Baudrillard, Jean 149

Bauman, Z. 90, 94, 147

Becker, H. S. 11, 19

behaviour 12, 25, 30, 32, 56, 72-3, $77,81,92-3,97,102,106,108-10$, $115,131,136$; animal mating 27 ; antisocial 102; ceremonial rules of 1 , 73; classroom 111; control 73; human symbolic 27 ; people's 72 ; in public places 81,92 ; respective 121 ; ritualized communicative 27

beliefs 17, 68, 85-6

Benson, S. 151, 154

biological studies 84

Birrell, Susan 15

Björling, S. T. 1-2

blackjack 10

blindness 92, 94

Blumer, Herbert 9, 11

Bocock, R. 27

bodies 29, 93, 103, 106, 108, 130-1, 134; disciplined 134; docile 131, 134; human 131; naked 152; upper 156

books 1-5, 10-13, 20, 29-30, 34-5, 43-7, 53-4, 58-9, 61-2, 68, 76, 83-4, 95-6, $114,133,145-7$; and articles 43 ; and collections of essays 10; emphasising tediousness and long-windedness; 43; 'excluded' 46; on frame analysis 68-9, $71,73,75,77,79,81,83,85,87,89$, $91,93,95,97,145-6$; on methodology $46-7,68,86,146$; provocative 10 ; on survey methods 47

boundaries 50, 53, 105-6, 137, 145, 153-4, 157-8; maintaining and managing 154; moral 154; stipulated 153; tax 153

Bourdieu, Pierre 20-1, 129 
breakdowns (of interaction order) 71, 73,127

'breaking frame' 53, 96-7, 140

Brents, B. G. 153-4, 158

British Journal of Sociology 10

brothels 153-5

Burns, T. 11-12, 22, 26

business schools 22

businesses $32,57,72,92-3,96,152$

Carlsen, Magnus 114

casinos 9-10, 149-52, 155-7; hotels 152, 154-5; industry 154; in Las Vegas 9

categories 25, 28, 50, 53, 58, 61, 122 , 154; central analytic 86 ; empirical 95 ; epistemological 88; metahistorical 89, 146; residual 78; social 58; temporal 88 Cavan, Sherri 13-14, 20

centres 2, 33, 130, 152; competing 130; old 152, 158; of power 130

century $10,23,26,28,113-14,130$, 135; eighteenth 130; fifteenth 114; nineteenth 26, 28, 114; twentieth 10 , 114,130

ceremonies 27, 29, 52; religious 29; and rituals 29

chance see games of chance

changes $16,28,65,91-2,94-5,97,104$, $106,114,116,125,128,130,157-8$; of a coercive nature 91; of levels from social interaction to a societal level 16; in social structure 91

character $21-2,49,51-3,63-5,78-9$, 81-3, 86, 89, 92-3, 108-11, 116-19, $122-3,125,130-1,134-5,157-8$; of chess 119; dynamic 147; fleeting 150 ; mechanical 109

chat conversations 101, 113, 115-19, $121-3,125-6,147$

chat lines 119-20

chess 101, 113-26; amateur 121; 'cheaters' 122; clubs 118, 123; computers 114, 121, 123; etiquette $115,117,126$; face-to-face 113, 115; grandmaster 121-2; online 97, 101, 113, 115-17, 119, 121, 123-5, 147; organisations 117; pieces 117; players $80,122-3$; rationalisation process of 114; sites 101, 116, 118, 121-2, 125; tournaments $117,123-4$; transforms from silent respectfulness to a loud-mouthed ego trip 125 Chicago School of Sociology 11 children $34,117,124,157$; chess-playing 117; in classrooms 111

cinemas 37

'civil inattention' 57, 82, 92-5, 106, 108,138

civilising processes $90-1$

claims 18, 22, 28-9, 39, 44, 59, 61, 63, 73, 77, 91, 95, 102, 127, 133, 140; by Erving Goffman 47, 69, 72; by Gregory Bateson 55; by H. P. Duerr 91; individual's 57

class $19,25,36,58,81,93,113,135,158$; disadvantaged 18; erased 23, 135; and global capitalism 23; perspective on 44; theorists 135

class status (symbols of) 10, 158

Clatskanie Chess Club 117

codes 32, 52, 63, 65; behavioural 63; of ethics 32 ; of honour 81 ; linguistic 63 ; moral 81; professional 81

coercive changes, in social structure 91 cold war $38,72,135$

Collins, R. 11, 14, 18-19, 28, 152

commercials (portraying the possible roles of men and women) 154

commitments 14, 16, 59, 109, 121; emotional 59; in interactions 109; subjective 50,64; total 123

'Communication Conduct in an Island Community' 9, 70

communications $15,36,55,57,60,85$, 105-6, 125, 137, 157; and actions given particular meaning 55 ; bracketed 104; forms of 118; ongoing 85,105 ; and strategic interaction 85 ; systems $104-5,110,149$ companies 32, 74-5; see also businesses computers $110,114,118,123$ concepts $2,4,12,15,26-30,34,49-51$, 53-5, 62-3, 65-6, 82-5, 88-9, 96-7, 107-9, 113, 128-9; central 128; cognitive 54, 65; communicative 54, 139; concrete 53; difficult 128; dynamic 97; of empiricism, humour, and empathy 11; expressive 55; formation of 16; and Reinhart Koselleck (German historian of concepts) 88; shared 59; spatial 53; swinging between narrow and broad usage 28

conceptualisation (used as a tool for systematisation, analysis, and interpretation) 15-16 
conditions $18,26,32,56,62-3,88$, $90,96,103,110,114,119,123-4$, 132, 137, 153; differentiated 153; for expression transmissions 110; societal 129; special 106, 123; structural 35; working 153

conflicts $20,39,66,72,74,76,85,92$, $106,129,137$; open 60 ; perspective of 38 ; and social dynamics 133 connections $14,16,23,25,31,33,71$, $73-4,79,81,90,95,101,120,128$, 131; channeled 103; temporal 89 consensus $25,38-9,82$; perspective 38 ; real 56; working 5, 25-6, 38-40, 46, $60,74,76,140,146$

constraints $61,90,131$; non-participant 104 ; of power 131; and selfconstraints 90

consumers $150-1$

context 22, 27-8, 34-6, 45, 47, 49-51, 54-6, 63-4, 75-6, 79, 81, 83, 85, 96, $103,105-6$; concrete 54 ; interactive 76 , $108,115,136$; science 69 ; of situations 63 ; social 71, 81, 96; surrounding 16 , 102; temporal 129

contextualising (in understanding social interaction) 47,87

contingency 5, 89-90, 92, 94-5, 147; 'double' 56; themes 90; and vulnerability at the 'micro-level' 90 contributions 11-12, 22, 70-1, 125, 141, 146; implicit 136; political 45; trenchant 12; unexpected 135 control 2, 35, 38, 47, 50-1, 53, 69-70, $73,75,79,111,121,123,131-2,134$, 137-9; impressions of $60,78,137$; information 57; interactions with other people 30

conventions $33-4,47,52,60,74,76$ conversations $17,37,45,69,82,86,103-5$, 109-10, 119-20, 136; constructive 101; face-to-face 103; ongoing public 102; political 1

Coser, L. A. 123

Cosmopolitan Hotel (Las Vegas) 155 countermoves (o f people) 74, 85-6 covert observations 150 critics 19,135

Dagens Nyheter 1

Dahl, R. A. 129-30

Daniels, Arlene 17

death $10-11,13,15,20,27,31$ deception 15, 37-8, 69

definitions 4, 16, 26-7, 31-2, 35, 38, 49-50, 59, 61, 63, 70, 75, 85, 87, 139,145 ; controlling 51; human 68; individual 18; of metasociality 85 ; mutual 139, 141; new 58; official 51; of people 18, 60, 139; of ritual 31 ; simultaneous 123; of the situation 60 , 62; social 58; unambiguous 26

democracy $23,32,145$

demolition 152, 155; controlled 152; of Las Vegas 155

Denzin, N. K. 19, 23, 44, 135, 140

Department of Sociology: California 9; Chicago 11

developments 55, 65, 71, 89, 114, 125, 131-4, 140; of chess 125; of Goffman's interactional and situational frame concept 49-66; modern societal 132; scholarly 11

dialects 58-9, 103

differences 26, 28-9, 79-80, 96, 105, $108-9,111,113,115,118,120$, $122,125,137,153-4,157-8$; basic 113; central 110; fundamental 121; significant 79; structural 137

discipline 14, 26, 79, 130-2, 134, 138; double 10; dramaturgical 35, 78, 137; of influence 138

Diski, Jenny 22-3

divorce 153, 155-6, 158

doctoral dissertations 4, 15, 25-6, 53, 70,111

Donati, P. 87

'dramaturgical loyalty' 78-9, 137

'Dubai Frame' 52

Duerr, H. P. 91

Durkheim, Émile 11, 17, 19, 25-6, 28, $30,32,60,72,91$

The Dwarf 79

dyadic problem-solving 85

Dylan, Bob 1, 3

dynamics 16, 64-5, 76-7, 79-82, 84, 96-7, 110, 133, 137, 147, 153, 157; economic 154; of encounters 16; of expression control and impression management 79 ; of framing 97 ; in gaming 80; situational 65

Elias, Norbert 90-1, 130

Emirbayer, M. 87

emotional commitments 59

emotional control 22 
emotions 85 ; and beliefs 85 ; and perceptions 85

empirical observations 53

engrossment $82,120-1,123-4$; and distance 120-1; levels of 123

environment 32, 64, 92, 94, 123, 151; spatial 81; urban 58

epistemological differences 16 epistemological realism 18

epistemological statements 87 equilibrium 25-6, 31, 38-9; ritual 31, 38-9; of social interaction 26

An Essay on the Organization of Experience 58

essays 10, 16, 29-30, 33; by Ervine

Goffman 10, 16, 19, 29-30, 33, 51, 54, 58, 63, 76, 79, 85, 150; 'Expression Games' 85; 'On Face-Work: An Analysis of Ritual Elements in Social Interaction' 29-30, 38, 76; sharing in the virtues and defects of Goffman's works. 16; 'Where the Action Is' 16

establishment 13-14, 88, 127; social 136; sociological 12-13

ethical guidelines 145

etiquette $1-2,23,40,73,116-18,120$, 135 ; in interactions between people 135; of politics 2-3; violation of 2-3 event economy $152,157-8$

events $44,47,50,61,64,69,74-5,80$, 86-9, 94, 133-5, 148, 152; chain of $16,58,64,90,114$; disconnected 43; immediate 63; macrosocial 94; misframing of 97 ; sequences of 65 , 114; unguided 50

everyday life $4-5,10,12,15-16,20-1$, 28-9, 44-5, 53-4, 68, 77, 136, 149, 157 ; obscuring of 28 ; of people living in Las Vegas 156-7; sociology of 129 everyday ritual 27,69

exchanges $31,60,73,85,88,128$; face-to-face 128; individual 127; mutual 39-40; of situations 88 ; of symbolic gifts 92

'exclusions' (Goffman) 46, 137

exercise of power 4, 60-1, 66, 97, 127, 129-34, 138-41; expressive 130; modernised 133; and resistance 66; spatial 129; special forms of 130 exhibitions $52-3,58$

expectations 5, 38, 44, 47, 59, 69, 73, $83,88-9,95,120,140$; horizons of 88-9, 146; legitimate 70; normative 76; people's 66 ; writer's 44 experience $38-9,46,56,58-9,64,66$, 87-9, 95-6, 123-4, 145, 148, 155, 157; economy 152-3; enriching 12; and expectations 88-9; of hunger 51; and observations 124; and ongoing activity 87; religious 46; space of $88-9,146$; as understood by Erving Goffman 88

'Exploring a Shadow World' 14

'Expression Games' 85

expressions 3-4, 35, 37-8, 44-5, 57-8, 61, $64,79,102-3,105-6,110-11,115-16$, $124,131,137-8,147$; bodily 58 ; contradictory 35 ; corporeal 2 ; correct 37; exuding (by individuals) 103; facial 106; given; given off; inscrutable 3; non-symptomatic 103; non-verbal 35; ritualized 34; significant 5, 79, 103; transmitting of 105-6, 110, 138, 147; verbal 106

face-to-face $105,111,113$; interactions 104; playing of chess $113,115,118$, 125

Facebook 105-7, 109, 147

faith 89,145 ; in progress 89 ; in science, the state and society 145

Fallers, Lloyd 12

families 9, 27, 52, 107, 156

Fannie Mae 5

'Felicity's Condition' 36-7

feudal society 113

FIDE see The World Chess Federation fieldwork 9, 21, 96

films 37, 55, 154-5

First Chicago School 11

Firth, R. 27, 31-2

Fischer, Bobby 114, 121-2

fixed lines (chats) 119, 125

flows 19, 39, 86, 105-6, 108, 123-4, 136; of expression 105, 124, 138; undifferentiated 115

'Footing' 16, 64-5, 87, 96, 109

Forms of Talk 10

frame $47,49-55,59,62-6,68-9,74-6$, $80,85-8,93,95-7,103,105,111$, 120-1, 139-40, 145-7; cognitive concept of 54,65 ; cohesive 65 ; communicative 111 ; defining 64 ; disputes in online chess 113-17, 119, 121, 123, 125-6, 147; empty 52-3; and framing $44,46,50,52,54,56,58$, $60,62,64,66,70,72,74,76,94-6$; interactive 102 ; loosely-organized 16 ; manipulating 62; phenomenon 52; 
prescribed 156; recommended

119; and ritual 34; shared 63, 75; temporary situational 95 ; visible 53

Frame Analysis 5, 43-7, 49, 58, 60-1, 63, $65,68-9,74,76,84,86-8,95-7,133$, $140,145-7$

frame concept 49-50, 55, 62-5, 75, 81, 88-9, 139-40, 147; abstract 54; communicative 75 ; interactive 139 ; situational 49

framed boundlessness (Las Vegas) 54, $149,153,155,158$

framework 5, 13, 47, 59, 61, 70, 96, 146; basic 69 ; interpretational 23,146 ; single 43

framing $38,40,44-7,50,54-6,58-60$, 62-4, 74-6, 78-86, 88, 94-7, 105, 120-1, 123, 139-41, 147; abstract 54; of activities 59; analytic 75-6; capabilities 104; functions 54; individual's 140 ; interactions in social media 101, 103, 105, 107, 109, 111; mutual 66; of online chess 123; of social interaction in $\mathrm{f} 2 \mathrm{f}$ and $\mathrm{p} 2 \mathrm{p}$ chess 95, 115, 120, 123, 128-9, 146; spatial 105 ; special 156

fraud 45-6, 62, 68, 137

Freud, Sigmund 11, 28, 129

Friedel, Frederic 122

frontstage 105

Gable, Clark 153

gambling 10, 16, 150, 152, 157-8

gambling clubs 152

games 45-7, 55, 68, 79-81, 85, 95-6, 101, 113-26, 136-7, 158; abstract 80; board 47; of chess 113, 116-17, 119, 124-5; and gaming 96, 118; legal 155; new 125; online $97,101,113,115-17,119$, $121,123-5,147$; role-playing 62 ; silent chess 120,125 ; social 56,83 ; theory of $58,68,85,89,113$

gaming $79,96,113,115,117-18,136-7$, 158; conditions in chess 118, 120, 124; encounters 79-81, 113, 136-7; and games 113

Gatlin, Justin 5

Geertz, C. 85

gender 23, 25, 36, 45, 68, 96, 132, 135

Gender Advertisements 10, 34

Giddens, Anthony 11, 15, 21, 90, 147

The Gift 33

Glitter Gulch (Fremont Street) 152, 154 globalisation 90
Goffman, Erving 1-2, 4-5, 9-23, 25-40, 43-7, 49-66, 68-90, 92-7, 102-9, 111, 120-3, 127-30, 133-40, 145-8, 150-1, 156-7; analyses social interaction as a kind of ritual 72; analyses the concept of keying 97; analysis of social interaction in public places 53; and the analysis of social interaction in public places 53; analysis of stigma 83; and the analysis of useful concepts 12 ; analytical tools for 53 ; assigned to the 'lunatic fringe' of sociology 20 ; claims interest in social interaction 69; cognitive perspective of 59, $65,86,130,134$; and commercial realism 34; complains that rituals can be both too well-filled and empty 33-4; concept of frame and framing $40,49-50,55,62-5,75,81,88-9$, 139-40, 147; concretises the meaning of frame analysis 47; and contacts with communication researcher Gregory Bateson 11; contribution of the influence of interacting actors on each other 136; death of 135; and the definition of frame 64; description of chess as a clean game 117; description of conversations as a communication system 110; and the descriptions by Winkin and LeedsHurwitz 23; develops his perspective using Durkheim's distinction between negative and positive rites 32 ; and 'dramaturgical loyalty' 78-9, 137; and the dramaturgical theory 22,78 ; essays by $10,16,19,29-30,33,51,54,58$, $63,76,79,85,150$; and frame analysis 68-9, 71, 73-5, 77, 79, 81, 83, 85, 87-9, $91,93,95,97,102,109,146$; and his answers to questions regarding social interaction 70; and his books 16, 20, $22,43,58,63$; and his description of lami-nations 52; and his doctoral dissertation 'Communication Conduct in an Island Community' 9, 70; and his doctoral students 13,17; and his emphasis on the sociology of religion 33; and his implicit power perspective 138; and his man-from-Mars style 11; and his methods of analysis 74,146 ; and hyper-ritualisation (exaggerated ritualisation) 34; and the information state of the individual $58,92,135$; inspired by the ideas of 
Everett Hughes 26; interactional and situational frame concept 49-66; invents three regions relative to the ongoing social interaction and to each other 78, 106, 157; merges situation and frame 64; methods of analysis 74, 146; moves away from an understanding of the interaction order 33; and the notion of supportive interchanges 33 ; obituary of 20 ; overarching perspective and interpretational framework 22-3, 146; paints a picture of mankind and society which is 'not very pretty' 21; perspective in social interaction 59; perspective on social interaction 4-5, 59, 65; and the phenomenon of ritual 29; portrays the power in a total institution as a mixture of coercive power and self-discipline 133; positivism of 18; and the relationship between state authority and interactional power 127; relationship to different theoretical schools 22; research style 15; and the sacredness of the individual 72; sociology of 5 , $11,17,20-2,25,29,45-6,49,52-3$, 56-7, 86, 89-90, 133, 135, 140, 145; and studies of influence 135; style of research and presentation 21-2; and the technical features expressed in Frame Analysis 23; and techniques of information control 83; texts of 43, 51, $76,86,135,147$; and views concerning conversations on social media 120 ; words of $10,17,87$

Goody, J. 28

Gottdiener, M. 152, 154, 157

Gouldner, Alvin 15, 22

Grahn, Lars 114

grandmaster in chess 121-2

Grimes, R. L. 27-9

guest researchers 9-10

guilt $62,71,73-4,93$

Hacking, I. 17-18, 61, 68, 127-8, 134

Hannerz, U.

harassment 102, 109-10; online experience of 102 ; and personal integrity in social media 102; prevention of 110

harmony $38-9,72$

Harvard Center for International Affairs 10

hell 3, 35-6

Helle, H. J. 14 hierarchical systems 73

history 5, 22, 88-9, 91, 155; development of 89; Las Vegas 155; person's 156

homes $9,118,123,138,151,154,156,158$

hospitals $138,154,157$

hotel rooms 14,150

hotels 149-53, 155; casino 152, 154-5; first high-rise 151; largest 149; luxury 149, 154; new 154; run-down Riviera 151; sister 154-5; theme 152

Hughes, Everett C. 11, 14, 26, 54, 150

human actions 28

human behavior 28

human relations 130

human subjects 51

human volition 50

human work 26

humour 11, 37, 40

hyper-ritualisation (exaggerated ritualisation) 34

identities 68, 113, 134, 149, 154; personal 53 ; social 83 ; and values of society 38 , 61,83

Illinois Chess Association 117

illness 14, 43, 46, 70

impression management 4-5, 30, 36, 45-6, 55, 60, 77-9, 96, 137-8; aid of 138 ; art of 138 ; dynamics, of 79 ; of groups 137

impressions 4, 16-17, 35, 39, 45, 79, 111, $125,137-9,147,158$; arts of 78,137 ; control of $60,78,137$; fostering of 17 , 138; managing of 138; people's 70, 79; transmission of 111

'individual information preserve' 57 individuals 14, 16-18, 31-3, 35-9, 49, 56-62, 64-6, 72-8, 81-3, 86-90, 92-5, $107-8,120-1,128,132-3,135-40$; acting in proximity to each other 70; appearances of 93; attacking institutional authority 33; awareness of their social skills 85 ; disciplined 130; free 132; gaining control of the actions of other people in situations that are shared 60; hierarchy of 73; independent 1 ; interacting $35,39,49$, $57,60,62,71,73,75-7,79,82,88$, 90, 96-7, 104-5, 136-7; normal 57; oscillating between being non-persons and persons 108 ; in public places 108 ; stigmatized 84; and violence 91

influence 4, 11-12, 22, 64-5, 120, 127-30, 132, 134 40, 147; anthropological 11; 
and individual actions 132; intentional 136-7; of interacting actors 136; interactive 135-6; mutual 136; people's 127; societal 113; strong 62; unified space 76

information 37, 57-9, 62, 79, 85-6, 103, 106, 110, 137; control 55, 83; incomplete 19 ; intimate 120 ; to outsiders 137 ; oversharing of $105,110-11,120$; strategies 57; transmitting 106 'information state' 58, 89, 111 inmates (asylums) 53, 133-4 institution, and practices 32,55 institutions 4, 45-6, 50-1, 53, 60-1, 66, $74,76,128,132-4$; and cultures 66 ; democratic 32, 145; mental health 9, 11; secular 27; social 4

instruments $36,71,91,103,115,131-2$, 140; of influence 140; multifaceted 36 intelligence activities 85, 111

'interaction order' $5,7,10,12,14,16$, $18,22-3,25-40,45-6,70-3,86,92-5$, 127-8, 135-6, 146-7; face-to-face 147; public 94 ; smooth 120 ; social 5,25 , 32,46

interactional power $127-9,131,133,135$, $137,139,141$

interactionists 44,65

interactions 30-2, 35-6, 40, 65-6, 74, $76-8,80,82-4,90,92-3,102-3$, $105-11,115,121-4,135-7,139-40$; body-to-body 108 ; conditions 147 ; contexts 79-80, 82; conversational 70-2; ethology 93; expression-rich 105; face-to-face 51, 103, 108, 111, 147; focus on 102; framing of 105 , 110,115 ; of individuals 74,88 ; levels 86, 90; microscopic 73; obligations 80 ; in public places $90,93,107$; in social media 102-3, 109; symbolic $13,56,119$; and tensions 66; unfocused $82,109,121-2,136$

Internet 23, 84, 101-2, 121-3, 152, 158; playing chess 122 ; trolls 102

interpretations $3,15,26,50,54-5,63,73$, 87, 89, 124; of expressions 124; literal 54 ; receiver's 2 ; social 58 ; voluntaristic 61 ; wrong 64

interviews $16,18,21,55,86$

James, William 49, 54, 58, 62, 75, 139

Jenkins, R. 136

jobs $2,13,43,96,156-7$

journals, Psychiatry 11
The Kandy-Kolored Tangerine-Flake Streamline Baby 156

Korchnoi, Viktor 117

Koselleck, Reinhart 88

Labov, William 12

Lagerkvist, Pär 79

Las Vegas 9-10, 54, 148-59; casinos in 9; fleeting character of 150 ; transgression of moral boundaries in 106,154

law schools 22

Lemert, Charles 11, 15, 43

Lofland, J. 22, 82

low-income jobs 2

Lukes, S. 128-9

management 10, 53, 81, 138; disciplined 82 ; of personal front 81 ; public 4

Manning, P. 10-11, 13

marriages 27, 153, 155-6

McCracken, R. D. 152-3

Mead, G. H. 107-8

mechanisms 13, 32, 38, 50, 75-6, 84, 88, 90, 94, 102, 106, 109, 128, 131-3, 147; boundary-maintaining 81 ; local 73 , 127; recurrent 87 ; social 90 ; in social media 106

mega-hotels 158

Menand, Louis 22

mental hospitals 53, 69, 134

mental illness 68

Merkel, Angela 3

messages 1-3, 29, 55, 63, 103-4, 111; automated text 118; on Twitter 3 metacommunications $12,54-5,85,105$ metaperspectives 5, 69, 145-6; critical 146; present 145; radical 145

metapolitics 3

metasociality $74,84-6$

microsociological paradigms, modern 14 minorities, vocal and antisocial 102 mobile phones 110

models 70-2, 97, 108; conventional sociological systems 71-2; ping-pong 105-6, 110; status-power 135 modern societies $28,30,33,91,130$; late $32,95,107$; secularised 32 modern sociology 12,90 ; see also sociology money 62, 132, 150-2, 154-8

Monte Carlo 149

moral careers 84

moral norms 81 
moral subjects 91

morality 71,158

motives $17,82-3,139,146$

Naegele, Kaspar D. 12

National Institute of Mental Health 9, 11

'The Neglected Situation' 87

Nevada 153, 156-8

The New York Times 155

The New Yorker 12

newspapers: Dagens Nyheter 1; The New York Times 155

Nobel, Alfred 10

Nobel prizes 3, 10

normality $5,43,92,154$; individual 57 ; in public places 92

norms $1,4,45,47,50,60-1,66,76-8$, $80,93,95,97,104,106,108-9$,

117-18; general 108; for interaction

139; of politeness and decency 78-9;

and rules 47, 88; special 109

novels, The Dwarf 79

objects $5,28,31-2,34,45,53,77,79$, $81,91-2,94,96,120,127,132,145-6$; of knowledge 53; sacred 30-3, 72, 76; sex 154

observers 14, 19, 69

offenders 56, 71, 82

'On Face-Work: An Analysis of Ritual Elements in Social Interaction' 29-30, 38,76

online chess $97,101,113,115-17,119$, $121,123-5,147$; anonymous playing of 122; and chat 147; experiences and observations of 124; games of 101; playing $113,115,120$; sites 113,116 online games $97,101,113,115-17,119$, $121,123-5,147$

opponents $116,119-21,124$; in a game of online chess 101; psyching the 116; time-wasting 116

oral presentations 11

organisations $4-5,19,33,46,50,56,59$, 72, 89, 95, 107, 134; and institutions 4; for playing chess 117

Oromaner, M. 20

"out of frame" 53

oversharing of information 105 , $110-11,120$

Parsons, Talcott 11, 18, 21, 56, 70

participants 19, 35, 38-9, 52, 59, 64, 71, $75,78,80,123,137,140$; individual 71 ; observations of 9-12, 14, 102, 113, 125 ; self-regulating $25,76,127$; socializing 19

pedestrians $94-5$

people $12,18,22,59,137$; actions of 58 , 140; and actors in shared situations 60,139

perceptions 19, 36, 51, 62, 85, 140, 146; inert background 50; of power 140 ; traditional 133

performances 4-5, 27, 29, 39, 64, 76, 78-9, 82, 110, 133, 137-8, 147; group 78 ; individual's 78 ; of interactions 78 , 133; normal 92; theatrical 55, 69 performers 17, 27, 39, 78-9, 103, 138, 148 persona-to-persona 103, 115, 118, 137; interactions 104, 113; played 115 persons $1,25-7,30,35-7,39,56,58$, $62,74-5,77-8,92-3,103,105-8$, 120-2, 137-8, 156-8; disorganized 43; drunken 155 ; human 87 ; interacting 35 ; relevant 89 ; special 11 ; terrified 50 ; young 133

perspectives $4,29,32,44,58,65$, $74,79,128-9,132,134,136$, 140,145 ; common 145; cultural 4; dramaturgical 4-5, 45, 77; epistemological 17; general 46; generic 5; interactive frame 75 ; mechanistic 129; metareflexive 74; metasocial 84 ; rationalist 31 ; social construction 18, 62, 68

Persson, A. 105

players $80,85,101,114-26$; in $\mathrm{f} 2 \mathrm{f}$ chess 125 ; Internet 123; rational 80; toplevel 122

playing 21 , 35, 47, 55-6, 96, 113, 115-19, 121-5, 131, 156, 158; blackjack 10; chess online 116, 121; conditions 125 ; games 124; in hopeless situations 116,118 ; online 117; programs 122 ; roulette 158

politeness and respect 25,146

politics 2-3, 68, 136; American 1; etiquette of $2-3$

positivism 17-18; of Erving Goffman 18; potential 17

positivists $17-18$

Posner, J. 20-2

Potter, Stephen 12

power 4, 60-1, 102, 104, 106, 108, $110,112,114,116,118,120,122$, 126-36, 138-41, 147; coercive 133-4; dimensions of 135 ; external 131 ; 
of influence 138, 140; relations 91 , $130-1,138$; resources 129 ; royal 113 ; separated physical 129; theories 128 , 130, 140; view on 136

practices $13,15,55,73-4,78,127,132$, 145-6

The Presentation of Self in Everyday Life 4-5, 10, 12, 15, 20, 29, 45, 53, 77

presentations 21-2, 43, 47; oral 11; of self $11-13,46,139$

presidential candidates $1-2$

Presley, Elvis 155

'primary frameworks' 50,52

profits $154-5$

projects $12,69-70,127,147$

prostitution 153-4, 156

Psychiatry 11

psychotherapists 43

public opinion research 14

public places $30,33,45,53,57,68,73$, 81-2, 90, 92-4, 107-9, 127, 135-6; atmosphere of interaction in 90 ; behavior in 81 ; in modern societies 33 ; social climate of 90 ; social interaction in $30,33,53,68,81-2,90,92,107$ publications 10, 15, 83; Asylums 45-6, 53, 133; An Essay on the Organization of Experience 58; Forms of Talk 10; Frame Analysis 5, 43-7, 49, 58, 60-1, 63, 65, 68-9, 74, 76, 84, 86-8, 95-7, 133, 140, 145-7; Gender Advertisements 10, 34; The Gift 33; The Kandy-Kolored Tangerine-Flake Streamline Baby 156; The Presentation of Self in Everyday Life 4-5, 10, 12, 15, 20, 29, 45, 53, 77; Relations in Public 30, 32; Stigma 5, 16, 20, 43, 53, 68, 83-4

punishments $60,71,133$

\section{Rappaport, R. A. 27}

real estate values 5

reality $15,17-19,34-6,39,44-6,49$, $51,58-60,62,68,72,80,137,140-1$, 151, 155; disclosed 138; imagining 60; relevant 80; shared 146; significant 17 regions $53,70,78,81,83,106,157-8$ regulations 3, 32, 109, 139; institutional 38, 83; moral 76; municipal 153; normative 37

Relations in Public 30, 32

relationships $4,14,22,26,28,34,38,40$, 70, 87, 89-90, 107-8, 124, 127, 130, 150; and answers to the interactive system 147 ; dynamic $46,90,140$, 146; hierarchical 19; objective 108; shaky 89; symmetrical 94; tense 157; unmanaged 97

religion $26,28,32-3,72$

research $15-17,19,21-2,28,69-70,83$, 93, 102, 129, 134, 147; assistants 9; interests 69 ; literature 84 ; orientations 110 ; on power $129,134,147$; and presentations $21-2$; projects 9 ; public opinion 14; on ritual 28 ; sociological $69,90,95$

rites $10,22-3,27,30-4,37,44-7,63-4$, 72-3, 79, 82, 88-91, 103, 114, 117, 131-2, 134-6; negative 32; positive $32-3$; religious 72 ; and rituals 23,135 ritual 5, 10-12, 21, 23, 25-34, 38-9, $45-6,49,51,55,57,66,69,72-3$, 76-7, 135; actions 27, 29-30, 34; equilibrium 31, 38-9; games 30 ; gestures 57 ; idioms 34 ; order 25,73 ; second definition of 31

'ritual, disequilibrium' 31

ritualisation $5,25-7,34,46,49,76,140$; and routinisation 29 ; structual theory 28 ; and vulnerability $26,34,38,51$, 66,90

rituals $5,21,23,25-34,45,55,57$, 72-3, 76, 135; contemporary 10; of everyday life 5; extent anchor 29; formal 27; human 27; religious 30 ; and rites 23, 135; social 11, 28, 32; twentieth century 28 ; uses of the term 31

Rocky Mountains 149

Rogers, M. F. 135-6

role-playing games 62

rule breakers 20

rules $2,30,34,47,50,60,64,69,71$, 73-4, 76, 78-83, 109-10, 113-15, 117-18, 153; basic 33; of behaviour $30,32,73,81,110$; breaking of 20 , 71 ; ceremonial 73 ; and conditions 153; of content 73 ; for entrepreneurs 2; ethical 109; and etiquette 118; flimsy 34; fragile 34; of irrelevance 80, 123; moral 77, 82-3; and norms 109, 117; of order 30 ; social 71; of standard chess games 117; transformation of 80,137 ; violating of 32 ; vulnerable 34

Runeby, Nils 150

Runyon, Damon 12

Russell, Bertrand 128-9 
sacred objects $30-3,72,76$

sacredness 28-32, 72; of the individual

(Goffman) 72; ritualised 31

Sartre, J.-P. 35-6, 92, 94

Schechner, R. 29

Scheff, T. J. 20, 63

Schelling, Thomas 10, 85

schools 2, 9, 32, 61, 69, 118, 133,

138, 157; business 22; free 153;

interdisciplinary 26 ; new 157 ;

of symbolic interactionism 21;

theoretical 22

Schütz, Alfred 46, 49, 58

'Second Chicago School' 11

self 4-5, 10-13, 15, 20, 25, 29-30, 36, $39,45-6,53-4,76-7,79,87,139$, 148; abasement 31 ; censorship 120; consciousness 123; control 30, 131; discipline 1-2, 90, 94, 133-4; interest 58; mobilization 80; non-socialised 12 ; objectification 94; presentations 35 , 111; restraint 94; ritual roles of the 30 self-presentation 35, 111

Seligman, A. B. 28

senior citizens 156

sense $63,65-6,69,76,80-1,87,92,95-6$, 105-6, 108, 120, 123, 128-32, 136,

140; conventional 104; of distance 120; social 64; special 123

sequences $27,29,37,39,52,87$, 159; brief interaction $87-8$; conversational 105

sex objects 154

shame $60,71,74,110,137$; feelings of 60, 74; thresholds 91

Sharron, A. 44

Shils, Edward A. 9

Short, Nigel 121

signals 27, 57, 104; contact 103-4; preemption 104; turnover 104

Simmel, Georg 11-12, 21, 30, 43

skin colour 132-3

Smith, G. W. H. 11, 13, 85

Snoek, J. A. M. 26-7

social action 4, 18

social behavior 10,85

social change 28

social climate 90

social constructions $18,61-2,68$; and

individual definitions 18 ; of reality 18

social dynamics 55, 63, 65-6, 68, 147, 156;

special 134, 151; tension-filled 158

social establishment 136 social identities 83

social illusions 5, 29, 36, 46, 68, 76, 134,146

social information 49, 56, 58-9, 83, 103; body-language-based 111; minimal 104

social interaction 4-5, 25-6, 29-40, 45-7, 49, 54-7, 63-6, 68-70, 72-4, 76-81, $95,115,120-4,127-9,135-8,145-7$; of civil inattention 93; contexts 49,84 ; dynamics 76,84 ; face-to-face 102,137 ; general perspective on 46 ; interpreted 25 ; observable 35 ; ongoing 78,85 ; in online chess 115 ; regular 28 ; rituals 38 ; in social media 107 ; spontaneous 80 social media 97, 101-7, 109-11, 120, 138,147 ; analysis of 97 ; closed 109; communication 107; conversation on 120; the interaction order in 109 ; mechanical character of conversations in 109; open 109

social norms 4, 74, 81

social order 70-2, 136; concrete 71 ; model of 56,70 ; and social interaction 70

social psychology $10,12-13,84$

social reality 15-16, 46, 68; conceivable 39 ; vulnerability of 46

social situations $27,34,49,62,64,66$, $83,85,97$; common 4 ; with other individuals 49

social structure $59,90-1,135$; changes in 91 ; coercive changes in 91 ; levels of 135

social workers 11

social worlds $61-2$; common 28 ; partitioning 51 society $4-5,12-13,15,21,23,25-6$, $38-9,59,61,65-6,72-3,76-7,83-4$, 90-3, 95, 127-30; anonymous 91 ; and institutions 128; modernised 72; premodern 28; western 94; white collar 23,135

sociological 11, 69, 90-1; analyses 12 , 72; approach 44; areas 45; canon 10; community 13; concept 136 ; establishment 12-13; group affiliations 14; imagination 10; lessons 94 ; objects of study 91 ; penetration 44 ; perspectives 12 , 46, 90; projects 46,74 ; system theorists 56

sociologists 10-13, 18-21, 28, 43, $85,90,95,135,147$; accessible 20 ; 
contemporary 20 ; inspired 11,26 ; layman's 20; popular 68; professional 20; unorthodox 10

sociology 9-15, 17-21, 23, 26, 28, $32,55-6,86,127$; academic 23, 135; books 20; individualist 91 ; inter-actionist 134; of religion 32-3; structuralist 91; taxonomic 19; understanding Goffman's 44; urban ethnographic 12

Soprano, Tony 151

Sopranos (TV series) 151

soul 22, 131

spatial environment 81

spatiality (of Goffman's sociology) 52 state $36,73,84,94,127-8,132,145$,

153-4; administrative 132; authorities 128; authority and interactional power 127; collective 84 ; democratic 72 ; fixed 83; modern nation 73, 127 ; monopolisation 91 ; 'personal safety' 94; representatives 145

stigma 96, 137; concept 83; 'management' 43, 96, 137; phenomenon 83

Stigma 5, 16, 20, 43, 53, 68, 83-4

stigmatised people 43,84

Stone, Gregory P. 12

students $11,17,23,33,135$

study $5,13,15,21,25,45,72-3,77$, 81-2, 85, 87-8, 91, 93, 105, 145-6, 150 ; gender 135; mechanisms 84 ; of power 129,135

suicide 72

Sweden 2, 114, 153; chess journalists 114 ; and personal integrity in social media 102; and tranformation attempts by municipal councillors 152 symbolic actions $27,31-2,72$ symbolic interactionisms 21, 44

'Symbols of Class Status' 10 systems 2, 4, 19, 32, 71, 75, 77, 103, 128-9; of interaction 77; interactive 147; queueing 74-5; requirements of $104-5$

takeback (chess) 116

tax boundaries 153

taxes $2-3,153$

teachers 9,11

television 2

texts $5,11,14-15,29-30,44,46,54$, $63,65,68,74,76-7,90,93,114$,
117-18; early 29, 31-2; by Erving

Goffman 64; in-depth 136; last 73; present 125

'the theatrical frame' 89

'thematise historical time' 89

themes 5, 13-14, 26, 29, 37, 76, 82, $90,139,146$; of influence 139; of politeness and respect 5, 76, 93; of ritual 29

thinking $15,73,85,107,124,145$; individual's 108; undeveloped frame 69

Thomas theorem 18, 60-1

Thompson, Hunter S. 151

threats $28,55,60,73,109,127$; to another's face 30 ; intensity of the 31 ; to rituals 28

time 9-15, 25-6, 36, 49-51, 71-3, 75-8, $86,91-4,105-6,116-21,123-5,128$, 133-5, 145-7, 149-50, 154-6; and place 128 ; and space 86

Time Magazine 10

tools $15,29,33,37,49,140$; analytical 53 ; common sociological 26 ; dichotomous 26

tourism $153,157-8$

tourists $152,157-8$

transformations $38,51-2,90,94,97$, 104, 114, 120, 132-3, 138, 152;

dynamic 147 ; horizontal 52 ; of power 133; standard 34

transgression of moral boundaries in Las Vegas 106, 154

transmission of expressions 105-6, 110, 138, 147

Trump, Donald 1-4

Turner, Victor 28

United States 3, 9, 13, 45, 153

University of Chicago 9, 12-13

University of Pennsylvania 10, 12

urban environment 58

users of social media 111

victims 31,43

violations $1-2,32-3,72,140$

violence $3,35,90,109,129-30$

vocal and antisocial minorities 102

Vollmer, H. 75

vulnerability 5, 25-6, 34-8, 46, 49, 51, $62,66,68-9,76,90,93,140,146-7$; of experience 38 ; of frames 62 ; of public life 93; in social interactions 36-7, 49 


\section{Index}

Warner, Lloyd 11

Weber, Max 12, 129, 131, 136

'Where the Action Is' 16

Wieners, B. 122

Williams, R. 15

Winkin, Y. 9, 11, 23

Wolfe, T. 156

women $1,23,34,70,135,154-5$; and attacks by online groups 102 ; overweight 156

work 10, 12-13, 16-17, 20, 22, 26, 31, $49,53,55-6,69,92,95,101,104$, 145-6; mutual 93; in public places 92; remedial 97

workers 135 working acceptance 56, 72

working consensus 5, 25-6, 38-40, 46, $60,74,76,140,146$

world 4, 9, 13, 17, 21-3, 31, 36, 38, 46, 53, 60, 64, 80-3, 146, 149, 157; contemporary 27 ; external 34 ; human 136; new 22; ongoing 87 ; secularised 30

World Chess Championship 114

World Chess Federation 116-17

World Congress of Sociology 14

World Trade Center 31

World War I 9

Wynn, Steve 154-5 